University of Louisville

ThinkIR: The University of Louisville's Institutional Repository

Electronic Theses and Dissertations

$12-2007$

\title{
The effects of transition intervention on students with mild disabilities.
}

Yvonne Anton Kelley Niemann 1939-

University of Louisville

Follow this and additional works at: https://ir.library.louisville.edu/etd

\section{Recommended Citation}

Niemann, Yvonne Anton Kelley 1939-, "The effects of transition intervention on students with mild disabilities." (2007). Electronic Theses and Dissertations. Paper 1062.

https://doi.org/10.18297/etd/1062

This Doctoral Dissertation is brought to you for free and open access by ThinkIR: The University of Louisville's Institutional Repository. It has been accepted for inclusion in Electronic Theses and Dissertations by an authorized administrator of ThinkIR: The University of Louisville's Institutional Repository. This title appears here courtesy of the author, who has retained all other copyrights. For more information, please contact thinkir@louisville.edu. 


\title{
THE EFFECTS OF TRANSITION INTERVENTION ON STUDENTS
} WITH MILD DISABILITIES

\author{
By \\ Yvonne Anton Kelley Niemann \\ B.S., Southern Illinois University, 1960 \\ M.A., University of Louisville, 1971 \\ Ed.S., University of Louisville, 1977
}

\begin{abstract}
A Dissertation
Submitted to the Faculty of the Graduate School of the University of Louisville in Partial Fulfillment of the Requirements for the Degree of
\end{abstract}

Doctor of Philosophy

Department of Teaching and Learning University of Louisville Louisville, Kentucky

December 2007 
Copyright 2007 by Yvonne A. Niemann

All rights reserved 
THE EFFECTS OF TRANSITION INTERVENTION ON STUDENTS WITH MILD DISABILITIES

\author{
By \\ Yvonne Anton Kelley Niemann \\ B.S., Southern Illinois University, 1960 \\ M.A., University of Louisville, 1971 \\ Ed.S., University of Louisville, 1977 \\ A Dissertation Approved on
}

November 12, 2007

by the following Dissertation Committee

Dissertation Co-Director

Dissertation Co-Director 


\section{DEDICATION}

This dissertation is dedicated to my parents

Mr. Thomas C. Anton, deceased,

and

Mrs. Rosemary Anton

who gave me the love of learning and invaluable opportunities in life. 


\section{ACKNOWLEDGMENTS}

I would like to thank my Co-chairs: Dr. Thomas Simmons, for his support and guidance, and Dr. Stephen Miller, for his patience and insight. I would also like to thank my committee members: Dr. Debra Bauder who showed me, through personal example, to dig in and get it done; Dr. Denzil Edge, who never lost faith that I would get it finished; and Dr. William Penrod, for his personal faith in me and support that I really could do it-and to all for their commitment and encouragement.

A special thank you to Tom who gave me opportunities in learning, teaching, writing, distance education, advising, and introduced me to professionals across the country in the transition field. A special thank you to Steve who helped me find ekstasis, for his endless editing, and his faith in me to persist in completing the journey. He is, indeed, a "master teacher," for in this process, he led me through statistics and learning to express research by example, high standards, and high expectations. Also, my gratitude goes to Dr. Joseph Petrosko for his support throughout this process.

To my husband, Tony, and my friend, Susan O’Daniel, thank you for helping me pay attention to details and for showing understanding and patience during those times when there was no light at the end of anything. They encouraged me and made me stick with it! Also, I am grateful to my children, Kathleen, Donald, and Douglas (deceased); family-in-laws, Byron, Michelle, Mark, and Shanan; and grandchildren, Kelley, Mary, Walker, Donna, Melody and Ali, who were so patient and encouraging over the years while I had my sights set on higher education which took time away from them! 


\begin{abstract}
THE EFFECTS OF TRANSITION INTERVENTION ON STUDENTS WITH MILD DISABILITIES

Yvonne Anton Kelley Niemann
\end{abstract}

December 11, 2007

The process of transition from high school to adult life is particularly important for students with mild disabilities because these students show a pattern of overwhelmingly low expectations and progress. Transition services, self-determination, and focus on outcomes are essential to improve success. Curriculum designed around the interests and abilities of the student, with assistance to meet goals through a coordinated set of activities, academics, work experiences, and personal insight is essential.

The STEP Grant supported students with mild disabilities in collaboration with the University of Louisville and a metropolitan school district in Kentucky. Helping students obtain their high school diplomas was emphasized. Students were involved in planning, personality development, work experiences, and connections to adult services. This dissertation constitutes program evaluation of this transition intervention follow-up program for high school students with mild disabilities $(N=50)$.

Data were obtained from district archival records for IEPs, Transition Plans, grades, personality testing (Self-efficacy and Locus of Control), and a STEP Grant Student Follow-up Survey. The quantitative or qualitative methods were specified for each 
different research question. Procedures included descriptive statistics, reliability calculations for the personality measures, ANOVA, correlation, chi-square, semipartial correlations, and qualitative analysis of student comments.

Important findings included (a) many IEPs lacked Transition Plans; (b) 46 of 50 students met STEP criteria for success and 100\% graduated from high school; (c) the personality measures were generally not reliable for this sample of low-socioeconomic status students with mild disabilities; (d) vocational plans, training/education, and jobs generally did not match; (e) wages were negatively related to LD (as opposed to MMD and $\mathrm{BD}$ categories) and attendance. However, results must be viewed with caution because there is no way of ensuring that participants were similar to the other 58 students who did not return surveys. Compared to students with mild disabilities who generally do not fare well with respect to transition outcomes, the students in this STEP Grant did manage to stay in school. Yet more detailed analyses indicated that this "success" was belied by the reality that most were in low-wage, low-status service jobs. 


\section{TABLE OF CONTENTS}

\section{PAGE}

ACKNOWLEDGEMENTS ..................................................... iv

ABSTRACT ...................................................................

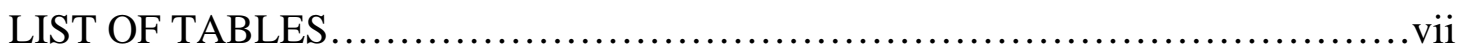

\section{CHAPTER}

I. STATEMENT OF THE PROBLEM..............................

Introduction.................................................1

Legislation.......................................................

Transition Planning...........................................11

Steps Toward Educational Progress (STEP) Grant...................19

The Problem Defined.............................................30

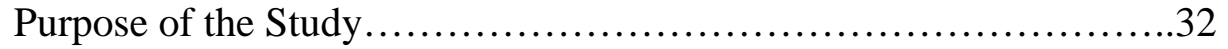

Research Questions.............................................33

Significance of the Study......................................37

Limitations of the Study.......................................37

Definition of Terms...........................................40

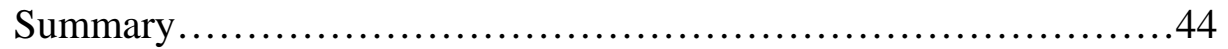

II. LITERATURE REVIEW ....................................47

Introduction.................................................47

Program Evaluation............................................48

Transition History............................................57 
Transition Effects............................................66

Transition Intervention Programs...............................95

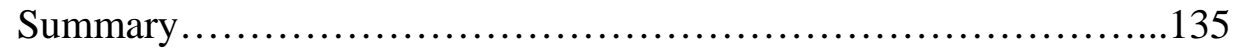

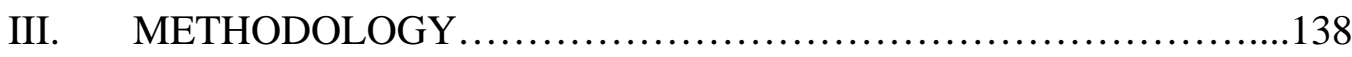

Introduction................................................138

Population and Sample.......................................140

Description of the Variables....................................141

Procedures......................................................155

Research Design..........................................158

Validity Considerations.........................................170

Ethical Standards...........................................174

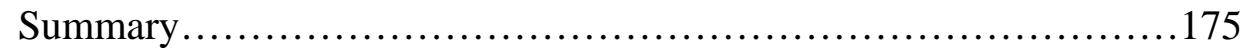

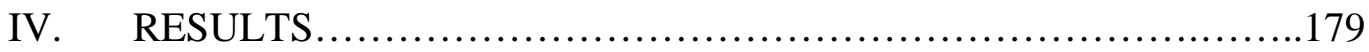

Introduction..............................................179

Data Checking and Coding........................................181

Descriptive Statistics........................................183

Psychometric Analysis...........................................188

Research Questions...........................................197

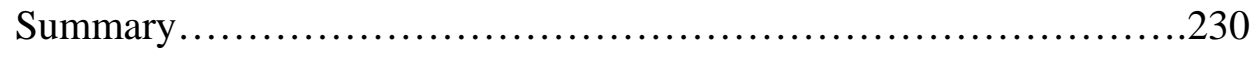

V. DISCUSSION AND CONCLUSION............................234

The Study in Brief.........................................234

Discussion.................................................237

Recommendations.............................................261 
Conclusions. .276

REFERENCES........................................................280

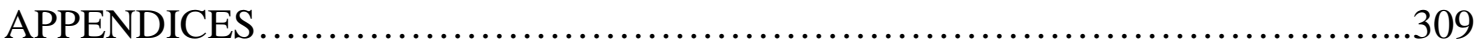

APPENDIX A: Cover Letter, Student Survey, Consent Form.................309

APPENDIX B: Human Subjects Letters of Approval........................319

APPENDIX C: Self-efficacy Scale, Scoring Guide for Self-efficacy

Scale

APPENDIX D: Locus of Control Scale, Scoring Guide for Locus of

Control Scale. 345

APPENDIX E: Operational Definitions and Codings of Variables....

APPENDIX F: STEP Grant Student Follow-up Survey

Comments, Question 8.

APPENDIX G: STEP Grant Student Follow-up Survey

Comments, Question 9.

APPENDIX H: STEP Grant Student Follow-up Survey

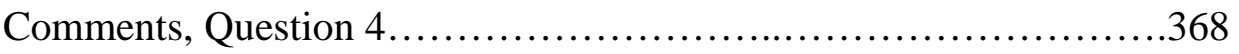

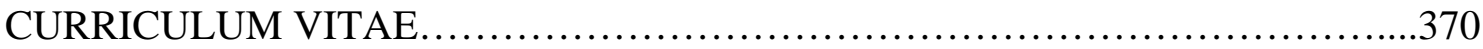




\section{LIST OF TABLES}

TABLE

1. Descriptive Statistics for Demographic Controls, Personal Identity...............185

2. Descriptive Statistics for Demographic Controls, Educational History..............186

3. Participation in STEP Grant by School........................................187

4. Descriptive Statistics for STEP Grant Intervention Factors......................187

5. Descriptive Statistics for Transition Outcomes, Hours and Wages................188

6. Psychometric Analysis for Self-Improvement Scale........................190

7. Psychometric Analysis for Self-efficacy (General) Scale............................192

8. Psychometric Analysis for Self-efficacy (Social) Scale.........................193

9. Psychometric Analysis for Locus of Control Scale...........................195

10. Evaluation of Individual Education Plan and Transition Plans.................198

11. Consistency of Transition Plan Goals and Transition Outcomes...............200

12. Career Goals, Vocational Training, and Jobs Among STEP Grant

Participants.........................................................202

13. Attainment of STEP Grant Criteria for Success.............................208

14. Descriptive Statistics for Personal Identity by School Attended................210

15. Descriptive Statistics for Educational History by School Attended..............213

16. Correlations between Demographic Factors and STEP Grant

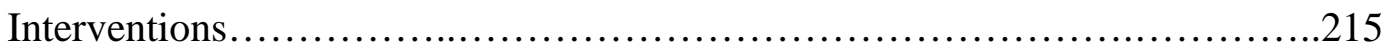

17. Correlations between Demographic Factors, Mediating Factors, and 
Transition Outcomes in Employment......................................217

18. Descriptive Statistics for Mediating Factors by School Attended.................219

19. Descriptive Statistics for Transition Outcomes by School Attended..............221

20. Correlations between STEP Grant Intervention, Mediating Factors, and Transition Outcomes (Hours and Wages)..................................223

21. Semipartial Correlations for STEP Grant Intervention and Mediating Factors Related to Transition Outcomes, Controlling for Six Demographic Factors.............................................226 


\section{CHAPTER I \\ STATEMENT OF THE PROBLEM}

Introduction

Fifty years ago, in an agricultural and industrial world, students were more likely to drop out of school after completing the eighth grade so they could have an advantage in employment. As Howard Gardner (2003, p. 3) pointed out, “only a small percentage of students received this much basic education before returning to the farm or proceeding to the factory.” Some of these students may not have been academically oriented or did not receive assistance from their families to attend college. Those who did drop out or stopped their education at the end of high school were not penalized in the job market.

Advancements were awarded based on hard work within the company and did not depend on formal education. Today, however, society is “driven by a highly technical global economy” (Harvey, 2001, p. 2) that is much more challenging for students without a high school diploma or post-high school degree. Employers want to hire people who have the ability to multi-task and who are able to travel to remote work locations of the company. Dropouts "generally do not possess these advanced skills to be competitive” (Harvey, p. 2) in business, industry, or education. The high school diploma serves more as a minimum entry requirement to the labor force in the current job market (Harvey; Hudecki, 2006; Stern, 2006).

Economic earning power affects many choices in life. Students who need to work more than 20 hours per week as they move from high school to adult life rarely enter post- 
secondary education (National Center for Research in Vocational Education, 2006). Many students may enter postsecondary education, but they are much less likely to enter as fulltime students or attend a four-year college/university if they are working. Those who work more than 20 hours per week are much more likely to attend part-time, delay entry, or go to a two-year community college or technical postsecondary institution. The jobs obtained with high school diplomas are often entry-level jobs, and without additional training, students are unable to obtain promotions to management positions. Likewise, economic status affects the ability to live independently and limits choices for housing. Employment, entrance to postsecondary education, and independent living are three major topics closely related to adult life status and healthy lifestyles for both regular and special education students.

For most students in regular education, these three areas of life are a normal part of the transition to adulthood. And, while not without anxiety and problems, most of these young people, with the support of their families, are able to manage this phase of life and settle into adult roles. But for student with disabilities, these specific aspects, and the larger transition process itself, are anything but routine. A number of scholars have documented these problems (Blackorby \& Wagner, 1996; L. Brown, Nietupski, \& Hamre-Nietupski, 1976; Clark \& Kolstoe, 1995; Flexer, Baer, Luft, \& Simmons, 2008; Flexer, Simmons, Luft, \& Baer, 2005; Halpern, 1985; Kohler, 1993; Morningstar, Turnbull \& Turnbull, 1995; Rusch \& Chadsey, 1998; Sitlington \& Frank, 1990; Szymanski, 1994; Will, 1983). Because of the growing awareness of these issues, research on the transition process has increased dramatically in recent years (e.g., Baer, 1996; Baer, Simmons, \& Flexer, 1996; Benz \& Halpern, 1993; Blackorby \& Wagner, 1996, 2004; Fourqurean \& LaCourt, 1990; Hughes, Eisenman, Hwang, Kim, Killian, \& Scott, 1997; Kohler, 1993; Wehman, Kregel, 
\& Barcus, 1985; Wehmeyer, 1992; Yesseldyke, Thurlow, \& Gilman, 1993).

One result of this research has been the development of a myriad of federally funded transition projects during the past ten years, specifically designed to facilitate transition services for high school students with disabilities. As the above citations note, the need for such services is tremendous. According to Kochhar-Bryant, Shaw, and Izzo (2007), “22\% of Americans with disabilities fail to complete high school, compared to $9 \%$ of those without disabilities" (p. 3). When compared to their non-disabled peers, "people with disabilities, ages 18-64, are less likely to be employed (32\% either full or part-time) than people without disabilities (81\%)" (p. 3). "Students with disabilities who enroll in postsecondary institutions are less likely to complete a bachelors degree (16\% versus $27 \%$ respectively) and $11 \%$ of college graduates with disabilities are unemployed, compared to $4 \%$ of those without disabilities" (p. 3). "Youths who attend college often experience negative self-concept, poor socialization skills, stress and anxiety, and have professors who are reluctant to help” (p. 3). “Compared to non-disabled peers, students with disabilities are more likely to live with parents and be socially isolated” (p. 3).

\section{Legislation}

Several federal laws targeted access to regular education and outline steps to assist special education students to stay in high school and work toward high school diplomas. The first major piece of legislation, titled Individuals with Disabilities Education Act (IDEA), began in 1975, and was amended in 1990 and 1997. This legislation ensured access to the general curriculum and focused on transition outcomes for students with disabilities (Kochhar-Bryant et al., 2007). The newest revision was re-titled the Individuals with Disabilities Education Improvement Act (IDEIA, 2004, as cited by Flexer et al., 2008, pp. 50-51) and contained many positive revisions for students with disabilities. This 
legislation expanded concepts of accountability for students with disabilities to ensure they have been included in statewide testing, with accommodations, and have received specific interventions for classroom learning. Paperwork for Individual Education Plans and eligibility reassessments for special education students was reduced. IDEIA legislation required a new Summary of Performance (SOP) to be prepared as the student leaves K-12 school services (Kochhar-Bryant et al., 2007, p. 75). This synthesis of achievement and functional performance for use by employment, postsecondary education, and adult agencies is intended to make transition more efficient.

Implementation regulations for school districts were released in July, 2006, but the new transition initiative authorized in IDEIA 2004 was not recommended for funding by the House Appropriation Committee (CEC, 2006). Inadequate funding of legislation has been a perennial problem with many of the educational legislative acts in the past. Budget strains are caused as school districts attempt to abide by the intent of the laws without full funding. More important, the lack of resources means that schools frequently are not able to meet fully the intent/requirements of the law. When this happens, it is the students with disabilities and their families who suffer, as well as the school staff who are burdened with more and more services to provide without adequate personnel or materials.

The No Child Left Behind (NCLB) of 2002 legislation was designed to narrow the gap between regular education students and several groups of other students, including students with disabilities. It was reauthorized in 2004 and targeted academic improvement, prevention, and intervention for students with special needs. This includes students who are disadvantaged, migratory, neglected, delinquent, or at risk. Transitional activities between institutions and home schools are strengthened, e.g., from residential schools, correctional facilities, adult jails, juvenile detention, or protective shelters. One of the main 
goals for this legislation was to help these students make connections with postsecondary education and change adult outcomes (as cited by Flexer et al., 2008, pp. 50-51, 136).

Two legislative acts, the reauthorization of the Elementary and Secondary Act (ESEA) (as cited by Flexer et al., 2008, p. 50) and the Carl D. Perkins

Vocational/Technical Act (as cited by Flexer et al., pp. 46-47) were enacted to encourage all students to stay in school and prepare for entrance to employment or postsecondary education. ESEA was passed in 1965 "to meet the needs of educationally deprived children, especially through compensatory programs for the poor” (Schugurensky, 2006, p. 1). It has been amended several times to include different groups of students who were at risk, and in 2002, the name was changed to NCLB (Bergeson, 2006). Bergeson described accountability in this legislation as ensuring "those students who are disadvantaged, [to] achieve academic proficiency” (p. 1). The Perkins legislation was very important since it "mandated coordination between vocational education, state vocational rehabilitation agencies and special education” (Flexer et al., 2005, p. 44). Even with this mandate, students with disabilities did not show dramatic improvement in vocational education placement or in obtaining jobs connected to their training area.

The Americans with Disability Act (ADA) of 1990 (as cited by Flexer et al., 2008, pp. 44-45) and the reauthorization of the Vocational Rehabilitation Act of 1992 (as cited by Flexer et al., p. 45) continued the focus on access to regular education and ensured inclusion in the work force or continued education upon graduation for students with disabilities. Both legislative acts focused on accessibility to public sites and services (Best, Heller, \& Bigge, 2005). The Goals 2000: Educate America Act (1994) made it clear that Congress intended to include students with disabilities in the general educational reforms (Morningstar et al., 1995). The language in this legislation stated specifically that it was 
consistent with ADA, Part B of IDEA, and Section 504 of the Vocational Rehabilitation Act (Committee on Labor and Human Resources, 1993). The School to Work Opportunities Act (STOWA) of 1994 provided transition support and work-based learning (Flexer et al., 2008, pp. 45-46). Specifically, students were to have opportunities in high school to explore career paths with matched academic curriculum to attain their expressed goals. Flexer et al., (2005) also stressed the linkage between secondary and postsecondary education so that the preparation was integrated with academic core subjects (p. 43).

Given these legislative mandates, general education reforms have identified better content organization and teaching methods to insure that students with disabilities were included in the opportunities afforded regular education students. Curriculum reforms have better identified career paths to qualify for higher education. Courses have been mapped from elementary, through middle schools, to high schools, and connected to postsecondary employment or continued education. These career paths have led to better preparation for students to accomplish the required coursework to graduate and gain entrance to increased opportunities. General education teachers have begun to understand how to organize teaching for all students and use a variety of teaching methods. All of these improvements have been linked to better achievement scores for many students. However, students with disabilities still have not made the progress they need to make better transitions.

\section{Focus on Transition}

Despite the changes in laws and educational delivery, many students with disabilities still do not complete high school with the ability to enter the job market or enter postsecondary education, nor do they have the requisite skills and problem-solving capabilities to establish residences independent of their families. The federal Department of Education became increasingly concerned about the quality of and outcomes regarding 
the transition to adult life of students with disabilities. Under their mandates (IDEA, 1990 \& 1997) school districts began to gather information and evaluate the quality of students' outcomes; a dismal picture began to evolve. Even with efforts to upgrade curriculum and provide vocational and transition services, students with disabilities were not completing high school at the same rate as their regular education peers and were typically unemployed or underemployed as adults (Kortering \& Braziel, 2000). The federal Department of Education funded the development of a number of transition demonstration projects toward this end during the 1990s. Thus, efforts focused on activities intended to facilitate transition to employment, postsecondary education, independent living, and selfdetermination.

\section{Connection to Employment}

Students enrolled in high school programs for career and technical education were found to be less likely to drop out and more likely to be in full-time, competitive employment after high school (Cobb, Halloran, Simon, Norman, \& Bourexis, 1999; Colley \& Jamison, 1998; Wonacott, 2001). Students with disabilities needed increased supports and experiences to make the connection to vocational education and work following high school. Enrollment in Vocational Education alone was not enough. Work experiences needed to be balanced with the requirements of membership in inclusive academic classes and completion of high school diplomas. The combination of academic and vocational experiences and higher expectations to perform at the same level as their regular education peers led to frustration on the part of the student with disabilities. Often, the students were unable to complete this demanding schedule without attending summers or extra years to repeat coursework that was failed. The National Longitudinal Transition Study (NLTS) reported that students with mild disabilities were more likely to be unemployed or under- 
employed two years after their graduation at a much higher rate than their same-age, nondisabled peers (Wagner, Blackorby, Cameto, \& Newman, 1993). The U.S. Department of Education (1997) concurred with this finding in their "State indicators in education" report and suggested that students who dropped out were also more likely to be limited to lowskill, low-wage jobs. Society ultimately has the burden of paying for the unemployment system, the high costs of incarceration, social services, and the reduced overall tax base (U.S. Department of Education, 1997).

Employers want workers who are more prepared to move to other jobs and who can solve problems in the work force. Higher-level skills are needed for better paying, competitive jobs to support independent living. Schools cannot continue teaching workrelated skills in simulated environments (Rusch \& Millar, 1996); there is a need to increase supervised work experience programs and help students with disabilities make the connection from school to work successfully. It was noted in the School to Work Opportunities Act (STOWA, 1994) that three-fourths of the nation's youth do not possess necessary skills to be successful in our changing workplace (as cited in Flexer et al., 2008, pp. 45-46). To be successful in employment, students need to learn both job seeking and job retention skills. Since many of the students with disabilities change to different jobs more frequently than their non-disabled peers, they also need job-changing skills. To address the major problem areas of employability, the following work related skills need to be taught: "physical self-reliance, valid self-evaluation, and self-adaptability or selfdetermination” (Best et al., 2005, p. 368). According to Harvey (2001), factors that make it difficult for graduates to locate jobs include the increased number of people looking for jobs, much higher technical requirements, and employers who demand more expertise for salaries paid. Generally, dropouts do not have these employment skills or the 
accompanying social skills.

\section{Connection to Postsecondary Education}

Research in postsecondary education showed that students with disabilities were enrolled at a much lower rate in the 1990s than their regular education peers (Blackorby \& Wagner, 1996; Rojewski, 1999). However, Eisenman (2000) found some improvement in the enrollment rate of students with disabilities in postsecondary education. She found that meaningful engagement and inclusion for students with disabilities in high school led to postsecondary improvements. Prior to these efforts, few educators or parents expected these students to attend colleges or technical settings after high school. Attitude changes and increased expectations from parents and educators have opened new doors for higherlevel preparation leading to jobs with increased responsibility and wages.

The American Council on Education (2001) estimated that in 1988 there were $16.1 \%$ of students in higher education reporting a learning disability; by 2001, the percentage had increased to $40.1 \%$. Students with various learning disabilities have always been enrolled in higher education, but many either did not disclose that they had a learning disability, or were not recognized as requiring accommodations (Wilhelm, 2003). The increased numbers of students with disabilities enrolled in postsecondary education may be attributed to two main reasons. One is that more students are considering and entering postsecondary education due to better preparation and increased expectations from parents and educators. A second is that more students are disclosing their learning disability when they enter postsecondary education and asking for accommodations for their disability. Although Wilhelm did not report estimates for students who completed college, many students with learning disabilities enter two or four year colleges, but without completing their programs. 
The ADA legislation (1990) required higher education institutions to provide accommodations to assist students with learning disabilities. Common accommodations include double time on exams, impunity from spelling errors, distraction free environments for exam taking, alternate formats for exams, readers, and other many other accommodations that increase success for functional limitations (Wilhelm, 2003). However, program requirements do not have to be altered to meet the ADA requirements. Thus, students with disabilities may face taking courses in areas that they had difficulty passing in high school or had courses waived to graduate.

\section{Connection to Independent Living Arrangements}

The third outcome for successful transition is the connection to independent living arrangements. In addition to emphasis on employment and postsecondary education, community skills needed to function successfully as adults must be part of high school experiences. Students with disabilities do not automatically learn these skills. Adult success in independent living is measured by the quality of life and the amount of autonomy or independence the person enjoys. Repetto (2003) emphasized the importance of preparing students for life roles as "workers, family members, friends, consumers, and community members” (p. 77) by including the following five transition-to-living skills: Self-determination; Academic Performance; Relationship Building; Consumerism; and Self-Maintenance. These skills need to be taught systematically in a variety of locations with supports from parents/guardians, friends, coworkers, and employers for students with disabilities to become successful in independent living (Barclay \& Cobb, 2001; L. Brown, Branston, Hamre-Nietupski, Pumpian, Certo, \& Gruenewald, 1979; Morningstar et al., 1995). It became clear that all of these skills need to be in the curriculum for all students with disabilities in order for them to be successful as adults in the community. 


\section{Transition Planning}

To determine how the present educational system attempted to meet these challenges, a brief look at educational change for special needs pupils was needed. Original legislation began in 1975 with the Education for all Handicapped Act, P.L. 94142. This became the first leg of the IDEA legislation and changed special education service delivery from segregated classes to inclusive classes in the general curriculum. Part of this legislation gave birth to the Individual Education Plan (IEP) which was intended to have both immediate educational impact and long-range planning goals. However, educators focused on immediate goals and IEPs, which evolved into a one-year outline for academic classes often disconnected to an overall plan.

The IDEA law in 1990 and amendments of 1997 added the requirement of Individual Transition Plans. This planning, to be done in preparation for the IEP, became the responsibility of the special education or vocational teacher, and often was written in isolation from student wishes or family input. Over-burdened school districts without fullfunding to implement these legislative changes did not have the resources to meet the increased demands for services. Small changes, such as including a regular educator on the IEP planning team, often met with resistance from administration since additional personnel were required to cover classes during the planning time.

Little preparation was afforded the special education student to gain skills necessary to participate in the IEP process and express wishes or desires for their future. Transition goals were often not included as part of the legally-binding IEP. When plans are based on the student's learning styles, interests, and abilities, successful transition is much more likely to occur (Flexer et al., 2005).

Transition planning, although mandated by the IDEA law since 1990 for students 
with learning disabilities, was often lacking goals for all three areas: employment, postsecondary education, and independent living. All educators must be aware of the connections between academic classes, career education, transition planning, and successful transition to adult life.

\section{Present Educational Delivery Systems}

Educational services for students with mild disabilities, who are the focus of this research, are now mainly provided through inclusion in general education and vocational education, with special education supports. This has altered the teacher's role for all three groups: regular, vocational, and special educators. Included in the special education definition are three main categories of students within mild disability: Specific learning disability (LD), Emotional/behavioral disability (EBD), and Mild mental disability (MMD). Students with LD, EBD, and MMD are included in this present research. These three categories are not all inclusive of the mild disability category, but they represent three of the larger categories. Other disabilities in this group may include the following impairments: speech or language; orthopedic; other health issues; visual; hearing; multiple disabilities; autism; and traumatic brain injury. The Kentucky Department of Education, Division of Exceptional Child Education's website provided explanations for these three categories of disabilities that are the focus of this study (KDE, 2006). Categories are elaborated in Definitions of Terms section.

\section{Collaboration}

General and vocational teachers were not accustomed to having another educator in their rooms and had not been prepared by many teacher education programs to accommodate special needs learners or collaborate with another person. They are accustomed to autonomous classrooms where they are the sole authority. Present 
educational mandates include students with disabilities in general education classes with supports delivered with special educators assigned as "resource" teachers. Collaboration activities between regular and special education teachers are varied, take more preparation time, and appear to be on a wide continuum. Team teaching, where both general education and special education teachers deliver the content, is at one end of the spectrum while special education services delivered in a self-contained classroom is at the other end. Success of these efforts is difficult to judge since there are many different models within single schools and even the same special education teacher could vary widely in collaboration responsibilities with different regular educators during a school day. Differences occur due to content delivery, expertise of the teachers involved, acceptance of the concept of collaboration, and mix of student's needs.

Many educators focused on making sure students completed high school requirements for academic and vocational classes and assumed that effort fulfilled the required transition support (L. E. Powers, Turner, Matuszewski, Wilson, \& Loesch, 1999). Teachers of regular education often have difficulty understanding the modifications or adaptations needed to assist special education students in learning the higher-level courses (Powers et al.). Students with disabilities need specially-designed instruction in order to succeed, but many regular educators have not been trained to develop supports or accept assistance from a special educator.

Inclusion

Considering inclusion from the student point of view, LBD students cognitively understand that they are not functioning at the same levels as their classmates and generally have lowered expectations for their futures and lowered self-esteem (Bingham, 1980; R. J. Miller, 1988; R. J. Miller, Lombard, \& Corbey, 2007; Patton \& Polloway, 
1982). With special education teachers struggling to support students in academic, vocational, and functional skill training, many of the students are not succeeding in meeting the high school graduation requirements. Many frustrations occurred for teachers and students, as preparing for statewide assessments seemed to lead the educational reform efforts.

Major educational programming changes are needed to help students learn skills necessary to take and pass regular education courses; to seek or keep jobs in the competitive job market; to become more independent in making choices; and to become more successful adults in the complex world (Harvey, 2001). Inclusion with regular education has made a difference in perceptions by educational staff as well as parents. Expectations that special education students in the LBD range could continue into postsecondary education are becoming more prevalent.

\section{Vocational and Career Education}

Many educators and parents depended on enrollment in vocational education to provide training for mildly disabled students to acquire skills to enter the job market directly after high school. The focus of vocational classes today includes high-tech requirements for meeting ever increasing business standards. Harvey’s approach (2001) was to use vocational education as a proactive means to promote connection to school, increase labor-market advantages, and help students make a successful transition to adult life. To do this, schools began to stress comprehensive career awareness at earlier ages for students and make the connections between curriculum and skills needed for careers. Vocational and technical education is closely connected to local job markets and provides hands-on work experiences. Vocational program skill charts were developed to move students through acquisition of skills in a sequential, competency-based manner. 
Harvey (2001) concluded that, although students with disabilities who participate in vocational education are more successful employees, "vocational education should not be looked upon as a panacea for special education” (p. 7). Special education teachers need to collaborate with vocational teachers as well as academic subject teachers to make this connection successful, but rarely does this happen due to staffing constraints mentioned earlier. Wonacott (2001) reported that students with disabilities who were mainstreamed into regular vocational or academic classrooms felt better prepared to keep their jobs and obtained paid jobs more often than those who did not participate in the mainstreamed classes.

Employers demanded that the vocational trades improve student knowledge base to meet higher technical standards, but school districts could not fund the entire gamut of vocational training needed by business. Training in common skills to prepare the student worker for many types of employment is needed, but rarely provided, for the mildly disabled student. Vocational/technical training has become increasingly more demanding to include higher-level skills required for preparing students to enter the work force (Levesque, Lauen, Teitelbaum, Alt, \& Libera, 2000). This shift has attracted more regular education students into vocational education as well as more students with special needs due to the Perkins legislation (National Center for Research in Vocational Education, 2006). However, research does not document improvement in the preparation of students with disabilities to gain employment skills.

\section{Self-determination}

Students with disabilities need experiences for career choices, but also need practice in using self-determination skills to learn how to control their own lives. Many times, society and families make choices for the person instead of teaching them how to do 
this for themselves. Teachers and parents need to help the student with disabilities learn to express their needs, wishes, and desires in order to take charge and work toward accomplishing their personal goals. Learning to participate in the IEP process is a good step in this process toward independence. Understanding social concepts and personal abilities as well as disabilities is a critical step in the process toward independence.

Essential to student progress is the understanding of targeted personality variables for this study, e.g., Self-efficacy and Locus of Control. These items are two prime ingredients in psychological development and affect how people face choices and demands of life.

\section{National Projects}

The federal Department of Education funded the development of a number of transition pilot projects in the late 1990s. A progression of activities intended to facilitate the transition to employment, postsecondary education, and independent living was identified in these federal grants and has been reviewed in Chapter II.

At the national level, the Secretary's Commission of Achieving Necessary Skills (SCANS) Report (1991) noted critical skills for success in today's labor markets for all students (U.S. Department of Labor, 1991; Phelps \& Hanley-Maxwell, 1997). These skills are grouped into three categories: Basic Skills, Thinking Skills, and Personal Qualities. School programs generally do include the first two, but the third, Personal Qualities, is frequently not included in school curricula and is a critical component for future successful adults. Personal Qualities areas and what each category included are:

(1) Responsibility, including effort and perseverance. (2) Self-esteem, reflecting self-value and self-views. (3) Interpersonal skills, focusing on effectively working with others. (4) Self-management, including self-assessment, self-monitoring, selfcontrol, and goal-setting. (5) Integrity and Honesty, reflecting use of ethics to make decisions. (U.S. Department of Labor, 1991, p. 16) 
Students with disabilities are generally lacking in many of these skills and most school programs have not identified courses or curriculum in which to teach them.

\section{Kentucky Actions}

To meet the national objectives and mandates, Kentucky responded with a series of projects and legislative actions that impact transition. In an unprecedented and sweeping move, the State Legislature (1990) dissolved Kentucky school regulations and mandated a series of target skills that all students should possess as they leave high school. This movement was named the Kentucky Education Reform Act (KERA) and gave new overall structure to curriculum in Kentucky public schools. First, the legislation included all students, including students with disabilities in curricular and testing requirements. Second, all curricular activities had to meet one or more of the KERA goals for students. New state-wide tests were devised to focus on the goals and an alternate portfolio method was added for $1 \%$ of the population in the most severely disabled category. Students with mild disabilities were generally exempted from participating in an alternate portfolio and were held to the same standards as regular education students. Teachers were not given training to implement these sweeping changes beforehand, so the process of assessment with accommodations and alternate portfolio assessment has evolved over the years.

Legislation was proposed in Kentucky (Teacher Quality Summit, 2005) that increased the graduation requirements in the areas of science and mathematics. Students with disabilities had difficulty meeting the old requirements and will have even greater difficulty with the new requirements. The size of the exemption pool has not increased, so special education teachers are expected to prepare mildly disabled students to participate in the regular testing. Accommodations that are used daily are allowed for testing purposes, but questioned closely by administrators and testing officials to see if they are necessary. 
To have accommodations during the assessment, the accommodations need to be added to the IEP and used daily. Each year, the scoring for the alternate portfolios has become more stringent so that it is increasingly more difficult for students with disabilities to score in the Proficient or Distinguished categories.

The Kentucky Department of Education (KDE, 1998, p. 4) revised the Program of Studies. This is the official description of courses which constitutes the overall academic content for the curriculum, to "ensure that all students across the Commonwealth are provided with the same content and have the same opportunities to learn at high levels” (p. 4). Each academic area was asked to align curriculum from elementary through middle to high school courses. Many changes were made to update subject matter and insure concepts were introduced in elementary school to support higher-level thinking by the time students were in high school. For instance, under the requirements of KERA (1990) and Carl D. Perkins legislation (1998), vocational education in Kentucky has evolved to correlate more closely to science and mathematics curriculum. Mandates to include LBD students in the regular curriculum resulted in sweeping changes to service delivery for special education. Both special and regular educators struggled with inclusion and collaboration activities.

A state-wide system as been developed to track students as they move to different locations and/or drop out. The state system categories were not counted the same as some local districts, so it was difficult to evaluate the actual drop-out rate. The Kentucky Department of Education began posting these figures on their website for general public knowledge. Since the present research is a partial program review of an intervention project designed to reduce dropouts and increase success in transition outcomes, the following comparison between Kentucky and local district dropout rates is provided. 
According to the Kentucky Department of Education School Year Data for Exceptional Child Education (Kentucky Department of Education, 2001), during 20002001, the three categories of students in mild disability range that are targeted for this study had the following percentages of diploma completers across the state: 36\% of MMD, 8.16\% of EBD, and $36.04 \%$ of LD. Non completer rates for the same categories were: $22 \%$ of MMD, 17\% of EBD, and 18\% of LD students (other possibilities related to uncertainties regarding student outcomes account for why completers and non-completers do not sum to $100 \%)$. Note that these figures do not include all special education categories, but focus on the three targeted groups for this research.

Data were also provided by counties. When compared to the state average, the local district involved with this project, Jefferson County Public Schools (JCPS), reported lower diploma and certificate of attendance graduation combined rates: MMD, 28\%; EBD, 8\% and LD, 30\% at the time of the STEP Grant. The JCPS non-completion rates were higher than the state average with MMD, 31\%, EBD, 20\% and LD, 23\% (KDE, 2004). The uncertainties noted above for the state data were specified here; included were drop outs (non-completers) as well as students who no longer received special education, maxed out due to age, moved but known to continue, moved but not known to continue, others, and those who were deceased. In order to improve this trend, a federal grant was written and implemented to improve services for LBD students exiting from the local school district.

$$
\text { Steps Toward Educational Progress (STEP) Grant }
$$

The JCPS system is the largest school district in Kentucky. The district provides comprehensive educational services for over 90,000 students from ages 3-21+. JCPS includes metropolitan Louisville and the surrounding suburbs; the entire county is one consolidated school district. Within this system, there are 22 high schools and full special 
education services throughout the district. Students attend elementary schools in grades P5 , middle school in grades 6-8, and high schools in grades 9-12+. Themes or magnets have been identified to attract students to inner-city schools, and a system of student assignment using school clusters with managed choice (Norton, 1998) is in place to insure all schools meet a targeted percentage range of minority students for desegregation purposes. The University of Louisville is a metropolitan university and is located within the boundaries of Jefferson County.

The STEP Grant began in 1996 as a pilot project to assist students with disabilities in preparing for postsecondary education or competitive employment following high school. It was funded through an Office of Special Education and Rehabilitation (OSERS) federal grant to the University of Louisville and implemented with the local school district, JCPS. The first intent of the project was to improve high school transition services for students with specific learning disabilities (LD), emotional or behavior disabilities (EBD), and mild mental disabilities (MMD). The second intent was to improve the infrastructure of postsecondary institutions to support these students in employment, education, or independent living venues. An assistant professor at the university served as the Primary Investigator (PI) for the project. At the completion of the three-year STEP Grant, a oneyear No-cost Extension was awarded by OSERS to complete grant activities. The STEP Follow-up Survey was one activity accomplished during the No-cost Extension year (2000) and was designed to gather information from the same students, instructors, and community members who participated in the intervention study.

\section{Scope of the STEP Grant}

Six participating schools were identified by the school district Exceptional Child Education staff as being in need of improved transition support services. Each school had 
large numbers of mildly disabled students who were at risk of dropping out of school and/or being unsuccessful at transitioning into employment and/or postsecondary education identified by the school staff.

Training was provided for 125 administrators and secondary teachers from targeted and other district high schools, plus 12 Elective Class teachers who taught classes at the six high schools (identified later in this research as Schools A through F). Training was also provided to 201 Professors, Associate Professors, and Instructors from the university, community college, vocational/technical schools, a prison educational facility, and Department of Vocational Rehabilitation staff. Transition linkages with the area postsecondary institutions and community agencies that support students after graduation were strengthened through this training. Training was provided for students in the elective classes. They were taught Content Enhancement Strategies (CES) and Self-advocacy Strategies for use in their high school and postsecondary settings.

The STEP Grant provided services and training from 1996-2000. The one year Nocost Extension allowed collection of data during the summer and fall of 2000 to ascertain effectiveness in two areas: The first section surveyed the 108 students with mild disabilities who participated in the project. The second section surveyed 338 instructors at high school and postsecondary institutions, administrators, and community agency representatives who had participated in training in the original project. Only student data was be considered in this current research.

\section{Purposes for the STEP Grant}

The purposes, as stated in the original STEP Grant request are as follows:

1. Develop and implement training of 150 regular and special education teachers and staff at the school district educational and vocational programs along with 150 faculty at the community college, community technical school, and the University 
of Louisville in Content Enhancement Strategies (CES) and life skills (LCCE) to improve instructional delivery to students with learning disabilities.

2. Develop and implement a transition/futures planning program to 90 (30 each year) students with learning disabilities, ages 16-22, which emphasizes student and family involvement and delineates specific career, living, and community outcomes and activities.

3. Develop and implement a jointly operated (by the community college, technical school, and the university) summer prep and academic year cooperative program to 90 (30 each year) students with learning disabilities, ages 18-22, that will provide postsecondary educational and career exploration and awareness, job shadowing, job seeking skills, job skill training, and remedial instruction.

4. Develop, evaluate, and replicate model program, materials, manuals, and articles by disseminating information on training methods and program features, and the model program of training in instructional strategies and enrichment/cooperative programs. (Simmons, 1996, p. 11)

The overall purpose of this project was to keep targeted students in school and better prepare them for transition outcomes in postsecondary education, employment, and adult living. The intent was to develop six model schools, then expand the process to all district high schools. Secondarily, the project provided training for those institutions and agencies who continue support for students with disabilities after high school.

The main purpose for the No-cost Extension was to collect and analyze follow-up data to determine success in the outcome areas of employment, postsecondary education, and independent living. The extension also allowed services to continue for students through the elective class. A literature review of recent research provided criteria to determine success for each of the outcomes. The methods and strategies used in the original study were to be analyzed for success in teaching and disseminated to other high schools in the district.

\section{Participants in the STEP Grant}

Students who were referred for this voluntary program were experiencing lower 
success rates in academic classes and were identified by school staff as at-risk for dropping out of high school. The grant application stated:

...each student that is accepted for participation in the project must meet the 'classic' definition of LD and, further, have significant deficits that would 1) preclude the student with LD from being accepted by any of the three participating postsecondary institutions, or 2) projected to be unsuccessful. (Simmons, 1996, p. 20)

To clarify admission to the project, teachers agreed on the following criteria for referral: student's self-reported desire to leave high school; number of discipline referrals; attendance records; difficulty in completing regular education requirements; socioeconomic status (free or reduced lunch); low self-esteem or lack of appropriate social skills, and, parental requests for help in keeping their student enrolled. Selection was not based on "race, creed, nationality, gender, or other non-pertinent characteristics of the individual student. All students had to agree that entrance to postsecondary training would be one of the transition goals on their ITP [Individual Transition Plan]” (Simmons, 1996, p. 20). All students with LD attending the six project schools were encouraged to participate. All students with staff referral, student agreement, and parental permission were accepted. The total number of student participants at the end of the third year was 108 across the six high schools.

The Follow-up Survey focused on students who had received services through the STEP Grant between 1996 and 1999. After permission was received, 50 of the 108 total students agreed to participate in the Follow-up Survey, returned permission forms, and completed surveys. The Contact Letter and Student Survey are included in Appendix A. Students were contacted by telephone if the written survey had not been returned within two months of mailing. Some of the students then returned the survey while others preferred to be interviewed by phone. Interviews were conducted by the Project 
Coordinator (PC) from the original study who knew the students well. He followed the written survey for the interview protocol.

The second section of the Follow-up Survey collected data from high school teachers and postsecondary staff at the area educational institutions where training through the STEP Grant was offered. After permission was received, 125 of the 201 participants agreed to complete the Follow-up Survey, returned permission forms, and completed surveys. This information was extensive and was not included in this dissertation.

\section{Implementation of the STEP Grant}

An advisory committee was formed under the direction of the PI. Membership included university teacher educators and staff, school district administrative staff, and representatives from the Department of Vocational Rehabilitation and Disability Resource Centers. This researcher served as a member of the Advisory Committee. The committee assisted in identifying best practices for organization of the elective class and also selected student materials. They identified linkages that needed to be strengthened for the transition process to be successful as the students moved from the school system to adult agency support. They developed a job description for the PC. The PI and PC attended training at the University of Kansas in a Train-the-Trainer Model for Content Enhancement and Selfadvocacy Strategies. They researched and ordered materials, organized educational kits, and developed staff training. Classes were phased in as staff training and student selection were completed at each school site. The first school opened the elective class in spring of 1996, and five additional schools (total of six) began in fall of 1997.

The advisory committee then developed a job description for a teacher assistant who would serve as the project Job Trainer (JT). Staff received training to help the students understand the connections between good attendance, work habits, career 
preparation, work experience, and postsecondary school outcomes. Both formal professional development presentations and on-going informal support sessions were provided throughout the three project years. The PC and JT provided hands-on modeling, demonstrations of materials, and sample lessons for the teachers. They delivered model mini-lessons, developed work experiences for students, provided on-the-job supervision, arranged interviews, and assisted with placement in part-time jobs.

Information was provided for parents and students, and applications for entrance to elective classes were accepted. The PC interviewed students and contacted parents. Although the students voluntarily applied and participated in this project, each student was required to adjust annual goals on his/her IEP with parent input. Goals were added to include the elective class, work experiences, and community activities connected to the grant. A certified special education teacher at each high school was appointed to teach the elective class. At the beginning of the project many students had expressed preferences for career goals that required postsecondary education. However, very few of these students had made applications or financial arrangements necessary to attend postsecondary education institutions. These students had not taken college entrance tests (ACT or SAT) or participated in college visitation days that were scheduled for regular education students.

A doctoral student at University of Louisville (this researcher) and the PC from the original STEP Grant were employed by the PI to collect follow-up data during the No-cost Extension. A Human Studies Application was filed with the University of Louisville Human Studies Committee by this researcher, approved in May of 2000, and has been renewed each year (See Appendix B). A Permission to do Research Application for the local school district was also completed by this researcher and was approved by their 
Research Department (See Appendix B). This researcher has also completed IRB training as required by the University of Louisville and has completed update training each year.

This certification is current until March, 2008.

\section{What Did the STEP Grant Provide?}

The grant provided support services, job development, and educational materials

for students in the project. Training in strategies, methods, and curriculum was provided for twelve teachers from six-targeted schools. Students attended a one-hour elective class daily. They received $1 / 2$ vocational credit per semester in the program. As summarized from Simmons (1996, pp. 36-38), the overview of the grant follows:

The model planning process evolved around the implementation of a secondary school age preparation program on the campuses of three postsecondary institutions. The elective class focused on three primary strategies: (a) the development of individualized transition plans through Kentucky's required transition planning structure; (b) the development of a training program for selfadvocacy, Self-Advocacy Strategy System (SASS) (VanReusen, Bos, Shumaker, \& Deshler, 1994); (c) the development of individualized supports and Content Enhancement Strategies (CES) (Lenz, Schumaker, Deschler, \& Beal, 1994; Schumaker, Denton, \& Deschler, 1984); and (d) life skills addressing educational/vocational needs of the student using the Life Centered Career Education Curriculum (LCCE) (Brolin, 1993). The SASS is a motivation strategy that students use when preparing for participating in an education or transition planning conference. It provides for a step-by-step method for students to organize their interests and desires prior to a conference and includes techniques to help the students express themselves appropriately during the conference (VanReusen et al., 1994). The CES is designed to teach the student methods to participate in the learning process and in that fashion can be applied to both academic classes as well as life-long learning (Lenz et al., 1994). The LCCE curriculum helps focus on choosing careers and generalized life skills to benefit students with learning disabilities. The teachers in the project as well as postsecondary receiving teachers were trained in all of these same materials.

Another goal of the project was to assess student self-awareness, knowledge, and capabilities required for the students' chosen careers. The resources used in this analysis include the United States Employment Services Assessments (Dictionary of Occupational Titles [DOT], General Aptitude Test Battery [GATB], Nonreading Aptitude Test Battery [NATB], Guide for Occupational Exploration [GOE]). 
Students were given assistance in learning about their personal disability and support structures needed to become successful in postsecondary training and education. Some of these supports included note taking, tape recording, concept organizing strategies, and study skills. In addition, the following assessments were scheduled for students during the elective class:

1. The Self-efficacy Scale (Sherer, Maddus, Mercandante, Prentice-Dunn, Jacobs, $\&$ Rogers, 1982).

2. The Nowicki-Strickland Locus of Control (NSLC) (Nowicki \& Strickland, 1973).

3. The Judgment of Occupational Behavior-Orientation (JOB-O) (Cutler, Ferry, Kauk, \& Robinett, 1995).

4. The Holland Self-directed Search (HSS) (Holland \& Powell, 1994).

5. Tests of Adult Basic Education (TABE, 1987).

Additionally, academic testing to determine reading and math levels were administered to provide appropriate supports. Collaboration with regular education academic teachers and vocational teachers was provided by elective teachers to pinpoint learning strategies to help students pass needed required courses.

The extended year program included funding for public bus training and career exploration on each of the postsecondary institution campuses. The Disability Resource Center staff at each postsecondary institution, PC, and JT provided training in how to complete the application process for postsecondary training; how to access services; and what career paths were available. Additionally they facilitated a variety of in-class experiences on each campus and taught pedestrian and bus riding skills. This researcher provided assistance with Community Based Education (CBE), safety, pedestrian, and public transportation skills. 
The No-cost Extension provided salaries for a full-time graduate student (this researcher) and part-time continuation salary for the PC. The other portion of the PC's salary was paid by the local district in 2000. In 2001, the PC was employed permanently by the district as the Transition Coordinator. The No-cost Extension also provided funding for mailing of surveys. This researcher and the PC collected all data, entered results in an SPSS database, prepared all mailings, and maintained records for the No-cost Extension.

\section{Programmatic Summary of the STEP Grant}

First, professional development was targeted to raise the awareness of materials and teaching strategies for use with LBD students. The grant provided training for local school district staff, postsecondary institution faculty and disability resource center staff, and representatives from Department of Vocational Rehabilitation staff. This collaborative effort strengthened cooperation and led to on-going efforts to raise the level of awareness and expertise in meeting the needs of the students with disabilities as they left public schools. Training material used and strategies developed in elective classes were to be disseminated throughout the school district for use by special education teachers in all middle and high schools. Through staff development connected to the grant, the expertise of the teaching staff in the six elective classes was perceived to be greatly enhanced, but this intense training did not filter to other staff in the project schools nor to other middle and high schools after the grant was completed.

Second, the initial start-up of the program took much longer than expected to recruit students, obtain parental permissions, and add the elective class to the high school schedule. Parents were often unresponsive to written materials; this necessitated telephone calls and personal meetings. Students had to be convinced that adding a class to their schedules would enhance their high school completion. Attitudes from both students and 
parents had to be changed to begin a spirit of cooperation and instill a feeling that the student could succeed in higher level learning. Teacher schedules had to be altered to cover the elective class period. After these barriers were overcome, a total of 108 students from the six participating schools were engaged in the project. These participants were only a small percentage of the total students in the LBD category attending those six schools. Many students who did not participate were doing well in their academic or vocational classes with existing supports and did not see the need to change their program. Other students at the lower end of the spectrum did not want to be in school and did not choose to participate in any additional activities. Efforts to obtain comparison groups from the six schools were not successful. District follow-up data collection systems were not in place at the time of the study, so data were unavailable for comparison.

Another delay in starting the project resulted from the need to follow district procedures to advertise jobs and interview prospective candidates. These procedures, which had to be followed according to the school district and teacher's union guidelines, caused a delay in the first elective class opening until mid-year of the first grant year. The other five schools were delayed until fall of the following year.

Optional summer sessions were organized for 30 days the first year and 15 days the second year. Not all students attended one or both summer sessions. Constraints in budget precluded expansion of the summer program for more days, or to other years. Many students obtained part-time summer jobs and did not want to participate for the small stipend available through the grant. Others wanted summers off for personal reasons. Funds were not available to offer a third year of summer programming.

The intent of the summer program was to introduce students to postsecondary campuses, thereby allowing them to experience classes in higher education. The Disability 
Resource Center staff provided an introduction to services. Faculty allowed students to visit classes in a career area of their interest. Several students were able to explore areas and expand their thinking about careers they had never considered prior to this participation. In addition, students were afforded an introduction to training for travel on the public bus system, which would have been the primary mode of travel for most of them after graduation.

Teachers were asked to repeat the above career planning tests each year so that student progress could be charted. This did not get done. With students' absences, school schedules, activities, student movement between schools, and other interruptions, many students completed only one test during their entire enrollment period while others had two or three. For this reason, statistical results from these tests were not included with the Final Project Report or the Follow-up Survey Final Report for OSCERS. Student data were complete for two of the tests: Self-efficacy Scale (Appendix C) and Locus of Control Scale (Appendix D). Other tests listed above had many incomplete results and were not analyzed.

\section{The Problem Defined}

Significant changes in the delivery of education for students with special needs have occurred over the past thirty years. Movement from separate and not equal services to inclusion with the general population with supports has impacted curriculum, support strategies, and program outcomes that are expected after the students with disabilities leave school services. With the shift to an outcome-based model, program evaluation concentrates on three major areas of life: Employment, Postsecondary Education, and Independent Living in the community. The NLTS2 (2005) study results show positive changes in these areas for students with mild disabilities. However, even with changes in 
the educational delivery system in collaboration, inclusion, vocational education, and emphasis on outcomes, students in the targeted groups were not improving graduation rates to access more difficult jobs or gain entrance to postsecondary education. Economic earning ability directly affects ability to live independently and overall personality development, e.g., self-esteem and locus of control. Additional improvements are necessary to ensure students in the MMD, EBD, and LD categories become successful adults.

Federal legislation has developed many mandates to help students with disabilities access the general curriculum and be better prepared to become responsible citizens as adults. Curriculum reform has identified improved career paths to access higher education and be better prepared for higher level jobs. Some improvement has been seen in employment rates, but not much increase of jobs with more responsibility or prestige. Some improvement has also been seen in the numbers of students with disabilities receiving high school diplomas and seeking postsecondary education. Little improvement has been seen in completion of college or technical-level coursework. These areas still need extensive improvement before students with disabilities can become more independent, meet their personal goals, and improve their quality of life as adults. Living independently as an adult depends on economic earning power, successful application of community skills, self-concept improvement, and hard work. These are not easy objectives for students with disabilities to reach.

Teacher education needs to be substantially improved to train all levels of teachers: academic, vocational, and special education, and all ages of students: elementary, middle, high, and postsecondary. Teacher training programs need to provide educators practice in support skills to help students develop their personal potential. Support skills include areas 
such as collaboration, inclusion, self-determination, self-efficacy, and locus of control. It is important to identify predictors of success while students are still in school so that development of these skills will allow students with disabilities to prosper as adults. Purpose of the Study

The present research addresses the issues delineated above for students with disabilities. Specifically, this research examines existing student data from an intervention project and Follow-up Survey which was completed in a Midwest metropolitan school district. The STEP Grant provided an elective class to assist students with mild disabilities in developing career goals, obtaining employment, exploring higher education related to their career goals, and providing specific learning strategies to help them complete high school diploma courses. This Grant provided training and support for high school teachers, students, parents, and postsecondary receiving teachers to connect learning to career goals and assist students in making a more successful transition to adult status. A description of the various parts and outcomes for the grant is in the proceeding section beginning on page 19.

Students were enrolled in one of six target high schools, received special education services in the mild disability range, and participated in the STEP Grant. According to the Exceptional Child Education Office, Kentucky Department of Education, the mild disability category includes students with Specific Learning Disabilities (SLD or LD), Behavior/emotional Disabilities (BD, ED, or EBD), and Mild Mental Disabilities (MMD). Mild disabilities together are often referred to as Learning/Behavior Disabilities (LBD). These categories are described more fully in the Definition of Terms section below.

This research is a partial evaluation of the STEP Grant and focused only on the students who were participants in the grant and their outcomes after graduation. The grant 
also contained data on the capacity building of teachers and other service deliverers (postsecondary educators, community agency personnel, and prison educators), but this study only examines the student data portion.

For analysis of this study, all subjects were enrolled in one of six target high schools and received special education services in the mild disability LBD range (MMD, EBD, and LD) and intervention services as part of the STEP Grant. Within the scope of this grant, this research seeks to determine if factors predicting success for students with disabilities can be identified for post-school outcomes. If predictors are evident, school programs could assess students early in their middle and high school years and enhance the educational program by utilizing this information to meet student's needs through the IEP process. Thus, the central research question for this dissertation is: What are the effects of the STEP Grant on the transition of students with mild disabilities to post-school outcomes?

\section{Research Questions}

The STEP Grant contains three types of data that represent Independent Variables: demographic, information on the intervention, and mediating factors (student Self-efficacy and Locus of Control). The transition outcomes represent the dependent variables: employment, postsecondary education, and independent living. Those relationships are depicted in Figure 1. 

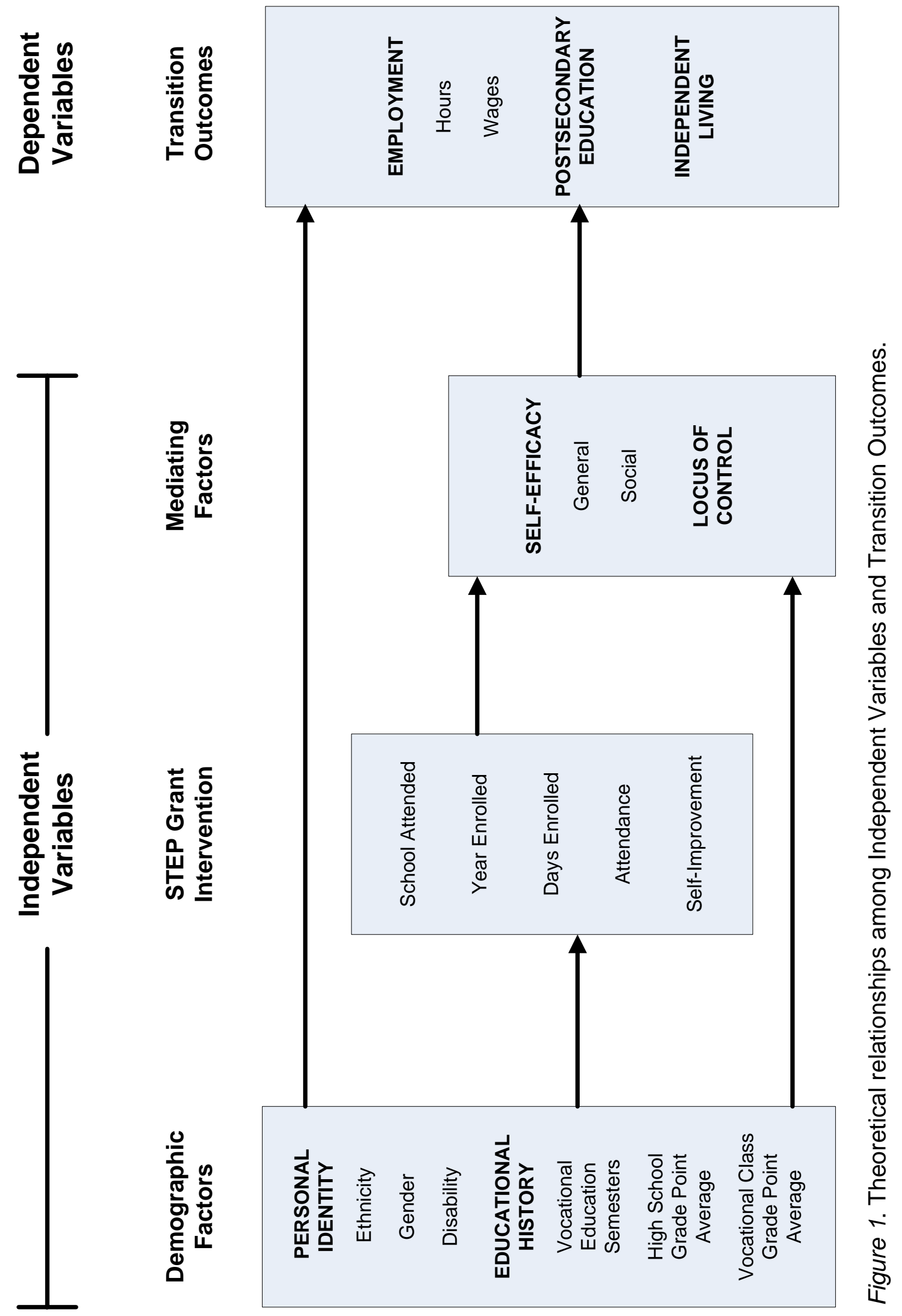
The following empirical research questions were addressed in this partial program evaluation. Both descriptive questions regarding compliance with regulations (and outcomes) for transition planning and relationships among the independent variables and transition outcomes are relevant.

1. With respect to transition planning:

a. How many of the students in the Follow-up Survey have a completed Transition Plan on file in the school district archives?

b. Did the student's career goal listed on the Transition Plan match the area of enrollment in vocational training?

c. Did the student's career goal listed on the Transition Plan match the first job after high school as reported on the Student Follow-up Survey?

d. Did the student's career goal listed on the Transition Plan match the postsecondary education major enrolled in at the time of the Student Follow-up Survey?

e. How many students had a match between the Transition Planning Goal, vocational education enrollment, and job held and/or postsecondary education major at the time of the Student Follow-up Survey?

2. What proportion of the students had completed transition (met criterion for success specified in the STEP Grant) at the time of the Follow-up Survey in:

a. Employment?

b. Postsecondary Education?

c. Independent Living?

3. To what extent are demographic factors related to:

a. Participation in the STEP Grant:

i. School Attended?

ii. Year Enrolled?

iii. Days Enrolled?

iv. Attendance? 


$$
\text { v. Self-Improvement? }
$$

b. Mediating personality factors:

i. Self-efficacy scores?

ii. Locus of Control scores?

c. Transition in Employment reported on the Student Follow-up Survey?

4. To what extent is participation in the STEP Grant

a. School Attended

b. Year Enrolled

c. Days Enrolled

d. Attendance

e. Self-Improvement

related to:

a. Mediating personality factors:

i. Self-efficacy scores?

ii. Locus of Control scores?

b. Transition in Employment reported on the Student Follow-up Survey?

5. To what extent are Mediating personality factors

a. Self-efficacy Scores

b. Locus of Control Scores

related to transition in Employment reported on the Student Follow-up Survey?

6. When controlling for demographic factors, to what extent is participation in the STEP Grant

a. Year Enrolled

b. Days Enrolled 
c. Attendance

d. Self-Improvement

and mediating personality factors

a. Self-efficacy Scores

b. Locus of Control Scores

related to transition in Employment reported on the Student Follow-up Survey?

7. What are students' perceptions of the STEP Grant with respect to:

a. Employment?

b. Postsecondary Education?

Significance of the Study

Research in special education is incomplete in the area of predicting success for students with disabilities. Several studies outlined best practices, but national standards have not been established for transition. Self-efficacy and locus of control are areas of personality development that have documented research findings focused on a variety of subjects. Special education research often refers to lessened self-efficacy and lessened locus of control connected to students with disabilities. However, little empirical research was found on this topic for special needs students. If predictors of success are identified, educators could focus attention on improvements to help students with disabilities to transition more successfully.

\section{Limitations of the Study}

The STEP Grant was designed as a pilot project to intervene with a difficult-toserve group of students in the Jefferson County Public Schools. These students were 18-21 years old and identified as at risk of dropping out of high school prior to completing 
graduation requirements. The grant provided research-based materials and strategies, but lacked the support to make the six schools cohesive in the implementation of the project. Only a small number of students with mild disabilities were enrolled in the project, instead of the entire special education population at each of the schools. No control group was identified, so comparisons between students who participated and those who did not is not possible.

During the STEP Grant, the students' level of participation and involvement in planning to choose careers as a part of the transition process were not measured. The PC and elective class teachers reported that some students had the attitude that they were marking time until they graduated and could not really change what happened to them, while others took a good look at themselves, the options available, and systematically applied what they learned to make their outcomes better. Because of possible differences in student participation and involvement and lack of measurement thereof, these factors were not included in the present research.

After the project was completed, a Follow-up Survey was distributed but only received approximately 50\% return. Thus, the number of students who answered the Follow-up Survey was a small number. Students were not prepared during their participation years for the Follow-up Survey. Other reasons for the small return may have been incorrect addresses or phone numbers; parents/relatives being unwilling to divulge information; students who did receive a Follow-up Survey may have not been able to comprehend the reason for or importance of the study and may have thrown it away; some students were incarcerated; and some may have just chosen not to respond.

The Follow-up Survey was limited to LBD students who participated in the STEP intervention program. No research was attempted with LBD students in the same schools, 
other schools, or regular students in the same or other schools. The district did contact students three months following graduation by phone, but the format of their contact was not as extensive as the STEP Follow-up Survey. Few students who had participated in STEP Grant answered the JCPS phone survey questions.

All of these issues limit generalizability of the findings. Specifically, several issues that follow should be noted explicitly. Data were collected from students who were in the STEP Intervention Grant during high school in the 1997-2000 school years. Depending on the cohort of the participants, attendance and participation years varied. The Follow-up Survey was done at a set time (the fall of 2000) which made the time out of high school vary according to graduation year.

With the small sample in this research ( $N=108$ in the project), and less than $50 \%$ response in the Follow-up Survey $(n=50)$, it would be very difficult to make broad generalizations about cohort differences over the course of the intervention, or regarding length of time after high school completion. However, given that these differences according to year of graduation were minimal, for this study any cohort differences were ignored.

The small number of cases available limited the statistical calculations that were done. This was particularly troublesome for the research questions that involved relationships, especially for any attempts to do multiple regression, since the number of cases available did not adequately support the number of variables of interest. That necessitated piecemeal analysis as was possible rather than an overall consideration of all variables simultaneously.

The teachers in the elective classes implemented strategies and record keeping with differing levels of accuracy. A few were proficient at keeping attendance, test results, and 
Transition Plans. Others did not internalize these skills vis-à-vis helping students progress or taking the purpose of the intervention seriously. In the original STEP Grant, no research data were gathered to compare teachers in this area. Thus, the quality of data on the students varies depending upon which school they attended. Such variations cannot be accounted for in this study.

The STEP Student Follow-up Survey was not validated on a prior group. Wording and format may have precluded students from understanding the concepts or questions. A better system of contacting students and providing verbal explanation may have resulted in greater returns, but this was not tested. The researcher has no way of knowing if the language in the survey, lack of interest, lack of reading skills, preference for receiving information verbally, or other factors prevented students from returning the Follow-up Survey.

With only a small portion of the LBD students at each school participating in the Follow-up Survey, it was difficult to generalize to the population of special needs students. Since the school district did not include a systematic tracking system at the time of the STEP Grant for all special education students, no comparisons between LBD students who were participants in the intervention program and Follow-up Survey and LBD students who did not participate at the same school or other district locations was possible.

\section{Definitions of Terms}

The following terms are common to the literature that is being discussed. A short definition follows the term with the source at the end of each entry.

Collaboration--“The process of professionals [regular educators and special educators] working jointly with others; willingly cooperating with others; and sharing in goal setting, problem solving, and goal achievement” (Mastropieri \& Scruggs, 2007, p. 
27).

Cooperative Education--School based programs where primary instruction takes place in the classroom and is supplemented with worksite experience (Sarkees-Wircenski \& Scott, 1995, p. 723).

Co-teaching--A general term that captures the specific application of collaboration in which two professionals form a partnership to instruct jointly a diverse group of students, including those with disabilities, in a general education setting. Arrangements may include: (a) One instructor teaching while the other observes; (b) Station teaching in which students are divided and rotate through groups led by the teachers; (c) Parallel teaching, in which students are divided in two groups and concurrently receive similar or complementary instruction from one of the teachers; (d) Alternative teaching, in which a small group of students is pulled to the side for purposes such as remediation, enrichment, or assessment; (e) One teaching, one assisting, where one teacher leads instruction while the other supports individual students; and (f) Team teaching where both teachers simultaneously share the direct instruction of the content (Wunder \& Lindsey, 2004, p. 2). Disabled--Individuals who are identified as disabled under the Americans with Disabilities Act (ADA)

...include any individual who has a physical or mental impairment that substantially limits one or more major life activities, has a record of impairment or is regarded as having such an impairment; or are evaluated under the Individuals with disabilities Education Act (IDEA) and deemed in need of special education and related services; and any individual considered disabled under the Rehabilitation Act of 1973. (The Carl Perkins Vocational and Applied Technology Education Act. (Sarkees-Wircenski \& Scott, 1995, p. 724)

Emotional-behavioral disability (EBD)--The definition used by the Kentucky

Department of Education, Exceptional Child Education for placement purposes is:

A condition characterized by behavioral excess or deficit when compared to peers 
and cultural reference groups which significantly interferes with a child's interpersonal relationships or learning process to the extent that it adversely affects educational performance; the comparison is across settings, over a long period of time and to a marked degree. (KDE, 2006, p. 1)

Locus of control--A belief that the power to effect change comes from within oneself (Steere et al., 2007, p. 32). Internal locus of control means that the person believes he/she can control how issues affect them. External locus of control suggests the belief that external forces control one’s life.

Internship--Planned vocational instructional experiences designed to provide students with additional technical competencies at a worksite (Sarkees-Wircenski \& Scott, 1995, p. 727).

Job shadowing--visiting a worksite and observing one or more employees performing the day-to-day duties of a job in which the student is interested (Burgstahler, 2001, p. 2).

Managed choice--A school organization model used to mix student socio-economic status and maintain desegregation that includes: clusters, magnet schools, traditional schools, satellite schools, schools with Advance Programs, honors programs, "regular" programs, and optional programs (Norton, 1998, p. 2).

Mild mental disability (MMD)--The definition used by the Kentucky Department of Education, Exceptional Child Education for placement purposes is:

A deficit or delay in intellectual functioning (at least two but no more than three standard deviations below the mean) and adaptive behavior (at least two standard deviations below the mean), which adversely affects overall academic performance to the extent that specially-designed instruction is required, and which typically manifests during the developmental period. (KDE, 2006, p. 2)

Peer tutoring--"Tutoring by same-age or cross-age students to increase student opportunities to respond, provide additional practice for targeted skills, provide corrective 
feedback, learn social skills, and improve academic skills” (Mastropieri \& Scruggs, 2007, pp. 175-182).

Problem-solving and decision-making skills--“determining reasonable courses of action when presented with challenges” (Steere et al., 2007, p. 32).

Self-advocacy--“Speaking up on one’s own behalf, stating needs and preferences” (Steere et al., 2007, p. 32).

Self-confidence--“A belief in one’s own abilities, determination to make things happen for one’s self” (Steere et al., 2007, p. 32).

Self-determination--“Ability to take greater control over one’s own life and decision making” (Steere et al., 2007, p. 31). “A combination of skills, knowledge, and beliefs that enable a person to engage in goal-directed, self-regulated, autonomous behavior” (Field, Martin, R. Miller, Ward, \& Wehmeyer, 1998, p. 115).

Self-efficacy--“A belief that one’s actions will have an impact and will positively affect one’s own future” (Steere et al., 2007, p. 32).

Self-management--“skills related to setting goals for oneself, monitoring progress toward those goals, and taking action to achieve goals” (Steere et al., 2007, p. 32).

Service Learning--Students gain job skills as they provide a community service in a non-paid volunteer service-learning experience. This application of knowledge and skills while contributing to the community can be with or without academic credit (Burgstahler, 2001, p. 2).

Specific learning disability (LD)--The definition used by the Kentucky Department of Education, Exceptional Child Education for placement purposes is:

Not achieving commensurate with age and ability level; has the intellectual ability but there is a substantial discrepancy between achievement and that intellectual ability in one or more of these areas: oral expression, listening comprehension, 
written expression, basic reading skills/comprehension, or mathematics calculation/reasoning; the discrepancy between ability and achievement is not due to a mental disability, visual, hearing or motor impairment, emotional-behavioral disability or environmental, cultural, or economic disadvantage. It includes conditions like dyslexia, developmental loss of the ability to speak and perceptual disabilities. (KDE, 2006, p. 1)

Transition services--As defined by IDEA legislation of 1990:

A coordinated set of activities for a student, with a disability, that: (A) is designed within an outcome-oriented process, that promotes movement from school to post-school activities, including postsecondary education, vocational training, integrated employment (including supported employment), continuing and adult education, adult services, independent living, or community participation; (B) is based on the student's needs, taking into account the student's preferences and interests; (C) includes instruction, related services, community experiences, the development of employment and other post-school objectives, and, when appropriate, acquisition of daily living skills and functional vocational evaluation. (Steere et al., 2007, pp. 11-12)

Vocational and applied technology education--organized content of a program structured as a series of intended outcomes or competencies which a student must master to attain an occupational goal. It involves the sum of all experiences and learning activities encountered in the classroom and laboratory and encompasses what is to be taught and what is to be learned (Sarkees-Wircenski \& Scott, 1995, p. 731).

\section{Summary}

Efforts to help students with disabilities improve their high school experiences and make a successful transition to adult life have been underway for over thirty years. To begin the current research, legislation supporting school programs and transition was reviewed. Transition planning guidelines and applications for students with disabilities were outlined. The STEP Grant was described along with the No-cost Extension that provided the existing data for this research. The problem, which is the focus of this research, was defined, and the purpose of this study was outlined. Research Questions were listed, along with the significance and limitations for this study. A brief summary of 
each of the major topics follows.

Legislation in the U.S., from early civil rights laws to the current NCLB, has increased access to quality educational procedures and strategies. This was necessary since large numbers of the school-age population of students with disabilities were prevented from participation in regular education classes and were not successful when they left public schools. Each successive piece of legislation was designed to strengthen long range planning for the successful transition of students with disabilities through the legally binding IEP process.

The focus on transition increased participation of students with disabilities in collaborative classes between regular education and special education teachers. As outcomes were identified through the large number of federal grants to states to implement transition programs during the 1990s, success in employment, postsecondary education, and independent living was outlined. Methods were devised to make the educational experience more accessible with supports and help students with disabilities achieve at a higher level.

Transition planning was mandated through the IDEA legislation to include selfdetermination skills and participation by students in the IEP meeting. Planning with students present during the meetings changed the tone, planning for the IEP, and transition plans. Student's wishes, desires, career goals, etc. were considered in the planning process. Inclusion in regular academic and vocational classes increased opportunities for these students. Emphasis on self-determination was the key for including personal attributes in areas of self-advocacy and locus of control. Both national and Kentucky demonstration projects have shown that increased success is possible with careful planning in place.

An overview of the STEP Grant, implemented in the local JCPS schools, was 
provided to explain the background for the student-focused program. The STEP Grant was designed for students with LD, EBD, and MMD to become more successful in employment, postsecondary education, and independent living. A Follow-up Survey recorded their status approximately one to three years after they left public school. School records provided information regarding their educational programs, attendance, and transition planning.

This research probes data from the intervention project and Follow-up Survey to look for predictors of success following high school. Educators could improve the curriculum to make the transition more successful for students with disabilities with a clear set of predictors. Identifying indicators of success would be a significant addition to the education of students of disabilities. However, due to the small number of students involved in this project, differences in application by school staff in the various schools, differences in participation by students, lack of validation of the survey instrument with students having mild disabilities, lack of control groups, and failure to set Follow-up Survey collection dates for the same interval of time following graduation, the predictive ability of the findings was be severely limited. Terms that were significant to the understanding of this research were defined.

Thus, this study represents a partial program evaluation of a collaborative intervention project by JCPS and the local university to improve the transition from high school to postsecondary status for students with disabilities in the areas of LD, EBD, and MMD. Specifically, the central research question for this study is: What are the effects of the STEP Intervention Grant on the transition of students with mild disabilities to postschool outcomes? 


\section{CHAPTER II \\ LITERATURE REVIEW}

Introduction

This research uses existing data from a transition intervention project in six high schools in a central U.S. metropolitan school district. In that regard, it fits into the category of program evaluation, but only in terms of the specific variables being used in this study, not for a full-program review. Information was gathered from the participating school district and a Follow-up Study after students left high school for comparison of independent variables in three areas: Demographic Factors, STEP Grant Intervention, and Mediating Factors. These variables were analyzed for effects on student outcomes in postschool outcomes of Employment, Postsecondary Education, and Independent Living (see Figure 1, p. 34).

For this chapter, the recent history of evaluation was reviewed, followed by evaluation pertaining to special education programs for transition to adult life. Critical information regarding the history of transition outcomes and research in best practices for the transition period was reviewed with respect to the research participants. The section on transition outcomes was organized around the following major themes for students with disabilities: (a) Effects of transition activities on employment; (b) Effects of transition activities on postsecondary education; (c) Effects of transition activities on independent living; and (d) Effects of personality development on self-determination and self-advocacy. Finally, the last section of this chapter reviewed empirical studies of transition intervention 
for special needs students.

\section{Program Evaluation}

Program reviews are based in the field of evaluation and have had a long history of development in the social sciences. The concepts of evaluation and history of development of the field of evaluation were reviewed for application to this study. "Program evaluation has a long history as a practice, but only became a recognized specialty in the 1960s" (Scriven, 1991, p. 285). Rossi, Freeman, and Lipsey (1999) stated that the field of evaluation has evolved as a "distinct specialty field in social sciences" since the early 1970's (p. 11). Evaluation originally was defined as determining the worth or merit of an evaluation object, and was expanded to include the identification, clarification, and application of defensible criteria to determine value, worth, merit, quality, utility, effectiveness, or significance in relation to those criteria (Worthen, Sanders, \& Fitzpatrick, 1997, p. 8). They gave credit to Scriven (1967) as being one of the first educators to outline the purpose of formal evaluation. Scriven believed that evaluation had many roles, but only one goal, which was to "determine the worth or merit of whatever is evaluated" (cited in Worthen et al., p. 8). In the 4th edition of his book, Evaluation Thesaurus, Scriven (1991) clarified his definition of evaluation as "the process of determining the merit, worth and value of something or the product of that process" (p. 139). Scriven's early writings $(1969,1980 \mathrm{a}, 1980 \mathrm{~b})$ explained logical sequences of concepts and how people try to connect data to value judgments or rank objects of evaluation as good/bad, better/worse, passing/failing, etc. Scriven (1980a) outlined four steps in the logic of evaluation; they are still used today:

1. Select criteria of merit on those things that the evaluand* must do to be judged good (pp. 6-7). 
2. Set standards of performance on those criteria that must be exceeded to warrant the label of "good" (p. 10).

3. Gather data pertaining to performance on the criteria relative to the standards ( $\mathrm{p}$. 11).

4. Integrate the results into a final value judgment (p. 15). (These were also cited in Shadish, 1998, p. 2).

*Evaluand is the term Scriven used as a "general term for whatever is being evaluated--person, performance, program, proposal, product, possibility, and so on...”. (Scriven, 1991, p. 139)

Scriven first distinguished roles of evaluation into categories of formative and summative in 1980a (pp. 6-7) and 1980b (p. 168), then clarified the definitions in 1991 (p. 340). The purpose of formative evaluation was to provide staff with useful program improvement information whereas the purpose of summative evaluation was to give decision-makers and consumers judgments about program effectiveness as compared to important criteria (quality indicators or standards). Both formative and summative evaluations must be conducted to determine the full effect of outcomes of programs. For example, in Kentucky, these formative and summative evaluation intentions are now incorporated into the Educational Professional Standards Board (EPSB, 2006) standards, which are used to evaluate teachers. Teachers learn how to develop lesson plans and how to assess students to show both formative (short-range) and summative (long-range) progress.

McNamara (1998) expanded the traditional definition of program evaluation. $\mathrm{He}$ emphasized the careful collection of information about the program, the participants, or some aspect of the program, so that the researcher could make decisions about the program. His research outlined at least 35 different evaluation types and pointed out that the type of evaluation that is chosen is based on what information you want to gather. Some of these different strategies to gather information include: needs assessment; 
accreditation; cost/benefit analysis; effectiveness; efficiency; formative; summative; goalbased; process; and outcomes.

Kirkpatrick (1994) described a four-level evaluation for Occupational Training and Development programs that is somewhat similar to what Rossi et al. (1999) later called proximal and distal outcomes in the field of evaluation. Kirkpatrick's levels built successively on the previous level in difficulty and time-consumption and are outlined below with reference to Rossi's levels. Kirkpatrick's levels are referenced from his book, Evaluating Training Programs (1994, pp. 21-26, and Rossi's descriptions from the book, Evaluation: A Systematic Approach (Rossi, Freeman, \& Lipsey, 1999, pp. 102-111).

Level 1: Reaction--How do the participants in the program react to it? (Kirkpatrick, 1994) This equates to the Affective Level 1 in Rossi et al. (1999).

Level 2: Learning--To what degree do participants change attitudes, improve knowledge, and/or increase skills as a result of attending the program? (Kirkpatrick, 1994). This is similar to the Cognitive Level 2 in Rossi et al. (1999).

Level 3: Behavior--To what extent does behavior change after the participant attended the training program? (Kirkpatrick, 1994). This is Behavioral Level 3 in Rossi et al. (1999).

These first three levels, Affective, Cognitive, and Behavioral, make up the proximal program outcomes in Rossi et al. (1999).

Level 4: Results--What final results occurred because the participants attended the program: increased production; improved quality; decreased costs; reduced frequency and/or severity of accidents; increased sales; reduced turnover; or showed positive return on investments? (Kirkpatrick, 1994). This is the programmatic Level 4 and is a distal program outcome in Rossi et al. (1999).

Both Kirkpatrick (1994) and Rossi et al. (1999) described evaluation as the final step in the process in these earlier works. However, Molenda, Pershing, and Reigeluth (1996) have added a level 0 and level 5 (for a total of six levels) to the model. In explaining their model they state:

...the Business Impact ISD Model uses a taxonomy of training evaluation based on 
the strata of impact ranging from stratum 0 , where only attendance is counted, with no pretense of measuring the learning outcomes, to stratum 5 which adds social impact: Attempts to ascertain the impact of the organization's changed performance on society. (Molenda et al., pp. 277-293)

Evaluation research in any field is both an applied research tool and a method to study program application for political and managerial uses. "Policy decisions can more easily be made to stop, change, or continue programs by including evaluation in the design of a program" (Rossi et al., 1999, p. 13). Large numbers of variables can be analyzed and provided to policy makers and stakeholders through the use of systematic data collection systems and development of technology and computer systems. Policy analysis and public administration of social programs depend on evaluation methods and outcomes to determine cost effectiveness and benefits (Scriven, 1980a, p. 9).

In the 1990s, reliance on sound evaluation standards became even greater, since resources were limited and public pressure to dismantle ineffective programs was great (Rossi et al., 1999). Program evaluation includes both the description of the performance that is being evaluated and the use of standards (or best practices) of the field being studied, to determine effectiveness of the program. Program evaluation standards were suggested by the work of Daniel Stufflebeam in 1975 (cited in Worthen et al., 1997, p. 441). The Joint Committee on Standards for Educational Evaluation published the Standards for Evaluations of Educational Programs, Projects, and Materials (1981), and revised and applied them to settings beyond K-12 schools in1994 (as cited in Worthen et al., 1997, p. 441). By applying these standards educators, may be able to determine how to improve programs to increase student success. These standards provided definitions and guidelines for practices in evaluation; four concepts have been incorporated to determine the quality of an evaluation study: (a) Utility; (b) Feasibility; (c) Propriety; and (d) 
Accuracy (Worthen et al., 1997, pp. 442-445). Several states have adopted these standards as a guide for evaluations of education and public-sector programs. A checklist based on these standards was developed "to judge adequacy of evaluation designs and reports" (Worthen et al., 1997, p. 445). The American Evaluation Association has adopted the “Guiding Principles for Evaluators" (Shadish, 1998; Rossi et al., 1999, pp. 425-450). These principles guide evaluators through the ethics of program evaluation and include: (a) Systematic inquiry; (b) Competence; (c) Integrity/honesty; (d) Respect for people; and (e) Responsibilities for general and public welfare.

The work of Campbell (cited in Rossi et al., 1999) outlined a perspective that policy and program decisions should emerge from continual social experimentation which tests ways to improve social conditions. Campbell extended the "experimental model from social psychology to evaluation research" (cited in Rossi et al., 1999, p. 29). Cronbach, another founding father of evaluation, disagreed with Campbell. He thought that every evaluation should be specifically designed to "meet the needs of the program decision makers and stakeholders" (cited in Rossi et al., p. 29). Problems arose when researchers tried to do a combination of what both Campbell and Cronbach implied, since projects were limited by time, money, level of expertise, efforts, and materials. Social programs, including education, do not easily lend themselves to experimental and control groups, since the general public wants the best programs, methods, and materials to be available for all participants. Thus, for full-coverage programs, such as this one, it is necessary to study outcomes from programs using best practices. Next, evaluation as applied to special education programs is reviewed.

\section{Program Evaluation in Special Education}

Johnson (1998) provided an overview of program evaluation in special education. 
He concluded that evaluation had been focused on compliance since the passage of the Individuals with Disabilities Education Act (IDEA) and that a shift in evaluation from compliance issues to focus on outcomes for students with disabilities was needed. In his study of four states, Johnson concluded that the emphasis on compliance occurred because states were having continuing difficulty with compliance issues. One section of the outcome data that Johnson suggested for the evaluation process was to "measure student achievement and social behavior over time, as well as student attendance, self-esteem, adaptive behavior, student satisfaction, and parental satisfaction" (Johnson, p. 6). When Johnson analyzed the extent of program self-evaluation, he found that process indicators and compliance were the two highest priorities states used in their efforts to evaluate special education programs. Outcome data such as student graduation rates, postgraduation status, and many other indicators of student success were not rated highly in the evaluation of programs. Focus on evaluation placed emphasis on specific things that the local districts knew would be measured and those items are emphasized--circular reasoning. This is consistent with the theories of decoupling and the logic of confidence (Meyer \& Rowan, 1977, 1978; S. K. Miller, 1992). Decoupling has to do with the notion that

...organizations built around efficiency attempt to maintain close alignments between structures and activities. Conformity is enforced through inspection, output quality is continually monitored, the efficiency of various units is evaluated, and the various goals are unified and coordinated. (Meyer \& Rowan, 1977, pp. 356357)

The notion of decoupling explains the way organizations maintain standards to legitimize the structure while varying the activities in response to practical considerations. (p. 357)

The logic of confidence and good faith explains the relationship between day-today activities that proceed in an orderly fashion. This allows the school to appear useful in spite of the lack of technical validation by external constituents. (p. 358) 
Following this logic of confidence, programs and schools are assessed on adherence to form and institutional rules rather than direct inspection of outcomes. Federal legislative mandates passed on to schools govern the scope of programs to educate students. When the accreditation process focuses on the adherence to the rules, rather than the outcomes, schools have limited the scope of the accreditation and can more likely meet their goals. If the focus is shifted to outcomes--where students ultimately end up as adults-the accreditation process becomes much more complicated. "Moving beyond the assumptions of the logic of confidence model was a necessary step if schools are to close the performance gap" (S. K. Miller \& Moore, 2005, p. 10).

Schools cannot control the adult environment or give students an educated bag of tricks that will fit all situations and deem them successful. The intent of the IDEA legislation was to improve outcomes in 1990 and 1997. However, little evidence of change was seen in these earlier versions; the Individuals with Disabilities Education Improvement Act (IDEIA, 2004) legislation is stronger in these requirements. The accreditation process must change to focus on outcome evaluation. The logic of confidence theory allows decoupled organizations to appear coordinated and proceed with the business of education in an orderly fashion. What educators need to keep in mind is that education is a process of change, not just a formal structure of record keeping. When applied to transition, the planning process of completing the proper planning documents and keeping student records is part of the organizational myth of efficiency without evaluating how the educational process is serving the student. Teaching students how to plan for transition, set goals, take on responsibility, instill good values, gain life-long learning strategies, and understand problem solving, etc., is much harder than simply focusing on the academic 
requirements needed and checking them off on a graduation plan. In other words, schools give the appearance of being organized for transition, but few changes are seen until student outcomes are considered.

Johnson's (1998) work identified other indicators of success for special education program evaluation, e.g., progress toward completion of the annual Individual Education Plan (IEP); improvements in student academic achievement; dropout rates; employment status; social behavior over time; attendance; self-esteem; adaptive behavior; and student and parent satisfaction with services. He found that the participants had not moved beyond simple compliance with federal regulations in evaluation of programs. Sechrest (1994) also found that program evaluators focused on process rather than program outcomes, since the study of outcomes was much more difficult.

With the implementation of IDEIA (2004), new requirements for tracking students are required to implement a system to connect high school training with outcomes. This section of the legislation, Indicator 13, required transition goals on the IEP to enable the student to meet the postsecondary outcomes in a reasonable manner. Schools are required to do a one-year follow-up report on students with disabilities in an attempt to improve school transition programming. Connected to this requirement, the Educational Professional Standards Board (EPSB) in Kentucky is working on implementing a system to extend tracking of students with disabilities. The students would be identified by teacher, and connected to where the teachers had received their teacher education certification training. When the system is in place, universities and colleges will be held accountable for the lack of student success in the future (M. Troupe, personal communication, September 15, 2006). This type of student/teacher/university education connection follows the work of Sanders (2004; see also S. K. Miller, 1992) known as a 
value-added system. The evaluation system takes into consideration "the influence of the district, school, and teacher on the rate of academic progress" (Sanders, p. 1). S. K. Miller pointed out that this type of evaluation "does more than just demonstrate that effective schooling is important; it also provides the most precise and reliable way to measure schooling influence" (p. 2).

George, George, and Grosenick (1990) described the process of program evaluation as a continuous assessment process to outline progress. This includes both assessment of student progress as well as the long-range impact of the program. If the goal was to help students become successful adults and lead a quality life, evaluations needed to reflect these items as important. The use of a continuous assessment process more closely fits the requirements of IDEIA 2004 and the tracking system being implemented by EPSB in Kentucky. By applying evaluation standards along with quality indicators evolving from application of IDEA 1997 regulations and subsequent amendments, special educators may be able to determine how to improve transition services to increase success for students with disabilities.

Several states implemented the self-study method in special education as a premonitoring activity to screen for problems prior to a site visit from the state or federal staff (Gonzalez, 1992). Kleinert and Kearns (1999) conducted a validation study to determine performance indicators and learner outcomes of Kentucky's alternate assessment for students with significant disabilities. Forty-four national authorities in best practices for students with moderate and severe cognitive disabilities validated these best practices to include in programs designed to help students with disabilities prepare for adult life. These indicators now comprise the core of best practices that are embodied in the performance criteria for alternate assessment in Kentucky. Performance indicators, which are used to 
measure individual student's alternate portfolios, include: Integrated environments; Functionality; Age appropriate choice making; Multiple settings for instruction; Communication; Academic expectations; Natural support; Targeted skills; Friendship; Parent involvement; and Assistive technology. In their review, several experts stated that alternative assessment and curriculum should be accomplished in instruction that was delivered to regular education as much as possible, and with expectations similar to all other students (Kleinert \& Kearns, 1999).

Hasazi, Furney, and DeStephano (1999) compiled a cross-case analysis of transition programs in three states and suggested that a set of six practices were common in model transition projects. These six practices were recommended to improve outcomes at every level of transition: (a) Promote self-determination through instruction and selfcentered planning, (b) Develop sensitive approaches to interagency collaboration, (c) Develop and systematically monitor professional development opportunities, (d) Maximize transition outcomes by fixing roles and responsibilities, (e) Expand school and post school options for specific populations of students, (f) Promote integrated approaches to educational reform. These authors also suggested that the use of post-school outcome measures for program evaluation and improvement should be expanded. Districts have focused on the legal paperwork, required through the Individual Transition Plan (ITP) and IEP, without evaluating their overall school programs to determine if students are obtaining services required by IDEA and its amendments (Baer et al., 1996). This history of evaluation and special education application has led to continuing improvements in outcomes and emphasis on the movement from school to adult life. The next section outlines the transition requirements with ties to present curricular emphasis.

\section{Transition History}


Transition from high school to adult life has been a focus of several legislative acts over the past thirty years. IDEA, Public Law 101-476, began as the Education for Handicapped Act, Public Law 94-142 in 1974. It was strengthened and renamed as IDEA in 1990, and amended in 1997 (Council for Exceptional Children, 2000). In 2004, it was renamed again as IDEIA. Each revision placed an ever greater demand on schools to reform curriculum, provide links to community services, and become accountable to help students with disabilities become more successful in this transition (Rusch \& Chadsey, 1998). Legislation that provided Career Education, School-to-Work Programs, and finally the IDEIA (2004) legislation had emphasized the need for a seamless exit from public school for all students. Other legislative acts affecting both general and special education included the Vocational Rehabilitation Act of 1973 with subsequent amendments, the Americans with Disabilities Act of 1990, School-to-Work legislation, and various other legislative reforms. These legislative reforms have reversed separate educational systems of the $60 \mathrm{~s}$ and ensured increased inclusion in regular education for students with disabilities. Improved outlooks for success as adults have resulted for students with mild disabilities.

Transition planning is an outgrowth of the career education movement of the $1970 \mathrm{~s}$ and 1980s (R. J. Miller et al., 2007). This movement was an attempt to connect academic learning with real-world application to careers for all students. It included paid and unpaid work, roles of individuals in society, and social skills work habits and attitudes toward work (Brolin, 1997; Brolin \& Schatzman, 1989; Flexer et al, 2005; Levinson, 1993; R. J. Miller et al.). However, the career education movement was never fully implemented on a national basis (R. J. Miller et al.; Sitlington, Clark, \& Kolstoe, 2000). As early as 1984, Madeline Will, Assistant Secretary of the Office of Special Education and Rehabilitation 
Services (OSERS), U.S. Department of Education, envisioned a bridge model representing connections from school education to post-school employment and support services. Her model led to high schools assuming the responsibility for transition activities. Halpern (1985) expanded Will's model to include three pillars representing Residential, Social and Interpersonal, and Employment areas of student and adult life. Wehman, Kregel, and Barcus (1985) outlined a series of steps for a successful transition that same year. Halpern (1993) added the Quality of Life component to Will's model for students with disabilities, and the focus on outcomes had begun. Halpern's new model included Quality of Life indicators and desired post school outcomes in areas of (a) Physical and material well being, (b) Performance of adult roles, and (c) Personal fulfillment (Halpern, 1993, p. 491). National transition research has identified quality indicators that make programs successful (L. Brown et al., 1976; Kohler, 1993; Westling \& Fox, 2004). As increased awareness allowed comparison of present programs and services to national best practices, research focused increasingly on compliance issues. Kohler (1993) pointed out that only a few of these "best practices" have actually been substantiated by research and much work has to be done to validate successful practices.

Since federal emphasis on program development has not yet resulted in national standards, "Best Practices" in transition from high school to adult life were identified from the many federally funded research grants in the 1990s. Kohler and Chapman (1999) compiled a list of best practices for the National Transition Alliance. Twenty promising programs throughout the United States were identified as providing effective transition services for special needs students. The following five concepts were most commonly included in best practices included in those 20 programs: (a) Student focused planning and development; (b) Career pathways and contextual learning; (c) Family involvement; (d) 
Business, labor, and community involvement; (e) Structures and policies, including evaluation (p. 8). These elements were subsequently included in federal grant funding requirements, as well as evaluation standards for federal accreditation of special education programs.

The coordinated set of activities, required by the IDEA federal law (1990), helped measure transition success for students with disabilities and was found to affect the entire K-12 curriculum--regular and special education, related services, and all school activities. The transition service delivery system included links with community agencies that provide services for students after they leave the public schools. NCLB (U.S. Department of Education, 2002, 2004) required increased inclusion for students with disabilities in the regular education system, as well as a better system of supports for students after they leave school services.

One essential item in this coordinated set of activities was the process of assisting students in determining career interests and aptitudes through a series of assessment activities. Career Assessments were required by IDEA (1990) by the age of fourteen, or at eighth grade, to assist students and school personnel to plan transition activities to help students meet their career goals. As students were assessed for career interests, aptitudes, and learning styles, high school curriculum was to be planned based on those assessments. (Sitlington, Neubert, \& Leconte, 1997) defined key concepts and principles for best practices in assessment. Career assessment and the inclusion of student and parent goals were noted to be essential items on which to build the school program. In practice, if special education students have not had opportunities on which to base wise choices, their chances of becoming successful will diminish. Conversely, unless student interests and choices are taken into consideration, the school program will not prepare them to obtain 
their chosen professions. An essential part of good transition planning is to obtain student and parental goals, and then provide experiences and courses to meet these goals. IEP goals and assessment criteria were needed to focus on instruction for adult life, education, employment, living arrangements, etc., which were also required by the series of IDEA laws.

Kohler and Chapman (1999) reviewed the literature on school-to-work transition. They noted that program evaluation in the field of special education transition identified many short-term effects but had not provided a detailed plan to affect and implement educational experiences for long-term improvements. Out of 106 possible studies, only 20 met the comparison criteria for research; many were descriptive and did not "empirically validate practices or concepts" (p. 8). Many studies did not fully describe dependent or independent variables. Only Benz et al., 1997 appeared to meet the criteria to "demonstrate a relationship between specific interventions and outcomes" (p. 14). Their study used a regression model to examine if "access to career planning and guidance, career awareness training, assigned work-based experience, and student/parent agreement about student's work and schooling goals would predict competitive employment and/or productive engagement" (p. 14).

In 1994, Judy Schrag prepared a review of 28 documents and reports which were used as background information for participants in the "Statewide Evaluation of Programs and Services with Students with Disabilities" Policy Forum for the National Association of State Directors of Special Education. One of these reports (Olsen \& Massanari, 1991) suggested that "effective indicators" for special education programs fell into six major areas: (a) Philosophy, policies, \& procedures; (b) Resource allocation; (c) Staffing and leadership; (d) Parent participation and community interagency involvement; (e) 
Instruction; and (f) Program and student outcomes.

The National Center on Educational Outcomes listed the outcomes and possible indicators for successful completion of high school. The indicators in 1993 were: Presence and participation; Accommodation and adaptation; Physical health; Responsibility and independence; Contribution and citizenship; Academic and functional literacy; Personal and social adjustment; and Satisfaction (Ysseldyke, Thurlow, \& Gilman, 1993). In 1998, a similar study was done and outcomes remained the same except for Accommodation and adaptation; it was replaced by Family Involvement (Ysseldyke, Krentz, Elliott, Thurlow, Erickson, \& Moore, 1998). The outcomes were modified to be used with both individuals and large scale assessments, eliminate redundancy and provide a consistent format. Suggestions are offered for six developmental levels (ages three and six, grades four, eight, and twelve, and post-school).

Halpern (1993) suggested that outcomes might be used to form and evaluate transition programs. He established the following three Quality of Life areas for adult life: The first area, Physical and Material Well-being, included Physical and mental health; Food, clothing, lodging and financial considerations; and Security and safety from harm. A second area was Performance of Adult Roles and included Access to the community; Vocation, career, or employment; Leisure, recreation activities, personal relationships, and social networks; and Educational attainment, spiritual fulfillment, citizenship (e.g., voting), and social responsibility (e.g., doesn't break laws). The final area Personal Fulfillment included happiness, satisfaction, and sense of general well being. By accepting Halpern's (1993) definition and implementing the three Quality-of-Life areas that he suggested, follow-up studies could determine the person's success or failure in adulthood. Many other studies found similar indicators. Hughes, Eisenmann, Hwang, Kim, 
Killian, and Scott (1997) organized a list of eleven outcome measures for students with disabilities from 181 intervention studies. From this meta-evaluation, the 268 different outcome measures were categorized into a conceptual framework for secondary students with disabilities. It was found that several measures cited in the literature as helping to make transition successful were not targeted in applied research. This supported what Kohler (1993) had reported as well. The categories that were identified by Hughes et al. were Personal development and fulfillment; Social acceptance, social status, and ecological fit; and Individual and social demographic indicators. These intervention studies targeted four settings, which are typical of adult life: Work, School, Community, and Home (Hughes et al., 1997).

IDEA 1990 mandated planning and services beginning at age 14 or eighth grade to assist the student throughout high school transitioning to adult life, but the 2004 legislation has moved this to age 16. NCLB in both the original (2002) and reauthorized form (2004) has added accountability from the states in providing success for all students. These regulations were designed to affect changes to standards for knowledge at all grades, assessment, and yearly progress toward these goals. Beginning in the 2005-2006 schoolyears, testing began for grades three through eight in reading, math, and science. In 20072008, science achievement must also be tested. The legislation holds schools responsible for progress for all students, as well as narrowing the gap between the high-achieving students and those in targeted groups. Students with disabilities comprise one of the targeted groups. Along with narrowing the gap, the focus needs to be toward increasing success in adult outcomes for students with disabilities.

Getzel and deFur (1997) pointed out that many transition studies placed importance on the transition process and the involvement of the student. By helping students express 
their wishes for the future and involving them in formulation of plans to reach their goals, both self-esteem and self-advocacy have improved. The young adults involved in their research increased ability to influence personal quality of life for the future.

Person-centered planning (PCP), the Magill Action Planning (MAPS) process, and the Choosing Outcomes and Accommodations for children (COACH) models are used extensively to teach students and their parents how to become involved in the planning process (Giangreco, Cloninger, \& Iverson, 1993; O’Brien \& Lovett, 1993; Vandercook, York, \& Forest, 1989; Westling \& Fox, 2004). These strategies address the need for teaching students how to make decisions, but other self-determination models may assist students in the development of self-awareness and leadership skills (Baer, 1996). Many students with mild disabilities are not involved with their transition planning. Their perception of what they can control in their education seems to be diminished by their low self-esteem and external personal locus of control.

Research done by Cummings, Maddus, and Casey (2000) showed that transition plans for students with learning disabilities often do not include employment needs or postsecondary adjustment skills. Model projects have generally focused on students with more involved disabilities (physical and moderate/severe) rather than students with learning disabilities. Kavale and Forness (1996) pointed out that it has only been since the late 1990s that educators recognized learning disabilities as a life-long condition. Educators formerly believed that learning disabilities were connected to "academics" and "disappeared" as the person blended into the community after high school. Thus, transition and individual education plans focused on academic skills for students with learning disabilities (Cummings et al., 2000).

Some states saw this gap in services and provided alternative programs for selected 
students with disabilities who wanted postsecondary education. For example, Maryland has fourteen alternative programs operating for their population of students with significant disabilities ages 18-21 (Grigal, Neubert, \& Moon, 2001; Moon, Grigal, \& Neubert, 2001; Neubert, Moon, Grigal, \& Redd, 2001). Some programs are attached to four-year or community colleges, and others are attached to community organizations to support employment, social, and recreation/leisure participation.

The Transition Research Institute at the University of Illinois (Kohler, 1996) proposed the transition taxonomy to be used as a checklist to compare educational planning and student involvement in the process of transition for the college-bound general and special education students. She found, as reflected in student outcome data in multiple studies, that the educational system for students with disabilities had not been effective in developing or delivering educational planning. Through this project, it was suggested that there was a gap between research and application. Furthermore it was indicated that "best practices" have not been supported by evidence of effectiveness.

Peters and Heron (1993) outlined five criteria to standardize effective transition practices. By using the theories of concept mapping, the growing list of transition practices was structured into the following five categories: (a) Career and vocational development; (b) Student-focused systematic planning; (c) Interagency and interdisciplinary teaming, collaboration, and service delivery; (d) Parent involvement in planning, education, and service delivery; and (e) Program structure and attributes. The 207 participants in their study represented a cross section of experts from a wide variety of states and helped clarify required transition planning factors for youths with disabilities. This study provided a framework for designing and evaluating special education programs and was easily understood by a wide variety of people. However, the study needed to be validated by 
including students, families, and teacher's perceptions, since these groups were not specifically included in the sample for this study.

Employment, Postsecondary Education, Independent Living, and Personality components are four major topics closely related to adult life status and healthy lifestyles for regular and special education students. They have been significant topics for federally funded transition projects during the past 10 years; implementation of programs utilizing these topics has begun to show improvement of transition services for high school students with disabilities. The next sections detail how each of these topics impacts students during the transition process.

\section{Transition Effects}

Outcomes of transition have been a major research topic for the past 15 years. Current literature for four of the major outcomes for transition is reviewed: Employment, Postsecondary Education, Independent Living, and Self-Determination, which includes Self-Improvement (Personal Insight and Future Planning ability), Self-efficacy and Locus of Control. In each sub-section that follows, research stating effects of transition on the area is detailed.

\section{Employment}

The first of the four outcomes targeted in this research is Employment. Society values people who work and contribute to the community. Current high school programming depends on vocational education to provide an important link between academic education and employment for students who are interested in accessing jobs during or immediately following high school. Vocational education at the high school level has a two-pronged goal: one is to assist students in directly entering into the job market, and the other is to prepare students to continue their education in postsecondary 
environments to lead to more involved careers. Hudecki (2006) summarized these two viewpoints by stating that vocational education is caught between developing broad career skills for students to enter the business sector and school reform that focuses on academics. It is difficult to develop skills in high school that will lead to both postsecondary education and careers (pp. 3-4).

The Perkins Act (1984) was the primary legislation supporting work force preparation and pushing for broader education reforms. The Perkins legislation was reauthorized in 1990 and contained Title IIIE, the Tech Prep Education Act. Through the Tech/Prep movement, high school and postsecondary vocational/technical teachers evaluated curriculum to devise a system of continuous services. Academic, career, and technical pathways were identified and became known as articulation agreements (joint agreement between high schools and postsecondary institutions). Faculties planned joint curriculum to eliminate repetition from high school to postsecondary classes under this model. Career-paths were clearly outlined and provided a smooth transition to higher-level training after high school with transferable credits. The advanced degree could then be completed in less time and students were provided with life-long learning opportunities (Proctor \& McElvey, 2001).

Parnell (cited in Ruhland, 2003, p. 4) noted that non-college bound students, the "neglected majority," could transition from school to the workplace more successfully through tech prep articulation agreements. Requirements for planning dictated by IDEA and NCLB suggested increased connections between planning (Individual Graduation Plan and Individual Education Plan), academic and vocational class enrollment, and student choices. Articulation agreements connected high school and college learning to assist the student in envisioning how to continue education in the post-high school environment. 
Students with mild disabilities do not choose many programs with articulation agreements due to the difficulty of the subject matter and lack of encouragement from faculty and family members.

When compared with all other students with disabilities, those with learning disabilities were least likely to receive help from a school or agency to find a job ( $48 \%$ vs. $15 \%$, respectively), and most likely to find their job on their own (19\% vs. 40\%, respectively). (Halpern, Doren, \& Benz, 1993, pp. 67-68)

Enrollment in vocational education is sometimes viewed as negative when compared to college preparation academic classes in high school. Westberry (2001) studied the effects of negative stigma in recruitment media associated with vocational courses. She found that media presentations for vocational opportunities and information to students and parents affected their acceptance or rejection of the opportunities being presented.

Transition from high school to careers or to postsecondary education needs to be clear to both students and parents so they can understand what paths are needed to reach personal goals. Research identified negative aspects for special education students receiving vocational training (B. L. Brown, 2003; Westberry, 2001; Wonacott, 2000), just as Fourqurean and LaCourt (1990) identified the negative aspects of receiving special education services. When public perception of vocational training and special education are negative, teachers and families internalize this message. Expectations for students are diminished. Students, likewise, become aware that these programs are not as prestigious as college-preparation classes. Students with mild disabilities have a difficult time understanding these innuendoes.

Some students choose to enter the job market directly from high school. LBD students may participate in vocational training in high school, but often do not find jobs related to their training. Unless LBD students are in vocational programs, they usually do 
not receive the functional application training of skills needed to be successful in postschool environments. As a group, students with disabilities typically leave high school with entry-level skills. The majority of these students are under-employed in jobs such as the fast-food industry and the janitorial sector, which entail repetitive-type tasks below their ability level (Benz \& Halpern, 1993).

Benz, Yovanoff, and Doren (1997) compared employment outcomes for students with disabilities (315 from Oregon and 107 from Nevada) to outcomes for another 131 students without disabilities from Nevada. Students with disabilities were selected from each state's Handicapped Census Count to represent primary disabilities and gender. Students without disabilities were selected from a statewide database of all students in Nevada who took mandatory proficiency tests in reading, math, and writing. Demographic variables considered included primary disability condition, student gender, family income, and family socioeconomic status. Benz et al. constructed the socioeconomic status variable and included four parent descriptors: educational achievement; occupation; gender; and marital status. These descriptors were measured and transformed into broad categories of social and economic status, e.g., unskilled worker or professional worker. Predictor variables included school-based (i.e., access to career planning and guidance, achievement of high academic standards), and work-based variables (i.e., participation in work experiences, instruction in work competencies, access to post-school planning and service coordination).

Benz et al. (1997) found significant differences on predictor variables in areas of personal and family characteristics (e.g., gender, ethnicity, household income). A strong relationship between competitive employment and interaction between disability status and gender was seen. Students who participated in work experiences, especially paid work 
during high school, acquired improved employment outcomes. This trend for greater success was obtained regardless of the disability category or required level of support. All females were less likely than males to be competitively employed one year out of school. Only $40 \%$ of females with disabilities were employed one year following high school compared to $71 \%$ of males with disabilities, $60 \%$ of females without disabilities, and $65 \%$ of males without disabilities. None of the other variables predicted competitive employment for any groups. Career awareness and problem solving skills seemed to be unrelated to competitive employment. Most non-disabled students scored high in reading, writing, and math, which produced empty cells in the cross-tabulation matrixes to compute an odds ratio. However, post-hoc analyses for the sample of students with disabilities showed strong significance for those who had high reading, writing, or math skills (two to three times more likely to be employed than students with low skills). Four of the predictor factors for students with and without disabilities were positive: (a) Two or more work experiences in the last two years of high school; (b) High social skills; (c) High job search skills; and (d) Having no continuing vocational instruction needs one year out of high school. If students had these qualities, they were two to three times more likely to be competitively employed one year out of high school. Other work-based variables tested in the study were unrelated to success in employment. In the area of school-based variables, only students' career-awareness skills predicted engagement, while the other four (reading, writing, math, and problem-solving) showed inconsistent relationships to productive engagement. The researchers concluded that educators needed to insure that career exploration activities were tied to work-based experiences.

According to Blackorby and Wagner (1996) many mildly disabled students change jobs frequently and spend a significant portion of their adult life unemployed. These 
circumstances often lead to a diminished quality of life and lowered self-esteem for the adult with disabilities. Research has shown that students who are self-determined are more independent and more likely to be employed for pay (Wehmeyer \& Gragoudas, 2004; Wehmeyer \& Palmer, 2003; Wehmeyer \& Schwartz, 1997). "Employment and quality of life are intertwined; it is difficulty to have one without the other" (Repetto, 2003, p. 79). Just as the entrance to employment is difficult for students with disabilities, the next section provides information on entrance to postsecondary education which seems to be even more difficult.

\section{Postsecondary Education}

Even with the student's interest and encouragement from school and family, the postsecondary institution often does not provide the level of support needed for success at the college level. Madaus (2005) served in the capacity of a university director of a program for students with learning disabilities and described the services that were offered. He reported that students and parents expected a "special education department" (p. 32) similar to what they had experienced in high school. He pointed out that although both Section 504 of the Vocational Rehabilitation legislation (1973) and ADA legislation provided accessibility and prohibited discrimination, only reasonable accommodations are required. This included establishment of a Disability Resource center or support person to explain accommodations and provide advice for students with disabilities. However, postsecondary institutions are not required to modify admission requirements, course content, or programs of study for students because of disability as high schools may do. The 504 Plan or IEP that is written in high school is not carried over to the postsecondary program (Madaus \& Shaw, 2004).

A strong transition program between high schools and colleges, with support from 
Vocational Rehabilitation, may allow optimal success for students with disabilities (Roessler, Fitzgerald, Rumrill, \& Koch, 2001). Supports for college faculty should be provided to understand specific adaptations/modifications and assistive technology that students need. Disability support services provided on campus need to include social supports as well as help for the students with disabilities to hone their self-advocacy skills. No special funding is available to the colleges for these support services, and services are not mandated other than the accessibility issues covered by Section 504 of the Vocational Rehabilitation Act of 1973 and the Americans with Disabilities Act of 1990 (Madaus, 2005). The 504 amendments prohibit discrimination in areas of recruitment, admissions, and benefits at the high school and college level. Both legislative acts mandate accessibility, but do not give specific levels of supports for students. Students need training in conflict resolution and how to advocate for what they need to be successful when they leave high school. In addition, many students with mild disabilities choose not to selfdisclose their disabilities when they enter colleges and try to blend in with the general student body (Madaus).

The traditional methods used in high school include accommodations, course waivers in the area affected by the disability, and subject-matter tutoring in the resource room. Most colleges do not allow course waivers for admission purposes or for completion of specific program plans (Brinkerhoff, McGuire, \& Shaw, 2002; Madaus, 2005; Madaus \& Shaw, 2004). Therefore, the student will need to learn more independent functioning, learning strategies and social skills to become successful in college settings. Brinkerhoff (1996) offered an extensive list of suggestions for high school programs to prepare students with LD for postsecondary education. She also pointed out differences between high school and college coursework for counselors to prepare students with independence, 
study skills, less contact from instructors, larger classes, and fewer supports (p. 119). Goldhammer and Brinckerhoff (1993) defined self-advocacy for college students with disabilities as "the ability to recognize and meet the needs specific to one's learning disability without compromising the dignity of oneself or others" (p. 1). This means that the students were able to understand their learning disability and appropriately express to their instructors what accommodations they need to be successful in the class (p. 1).

Halpern, Yovanoff, Doren, and Benz (1995) conducted a 3-year follow-along study beginning with a representative sample of students 17 years of age or older in their final year of high school. They examined predictors of participation in postsecondary education for students with disabilities in Oregon $(n=315)$, Nevada $(n=107)$, and Arizona $(n=$ 565). All three samples were selected to be representative of their underlying populations in terms of disability, geographic location, minority status, and gender. No differences were seen between samples; "in subsequent data analysis, the Oregon and Nevada samples were combined to develop a predictive model" and make the sample sizes more similar for comparison (p. 153). Information was collected with five instruments: Post-school (student interview and parent interview) and In-school (student interview, parent interview, and teacher questionnaire). Students and parents were interviewed using a computer-assisted telephone procedure. The instruments and interview procedures were field tested and revised prior to this study (p. 153). Interviewers participated in six days of training and inter-interviewer agreement was assessed on a randomly selected $6 \%$ of all interviews (agreement of 95-100\%, median of 98\%) (p. 154). A set of independent (predictor) variables and dependent variables (outcomes) were defined dichotomously for logistic regression analyses. For outcome, participation in postsecondary education of any type during the first year after leaving high school was scored $(0=$ no, $1=$ yes $)$. Types of 
outcomes included: GED completion, post-school short course, community college, fouryear college, private vocational/technical school, job corps, sheltered workshop or rehabilitation facility, and the military (p. 155). Data analysis was accomplished using multivariate logistic regression analysis. The three-step process to select independent variables included: (a) Examine "bivariate relationships that theoretically relevant variables had with participation in postsecondary education. If the independent variable had no relationship, it was dropped from further analyses" (p. 155); (b) Two-way interactions among independent variables were analyzed; (c) The most promising independent variables and interactions were analyzed using a logistic regression model to obtain prediction of participation in postsecondary education (p. 155). A final model was determined using the Oregon/Nevada $(\mathrm{O} / \mathrm{N})$ combined sample. The model was replicated using the Arizona (A) sample. Results showed participation rates were larger than previous studies found in literature reviews ( $58 \%$ of the $\mathrm{O} / \mathrm{N}$ and $62 \%$ of the A sample attended). This higher participation rate is probably explained by the definition of "participation" that was used, whereas, some other studies only used community colleges, four-year colleges, and vocational schools that serve the general population. Using the logistic regression as the method of analysis (Hosmer \& Lameshow, as cited in Halpern et al.) the following potential predictors were removed from further analyses: student gender; student ethnic status; family income; disability status of mental retardation, learning disability, and emotional disturbance; drop out status; prevalence of integrated instruction; and congruence of student/parent expectations. Six significant predictors remained: (a) High scores on functional achievement inventory; (b) Completing instruction successfully in certain relevant areas; (c) Participating in transition planning; (d) Parent satisfaction with instruction received by the student; (e) Student satisfaction with instruction received; (f) 
Parent perception that student no longer needed help in certain critical skills. Charts showing the odds ratio were provided. Interaction odds ratios were statistically adjusted for main effects, using calculations recommended by Hosmer and Lameshow (as cited by Halpern et al., p. 160). The elimination of the nine predictors that did not work was significant since it seems to indicate that program and policy development efforts need more effort than overcoming demographic bias (p. 161). Since demographic data were significant in a previous study concerning employment (Halpern et al, 1995), it is possible that similar bias may not exist when postsecondary education participation is considered (p. 161). Three additional "nondemographic variables were found to be ineffective predictors in both samples" (p. 161, emphasis in original): participation in integrated instruction during high school, student drop out status, and the existence of expectations agreed on by both student and parent that postsecondary education was the goal. Also, a lack of predictive power for disability and dropout status was notable since other studies have found all of these as significant (D'Amico, 1991; Wagner et al., 1992, 1993, as cited by Halpern et al.). No explanation was given for the lack of student and parent expectation. From the list of predictors that were significant, five instructional domains were considered: reading, writing, math, problem solving, and getting along with other people with respect to these aspects: was instruction received and completed; how competent the student was in these domains; and whether or not the student needed continued assistance in these domains (p. 162). Participation in transition planning was positively correlated as well as student and parent satisfaction with the high school instruction. Predictors need to be considered in policy and program development to assist students with disabilities in attaining entrance and becoming successful in postsecondary education.

Halpern et al. (1995) replicated studies and compared results from similar studies in 
1990. They found that these six variables remained constant. Parents identified performance in areas of: reading, writing, math, behaving responsibly, and problem solving. The new study identified six predictors associated with participation in higher education: high scores on a functional achievement inventory, completing instruction successfully in relevant curricular areas, participation in transition planning, parent satisfaction, student satisfaction with instruction received, and parent perception that the student no longer needed help in certain critical skill areas. A positive score on these following three variables predicted success in participation at the postsecondary level: (a) Instruction was received and completed by the student, (b) Ratings of student competence in these domains, (c) Ratings concerning whether the student no longer needed assistance in these domains (Halpern et al., p. 162).

Lock and Layton (2001) examined success in postsecondary education and selfadvocacy. They worked with students with learning disabilities in high school to develop a Self-Advocacy Plan to prepare for discussions with entrance advisors and professors at the college level. Students showed they were able to increase their success when they were able to identify and communicate their learning needs to professors. They used the Learning Disabilities Diagnostic Inventory (LDDI) (Hammill \& Bryant, 1998, p. 7) to selfdiscover their own learning strengths and weaknesses in areas of Listening, Speaking, Reading, Writing, Mathematics, and Reasoning. From this list, the student and disability support person developed accommodations that were critical to their success. The student could implement some of these items while others needed instructor supports. The LDDI offered the student suggestions for overcoming identified weaknesses for personal improvement and for negotiating with the professor (Hammill \& Bryant). By planning with an advisor, students with learning disabilities may learn to compensate successfully to 
overcome the learning disability and learn to advocate for themselves. Even with some indicators of supports available, many colleges do not have the funding to provide these forms of assistance. Thus, students with disabilities still have a very low rate of completion of two-year or four-year degrees (Blackorby \& Wagner, 1997; Murray, Goldstein, Norse, \& Edgar, 2000).

In addition to employment and postsecondary education, students with disabilities also need supports for living independently from their families. The next section gives an overview of the independent living movement and effects of transition planning in this area.

\section{Independent Living}

"The process of leaving home is an important part of the transition to adult life" (Buck \& Scott, 1993, p. 1). Buck and Scott evaluated the movement out of the family home for 36,000 individuals from 1968 to 1987; they found that women were more likely to leave than men, not only due to marriage, but also to premarital residential independence. Family factors such as parent's education as well as continuing in school decreased the likelihood of marriage and increased the likelihood of leaving for independence for women (Aquilino, 1991; Buck \& Scott). If either parent had a college education, the chances that both men and women leave for marriage are reduced. For men, having a parent with a college education also reduced their chances of leaving for independent living. Other researchers (Bramston \& Cummins, 1998; Goldscheider \& DaVanzo, 1989) studied the effect of stress coupled with the move into independent living for students with intellectual disabilities. Stressors were studied as clients changed living arrangements, changed jobs, experienced the death of a friend, and had minor problems to solve. The stressors seemed to be related to general health decline (Bramston \& Cummins; 
Folkman \& Lazarus, 1985). Researchers noted that the control felt by the client had a direct impact on how the stressors affected their ability to cope.

This connection seemed to be personality based. As the clients worked through their situations, they gained personal insight and increased capabilities to handle stressors. With understanding came increased personal control (Bramston \& Cummins, 1998). Wilson (1998) explained the connection between self-determination, choices, and control. She explained self-determination as "the individual's ability to express preferences and desires, make decisions, and initiate actions based on these decisions" (p. 3). The concept of control expands the principle of self-determination to focus on the extent to which individuals are "independent, self-sufficient, and capable of gaining access to the resources necessary to freely act on their choices and decisions" (Wilson, 1998, p. 3; see also Kregel, 1992). These three concepts directly affect quality of life for individuals with disabilities and relate to mandates in IDEA legislation. R. I. Brown, Bayer, and MacFarlane (1988) stated that quality of life can be viewed as the degree to which an individual has control over his or her environment (pp. 111-112). Halpern (1993) examined student and family characteristics, school programs, and school outcomes to see if there were predictors for quality of life indicators (p. 496). He found predictor variables were significant in areas of behavior, primary disability category, gender, proportion of classes in relevant areas that were passed, and student satisfaction with the high school experience. Giordano and D’Alonzo (1994) explored the connection between transition and independent living and decided that the "transition to social integration, community participation, employment, and independent living by persons with disabilities can be a life-long process" (p. 4). They defined success as being employed and thereby "securing maximum quality of life as empowered citizens" (p. 4). 
Sitlington (1996) called transition to living the "neglected component of transition programming for individuals with learning disabilities" (p. 1). She suggested that students with learning disabilities needed preparation for life in the community to be able to select and maintain a home, be involved in community and leisure activities, and maintain personal/social relationships. Several researchers have explored living status one year after high school and found that between $54 \%$ and $70 \%$ of the individuals were living with parents or relatives while only $22 \%$ to $39 \%$ were living independently (Haring, Lovett, \& Smith, 1990; Roessler, Brolin, \& Johnson, 1990; Scuccimarra \& Speece, 1990). Approximately $8 \%$ to $10 \%$ were married (Sitlington). Sitlington and Frank (1990, 1993) found that $49 \%$ of their sample lived independently three years after leaving school. Major needs for students with learning disabilities were academic, social, personal, and vocational. The two most critical needs for adults with learning disabilities were vocational training and the ability to acquire a positive self-concept, self-understanding, and selfacceptance (Hoffman et al., 1987). Major cognitive, affective, and motivational characteristics of individuals with LD included "the poor sense of self, often stemming from failure in school and the creation of mal-adaptive defensive behaviors that are unacceptable in society" (Sitlington, p. 5). The concept of poor visual imagery prevented many LD adults from envisioning themselves as competent, self-sufficient adults, while learned helplessness caused "passivity in learning and a crippling lack of independence" (Sitlington, p. 7).

Several researchers connected the independent living movement with social activism. L. Smith, Smith, Richards, Frieden, and King (1994) stated that the independent living movement evolved from the social activism of the late sixties and early seventies. The social activism movement emphasized "giving control to the person with a disability 
so that he or she can alter the environment in ways that increase the full range of life options" (L. Smith et al., p. 1). The Robert Wood Johnson Foundation promoted development of model service delivery and supported eleven independent living centers in 1993. The Foundation focused on health and well-being of persons with disabilities and tested new approaches for generating revenue to support expanded services.

The original legislation for supporting Independent Living was mandated in 1978 through the Amendments to the Rehabilitation Act, Title VII, Part B; however, programs did not begin until 1979 and funds were not appropriated until 1986. By 1993, funding was capped at 1 million dollars per state. The 1992 Amendments added requirements for independent living assessments and only supported individual independent living rather than group facilities for clients (L. Smith et al., 1994).

Centers for Independent Living (CILs) are community-based agencies run by people with various disabilities. Services typically include the following components: advocacy skills training, housing assistance, job training and coaching, benefits advocacy, transportation training, training from peer counselors, mentoring sources for education after high school, training to empower youth, and promotion of self-determination (deFur, 1999; Lattin \& Wehmeyer, 2003). CILs with support services assist youth in developing self-awareness, self-esteem, leadership, and self-empowerment skills. Ultimately, these skills lead to long-term achievement and enhanced quality of life (Giordano \& D’Alonzo, 1994; Halpern, 1993; Wilson, 1998). The willingness to accept outside help is determined by the person's self-concept. Services such as practical assistance, peer counseling, advocacy, home maintenance, and skills training are needed to fill the gap (Harp, 1990). As a result of Harp's work, CILs now exist across the United States to provide these services. Even though the IDEA legislation mandated coordination between schools and 
adult agencies, the independent living movement did not embrace responsibilities to train self-determination or provide similar activities to support students with disabilities throughout their lives. CILs should play an important role in continuing the support for self determination that is begun by high school programs.

Brickman and Deyo (1991) reviewed the history of literature that connects psychological factors with supported programs for independent living. During the 70 s and 80s, the work on child and adolescent development paralleled the supported living programs development (Brickman \& Deyo; Masterson, 1985; D. Miller, 1983). Youths with impaired self-esteem tend to see their connections to Supervised Independent Living (SILs) programs as just another step in their isolation and failure. They had many fears about moving away from the family support to real independence; the developmental deficits experienced by these youths early in their lives compromised their capacity to reach independence (Brinkman \& Deyo). The Huron program in Ann Arbor, MI, allowed the clients to maximize their support as needed, coupled with as much independence as they were able to manage. It was organized to assist movement into less structured phases as the client matured and was able to manage more efficiently the feelings of loneliness, incompetence, hopelessness, facing the job market, and intensified peer pressures. The support provided the scaffolding for the client to form healthy attachments, increase self esteem, and build resiliency.

In 1990, a collaborative effort was organized by the University of Kansas, the Research and Training Center on Rural Rehabilitation Services (RTC: Rural) and the Association of Programs for Rural Independent Living. Seven award winning programs were identified as model, innovative independent living programs. These programs focused on community partnerships for accessible housing, community supports for 
farming communities, advocacy and accessibility of public buildings and transportation, peer supports, and personal in-home assistance (Mathews-Berenson, 1992).

Giordano and D’Alonzo (1994) linked transition and independent living. They stressed the importance of beginning early to prepare people for social integration, employment, and community living. "Because independent living fosters skills that generalize to successful employment, the opportunity to live independently can be critical to successful transition" (Giordano \& D'Alonzo, p. 2). They identified the following skills as important: financial responsibility, sensitivity to the needs of others, commitment to community interests, personal planning, and decision making (Giordano \& D'Alonzo; Stumpf, 1990).

As the independent living topic has been explored, many aspects of personality were identified as critical for the student with disabilities to become an independently functioning adult. The next section explores how critical personality traits directly affect the transition from high school to adult life.

\section{Personality Development}

To understand personality development and how it effects transition planning, the components that lead to self-determination and self-advocacy are explained. Students with disabilities have many stresses on basic personality development as they mature. Before individuals can become self-determined or advocate for themselves, they need to develop positive outlooks with respect to personality traits such as self-concept, self-esteem, selfacceptance, Self-efficacy, and locus of control, among others. These concepts are part of the person's personality and affect how the person plans for the future and meets the stressors of life.

Self-determination and self-advocacy have been identified as key elements in 
transition planning by IDEA legislation. With respect to self-determination, Wehmeyer (1992) offered the description, “acting as the primary causal agent in one's life and making choices and decisions regarding one's quality of life, free from undue external influence or interference" (p. 305). Westling and Fox (2000) define self-determination as "the need and right to make personal choices" (p. 507). Several approaches emphasizing selfdetermination have been researched in conjunction with career planning strategies. One of these, the IPLAN Strategy (Van Reusen \& Bos, 1990), taught teachers strategies for involving students in planning, taking charge of their own IEP meetings, and assuming responsibility for life planning. This is the strategy that was offered to teachers who participated in the Steps Toward Educational Progress (STEP) intervention project from 1997-2000.

Training in self-determination and learning to make choices can begin early in the student's elementary years. Self-determination can greatly influence career choices when formal transition planning process mandated by the IDEA laws begins at age 14. Since the new IDIEA law (2005) has changed this requirement upwards, to age 16, students may not have the background to make the necessary choices for successful planning. Selfdetermination needs to be introduced at an early age and continued throughout the educational years.

The concept of self-advocacy is related to self-determination, but extends the concept to include "advocating for one's rights and the rights of other individuals with disabilities" (Westling \& Fox, 2000, p. 508). Before persons can become self-determined, advocate for themselves, and make successful life choices, it is important to understand how individuals view themselves. "Variables such as self-esteem, locus of control, and achievement motivation may play an important role for educators in understanding how to 
help students develop the problem-solving and higher-order thinking skills necessary for survival in the 21st Century" (Tyler \& Vasu, 1995, p. 2).

Several researchers focused on the benefits of self-determination, self-advocacy, and person-centered planning (O’Brien \& Lovett, 1993; Wehman, 1996), but Getzel and deFur (1997) outlined the strong connection between these strategies. Their research supported the formation of a support network to sustain ongoing success in adult life. Without this network of support, many students with disabilities will not be able to obtain or sustain their desired future plans. The National Longitudinal Transition Study 2 (NLTS2, 2005) has also investigated differences in the areas of self-concept and selfdetermination of children with mild disabilities. Many more schools are including this training along with social training in their curriculum for children at younger ages. This part of the study was included in NLTS2 because there has been an increase of selfconcept and self-determination training in the high school curriculum after IDEA amendments of 1997.

Szymanski (1994) suggested that empowerment for students with disabilities grew from early childhood through adulthood. She pointed out that the life-span and life-space concepts grew from Donald Super's (1990) theory of career development as well as other related theories (Curnow, 1989; Hershenson \& Szymanski, 1992; Osipow, 1983; Roe, Krumboltz, \& Hershenson, 1990; Super, 1969, 1990; Szymanski; Szymanski, Turner, \& Hershenson, 1992). The concepts of self-determination and autonomy are keys to empowerment of students, families and communities.

Personality differences have been shown to affect both employment aspects as well as postsecondary education. Fourqurean and LaCourt (1990) identified affective issues (e.g., poor self-esteem, a lack of self-acceptance, vocational success, and personal 
independence) in a follow-up study on employment and postsecondary education. The most common problem identified by subjects was the "ability to establish and maintain appropriate social relations with co-workers and job supervisors" (Fourqurean \& LaCourt, p. 19). In postsecondary education, issues related to educational difficulties were identified (reading; math, and chemistry; study habits; writing assignments and essay tests; appropriate accommodations) and also the "social emotional or affective issues ranging from relating to instructors or peers, to being unprepared for the numerous demands of college life" (Fourqurean \& LaCourt, p. 19). Students were asked what would have helped them develop these skills earlier. They identified the need to develop a more positive image in high school, including issues such as overcoming shyness, increasing social skills, and improving self-concept. Several parents and students mentioned the negative stigma of being assigned to special education classes. Comments centered on lack of understanding of learning disabilities, lower self-confidence, and lower self-esteem. "Above all, the terms self-concept or self-esteem emerged as the key words most frequently used in describing the long-term effect of the student's handicapping condition" (Fourqurean \& LaCourt, p. 21).

Self-efficacy

Self-efficacy and locus of control are basic elements of an individual's personality development. Self-efficacy is the perception of the person that their actions can positively affect their future (Steere et al., 2007). In Bandura (1977) the social cognitive theory was initiated and Self-efficacy was described as the inner ability to pursue goals and tasks and work toward the completion of those tasks. S. Smith, Kass, Rotunda, and Schneider (2006) described Self-efficacy as the way persons look at their own ability to work toward a goal or take action required to attain a level of performance. A strong sense of Self-efficacy 
allows the individual to be resilient when faced with multiple roadblocks in pursuit of a goal. Individuals with strong Self-efficacy possess internal attitudes to think they have the ability to achieve and to improve the situation when faced with the possibility of failure. A high sense of Self-efficacy allows the person to solve problems more readily (S. Smith et al.). Bandura (1989) described persons with high Self-efficacy as "viewing themselves successfully executing a task" which provided positive guides for performance while those persons with low Self-efficacy "viewed themselves as failing on a task and focused on events going astray" (as cited in S. Smith et al., p. 172).

Strausser and Berven (2006) devised a Self-efficacy job seeking scale based on Bandura's work. When applied to job-seeking skills, Self-efficacy refers "to an individual's confidence in his or her ability to successfully execute job-seeking behaviors" (p. 206). The psychological factors in the job search are the target for their Self-efficacy job seeking scale, e.g., "work personality, self-concept, adjustment to disability, Selfefficacy, and outcome expectancies that are important in a successful job search" (p. 207). Self-efficacy and self-concept are different ways of looking at oneself (Pajares \& Schunk, 2001). While Self-efficacy centers on how the person judges confidence in his/her abilities to execute goals, self concept provides perceived evaluation of self-worth. Self-efficacy beliefs are more closely related to academic achievement than self-concept (Lackaye, Margalit, Ziv, \& Ziman, 2006; Marsh \& Hau, 2004; Pajares \& Schunk; Pietsch, Walker \& Chapman, 2003).

Three types of Self-efficacy have been identified: academic, social, and emotional (Bandura, Barbaranelli, Capara, \& Pastorelli, 2001; Bandura, Capara, Barbaranelli, Pastorelli, \& Regalia, 2001; Bandura, Pastorelli, Barbaranelli, \& Caprara, 1999; Muris, 2001). In Jones and Jolly's (2003) study, the relationship between family and adolescent 
Self-efficacy was explored. They found no support for negative effects based on family structure, but did find significant correlates in race, academic performance, income, and parental support. Demographics, along with Self-efficacy, are considered in this present research.

Sherer, Maddux, Mercandante, Prentice-Dunn, Jacobs, and Rogers (1982) authored The Self-efficacy Scale that was used to gather Self-efficacy General and Self-efficacy Social test scores for the current study. Their scale is based on the premise that past experiences and attribution of success to skill or chance results in two different levels of Self-efficacy. One score is for a Generalized Self-efficacy expectation, while the other score is for a Social Self-efficacy subscale. They tested their theory against Locus of Control, Personal Control, Social Desirability, Ego Strength, Interpersonal Competence, and Self-esteem measures to provide construct validity. The Self-efficacy Scale has a positive relationship with vocational, educational, and military successes in testing use over the years. When individuals believe they can accomplish an outcome, they undergo a behavior change which differentiates the process of attaining the goal different in three ways: (a) The individual is more likely to try to perform the behavior initially, (b) The individual gives more effort to trying to attain the goal, (c) The individual applies more persistence in the face of adversity (Sherer et al.). Their research confirmed that the test was not tied to a specific behavior or situation. It has been widely used and is available on the web for use without copyright fee. High Self-efficacy was associated with "internal orientation as measured by the I-E Scale [Internal-External] and its Personal Control subscale" (Sherer et al., p. 669). It should be recognized that scores on the Sherer et al. Self-efficacy Scale should not be interpreted in isolation from real-life experience and context. The goal is not a high score on the scale, per se; rather, it is the person's sense that 
he/she actually possesses these attributes of self-control and self-completion, i.e., the underlying construct. A high score alone is not enough unless the person has had some success experiences on which to build. Positive outcomes build a circle of success with the individual experiencing more success and subsequently attempting more and persisting longer in the attainment of a specific goal.

The discussion on the limitations of a generalized Self-efficacy measure is illustrated by various applications of the Sherer et al. (1982) scale. Sherer et al. themselves note that, "The Self-efficacy scores were associated with the ability to keep a job, but not with success in education or with military rank" (p. 670).

Empirical research studies were supplied by Mark Sherer, author of the Selfefficacy Scale, in 2000, in response to a request to include his test in this dissertation. The following topics were the target for these research projects: the elderly (Bosscher \& Smit, 1998); Spanish adults (Caballo, 1993); relationship between parental autonomy and children (Erford, 1995); vulnerability markers and protective factors for prevention of schizophrenia in children and adolescents (Godoy, Muela, Sanchez-Barrera, \& SanchezHuete, 1995); hospitalized mentally ill patients (Hays \& Buckle, 1992); medical and psychosocial aspects of epilepsy (Helgeson, Mittan, Tan, \& Chayasirisobhon, 1990); hospital social workers (Holden, Cuzzi, Rutter, Chernack, \& Rosenberg, 1997); adult attachment styles (Jang, 1997); language differences (Keane \& Morgan, 1991); five ways of operationalizing Self-efficacy (Lee \& Bobko, 1994); attachment bonds with parents (Mallinckrodt, Coble, \& Gantt, 1995); attachment patterns in psychotherapy relationship (Mallinckrodt, Gantt, \& Coble, 1995); Hindi translation and factor structure (Mattoo \& Malhotra, 1998); comparison of Likert scale and traditional measures (Maurer \& Pierce, 1998); personality characteristics and family environments of short term counseling clients 
(May \& Sowa, 1994); Japanese version of generalized Self-efficacy Scale from the life span perspective (Narita, Shimonaka, Nakazato, Kawai, Sato, \& Osada, 1995); factor structure and convergent validity of the Italian version (Pierro, 1997); comparison of Selfefficacy with self-esteem (Stanley \& Murphy, 1997); out-of-body experience and personality functioning (Tobacyk, Wells, \& Miller, 1998); health locus of control and Selfefficacy beliefs in a healthy elderly sample (Waller \& Bates, 1992); effects of cognitive and experiential group therapy on Self-efficacy and perceptions of employability of chemically dependent women (Washington, 1999); and task, domain, and general efficacy development (Woodruff \& Cashman, 1993).

Klassen (2002) identified 22 studies that included Self-efficacy with students with LD. He noted that in the past 20 years a considerable amount of research was done with the construct of "self" and learning disabilities, but no comprehensive review of academic functioning in this regard (p. 89). The purpose of Klassen's research was to "examine how students with LD (with poor task analysis and metacognitive skills) calibrate their efficacy beliefs with criterial tasks (p. 90). Metacognitive refers to "the awareness of one's cognitive processes, cognitive strengths and weaknesses, and self-regulation" (Flavell, as cited in Klassen, p. 89). Calibration has to do with the "degree of congruence between efficacy beliefs and actual performance" (p. 89). The review is specifically limited to studies investigating experimental and correlational research related to perceived Selfefficacy of LD students in the educational context. Nine studies were done between 1985 and 1989 and 13 published after 1990; the age of participants ranged from six years to college age; and the number of participants ranged from 3 to 336. Even though there is a large body of research on LD students and reading ability, the Self-efficacy studies covered a wide variety of topics: eight studies focused on writing, five studied math skills, one 
study examined reading, one study looked at career and vocational interests; and seven studies were general academic functioning or "mixed" academic functioning (p. 91). Gender was included as a variable in 5 of the 22 studies with either low numbers of girls for comparison or no significance found. There were some mixed findings, but in all but two studies, "increases in performance skills following intervention were mirrored by increases in measured Self-efficacy beliefs" (p. 91). Of the nine studies designed to explore the relationship between LD and typically achieving students, none of the studies used low-achieving students as control groups. LD students were more apt to overestimate their Self-efficacy and overestimate their abilities as well. Calibration between misestimating Self-efficacy or skills was difficult to determine since many of the studies did not have enough detail to determine this factor. For example, writing samples that were re-written were more difficult to score than math problems in which the differences were clear. One study described what was called the "self-protective" function in which a "façade of competence" was erected by the LD students to hide their academic difficulties (Alvarez \& Adelman, as cited in Klassen, p. 95). The variety of skills covered make this literature review valuable in reviewing LD student perceptions of Self-efficacy as related to their performance skills. Limitations to this type of review included concept blurring where the measures described strayed from the basic definition of Self-efficacy. The study gave teachers and researchers insight to LD students and Self-efficacy and suggested that short examples of Self-efficacy estimates prior to a learning experience might help students with LD to predict their Self-efficacy better over time. Replication of the instruments used needed to be done for validity and reliability. More research is needed on methods to uncover accurate self-beliefs of students with LD (p. 100). Similarly, more research is needed to explore gender differences and developmental changes longitudinally. None of 
the studies used low achieving LD students who often make up the bulk of the LD students.

Despite these limitations, the Self-efficacy Scale (Sherer et al., 1982) was utilized in the larger project upon which the current study is based. This instrument measured how individuals believed their personal competence and control affected their ability to do something. It was concerned "not with the skills the person had, but with perceptions of what one can do with whatever skills one possesses" (Bandura, 1986, p. 391). The original Self-efficacy Scale had 36 questions, but thirteen items were taken out since they did not load at the .40 level or above (Sherer et al., p. 665). The test was validated with 23 items with two subparts. The first group of questions is called the General Self-efficacy score (GSE). Factor 1 of the test has 17 questions and accounted for $26.5 \%$ of the total variance. "Items loading on this factor measure self efficacy without reference to any specific behavioral domain" (p. 665). Factor 2 of the test had six items which accounted for $8.5 \%$ of the total variance measured the Social Self-efficacy score (SSE). These items reflected efficacy expectancies in social situations. "High scores on both sections indicated high Self-efficacy expectations" (p. 665). There were 7 filler items that are not counted. The two sub-sections are not added together. "Cronbach alpha reliability coefficients of .86 and .71 were obtained for the General Self-efficacy and for the Social Self-efficacy subscales, respectively" (p. 665).

\section{Locus of Control}

Early research by Rotter (1966) defined locus of control as a person's expectancy of internal control over behavioral outcomes rather than luck, fate, or circumstances controlling what happens to them. The study of locus of control has been linked with higher school performance (Chubb, Fertman, \& Ross, 1997; Nunn \& Nunn, 1993) and self 
esteem in occupations (Wang, Kick, Fraser, \& Burns, 1999). Wehmeyer (1993) linked locus of control to the education of students with disabilities. He examined variables such as self-determination, self-reliance, and self-advocacy as important outcomes. Students with disabilities need to become aware of their patterns of thought regarding assuming responsibility for their own lives and shifting away from parental and educational control of their lives. When the locus of control is shifted from adult manager to the student's responsibility, personal feelings of self-worth could be enhanced if the efforts are successful (Luther, 2001).

The Locus of Control Scale (Nowicki \& Strickland, 1973) focused on the personality trait of how the person perceived themselves as being in control of their destiny. It is based on the questionnaire developed by Rotter (1966) as part of his Social Learning Theory, which integrates learning theory with personality theory. Social Learning Theory as proposed by Rotter (1954) departed from the learning approaches of that time, psychoanalysis (based on Freud's writing) and behaviorism (based on psychological motivational principles) (Rotter, 1993). He chose the empirical law of effect as the motivating factor--people are motivated to seek out positive stimulation, or reinforcement, and avoid unpleasant stimulation. He combined personality study and behaviorism and set forth the main idea that personality represents an interaction between individuals and their environment (Rotter, 1993).

Bandura's writing suggests that behavior theory has an emphasis on experimental methods, focuses on variables we can observe, measure, and manipulate, and avoids whatever is subjective, internal, and unavailable (as cited by Boeree, 1998). This suggests that personality theory is based on environment which causes the behavior. Bandura thought this was too simplistic and added that both are true: environmental causes 
behavior, and behavior also causes environment. In other words, "the world and the person cause each other" (Boeree, p. 1). Bandura later looked at personality as an interaction among three parts: environment, behavior, and the person's psychological processes (ability to imagine in one's mind, and language) (Boeree, p. 2). Bandura is considered the father of the cognitivist movement of learning theory. His extension of the personality theory led to observational learning (modeling) and self-regulation. Both social learning theory and personality theories help explain how self-concept and locus of control fit into this present research.

The locus of control measure (Nowicki \& Strickland, 1973) provided a generalized expectancy for internal versus external control of reinforcement. Rotter (1966) believed that motivation led people to seek positive stimulation and avoid unpleasant stimulation. He described personality and behavior as constantly changing. His theory ranks people's beliefs about what is reinforcing to them in terms of a scale ranging from internal to external. Since this is an interactive factor, the person might be internal in one situation and external in another (Estrada, 2006; Rotter, 1966). According to North Central Regional Educational Laboratory (2005) guidelines, persons who have internal locus of control are in charge of their own behavior versus persons with external locus of control who see fate, luck, or external circumstances as causing things that happen to them. McCombs (1991) restated this concept to say that the person thinks, "I choose to direct my thoughts and energies toward accomplishment. I choose not to be daunted by my anxieties or feelings of inadequacy" (p. 1).

Several researchers link locus of control with achievement (Estrada, 2006; Kalechstein \& Nowicki, 1997; Nowicki \& Duke, 1974; Young \& Shoor, 1986). Kalechstein and Nowicki (1997) reported in a meta-analysis that "the generalized and 
specific control expectancies were related to academic achievement" (p. 1) in many instances. Locus of control of reinforcement, based on Rotter's (1983) theories, was explained by Kalechstein and Nowicki (1997) as:

...the degree to which persons expect that a reinforcement or an outcome of their behavior is contingent on their own behavior or personal characteristics versus the degree to which persons expect the reinforcement is a function of chance luck or fate, under control of powerful others, or is simply unpredictable. (p. 489)

The Locus of Control Scale (Nowicki \& Strickland, 1973; J. D. Brown, 1996) used in this study thus fits into personality theory and gives a deeper meaning to student choices that were expressed. This instrument centered on student perceptions of being in charge of their own destiny. High scores on this test indicated that the person perceived that things that happen to them were largely due to their own actions. This would be scored as an Internal Locus of Control. Low scores on this test indicated that the person had the perception that events that shaped their lives were due to forces and factors outside their own control. This would be scored as an External Locus of Control. It is generally recognized that "students who had a more Internal locus of control gained higher levels of academic achievement and were more successful adults than students with External locus of control" (Liebert \& Spiegler, 1990, p. 448).

The 40-item scale was developed in a series of studies involving over 1000 male and female children from grade three to twelve (Fisher \& Corcoran, 1994, pp. 525-527). Participants were primarily white with all socioeconomic levels represented. Student scores become more internal as they grow older. The score is obtained by adding the number of items that are scored "correctly." YES is correct for items 1, 3, 5, 7, 8, 10-12, $14,16-19,21,23,24.27,29,31,33,35-39$, and NO for the remainder. Higher scores reflect more external locus of control. The Locus of Control Scale has only "fair internal 
consistency overall, with split-half reliabilities increasing with age: .32 for grades $3-5, .68$ for grades $6-8, .74$ for grades $6-11$, and .81 for grade 12 " (p. 503). Concurrent validity is also fair and correlates significantly with three other measures of locus of control and a number of academic and nonacademic behaviors. Race, socioeconomic level, and sex seem to mediate some of those findings, but do not seem to be affected by social desirability response set (p. 503).

\section{Transition Intervention Programs}

\section{National Programs}

In an effort to review recent empirical research, library and internet searches were conducted in each of the four sections pertinent to this paper: Employment, Postsecondary Education, Independent Living, and Personality Development. Many of the articles found were descriptions or suggestions on how to improve or important aspects to include in a training program, but were not based on empirical research methods. This is similar to the findings that Kohler and Chapman found in their extensive transition literature review (1999). Atwell and Cobb (2006) also reviewed the literature and offered their map of intervention literature in secondary education transition. Even though the Office of Special Education Programs (OSEP) funded more than 100 model projects between 1988 and 1990, and multiple demonstration initiatives were funded in the 1990s, an organized, systematic site did not exist to review the extensive body of knowledge. Thus, in 2001, the What Works in Transition: Systematic Review Project, centered at Colorado State University, was awarded a contract to review projects systematically and identify from the evidence ideas that work to improve outcomes for students with disabilities. This project attempts to catalog and identify gaps in the literature to give OSEP direction for future research. 
Atwell and Cobb (2006) gave credit to Wehman who pointed out that even after twenty years of intensive work in transition, the majority of students with disabilities leave high school with dim prospects for their futures: under- or unemployment, underrepresented or unsupported in postsecondary education, and not living independently nor satisfied with their social lives (cited in Atwell \& Cobb, p. 4). Even though 1,461 transition studies were identified, the final review only included 164 due to lack of sufficient reporting of data, inadequate specification of intervention or outcome measures, lack of clarity on participants such as insufficient numbers or descriptions of disabilities included, lack of comparison groups, etc. (p. 6). Their final product offers studies grouped in six intervention areas: transition planning, vocational/employment preparation, social skills, self-determination, life skills curricula, and counseling. They provided a table describing the eight design standards with internal and external validity. The four major groups of design types were: between-group studies, single-participant studies, qualitative studies, and within-subjects studies (mostly one group pretest-posttest studies) (p. 9). Outcomes were organized into the five areas (1993) used to define transition: social relationships, academic involvement, career development and vocational pursuits, maintaining a home, and participation in the community. As reviews are completed, they become available on the web site of the National Secondary Transition Technical Assistance Center. The following reviews of empirical research are offered to support the research in this project.

\section{Summer Activities Research}

A unique study by Hughes et al. (2004) examined the summer activities of youth with disabilities living in high-poverty neighborhoods. The participants had taken vocational classes and participated in a self-determination curriculum in the previous school year through a three-year grant called Project OUTCOME. Factors that negatively 
influenced employment outcomes for youth included disability, minority, and poverty status. In combination, students were at additional risk for lowered employment possibilities. No previous studies have examined summer experiences of minority youth with disabilities from high-poverty backgrounds. The 31 participants were part of a threeyear federally funded Project OUTCOME and attended a comprehensive high school (1,018 students) in a large urban school district. School records indicated that approximately $38 \%$ of the students exited by dropping out, $85 \%$ received free or reduced lunch, and 16\% received special education services (p. 29). Only 29\% of all ninth graders passed the state achievement test for diploma status which put the school into a lowperformance category.

Project OUTCOME (Hughes et al., 2004) students attended sessions two times per week for 45 minutes with 6-9 students in a group. The Next S.T.E.P. curriculum was implemented (Halpern, Herr, Wolf, Doren, Johnson, \& Lawson, cited by Hughes et al., p. 30). Twenty-five of the 31 students in the project participated in the summer study. The six who did not participate had moved, graduated, or were unable to be contacted. Participants were 14-16 years old, $60 \%$ male, and 72\% African American (p. 30). Disabilities included: Learning disabilities (60\%), mild mental retardation (24\%), severe emotional disturbance (12\%), and language impairment (4\%). Twenty-three students lived with family members and two lived in a residential facility for youth offenders (p. 31). All were in self-contained or resource classrooms with limited involvement in general education, were enrolled in average of two vocational classes, and had not participated in community-based job training (work study or coop). None of the 25 participants had passed the state achievement test. Telephone interviews were conducted using a structured interview protocol. Questions were developed through a review of studies on outcomes (e.g., U.S. 
Bureau of Labor Statistics, 2000; Wagner et al., 1991). All interviews were conducted over a two-week period beginning five weeks after the school year was over; up to 12 attempts to contact each student or family member were made (p. 33). Interview information was compared to school records, teacher and student tests given in the spring semester, demographics, school attendance, GPA, and general and vocational courses.

Results (Hughes et al., 2004) indicated that only six (24\%) of the students were employed for wages (fast foods, groceries, and movie theaters) with average wages of $\$ 6.25$ (range, $\$ 5.50$ to $\$ 7.00$ ). Four worked full time and 2 part-time. Of the 19 unemployed (75\%), 15 were seeking employment (but only 5 had actually completed applications). Activities participated in included "hanging out" with friends or family, odd jobs, and not involved with any specific activity (p. 35). Three who were volunteering or doing odd jobs were satisfied with their summer activities, 10 were dissatisfied, and two did not respond when asked (p. 35). Few differences were found in terms of age, gender, IQ, or ethnicity for students employed versus those who were unemployed. Students who were employed had disability categories of LD or MMR; no students were employed in the ED or language impaired categories. The records review indicated that employed students had higher attendance, higher GPA, and higher enrollment in general and vocational classes. Both student and teacher ratings on the Transition Skills Inventory (TSI) measure (Halpern et al., cited by Hughes et al., p. 32) were higher for the employed students. On the Behavioral and Emotional Rating Scale (BERS) (Epstein \& Sharma, cited by Hughes et al., p. 33) employed students had fewer behavioral deficits than unemployed students.

Hughes et al. (2004) suggested further research to understand the factors needed to overcome barriers to high-poverty backgrounds and neighborhoods, lowered expectations, and lack of motivation for students with disabilities. School, home, and community 
partnerships were needed to address this situation. Programs needed to be strengthened to provide job seeking and job maintaining skills for students in high-poverty areas with limited job opportunities. Some type of community support network was needed to bridge the summer months. Limitations of the Hughes et al. study included a narrow snapshot of students' situation at a particular point of time in the summer--a longitudinal record would provide a richer insight into the challenges these students face. The sample size was small which limited generalization and no other high-poverty school was included for comparison. Assessments of other community factors such as available public transportation, parent preferences, available job market, etc., were needed for impact on students' employment. Also, no comparisons were made to students without disabilities who attended the same school and lived in the same neighborhoods. The appropriateness of the curriculum used (Next S.T.E.P., TSI, BERS, and other materials) needed to be tested for use with adolescents from diverse backgrounds (p. 40). The lack of high-stakes testing achievement should be addressed since lack of diploma status curtails opportunities for future employment (p. 40).

\section{Parent Perceptions of High School Curriculum, Planning, and Expectations}

Grigal and Neubert (2004) conducted a survey of 234 parents of students with disabilities in two urban school systems. They included parents of secondary level students with high- and low-incidence disabilities in order to obtain parents' importance of instructional domains, transition planning, and post-school expectations. (Generally, students with mild disabilities [LD, EBD, MMD, Vision, Hearing Impaired, Speech/Language Disabilities, and Other Health/Physically Disabilities] are included in high-incidence disabilities. Low-incidence disabilities would include students with: Moderate/Severe Disabilities, Autism, Traumatic Brain Injuries, and more involved 
Multiple Disabilities.) The purpose of their research was to provide parent perspective on in-school values and post-school expectations that have not been assessed in previous research, and expand the population focus to ethnically diverse urban settings. Comparisons were made between parents of high- and low-incidence students. The findings are part of a larger study in which parents in secondary special education were surveyed about transition and self-determination (Grigal, 2001; Grigal, Neubert, Moon, \& Graham, 2003).

Grigal and Neubert (2004) expanded a composite from previous research to focus on parents' current values and post-school expectations (p. 70). Directors of Special Education from two Mid-Atlantic school systems randomly selected names and addresses of 984 parents with a son or daughter with disability in high school between the ages of 1621 years. Both school systems were in urban areas bordering a metropolitan city. Surveys were mailed with cover letter and postage-paid envelope. Subsequent follow-up was done with non-responders. All were told they would be entered into a random drawing for three prizes as incentive to complete the survey. A total of 234 parents responded (24\%) with mothers making up $82.5 \%$, fathers $9.8 \%$, grandparents $5.6 \%$, legal guardians $1.7 \%$, and no response $.4 \%$. Results were given in mean ranks for each response and chi-square analyses were conducted for between group comparisons. Parents of the low-incidence group (33\%) ranked life skill instruction as number one importance compared to only $15.2 \%$ of parents of high-incidence group. Significant differences were also noted in areas of academic (high-incidence group was higher), and community-based instruction (low-incidence group was higher). In transition planning, both groups ranked education first; the low incidence group ranked residential needs next highest while the high-incidence group ranked employment next highest. In the Future Living Arrangements category, four choices were 
offered (home with family, group home, apartment with friend, own home). The lowincidence group (45\%) ranked home with family as first choice and high incidence group (own home) as their number one option. This is not surprising since students in the lowdisability range have more involved disabilities and need more support. Outcome potentials after exiting school system were offered (i.e., live independently, manage own finances, employment in community, make friends, attend college). No significant differences were found between the two groups of parents. For the in-school values, the authors noted that although the self-determination requirement was only recently required at the time of the study, $61 \%$ of the low-incidence group and 58.6 of the high-incidence group ranked it as choice one, two, or three (p. 77). Both groups ranked education and vocation above recreation and social activities. College was the most desired post-school outcome for both groups (57.9\% for low-incidences, 63.2 of the high-incidence) which was surprising.

Limitations that were mentioned by Grigal and Neubert (2004) included: (a) There is a need for a higher rate of return for the survey, (b) All participants were from two racially diverse, large, urban school systems (generalizations would be difficult to other areas), (c) Self-reporting from parents could inaccurately reflect their values or possible terms/options in the survey might not have been understood by all (p. 81). The authors suggest that further research is needed in areas of parental values assessment related to the type of high school program offered, that teacher preparation needs to include recent research and changes, and that both groups of parents want college as an option for their student with disabilities.

High School Male/Female Differences in Outcomes

Coutinho, Oswald, and Best (2006) conducted a study to ascertain differences in 
outcomes for female and male students in special education. They used a data set from the 1988 NELS-88 National Education Longitudinal Study to examine outcome variables for gender differences in special needs students. Using the 1998 group who were still present in 1994, the total included 13,391 participants (6,526 males and 6865 females). They were divided into four status groups: special education (SE), low achieving (LA), typically achieving (TA), and gifted and talented (GT). Twenty-four variables were selected to represent a range of socially significant outcomes. Data analysis was done using a general linear model or multinominal logistic regression model with a two-step process to isolate gender effects (p. 50). The first step used gender, group, race, and gender by group interaction. If no significant effect was seen, the variable was dropped. If the gender-bygroup interaction was significant, analysis of the outcome variable was continued. The second step used an adaptation of a logistic regression model including 22 school, family, and individual predictors: percentage minority in school, percentage of students in special education, percentage of students in gifted programs, urbanicity, family socioeconomic status, number of risk factors for dropping out of school, how often a parent talks to the child about school, how often a parent helps with homework, whether anyone is home when the child returns home, student grades, standardized test scores, locus of control, self concept, likelihood of post-high school education, higher education plans, retention, disruptiveness, absenteeism, counseling about career, counseling about courses, employment, and hours spent on homework. This model was found to predict whether a student was likely to be in one of the four groups. The authors found significant gender-bygroup interaction $(p<.05)$ in the second step to suggest differential gender effect existed (p. 50). Results indicated that in employment, there did not seem to be differences in gender between the four groups: both special education and non-special education women 
were employed in clerical positions more than men $(p<.05)($ p. 51). Similarly, more men than women were in skilled or technical positions across groups. There were gender effects for months employed and average hours per week across groups with men having higher number of months and hours than women. Three post-school employment satisfaction outcomes were considered: satisfied with opportunity to use past training or education, employer provided medical benefits, and job satisfaction. There were no differences in gender for the first two variables, but the average job satisfaction was significant $(p>.05)$. Males had higher job satisfaction than females. For the area of post-school education and aspirations, significance was seen in the drop out rate with $26 \%$ of the SE students dropping out and $16 \%$ of the non-SE students dropping out $(p<.05)$ (p. 52). Significance was also noted in future job expectations with more women than men expecting to be in clerical, professional, sales and service and more men than women expecting to be in skilled technical, owner, and other positions in all groups $(p<.05)$ (p. 53). In total, a significant main effect for gender was observed for 12 variables with men being favored. Women were favored in post-school education and were less likely to be arrested. The SE group held to this trend with men being favored in employment, earnings, receipt of high school diplomas, etc.

Limitations of the Coutinho et al. (2006) study include effects in changes in transition services over the past several years; generalization is limited since the sample of students in special education is unlikely to include adequate representation of moderate/severe students; parent/faculty reports rather than record reviews may have misclassified some students; and the survey methodology did not allow for verification of outcome data. Due to the number of logistic regression models, Type 1 error probability is elevated (p. 57). 
Findings of Coutinho et al. (2006) study show the need for improved services for women with disabilities. They were less likely to receive high school diplomas, worked fewer hours, earned less, and were more likely to be a biological parent. They suggested that expanded career development, improved self-determination skills, and transition planning needed to be implemented. The authors pointed out that these same recommendations for gender are needed for students in the LA group as for SE (pp. 57-58). Differences between LD Dropouts and Graduates

Kortering, Haring, and Klockars (1992) "studied the utility of a linear discriminant function to distinguish between students identified as LD who had been released from high school under codes suggestive of school dropout $(n=213)$ or graduation $(n=92)$ " (p. 422). Variables considered were ethnicity, reading ability, family intactness, family socioeconomic status, school transfers, and school initiated interruptions. The authors noted the difficulties in identifying students who dropped out since many different codes are used by school districts and totals are counted differently. [NOTE: this is a factor that has been addressed by NCLB in an attempt to clarify this issue on a nationwide basis.] Participants were from a large urban school district in the northwestern United States that had between four and five percent of LD students in their student population of 45,119 students. In this district, the LD population comprised $75 \%$ of secondary special education students and $75 \%$ of those who dropped out of school. Ethnicity included $45 \%$ white, $39 \%$ Afro-American, 7\% Asian, 5\% Latino or Chicano, and 4\% Native American. Socioeconomic status included $34 \%$ of the students on free or reduced lunch during the 1987 1988 school year. The mean age of participants at the time of the study was 18.3 years ( $S D$ $=.75)$ for the LD graduates and $17.2(S D=1.4)$ for the LD dropouts. Both groups had IQ scores within the lower normal range; the majority of both groups were male (p. 428). 
They employed Morrow's (1986) definition for drop out: “(1) Is student actively enrolled?

(2) If not, has the student's enrollment been formally transferred to another legitimate institution? (3) Has the student been awarded a high-school diploma or its equivalent?" (p. 344). If answers to all three were negative, the individual was considered a drop out. The purpose was to determine if accurate discrimination could be made between LD students who dropped out and those who received diplomas.

Kortering et al. (1992) used $t$ test statistics to analyze individually the six independent variables. "To control for Type I errors, each test was evaluated at the .01 level of statistical significance making for an experiment-wise error rate of less than .06" (p. 429). The discriminant analysis was used to see if a combination of the six variables would form a linear discrimination to differentiate between LD students who drop out versus those who graduate. The univariate analysis $t$ test evaluated the relationship between the groups and all six independent variables (p. 430). There were no statistically significant differences found between groups for ethnicity, reading, or family socioeconomic status, but there were significant differences at the .01 level for intactness, transfers, and releases. The discriminant function constructed weighted variables of schoolinitiated interruptions, family intactness, and school transfers most heavily. Kortering et al. correctly predicted an overall accuracy rate of $72 \%$. Findings suggest that LD students in this urban setting are leaving school without graduating at an alarming rate $(28 \%$ had already been released one time prior to being identified as a dropout and $43 \%$ had dropped out two or more times previously). Future research needs to extend these findings to younger groups of students to help understand how to prevent students from dropping out. Community factors need to be addressed along with school concerns since factors such as family intactness and socio-economic status are not within the school's parameter of 
influence. Schools need to identify these students earlier and figure out ways to keep them in school if the opportunity to interrupt the social cycle within school, community, teacher, and society exists.

\section{Special Educators' and Employers' Perceptions}

McCrea (1991) compared the perceptions between special educators and employers. Many previous studies have focused on obstacles to successful employment; reasons individuals with disabilities lose their jobs; factors contributing to job maintenance and termination; adequate preparation for adult life; and appropriateness of employment and potential for employment. However, no previous studies had investigated the differences between educators and employers related to job-related skill importance. The purpose of the study was to "determine the relationship between employers' perceptions and special educators' perceptions as to which skills and skill categories are most relevant to job success" (p. 122). The authors used an instrument developed by Chamberlain (1988) which identified employer's important skills for the San Diego County area (p. 122). Factors were grouped into social, personal, communication, and work-related categories. Scoring was on a Likert scale with 1 related to most job success and 4 being the least closely related. At the end, both groups were asked to list five factors they considered most important for job success (from the list or from other sources). Participants were 109 special educators from three Calhoun County and five Western MI school districts who were enrolled in university graduate or undergraduate classes. The employer group was made up of 133 employers from Calhoun and Kalamazoo Counties, MI, who currently employed students with disabilities in areas of fast foods, hospitality, or service-oriented businesses.

McCrea (1991) delivered and picked up the questionnaires in person to the 
educators, mailed them to 93 employers, and hand delivered 43 to others. Special educators returned 80\% (17 males and 70 females; ages between 21 and 61; and teaching experience over 20 years). Employers returned $75 \%$ (60\% by mail and $90 \%$ delivery/pickup; 65 males and 35 females; majority with title of manager or assistant manager; job experience spanned over 30 years; employing from 3-3000 employees with disabilities; and 53\% with at least one person with disabilities on the payroll currently). Results showed that educators and employers ranked the factors differently: Educators ranked work-related, 1; social, 2; communication, 3; and personal, 4, while employers ranked work related, 1; communication, 2; personal, 3; and social, 4. Data analysis included a Spearman rho $(r)$ coefficient analysis to assess relationship between rankings of educators and employers. The $r$ value was based on zero (0.00) to one (1.00). The two factors agreed upon were personal $(r=1.0, p<.05)$ and social $(r=.9, p<.05)$. The other factors were not significantly positive (communication, $r=.5$; work-related, $r=.05$ ). No significant differences were found between ratings of educators with or without teaching experience or between educators' two groups and that of employers. Comparing the five factors that were asked for at the end of the questionnaire, there were several mentioned by either educators or employers that were not mentioned by the other group. "Employers judged being able to read and write; understand the work routine, and follow instructions to be more critical to job success than did educators" (p. 128). Educators ranked the following higher than employers: "responding appropriately to supervisor correction, being able to communicate basic needs, and displaying a socially acceptable attitude" (p. 128). These factors seem to correspond to special education curriculum.

Limitations to McCrea's (1991) study included the differences between groups ( $80 \%$ of educators were female while $65 \%$ of employers were male) and prior job 
experiences for educators were not explored. Further research would be needed to modify training of school-age students with disabilities to be more closely in line with employer needs. Also, pre-service training needs to be updated to train educators effectively for awareness of these challenges (p. 129).

Increasing Enrollment of Students with Disabilities in Vocational Education

Weinsenstein, Stowitschek, and Affleck (1991) reported on a model demonstration project funded by OSEP, U.S. Department of Education, and collaboratively designed by staff from the University of Washington and the Highline School District (Seattle, WA). The purpose of the model was to increase enrollment numbers of students with disabilities in vocational education, provide support for students with disabilities who were already attending regular vocational classes, and increase retention for graduation. The purpose for the study was to determine, through formative and summative evaluation, impact on enrollment and retention: demands on resources, teacher time, and other factors impacting acceptance or rejection of the model. A moderate-sized school district with four high schools was selected for model implementation. High School One (HS One) was selected by district administrators due to the high loss of students through dropping out, low attendance, and low participation rate in vocational classes. High School Two was included the second year. The other two high schools were involved in planning along with special education and vocational administrators from adjoining school districts. Thus, comparison site programs began to implement elements of the model as the study progressed. All students had mild disabilities (LD, MMD, and BD). A formative field test in the second year with HS One collected data through parent, teacher, and student interviews, contact logs, course records, and employment surveys. A summative field test was conducted in year three to examine student enrollment in vocational education across 
all district schools and compare enrollment to the adjoining school districts. The least impact was with parents' knowledge and interest in the child's vocational education; samples of 15 and 30 parents respectively, showed no change as a result of receiving or not receiving the vocational brochure. Over 200 mailings only resulted in three requests for more information (p. 139). Vocational and special education teachers rated six variables on a 5-point scale (relevance of vocational education in preparation for adult life; vocational preparation of special education leavers; students' utilization of vocational programs; level of support services; change in knowledge of contact with special or vocational educators; and vocational education programming for special education students). Model school educators increased their average ratings by at least a half step; model special education teachers rated variables consistently higher in second year than did comparison high schools. Higher percentages for students in model schools were seen in part-time jobs than comparison schools, but both groups were similar in wages and hours worked per week. Over the two-year period, enrollment for special education students increased from $45 \%$ to $68-76 \%$ (p. 139), with model schools enrolling approximately $20 \%$ more than comparison schools. Course completion rates were $63 \%$ for model sites and 39\% for comparison schools. A $27 \%$ decrease in disciplinary referrals was seen at the model sites. Graduation rate increases and GPA comparisons were not significant, but were slightly higher than before.

Results from the Weisenstein et al. (1991) study showed that special and vocational educators working collaboratively could improve special education student outcome and that the process of informing parents about vocational opportunities, aiding student entry, supporting students as they complete vocational courses, and ensuring students' entry to the work force was a positive, ongoing model. Since there was not a follow-up component 
to this study, it limited understanding of long term effects and employment outcomes. The project was also limited due to the short, two-year study period. Impact on student outcomes was substantive in that more students with disabilities enrolled in and were taking a greater variety of vocational courses than before the projects. Five recommendations were made for future implementers: (a) Teachers and administrators must plan together since it is the teacher who will have the responsibility for program implementation, (b) A coordinator for at least $25 \%$ time is needed to organize recruitment, guidance into correct areas, and ongoing support, (c) Middle and high schools need to be included. Middle school teachers need awareness of program opportunities to counsel with students and parents early in the process, (d) Joint consultation is needed between vocational and special educators for student support, and (e) Both sets of educators need ongoing training in the needs and capabilities of students with disabilities, vocational competencies, and cooperative consultation techniques (p. 143).

\section{Teaching Skills of Self-Determination}

Durlak, Rose, and Bursuck (1994) used direct instruction to teach selfdetermination skills to high school students with LD in a large, mid-western suburban setting. The purpose of their study was to see if students could learn to state their own disability, including strengths and weaknesses, tell teachers how their disability impacts their academic and social performance, identify personal instructional accommodations needed, and identify strategies for arranging accommodations with regular classroom teachers (p. 51). The subjects were eight high school students who met the following state and federal standards for specific learning disability: (a) At least average intelligence as measured by the Weschsler Intelligence Scale for Children-Revised (Wechsler, as cited by

Durlak et al., p. 52) or the Wechsler Adult Intelligence Scale (Wechsler, as cited by Durlak 
et al., p. 52), (b) Demonstrated deficits in specific academic skills measured by Wide Range Achievement Test (Jastak \& Wilkinson, as cited by Durlak et al., p. 52) or the Woodcock-Johnson Psycho-Educational Battery (Woodcock \& Johnson, as cited by Durlak et al., p. 51). Demographically, seven students were male and one female, seven were white and one was Hispanic. The students were from 15-17 years old and were enrolled in general education classes most of the day. The researchers had a panel of 15 experts verify the list of skills to be acquired by the students: (a) Ask for clarification of lecture material from class, (b) Tell a teacher that he/she has a learning disability, (c) Make an appointment with a teacher to discuss needs and/or accommodations, (d) Ask a teacher if a tape recorder may be used to record class lectures, (e) Obtain teacher approval for another student to take notes or to copy another student's notes, (f) Ask the librarian for assistance, (g) Make an appointment with a resource person (outside the classroom) for academic assistance. Continuous measures for the study were based on behavior observations using a checklist made up of these skills. Points were assigned to each step so that a total score could be obtained. A point was added for appropriate eye contact, voice tone, and posture during each task. Scoring was the same for baseline and intervention. Additional pre-post measures were taken to record changes in assertiveness, technical adequacy, self-awareness, and self-advocacy. The study used a multiple-baseline design across behaviors. Students were video-taped using the behavior-rehearsal training. This allowed for verification by two recorders as well as classroom use for giving the student feedback. Training strategies used were direct instruction (Carnine, Silbert, \& Kameenui, 1990) and the learning strategy (Ellis, Lenz, \& Sabornie, 1987; Schumaker, Deshler, \& Ellis, 1986). Students, teacher aides, and teachers received training in all strategies prior to baseline. Student training was held twice weekly for 30 minute for the first semester and 
once weekly for 50 minutes during the second semester due to scheduling constraints. When all students had successfully completed all seven tasks, they were asked to practice in non-training settings following a set schedule of contacts and pairing of steps when needed. Students had the contact person record their progress on a short checklist that they returned to the trainer. During baseline, $42 \%$ correct answers were recorded as the average for all eight students. After intervention training, $82 \%$ were correct after one training session. After one week, all students completed the maintenance check at $100 \%$. Within one to two weeks, generalization of tasks was occurring at a rate of 4.38 out of 5.0 points. This systematic procedure showed clearly that students with LD can learn the steps required for self-determination if direct and specific training is used. Some discomfort was felt by the students when describing their disability and asking for accommodations. Two students were not able to complete this step successfully. In reviewing their situations, it was found that both had been identified with LD early in their educational years and both sets of parents often advocated for their students. Learning communication skills and learning to advocate for one's self are two important skills for adult success. Additional research is needed to see if the skills learned in school would generalize to different settings in the community. Continued professional development is needed for staff to apply the procedures to other self-determination skills. Longitudinal research would be needed to see if the skills would transfer to postsecondary settings as well. Students for the study were not selected randomly, but were chosen by resource room placement and parent permission. Student skill acquisition was based on performance on role-play sessions, not actual high school settings. Maintenance was judged with a paper/pencil task rather than a performance/observation due to time constraints. Thus, students may know about the topic but not be able to perform the tasks in real situations. The whole topic of self- 
determination is a very complex subject and the tasks selected were only part of the overall task. Additionally, collaboration between all educators and between educators and community persons needs to be targeted and increased for the skills to be transferable to the next level of settings.

Teacher/Transition Specialist Views on Meeting Transition Practices

Zhang, Ivester, Chen, and Katsiyannis (2005) addressed transition practices as "viewed by special education lead teachers and district-level transition personnel in South Carolina" (p. 15). The purpose of their research was to examine South Carolina school district engagement in providing transition practices described in the literature. Middle and high school special education lead teachers and district-level transition personnel were surveyed to determine the extent to which their district engaged in the following practices: types of transition services, means of service delivery, division of responsibilities, levels of participation, agency involvement, and self-evaluation (p. 17). Participants were 105 middle and high school lead teachers and 37 transition personnel who completed the survey. Instructional settings represented included resource rooms (35\%), self-contained special education (41\%), inclusive classrooms (1\%), itinerary (3\%), multiple (12\%), and other (12\%). The survey instrument was patterned after the Project SIGHT survey, part of the systems change project, with reviews by special education coordinators, personnel representing the University of South Carolina's Center for Excellence, the South Carolina Department of Education, local education agencies, the Department of Vocational Rehabilitation, the Developmental Disabilities Council, and the Office of the Governor. Items included service coordination; key stakeholders' involvement; linkages to service agencies; adult service agencies' participation; work-based experiences; transportation; and transition service categories. A Likert scale from 1-5 (strongly agree, agree, disagree, 
strongly disagree, and not addressed by school) was used. Surveys were mailed with directions to complete and return a self-addressed stamped envelope within one month. Follow-up letters were mailed to non-respondents. Data analysis was done through frequency and descriptive statistics and comparative analysis to examine similarities and differences between lead teacher ratings and transition personnel ratings.

Results from Zhang et al. (2005), showed that transition programming responsibility was distributed as follows: $44.4 \%$ transition coordinator, $23.9 \%$ multiple people, $19 \%$ special education director, $13.9 \%$ classroom teacher, $1.4 \%$ guidance counselor, and $2.1 \%$ other. Transition coordinators carried the following responsibilities: establishing employment sites, 52.1\%; facilitating student job placement, 52.1\%; facilitating student assessment, 45.1\%; facilitating student assessment, 45.1\%; facilitating teacher training for special education transition curriculum and services, $44.4 \%$; providing supported employment services, 43\%, and other, $16.2 \%$ (p. 18). Involvement in IEP and transition planning meetings identified special education teachers $(89.4 \%)$, followed by parents $(85.9 \%)$, general education teachers $(82.4 \%)$, the student $(82.4 \%)$, guidance counselors (64.8\%), and vocational teachers (54.38\%). Agency involvement in transition services showed the following: Vocational Rehabilitation, 71.1\%; Department of Disabilities and Special Needs, 62\%; Department of Mental Health, 34.5\%; Department of Social Services, 28.9\%; Continuum of Care, 19.7\%; Employment Security Commission, 16.9\%; Commission for the Blind, 14.8\%; Social Security Administration, 12\%; Health Department, 10.6\%; and South Carolina Services Information System, 8.5\%. Types of school experiences or information included the following: school based work experiences, vocational and occupational courses, career information, job shadowing, assistance from job coach, internships, and supported employment, in descending order. Types of 
businesses for employment included grocery, $68.3 \%$; fast food, $65.5 \%$; restaurant, $59.2 \%$; retail store, $42.3 \%$; service industry, $40.8 \%$; construction, $33.1 \%$; and manufacturing, $28.2 \%$. Farming was least reported business with $12 \%$. Evidence regarding transportation for work experience by school district showed that overall $6.2 \%$ did not believe this item applied to them, with distribution ranging from school bus, $37.3 \%$; activity bus, $21.1 \%$; teacher's personal vehicle, $17.6 \%$; and other, $26.8 \%$, including student or parent vehicles. District ratings on how well they addressed each of the 15 criteria were done on a 5 point scale from 0-4 (not addressed by school, strongly disagree, disagree, agree, and strongly agree). The following factors were addressed more than others: IEPs and transition plans, career information, functional skills curriculum, transition education for compliance to special education legislation, and independent living skills curriculum (p. 19). A comparative analysis between teacher and transition coordinator responses was made using an independent $t$ test with the transition personnel rating 14 of 15 practices higher than the teachers. The first one, IEP and transition plans, was similar between groups with teachers $(M=3.01)$ and personnel $(M=2.97)$. Overall rating differences were statistically significant $(t=2.80, d f=113, p<.01)($ p. 20$)$. Almost all $(94 \%)$ of the transition coordinators reported having transition plans were in place by age 16 , and $54 \%$ reported they were in place by age 14 . More than $80 \%$ of the transition personnel reported that parents and students were involved in planning and $92 \%$ indicated that individual assessments are used to determine interests, skills, and abilities (p. 20).

Results from Zhang et al. (2005) indicate that various members of the school took responsibility for transition services with transition coordinators or special education directors responsible for transportation in $63 \%$ of the cases. When teachers must assume this responsibility, they often "do not have the authority or knowledge base to access or 
disseminate resources and information" (p. 21). The researchers clearly recommend defining and delineating responsibility so that all aspects of transition are coordinated. Transition coordinators need to establish work sites, facilitate job placements, and expedite student assessments to include all aspects of transition. Special education teachers were the most frequent participants in the IEP and transition planning process. However their participation rate was only $89 \%$ rather than the $100 \%$ required by law; parents and students were reported at $82.4 \%$ which is also far from the federal requirements. Agency involvement needs to be addressed to bridge the gap between high school and postsecondary responsibilities (p. 22). Schools need to do a better job at providing supported employment experiences to students with disabilities and expanding the types of business opportunities for employment. Transportation is always an issue in rural areas without public transportation and needs to be addressed by communities for post-school options. Findings provide insight into status of local schools transition practices.

Limitations mentioned by Zhang et al. (2005) include limited generalization from South Carolina to different states due to the differences in other states. Also, only a fraction of the lead teachers and district-level transition personnel responded, which may skew results statewide. The survey may not provide thorough lists of choices and may not lend to in-depth investigations (p. 24). Further research is needed for in-depth investigations of parent and student participation, issues related to supported employment, and special education teachers' knowledge about transition planning (p. 24). Research needs to be tied to follow-up studies and identification of approaches for life skills curricula, high standards, and requirements for high-stakes testing. (p. 24).

\section{Transition Components in the IEP}

K. M. Powers, Gil-Kashiwabara, Geenen, Powers, Balandran, and Palmer (2005) 
analyzed transition components of 399 IEPs to identify effective transition planning goals. The first purpose was to determine the extent of transition planning in the transition plan component of the IEP; the degree to which IDEA mandates were followed; and whether effective transition practices were included. The second purpose was to determine if demographic factors (gender, disability type, district residence, race, and ethnicity) were associated with transition plan quality (p. 48). The setting was two large, urban school districts in the Western U.S. with diverse ethnic representation. Twelve percent received special education services in District One and 8\% in District Two. Random selection of 399 IEPs of special education students between 16 and 22 was accomplished using a threelevel nesting sampling design: Gender (50\% female), Ethnicity (50\% non European American), and Disability (equal proportions of learning, physical, cognitive, and emotional disabilities) (p. 51). This allowed sufficient numbers in each group to be able to compare groups even though some factors were over-represented. A staff person in each district copied IEPs and removed personal identifiers. A modified version of the Statement of Transition Services Review Protocol (Lawson \& Everson, as cited in Everson et al., 2001) was used to evaluate each plan in accordance with IDEA 2004 mandates and effective practices identified in the current literature. The average inter-coder agreement was $86.5 \%$ across all items. Results showed 1,747 Transition Plan goals sorted into 12 goal areas ranging from employment with $63.7 \%$; transportation, $60.9 \%$; community recreation/leisure, 50.4\%; postsecondary education, 44.6\%; and health/medical, 36.3\%. Fewer than half had housing, independent living other than transportation and medical, adult services, vocational training, non-recreational community participation, or other independent living goals listed. Adult education was rarely was mentioned, $6 \%$ of the IEPs had no transition plan, and six had no goals for a total of 24 students missing transition 
planning totally (p. 53). Many (63.1\%) had minimal details on specific achievements targeted, and only $6.4 \%$ detailed supports or accommodations needed. No action steps were listed for $33 \%$ of the goals. Even though the student had not signed the IEP, $14 \%$ listed the student responsible for carrying out the action steps. Nine percent of the goals had no one designated as responsible, and agency assignment was low. Differences were found between the two districts for 6 of the 12 goals. Gender differences were not significant in terms of planning. In the area of ethnic differences, the research stated that Hispanic American students were more likely to refer to cultural values or background in the planning process. Students with developmental disabilities (DD) were less likely to be working toward a standard diploma. Only $10.4 \%$ of DD students had an employment goal on the plan; they were less likely to attend the IEP meeting; and also less likely to have a postsecondary education goal or reflect evidence of their desires. Significant differences were seen in diploma type with the diploma-bound students more likely to include postsecondary education or vocational training goals.

Limitations for the K. M. Powers et al. (2005) study included the following: (a) The written IEP may not reflect the complete range of services. However, it was noted that if the IEP is the only legally binding agreement, and services are not detailed, then inferences as to what is actually happening cannot be made; (b) Signatures on the IEP may be misstated since teachers routinely signed as the administrator's designee; (c) The absence of parent and student signatures suggests minimal to no involvement; (d) Findings cannot be generalized since results are particular to these two districts. The over-sampling may have skewed results. A disconnect was seen between type of work experiences and career interests which may represent a gap between established career and entry-level positions. The authors suggested that more research is needed to confirm this finding. Many work 
experiences are overly narrow and are not individualized to students' interests. Few differences were found based on gender or ethnicity which may mean that planning was not specific to include these factors. This study was done just prior to 2004 IDEA requirements were released, so updated research will be needed as schools change their programs and follow-up methods to meet the new requirements (p. 58).

\section{Seamless Transition for Math and Science Content Areas}

Lamb, Brown, Hodges, and Foy (2004) examined the differences between high school and college science curricula to promote a seamless transition for high school students with disabilities to math, science, engineering, and technology education at community colleges. Participants in the Bridges Project were high school students (9 from Holt High School and 16 from the Lansing, Michigan Tri-County Region) in partnership with Lansing Community College. Students enrolled in a college success class that was focused on self-determination/self-advocacy skills and continuing career exploration. They developed a self-advocacy plan and presented it to the faculty showing classroom accommodations necessary for their learning. They interviewed a person on the job in their selected career; made observations in the field; and researched education required, salary range, and future employment trends. Through this process, 20 students revised their career goals and five completed the requirement undecided. At the end of the three-year project, 22 were still in college, one joined the military, one relocated to another state, and one went to work full time. The majority of students could better define self-determination $(90 \%)$ and self-advocacy $(80 \%)$, while $75 \%$ reported more confidence in speaking with professors about accommodations and $80 \%$ talked with instructors about their needs.

Based on student experiences and staff teaching experiences, Lamb et al. (2004) made the following recommendations to improve the program: Teach and practice self- 
advocacy skills in high school. The course syllabi should include a statement of the college's accommodations policy with invitation to meet with professor. Strategies need to include auditory, visual, and kinesthetic modes of information processing to maximize learning. Independence in learning needs to be emphasized at both high school and college levels. Guided notes for lectures should be provided. All teachers need to expect active engagement with high expectations. Frequent feedback should be provided at both levels. Students should take responsibility for own learning needs through self-advocacy.

\section{Parent/Teacher Perspective on Science Careers}

Alston, Bell, and Hampton (2002) examined perceptions of 140 parents and 323 teachers regarding science and engineering careers for students with learning disabilities. Eight variables were investigated: facility access; expense of accommodations; role models; teacher understanding of student academic needs; length of learning time; student aptitude and educational preparation; career guidance; and employer attitudes (p. 265). The purpose was to identify factors which precluded and fostered science and engineering for persons with disabilities (p. 265). The parent group included 97 females and 43 males; the teacher group included 219 females and 140 males. Ages of participants ranged from 23 to 63 with a mean of 44 in the parent group and 41 in the teacher group. Teacher specialties included science, math, and special education. Expertise in instruction of students with disabilities included 50\% who had taught them for less than five years, $20 \%$ between 6 and 15 years, and $30 \%$ over 15 years. A Masters was the most common degree for the teachers (p. 266).

A demographic questionnaire (Alston, Hampton, Bell, \& Strauss, 1998) devised in a previous study by Project Pursuit Staff was used to gather information from the students. A 12-item questionnaire was used to measure parents' and teachers' perceptions on a five- 
point Likert scale from 1-5 (strongly disagree, disagree, neutral, agree, and strongly agree). Psychometric properties revealed three factors: (a) Human and environmental; (b) Student aptitude; and (c) Teacher influence. In terms of reliability, Cronbach's Alpha was calculated: Factor $1, \alpha=.76$, Factor $2, \alpha=.66$, and Factor $3, \alpha=.72$ (p. 267). Validity was analyzed using an item-factor congruence index (Crocker \& Algina, 1986; Hambleton, as cited in Alston et al., 2002. p. 267). This index was used to determine the extent an item had content validity for a particular factor. Expert raters used the following scale: $+1=$ measure factor; $0=$ uncertainty; and -1 , no match. A 1.00 was the highest value and was obtained only when an item matched to one and only one factor by all expert raters. A content validity coefficient of .73 was obtained, with a range of .33 to 1.00 for individual items.

Alston et al. (2002) used the following procedures for student recruitment: mailings and phone calls from project staff at a large Midwestern research university; workshops to introduce participants to opportunities in science and engineering; demonstrations of useful technology; and dissemination of information on legal rights of students with disabilities at the postsecondary education level. Analysis included a descriptive analysis of data to determine participants' mean scores on survey items; a multivariate analysis of variance (MANOVA) for each of the three factors with the Parent or Teacher category as independent variable; and a Hotelling's Trace univariate analysis used to determine significance between the parents and teachers at the item level. Significance level was set at .05 (Alston et al., p. 268).

Results for Alston et al. (2002) included the fact that parents more than teachers, felt that teachers do not make the necessary effort to accommodate students with learning disabilities, and employers in science and engineering fields were reluctant to hire persons 
with learning disabilities. Both groups had the perception that counselors discourage students with disabilities from entering science and engineering; noted the lack of a universally accepted definition of learning disabilities; and noted lack of role models in science and engineering. The two groups disagreed on accommodation strategies, encouragement, preparation for science classes, and employers being reluctant to hire students with disabilities. Suggestions included: (a) Work with Vocational Rehabilitation for identifying the obstacles in pursuing training or employment, (b) Encourage school guidance counselors to hold workshops with students, parents, teachers, and employers to educate students with disabilities on issues and demonstrate the potential of students with learning disabilities, (c) Establish mentoring programs with local universities to connect presently enrolled students with learning disabilities who are majoring in science and engineering with local businesses that have employees with learning disabilities working in science and engineering settings, and (d) Vocational rehabilitation counselors need to arrange for job shadowing and placement activities to assess and counsel with students with learning disabilities (p. 273). Limitations were noted in that the sample was only from parents and teachers from the Midwest who may have views different from other parts of the country. Further research is needed to include a more representative group of parents and teachers with explicit criteria to describe learning disabilities prior to the survey

(Alston et al., pp. 272-273).

\section{Model College Supported Education Program}

A model supported-education program for students with disabilities was described by Getzel, McManus, and Briel (2004). This study by Virginia Commonwealth UniversityRehabilitation Research and Training Center (VCU-RRTC) was to determine effectiveness of a supported-education model for college and impact of services and supports on student 
outcomes. Intensive supports were provided for a cohort of 26 students who entered through referral by faculty or self-referral. Each student was given assistance to develop a student profile and individualized Academic support plan. Based on needs of the plan, student and academic specialists scheduled office visits or communicated by e-mail or telephone to determine effectiveness of the supports.

The purpose of the Getzel et al. (2004) study was to examine the relationship between intensity and frequency of services and student performance and retention. Intensity was defined as the number of contacts students had with staff members. Frequency was measured by number of times services and supports were used by students. Students self-reported their use of these services during formal structured interviews. When the intensity and frequency were collected, the group of 26 was divided into 11 in the Frequent group and 15 in the Infrequent group. A comparison of outcomes (GPA, academic progress, and retention) was done. Also differences between groups was accomplished by comparing grades, class attendance, types of supports used, number of resources accessed on campus and community, and overall adjustment to college. Data were also collected from structured interviews to determine satisfaction with services, feedback on delivery, strategies and supports, and effective university and community resources.

Results from Table 1 in Getzel et al. (2004) described learning routines, organizational strategies, role-playing, stress management, and self-advocacy. Students identified career exploration activities as very helpful in identifying course of study and career goals. They reported that participation gave them a better understanding of their disability and learning strategies. A summary of outcome results included the following: Eight of eleven in the Frequent group progressed in good standing ( 1 graduated, 2 were on 
dean's list, 5 progressed in their program in good standing, 1 was dismissed from the program, but not from the university; none were on academic probation or warning, and 2 left for personal reasons); Eight of thirteen in the Infrequent group progressed in their program in good standing ( 1 was dismissed from the program but not the university, and 4 were on academic probation or warning). GPAs differed with the Frequent group attaining 3.03 while the Infrequent group received 2.29 (p. 4).

Limitations of Getzel et al. (2004) included the following: Larger numbers are needed to generalize effectiveness of the model and services. Comparison data are needed to determine outcomes from the supported model versus students who do not participate. The model needs to be tested in a variety of settings of 2- and 4-year colleges and universities. Further efforts to prepare students with independence skills and entrance to postsecondary education are needed. Future research should utilize a rigorous design to control for personal issues and group differences (p. 5).

Summer Transition Program to College

Project Excel (Serebreni, Rumrill, Mullins, \& Gordon, 1993) was a six-week summer transition program for high-achieving students with disabilities at the University of Arkansas. The purpose was designed to: (a) facilitate transition to college for incoming students with disabilities; and (b) promote academic excellence. Twelve high-achieving students with disabilities (H.S. GPA of 3.0 or higher and ACT composite scores of 22 or higher) received academic advising and personal counseling, enrolled in six hours of college credit, and participated in a wide range of social and recreational activities (p. 1). Students were from Arkansas, Texas, and Illinois. The distribution represented students with different disabilities: blindness (2), deafness (1), learning disability (7), spinal cord injury (1), and attention-deficit hyperactivity disorder (1). A detailed description of 
accommodations and services was provided in the program description. Most students were in the middle to upper-middle class socioeconomic status. Eleven students were of European-American descent, one African-American (consistent with the University's 8\% minority enrollment). The 12 project students had a mean H.S. GPA of 2.76 and mean composite ACT score of 21.5. Existing disability student services staff, graduate assistants, and interns assisted with program administration, academic instruction, counseling, university orientation, special events, and other activities. Full time personnel included a program director, certified school psychologist, English instructor, and "accommodators" (readers, note takers, and sign language interpreters).

Data for Serebreni et al. (1993) were collected on a post-program Likert scale evaluation questionnaire. Students rated the Project Excel from good to excellent. The mean GPA for the English class and Assistive Technology laboratory course were 2.84 for their first semester. This was markedly higher than the 2.34 mean GPA for all first semester freshmen at the University of Arkansas. Limitations of the study were the small sample size and absence of an equivalent comparison group so that inferential statistics could not be computed for evaluation.

\section{Technology Support for College Students with Disabilities}

A follow-up study was conducted by Kim-Rupnow and Burgstahler (2004) to identify the value of technological support through various components of the DO-IT Scholars program. The full program description was covered in previous research. This research focused on the impact and value of a technology-based exemplary program for students with disabilities on college campus. A total of 173 scholars participated in the DO-IT program from 1993-2000. Of those, 155 received a questionnaire electronically (or could request an email version). Non-respondents were sent a printed survey with postage- 
paid return envelope. Seventy-five scholars responded (44 by web-based questionnaire, 3 via email, and 28 via postal mail) resulting in a $48 \%$ response rate (p. 2). The survey was designed to assess perceptions of the impact that participation in the DO-IT program has had on their lives and to ascertain value of program features. Both quantitative and qualitative approaches were used. Analyses were frequencies, means, and other descriptive statistics. Participants were $52 \%$ male and $48 \%$ female. The study included students with ages ranging from 16 to 22. Disabilities included Mobility, 41\%; Sight, 13\%; Learning, 12\%; Hearing, 9\%, Speech, $1 \%$; and Other (including multiple disabilities), $23 \%$.

Kim-Rupnow and Burgstahler (2004) found that $86 \%$ who were employed indicated social skills were helpful for them in getting their jobs. A Chi-squared test revealed that social skills were marked significantly higher than other skills by those who had jobs. Internet activities ratings of valuable or extremely valuable were as follows: $87 \%$, access to adaptive technology; $84 \%$, access to information and resources; $72 \%$, access to computer at home; $64 \%$, online communication with peers; and $63 \%$, online communication with adult mentors. The $43 \%$ employment rate does not accurately reflect the true impact of the program since more than half of the respondents were still in college. Limitations included the following: (a) Only program participants were contacted so this does not represent a cross section of students with disabilities; (b) The study was based on 75 of 155 DO-IT Scholars with $69 \%$ being recent scholars who entered between 1997 and 2000; (c) No control group was available and the impact was solely on selfreporting by respondents; (d) Improvement of skills was a perception of self-rating, not a measure of quantitative growth; (e) Both technology and in-person techniques were used through the larger study so that it is impossible to attribute values to each approach as implemented. Recommendations for further research included long-term follow-up with 
comparable non-participant peers; further data gathered from parents, high school teachers, and counselors; utilizing external evaluations; and surveying project staff to evaluate effectiveness. Timing for collecting evaluation data should occur at critical steps so that it was gathered from all participants at the same time in the program. Also, further analysis of the different categories of disabilities and the relationships between different types of disabilities and supports should be conducted. Lastly, more empirical research is needed for long-term impact of summer programs, peer and mentor supports, work-based learning, and other college and career transition supports (Kim-Rupnow \& Burgstahler, 2004).

\section{Outcomes for College Students with Disabilities}

Madaus (2006) conducted a follow-up study with a group of LD college students to determine graduate outcomes. The significance of Madaus' study was that there was limited research existing on employment outcomes of LD students who graduate from postsecondary institutions. The present research extended an earlier investigation (Madaus, Foley, McGuire, \& Ruban, 2001) to a larger nationally representative sample.

Participants in Madaus' (2006) study included 2,131 graduates with LD from four eastern and two western schools. Institutions included small to large schools and represented various models (an open-enrollment community college, two community technical colleges, two public universities, and a Research 1 university). The sample included associate, bachelors, or advanced degree graduates. All participants had to be registered as an LD student with Section 504 plan on file. A contact person at each site verified the names, collected addresses, and conducted mailings for confidentiality. The survey was mailed in three waves at each school and included a web-based, electronic survey as well as mailings. Response rates from $11 \%$ to $53 \%$ were received. A total of 1438 graduates were included in the final sample with $N=500$ responding (pp. 21-22). 
Madaus' (2006) survey instrument was based on the earlier version by Madaus et al. (2001). A panel of content experts and four university graduates with LD updated the survey. Demographics, ADA status, Job satisfaction, and Employment Self-efficacy were collected. Scores for Sections two, three, and four were on a five-point Likert scale ( $1=$ Strongly Disagree to $5=$ Strongly Agree). Construct validity for these sections was investigated via principal-component analysis procedures with the three areas found to be unique factors. Cronbach's alpha reliability estimates were .90 for Job Satisfaction scale; .94 for Employment Self-efficacy scale; and .73 for the ADA scale.

Results from Madaus (2006) included the following: There were 51\% males and 49\% females in the study. Ethnic backgrounds included White Non-Hispanic American (92\%); Hispanic or Spanish Surnamed American (2.8\%); and Black, Non-Hispanic American (2\%). Average age was $31(M=31.3 ; S D=6.1)$. Thirty seven states were represented. Eleven percent reported having a second disability in addition to LD (hyperactivity, 43\%; physical disabilities, 15\%; and medical disabilities, $11 \%$ ). Eight were English-as-a-second-language students. Graduation years spanned from 1979 to 2003, with the most common being 1999 (10\%), followed by 1993 and 2000 (9\% each). Graduation exit data showed $8 \%$ in undergraduate programs, $40 \%$ graduate programs, and $26 \%$ in specialized professional training programs. Students obtained degrees that included BS (71\%), Master's (23\%), juris doctorate (2\%), and doctorate (1\%). Data on the level of employment showed a range from $75 \%$ full time ( $35 \mathrm{hrs}$ or more per week) to $5 \%$ for 21 $34 \mathrm{hrs}$ per week and $6 \%$ for $20 \mathrm{hrs}$ per week or less. The most common reason for holding part-time jobs were being in school (33\%) or caring for children (31\%). Seventeen percent were working part-time while looking for full-time employment. Common employment areas were Business (29\%), other (27\%), Education (18\%), and Health Care (9\%). The 
Other category was a wide ranging list. Respondents had held an average of 2.6 jobs ( $S D=$ 1.7) since graduation with average length of time 3.5 years $(S D=3.0$, Range $=1$ year to 16 years). Salaries ranged from $11 \%$ earning less than $\$ 10,000$ to $16.7 \%$ at more than $\$ 90,000$. The most frequent salary range was between $\$ 30,000$ and $\$ 40,000$ (19\%). A Chisquare analysis revealed a significant relationship between gender and level of salary ( $\chi^{2}$ $[2, N=417]=54.253, p<.001$, Cramer's $V=36$ ). Males were more likely to have higher earnings than females and more likely to be working full time and receiving full benefits than females. Twelve percent of the graduates reported they were unemployed. Twentyfour percent reported being laid off from a job. Only 55\% self-disclosed their learning disability to the employer. The most common reason for not disclosing was that there was no need to or no accommodations were needed. In the $12 \%$ who did request formal work place accommodations, $28 \%$ were denied. The results generally are comparable to those of the general workforce in the U.S. and are much more favorable than those adults with LD who do not attend college. Those 5\% looking for work are comparable to the unemployment rate in the U.S. at the time of the data collection (5.7\%) (U.S. Department of Labor, 2004). Salaries compared favorably with the general population, including the fact that males earned more than females.

Limitations from the Madaus (2006) study were the small sample size, with only $35 \%$ return, and use of a mailed survey. The investigator had to rely on institutional records and the services of their staff for up to date records. There was no way to know if the graduate received the survey or chose not to answer. Another limitation was that the respondents were overwhelmingly white and graduates of institutions with formal support programs for disabilities. Therefore, generalization to the general population of graduates is not possible. Additional research is needed to gauge the status of college graduates with 
LD as the economy changes. Research is needed from a broader range of institutions as well as empirical data on use of specific strategies in the educational process.

The preceding studies are not all-inclusive, but are representative of empirical research in various facets of transition for students with mild disabilities at the national level. There is a need for future studies to follow good research guidelines to have empirical reports that can be replicated in other settings. If this is done, then the quality of transition services will improve. The following section details some of the response that Kentucky made to the federal mandates to improve transition for students with disabilities in recent years.

\section{Kentucky Programs}

From the federal and state mandates stated in IDEA and the school reforms in Kentucky, several initiatives have evolved to focus attention on transition outcomes for students with disabilities. The following descriptions provide insight to state and local transition programs and/or products.

The Kentucky Systems Change Project was a statewide federal grant designed to increase capacity and build community networks (1990 to 2000). This program involved school districts and community representatives to develop criteria to measure quality indicators and improve services for special education students. School staff, parents, and community representatives received professional development from state department trainers in building community infrastructures to provide improved school services and support systems for students with the most severe disabilities (KDE, 2000). One example would be the Comprehensive Care System in Kentucky that had responsibility to support mentally and physically challenged adults with limited federal and state monies. A regional system of delivery was formed to organize and provide on-going support services 
including counseling, respite, and other services. Some improvement in school and support services was noted during the ten-year period of the federal grant; however much more improvement is needed.

The Kentucky Transition Project (KDE, 1993) was a five-year federal grant to provide professional development for state-wide school staff and administrators to improve transition services from 1993-1997. The quality indicators that were used to determine effective transition included: Inclusion; Functional Curriculum; Access to Vocational Education; Provision of community-based instruction; Dropout prevention; Provision of systematic transition planning; Interagency collaboration; and Parent and student involvement. This project assisted school districts across Kentucky in updating and organizing programs designed to provide quality transition for students with disabilities. This project did not provide a detailed evaluation system for schools to measure progress, nor did it provide criteria to measure attainment of goals. State efforts thus centered on compliance issues as suggested by Johnson's (1998) research (described above). As a participant in this grant, JCPS added three additional success indicators to the list for their evaluation of the Kentucky Transition Project (1993-1996). These focused on: (a) the need to improve support of the local school administrator; (b) the need to define and implement the transition facilitator position at each school; and (c) the need to increase teacher participation in workshops on transition and implement the principles of transition planning in their schools. Again, no additional funding was provided for these activities. Teachers and administrators who attended the professional development sessions seemed overwhelmed with the long-range transition requirements and then were assigned additional duties in the area of transition. They seemed to focus their efforts on compliance issues of the student transition plan since managing long-range planning was looked on as 
extra duties. Some transition planning activities were included in the Individual Education Plan (IEP) for the student with disabilities if services could be provided within existing classes/monies. No additional services were commonly written into the IEP, since that would legally mandate the services and funding by the local district. Employment support activities were assigned to Vocational Education, if the student were participating in those classes, or coordinated with the Department of Vocational Rehabilitation (DVR).

Another cooperative effort, Community-Based Work Transition-Job Trainer Program (CBWT-JT) (DVR, 1995), was funded jointly with DVR and local school district funding and still operates in the schools today. Three-fourths of the support funding for CBWT-JT came from DVR and one-fourth from the local district. This money was used to hire job trainers to support students with disabilities during their final two years of high school and assist them in obtaining work experiences and competitive employment by the time they left school services. This CBWT-JT program was used in many school districts across the U.S. and provided support for small numbers of students. In JCPS, this project was renamed, Career Opportunities through Vocational Exploration (COVE), and served students with disabilities in their final two years of school eligibility. Not all students with disabilities participated in COVE since student eligibility was based on need and projection for independent or supported employment. Many students needed assistance with transportation, budgeting, independent living, and other personal issues on a continuing basis in order to be successful in employment. The funding for continued support following graduation was minimal once the school training phase ended.

Two college support programs were begun in 2001 and 2003. These were collaborative, alternate public school programs between the school districts and the colleges involved. They served 18-21 year old students with moderate/severe disabilities. 
First, Asbury College, in cooperation with Danville City and Jessamine County Schools in Kentucky, opened their program in 2001 (Lakes, 2006). Similarly, the University of Louisville began a cooperative program with Jefferson County Public Schools (JCPS, 2003). In both of these programs, local schools provided staff, and the postsecondary institution provided the space, with the students remaining under public school services. Students were included in some college classes, with their same-age peers, with support from the public school staff, and participated in the special class held on the college campus, student activities, and other services offered by the universities. This type of programming is not usually available to students in the LBD range, since these students are expected to complete the high school program about age 18, leave public school services, and then pursue postsecondary outcomes. The two alternate programs gave MSD students an option to participate in college that would not usually be open for them since most of these students will not complete graduation requirements for the high school diploma that is necessary to gain entrance to college (many special needs students receive a certificate of completion in lieu of a diploma).

A transition checklist was developed by the Ohio Valley Educational Cooperative (OVEC) (1999). OVEC is an organization comprised of 11 school districts surrounding the Louisville area. The transition specialist developed a Guide for Transition Planning and a Transition Plan Worksheet for local districts to use. The series of quality indicators for transition programs were developed for student success at entry, intermediate, advanced, and exit levels so that students, parents, and teachers could easily see progress and needs in twelve areas: Classroom instruction; Career exploration; Attendance/punctuality; Personal hygiene; Behavior/Social skills; School performance; Transportation skills; Vocational assessment/career planning; Self-advocacy; Rehabilitation services; Community transition 
resources; and Community based training. This guide follows many of the indicators that Halpern (1997) suggested as important for successful transition and was of sufficient quality to be used as reference material for professional development sessions for teachers in JCPS by this researcher and others.

The University of Louisville (Simmons, 1997) conducted a Systematic Training in Transition Supports (STTS) grant during 1997-1999. Forty-two schools in medium to rural population areas of Kentucky were given professional development training and support to increase transition planning and success rates for students with disabilities. (It should be noted that the author of this dissertation was the Project Coordinator for this grant.) No increased funding for additional staff was provided to the school districts from the federal or state level during this period of time. Principals and teachers cited lack of time to implement services during the school year with no additional staff. Local districts in rural areas also pointed out the absence of community services to support students during and after the transition period. For instance, in many parts of Kentucky, a student would have to travel over an hour to get to the local DVR office and, if deemed eligible, would receive limited support services for competitive employment. Supported Employment Agencies for continued support were not organized in many areas of the state due to lack of funding and leadership. In rural areas, employment availability is severely limited for all populations. Thus, even with the long-range transition planning in place, many students would graduate, obtain minimum wage jobs, live at home, and have limited contact with recreation or community agencies for support when they left high school.

The Kentucky programs highlighted above were organized to increase supports for special education students as they move from school to community supports. Efforts at increasing success in the area of Transition continue to be implemented with various levels 
of success across Kentucky. The increased emphasis on inclusion with general education competes with time in the school schedule to expand transition services and work experience. Since the IEP is the legal document for outlining school services, the Kentucky Division of Exceptional Children has mandated that transition services be stated on student's IEP plan.

The six initiatives described above are representative of model programs/projects for Kentucky. Continuation grants have extended professional development and assistance to both urban and rural districts as the need to improve transition planning and services continues.

\section{Summary}

In the current United States business climate, community and policy makers expect schools to prepare flexible, mobile workers who can multi-task. Students with disabilities who leave school prior to graduation are at a distinct disadvantage for finding jobs and find themselves under- employed or unemployed at a much higher rate than young adults who pursue college or advanced technical schools. Federal legislation has been in place for over 30 years to pave the way for students with disabilities to be included in the general curriculum and advance to more successful outcomes. To date, however, school programs are still not sufficient to improve the status of students with disabilities in areas of employment, entrance to postsecondary education, and living independently or in developing stronger personality traits for self-determination.

Research has identified key elements for best practices in transition. Special education program evaluation has focused on paperwork needed to abide by the letter of the law, rather than outcomes based on the intent of the law. States are faced with new requirements from legislation for special needs students (IDEIA 2004: Public Law 108- 
446). Indicator \#13 requires follow-up with graduates one year after they leave high school services. States also have mandates through NCLB legislation to narrow the achievement gap between special education students and typical high school students. Formative assessments using national best practices are needed to guide schools in improving outcomes for students with disabilities. Curriculum and supports are needed with additional flexibility to keep students with disabilities moving toward graduation requirements. Better preparation for entering employment, postsecondary training, and successful self-sufficiency for independent living are needed for students with disabilities to become functioning citizens in the community.

Transition planning based on student interests and abilities has been in place since the early 1990s. Federal legislation continues to grow more specific to guide schools' efforts in providing a coordinated set of activities leading to successful outcomes as mandated by the IDEA (2004) legislation. Transition teams must go beyond the basic letter of the law and begin to provide curriculum, work experience, personal guidance, and selfdetermination activities to students with disabilities. This will allow them to work toward self-identified goals for adult life. A system that allows for personal differences and planning of individual goals is individualized, not a "one-size-fits-all curriculum." The focus on postsecondary education for regular education students must be expanded to include students with disabilities. Educators need to envision curriculum to tie what is being taught directly to outcomes desired by students with disabilities.

The NLTS (Wagner et al., 1993) has provided realistic overviews of outcomes for students with disabilities. Educators and family attitudes affect personality factors from an early age and lead to continued dependency throughout adult life for students with disabilities. By evaluating outcomes and preparatory programs, it may be possible to 
identify predictors for success.

This chapter has reviewed connections between employment, continuing postsecondary education, independent living and the various concepts of personality development (self-determination, self-advocacy, self-improvement (personal insight and ability to do future planning), self-efficacy, and locus of control). That body of research provides strong confirmation that students with disabilities can improve their learning significantly if sequential programs are offered using systematic, research-based practices. Teaching strategies and specific learning routines that follow those best practices need to be incorporated into educational programs.

A number of intervention projects have been instituted to help schools and communities improve the quality of instruction and related services for students with disabilities regarding transition to adult life following high school. Among those interventions was the STEP Grant, sponsored by OSERS and involving a collaborative effort between JCPS and the University of Louisville to improve outcomes for students with mild disabilities. The STEP Grant, initiated at six high schools, provided intervention services for students with disabilities and followed up with them one year after graduation.

The present research examines demographic factors, intervention data, and student self constructs (Self-efficacy and Locus of Control) to determine the effects on transition in the areas of employment, postsecondary education, independent living, and selfdetermination for students with disabilities. More succinctly, this study is a partial summative evaluation of the STEP Grant to see if these factors made a difference in outcomes at the time of the Follow-up Study following high school, analyzing student data from the three-year intervention program. 


\section{CHAPTER III}

\section{METHODOLOGY}

\section{Introduction}

Students with disabilities have historically had lower graduation rates and lower expectations and outcomes after leaving high school, as compared to students without disabilities, according to data from the National Longitudinal Transition Study 2 (SRI, 2006). Legislation has been in place for over 25 years to improve educational programs and transition services without much impact on outcomes. Results from a pilot project in a large, urban school district were analyzed to look for predictors of success identified by transition research. Independent Variables considered were Demographic Controls (Personal Identity and Educational History), STEP Intervention Program Factors, and two self constructs utilized as Mediating Factors.

The purpose of this study is to conduct a partial program evaluation of the STEP Grant, focusing on specific transition outcomes and the interrelationships among the Demographic Variables (Personal Identity--Ethnicity, Gender, Disability--and Educational History--Semesters of Vocational Education, High School Grade Point Average, Vocational Grade Point Average), the STEP Intervention Program (School Attended, Year Enrolled, Days Enrolled, Attendance, and Self-Improvement), Mediating Factors (Selfefficacy--General Test Scores and Social Test Scores--and Locus of Control Test Scores), and two Transition Outcomes (Employment and Postsecondary Education). Correlation is the primary strategy for data analysis. Data were obtained from students who participated 
in a three-year intervention project and student survey in a large Midwest, urban school district. The research emphasizes the search for predictive factors, not model testing. This is an exploratory study that uses mixed methodology including inspection of existing district archival records and additional data from the STEP Grant.

Quantitative analysis analyzes information from school district records, student test scores, document analysis (IEPs and Transition Plans), and the STEP Grant Student Follow-up Survey. (See Appendix A for a copy of this instrument.) The survey was designed to determine students' initial employment and participation in postsecondary education as these outcomes related to transition planning, high school education, demographics, the STEP intervention, and student personality test scores. Information from student records provides additional data for analysis. In addition to the quantitative methodology described above, students' open responses to two survey questions provide qualitative data for depth in understanding students’ comments regarding program improvements. Triangulation of quantitative and qualitative data constitutes the mixed design.

The data in this study are derived primarily from a questionnaire, which Scriven (1991) describes as a "basic instrument for surveys and structured interviews" (p. 298). Walonick (2004) notes that survey research allows generalization from a sample to make inferences for an entire population if the sample follows accepted statistical rules for data collection. Stratified sampling techniques would sample each subpopulation according to the rate at which the subgroup was represented in the general population. Random sampling methods are designed to give each member of the population an equal chance of being selected. However, generalization in this study is severely limited and must be done very cautiously for a number of reasons: because the sample represents a small population 
that was not randomly selected nor stratified, because no regular education peers were included, because only a small portion of the students with disabilities at the six high schools were included, because all students in the STEP Grant and STEP Student Followup Survey were members of the intervention class, because the classes were at six different high schools with twelve different teachers, and because the researcher was both an observer and a participant.

The remainder of the chapter is divided into seven sections. First the Population and Sample are defined, followed by the Description of the Variables (Independent and Dependent). Procedures for data collection are explained, including survey development and obtaining existing data. The Research Design incorporates the specific methodological approach for each of the different research questions. Validity Considerations are discussed. The Ethical Standards section explains fundamental treatment of respondents, particularly for human subjects' protection. Finally, the chapter ends with a brief Summary.

\section{Population and Sample}

The invitation to participate in the original STEP Grant was issued to all students with mild disabilities (LD, BD, and MMD) who attended the six identified schools in a Midwest Kentucky school district. That group constitutes the population from which the sample was drawn. The sample is composed of only those students who participated in the STEP elective class and activities. Thus, the students in this sample elected to participate. One hundred and eight students with the above mentioned mild disabilities participated in the STEP Grant, which provided support classes and activities designed to assist in transitioning to employment, postsecondary education, and independent living. For the current study, those students from that group who were willing to complete the Student 
Follow-up Survey were included in these analyses. Fifty of the 108 participants (46\%) in the transition project returned the STEP Grant Student Follow-up Survey, representing the sub-sample of interest in this research.

Thus, the final choice of students $(n=50)$ in this study was not randomly selected. There are three layers of distinction: the population (all students with mild disabilities in the six high schools), the sample ( $N=108$, participants in the STEP Grant), and the subsample ( $n=50$, the target of this partial program evaluation). No regular education students or students with mild disabilities who also attended the six high schools but did not participate in the STEP Grant were surveyed. All students who participated in the STEP Grant were sent the Student Follow-up Survey, but there are no follow-up data on the 58 who did not complete the survey. Thus, there is no way of knowing the extent of any differences between those students who were part of the population but did not participate in the STEP Grant, nor any differences between those who were part of the STEP Grant but did not complete the Student Follow-up Survey and those who did (the sub-sample that comprises the database). In effect, there are no comparison groups and generalization of the findings should be done with extreme caution.

\section{Description of the Variables}

In this section, variables are described conceptually with reference to the literature as appropriate. The actual operational definitions, including codings and level of measurement, were attached in Appendix E. The description of the variables is organized according to Figure 1. The rationale for the inclusion of the three types of Independent Variables (Demographic Factors, STEP Grant Intervention Factors, and Mediating Factors) and Dependent Variables (Transition Outcomes in Employment and Postsecondary Education) in the model is grounded in theoretical and conceptual considerations as 
derived from the literature, as well as their availability from the STEP Grant.

\section{Independent Variables}

Three conceptually distinct types of Independent Variables are used in this research: Demographics, STEP Intervention Program Factors, and Mediating Factors. The first type, Demographic Factors, is grouped into two sections: Personal Identity and Educational History. Personal Identity included Ethnicity, Gender, and Disability; Educational History included Semesters of Vocational Education, High School Grade Point Average, and Vocational Education Grade Point Average. These factors were available from school district records and represent factors that frequently are used in research. Differences in ethnicity and gender have to do with societal roles, family nurture, socioeconomic standing, and class structures.

The second type of Independent Variables, STEP Grant Intervention Factors, is comprised of the School Attended, Year Enrolled, Days Enrolled, Attendance, and SelfImprovement. School district records provided the first four factors while SelfImprovement was obtained from the STEP Grant Student Follow-up Survey. These factors have to do with the amount of time the student spent in the intervention program and can possibly be connected to changes that occurred because of their participation.

The third type of Independent Variables is Mediating Factors; student scores were obtained from personality tests which were administered during the STEP Grant Intervention (Self-efficacy--General and Social--and Locus of Control). The personality factors are indicative of how students perceive the world and interpret their actions and reactions as capable of controlling or changing what happens to them. The literature reviewed in Chapter II suggests that all of these factors are important in the development of skills that pertain to transitioning from high school to adult life. Explanations are offered 
for each of the variables to explain the complexity and relationships among variables. Demographic Factors--Personal Identity

Personal Identity, the first sub-section of demographic factors that was considered, is comprised of personal indicators connected to family. Ethnicity, Gender, and Disability affect the personality of the person, how they relate to family, their community, and the greater world.

Ethnicity (ETHN). Based on the historic underachievement of African Americans in the Americas and the urban district in which the STEP Grant was conducted, the nominal coding utilized here implies achievement differences for the traditionally underserved group (see Yaffee, 2003, who notes that the terms categorical and nominal can be coded differently depending on their content). The 0,1 coding is for situations that simply name categories. The 1, 2 codes are used when the categories have inherent or implied ordering (see Appendix E). Although the participating school district has approximately 40 different ethnic groups represented within the overall school population, historically, the primary minority was African American, a legacy of segregation and the migration of rural blacks attracted to the industrial jobs available in this urban community. This coding is also consistent with the fact that only white and black students participated in the STEP Grant. Ethnicity was available for the participants in the larger STEP project as well as the subsample group members who responded to the STEP Grant Student Follow-up Survey.

Gender (GEN). Females with disabilities generally fare worse in making successful transitions to adult life than males (Blackorby \& Wagner, 1996). For females with disabilities, the National Longitudinal Transition Study 2 (SRI, 2006) has demonstrated a similar trend, patterns that continue to reflect lower expectations from teachers, parents, and society regarding women’s educational potential and career prospects. 
Disability Category (DIS). All students in the project had been identified as in need of special education services through individual assessments. Each student had an IEP which was modified to participate in the STEP Grant, and each met guidelines for learning disabilities, behavior disabilities, or mild mental disability range of functioning according to Kentucky Department of Education standards.

Other demographic factors. The socio-demographic variables in this study are limited to those just defined. Other background factors are common in both social and educational research; however, circumstances concomitant to the STEP Grant precluded their inclusion in this study. Although family socioeconomic status (SES) is also a common factor in transition studies, it was not considered as a demographic factor in this research because it was used as one of the criteria for entrance to the program. All students in the original intervention project (both the STEP Grant and subsequently the STEP Grant Student Follow-up Survey) were on free or reduced lunch. Other factors connected to socioeconomic status and common in transition research are parental educational background and family structure. No information was collected on either family educational levels or family relationships of the students (two parents, one parent, grandparents, etc.) for this study. Therefore, these social class constructs are not utilized in this study.

Demographic Factors--Educational History

Within Demographic Factors, there are three additional factors that comprise school-related information about the person. This section, Educational History, is limited to semesters of vocational education, high school grade point average, and grade point average in vocational classes.

Vocational Education Semesters (VSEM). All students received one vocational 
credit for taking the elective STEP class. Vocational programs offered at the project schools varied by high school, and the number of these classes taken by students differed. Enrollment at the school was required in order to attend the vocational programs offered by that school; there were no students who were part-time or took only vocational classes, and there was no busing between schools for programs. Thus, both the number of semesters enrolled in classes and the variety of career areas which were explored varied from student to student. Participation may also be indicative of the lack of experiences students with disabilities have prior to making career choices, or the lack of knowledge students with disabilities have about the nature of different careers. Other factors also affect decisionmaking, e.g., academic ability; physical requirements to lift or carry objects, stand, move, or sit; as well as the environmental factors of climate, noise level, crowded working area, etc.

High School Grade Point Average (GPA). The total credits that a student completed while in high school is reflected in this variable. Information was obtained from school district records. At the time of the STEP Grant Student Follow-up Survey, twentytwo Carnegie credits were required for graduation. Grades reflect the policies and grading system of JCPS and the judgments of the teachers in each school. There is no way of knowing whether these assessments vary from staff to staff or across regular and special education students with respect to factors such as assignments, tests, or efforts.

Vocational Grade Point Average (VGPA). The grade point average for vocational classes is calculated for comparison to the overall HSGPA. Vocational participation in high school has been an indicator of more success in employment after high school for students with disabilities as seen in the NLTS studies (Blackorby \& Wagner, 1996; SRI International, 2006). This information was obtained from school district records. 
Some students attended vocational classes all four years, while others only attended a year or two. All students attended one vocational area, the elective class, for two semesters, while others attended more than one year of the elective class and several vocational training classes in addition.

STEP Grant Intervention Factors

The second group of Independent Variables is labeled STEP Grant Intervention Factors. These include the School Attended, Year Enrolled, Days Enrolled, Attendance, and Self-Improvement. These factors reflect the degree of participation in the intervention program and personal changes that occurred because of participation.

School Attended (SCH). The STEP Grant was conducted at a Midwest school district located in an urban setting with 22 high schools. School district special education administrators chose the six project schools based on high levels of dropouts in special education, students on free/reduced lunch, and students with unsuccessful transition from those schools. The schools differed in population, location in the city, teaching staff, vocational programs available, and the STEP Elective class teachers. Collectively, these factors may have affected students' enrollment in the program and progress toward transition goals because the schools clearly did not represent random participation. To protect anonymity of the students, the schools have been identified by the letters A-F.

Year Enrolled (YEAR). After students volunteered for the STEP Grant, parental permission was obtained and the IEP had to be amended to include participation in the STEP Grant intervention through the elective class before students could be enrolled in the program. STEP began in the spring of 1997 (1996-1997 school year) with only one school and expanded in the fall of 1997 to five additional locations. Thus, the program was available different numbers of years at the six schools. Additional students also entered in 
1998 and 1999. As teachers and students experienced the curriculum and gained expertise in the various strategies used in the program, changes may be evident depending on the year enrolled. Further, there were changes in school staff so that the year of entrance to the program may have had an effect on program outcomes.

Days Enrolled (DAYS). All participants in the STEP Grant had at least one year of participation in the STEP Elective class and intervention activities. However, the actual days of enrollment depended on availability of the STEP Elective class at their high school, parent permission to enter the program, the date of completion of the amendments to the IEP to include the STEP Elective class, and the student's voluntary enrollment in the project. All of these influenced the actual number of days the project was available for a given student. This factor reflects the days of actual membership in the intervention project.

Percentage Attendance (\%ATT). School attendance is frequently a factor that is predictive of success for students in general, and particularly for students with disabilities. Students with poor attendance miss important information, frequently fall behind in their work, and often have a laissez-faire attitude toward school that may carry over to the work environment. This factor denotes the percentage of days actually attended in the STEP Grant Intervention.

Self-Improvement (SIMP). This variable is closely related to concepts used in selfdetermination and self-advocacy as related to self-awareness and future outcomes (Blalock \& Patton, 1996; Halpern, 1993; Wehmeyer, 1992, 1993). In the STEP Grant, as students experienced transition services, their personal awareness of interests, career goals, and abilities were enhanced. Self-Improvement is reflected through answers to ten questions on the STEP Student Follow-up Survey. Five items addressed students' understanding of their 
own abilities or learning styles and ways to improve, which measures the student's selfawareness and how the program helped them gain this insight. Five additional statements tapped students' perception of the help the STEP program gave them in preparing for their future: two questions targeted on choosing job or career areas and training after high school; one question related to transition planning for all of the above; and two final questions focused on students’ perceptions of how the STEP Grant prepared them to make better choices in planning for the future. Combined, these ten items provide perspective on the ability of students with disabilities to orient their future toward self-improvement.

\section{Mediating Factors}

The final group of Independent Variables is conceptualized as Mediating Factors, i.e., internalized student self constructs that moderate how the STEP Intervention Program factors affect transition outcomes. Two tests (Self-efficacy [General and Social sub-tests] and Locus of Control) were administered in the original STEP Grant. Testing was done in the elective class while students were in their final two years of high school. The grant specified that pre- and post-testing would be accomplished, but only one test was recorded for most participants. As a result, no comparison of growth was possible. Scores from the first test administration for the students were used in this research.

Among the categories of testing outlined by Gall et al. (1996) are specific personality characteristics. One of these is the measure of self-concept, defined as "the set of cognitions and feelings that each individual has about himself or herself” (Gall et al., p. 272). The Self-efficacy Scale used Likert-scale responses to measure attitudes while the Locus of Control test used YES/NO answers (see Appendices C and D for test items). The items on the instrument are sentences that participants typically score on their level of agreement. 
Self-efficacy Scale. The first personality-related test used with the STEP Grant participants was the Self-efficacy Scale (Sherer et al., 1982). This test has two sections (General and Social) which are interpreted separately. According to instructions on the test (Sherer et al., 1982, p. 1), the questionnaire is a series of statements about "personal attitudes and traits.” Students are to read the statements and decide to what extent it describes them.

Self-efficacy-General (SGEN). The General section of the Self-efficacy Scale measures how individuals believed their personal competence and control affected their ability to do something and the extent of actually doing it. Based on 17 items, this section of the test was concerned "not with the skills the person had, but with perceptions of what one can do with whatever skills one possesses” (Bandura, 1986, p. 391).

Self-efficacy-Social (SSOC). The Social section of the Self-efficacy Scale measures social relationships. The six items reflect efficacy expectancies in social situations, that "belief in one's ability to deal effectively with others is more important in academic achievement or military promotion in rank” (Sherer et al., 1982, p. 669).

Locus of Control (LOC). The second personality test administered to STEP Grant participants was the Locus of Control Scale (Nowicki \& Strickland, 1973). This instrument centered on student perceptions of being in charge of their own destiny. The designations of Internal and External are considered by the authors to have positive and negative connotations, respectively. The scoring key (see Appendix E) is based upon presumptions that each statement has a "correct" answer with respect to the internal orientation, the preferred status. High scores were considered External Locus of Control and indicated that the person had the perception that events that shaped their lives were due to forces and factors outside their own control. Low scores were considered Internal Locus of Control. It 
has generally been recognized that "students who had a more Internal locus of control gained higher levels of academic achievement and were more successful adults than students with External locus of control” (Liebert \& Spiegler, 1990, p. 448).

\section{Dependent Variables}

The STEP Grant was a federally-funded project designed to overcome barriers to transition success for a group of mildly disabled students (Learning Disabilities, Behavior Disabilities, and Mild Mental Disabilities) from six JCPS high schools. The grant years (1996-2000) covered a period of time when federal grants were issued to help public schools understand how these students could be successful if they were given adequate supports. The students who volunteered for this project were identified due to their at-risk status for dropping out of high school. Supports for this project included an elective class to provide academic assistance to finish high school requirements for graduation as well as vocational exploration of careers and connections for employment and postsecondary education.

Within this context, Dependent Variables for this study are the student outcomes (Employment, Postsecondary Education, and Independent Living) at the time of the STEP Grant Follow-up Student Survey. These are common outcome factors in transition research and represent critical areas for adult success (Blackorby \& Wagner, 1996; Halpern, 1993; Kohler, 1993). Those three broad outcomes represent the dependent variables for this partial program evaluation. However, the actual definition of these three constructs is complicated by the purpose of the STEP Grant. During the Grant years the participants, who were identified as likely to drop out of high school, had little focus on higher paying jobs or entering postsecondary education to qualify for a better career. Many of these 
students only hoped for a part-time job and continued support for living expenses from their families.

In reality, adults need full-time, reasonably-paying jobs to function independently from their families in the community and support themselves. Further, the status of an individual in society is measured by the type of job held, earnings, and professional responsibility. The STEP Grant Follow-up Survey provided information on these graduates for jobs they held since leaving high school. In some cases jobs at the time of the Followup Survey were the second or third positions obtained after graduation, because the survey was done at a set time, not based on length of time following high school.

Information available for this partial program evaluation exists on more than one level. Accordingly, this study addresses the transition outcomes in distinct ways and the dependent variables differ in each case, as specified below.

First, Research Question 1 provides information on the quality of the Transition Plan, a part of the students' official IEP while they were completing their high school programs. Then, recognizing that the STEP Grant was designed to prevent dropouts, Research Question 2 addressed these outcomes with respect to STEP criteria specified in the STEP Grant Student Follow-up Survey. Third, Research Questions 3-6 also examined the data using finer grained measures that go beyond compliance with Special Education regulations and drop-out status. This information connects program evaluation and policy analysis, the larger focus of this research. However, difficulties in gathering information on post-secondary education enrollment and living arrangements precluded any more specific measures in that area; therefore quantified measures of the transition goals for RQ3-6 were limited to employment. (Research Question 7 also examined information going beyond IDEA compliance and the STEP Grant criteria but from a qualitative perspective.) 


\section{Transition Planning Criteria (RQ1)}

RQ1 addressed aspects of transition planning that are mandated by IDEA law: (a) number of students with completed Transition Plans on file in the school district archive; (b) career goals that matched vocational education enrollment; (c) career goals that matched jobs at time of the STEP Grant Student Follow-up Survey; (d) career goals that matched postsecondary education majors at the time of the STEP Grant Student Follow-up Survey; and (e) transition planning goals, vocational education enrollment, and job or career major matches after graduation.

\section{STEP Grant Criteria (RQ2)}

Criteria for overall transition success were measured according to the loosely held criteria detailed from Benz et al. (1997, p. 155): (a) full or part-time employment; (b) full or part-time enrollment in post-secondary education; (c) full time homemaker; (d) enlistment in military; (e) full time disability with subsidy (SSI or SSDI); or (f) residing in independent or supported living arrangements.

STEP Grant criteria for Employment (EMPL). At the end of the STEP Grant, participants were deemed successful if they were employed between 20 to 40 hours per week, enlisted in the military, or were a homemaker. The first job listed in the Follow-up Survey was recorded for purposes of measuring success in the STEP Grant.

STEP Grant criteria for Postsecondary Education (PSE). Status for continued education after high school was measured as successful if the participant was enrolled in any school at the time of the STEP Grant Follow-up Survey: (a) a four-year college, (b) a two-year college, (c) a Vocational Technical School, or (d) had been enrolled in any educational setting since leaving high school.

Postsecondary education is complicated by the fact that some students work part- 
time and attend school at the same time. For the STEP Grant, this information was accounted for as follows. The STEP Grant data collection survey was unclearly stated so that some recipients volunteered information and others did not. A YES answer for any of the questions on full-time, part-time, and attendance at any time after high school was counted as successful in postsecondary education for purposes of the STEP Grant completion.

STEP Grant criteria for Independent Living (INDL). The STEP Grant outlined measures of success which were broadly defined in this area. Participants were recorded as successful if they paid rent to live with their parents or a friend, or were married and living with their spouse. No additional information on receipt of SSI or SSDI subsidies was available to measure this factor more closely. Complicating this outcome, "typical" college students receive support from their families as would also likely be the case for students from this target group. Both of the previous outcome factors, Employment and Postsecondary Education enrollment, directly affect how independent the participant can be in personal living arrangements; however, those interrelationships were not addressed in the STEP Grant.

Quantitative Measures (RQs 3-6)

Employment. For these quantitative relationships, employment status was examined based on the first job held as reported on the STEP Grant Student Follow-up Survey. Two quantitative measures were recorded.

First Hours Worked (HOUR). The number of hours worked per week on their first job is an indicator of the extent of full-time employment obtained directly after high school.

First Wages Earned (WAGE). The wages earned from the first job after high school 
are an indicator of relative success on income. Full-time homemakers' hours were counted as equivalent to full time (40 hours per week) and assigned wages at minimum wage of \$5.15 (Department of Labor, 1999). This is consistent with the original STEP Grant criteria and with the following researchers: (a) Haddad and Kapp (1991, p. 2) noted that, "the home care industry reimburses its workers with poor wages and benefits"; (b) Redfearn (1996) stated that the average starting wage for home care workers was $\$ 4.90$ to 6.86 per hour; and (c) Keefe (1999) in an extensive report on Human Resource Issues in Home Care, stated:

The majority of personnel employed in the home care industry are at an entry-level Position and perform a range of basic and instrumental activities of daily living (ADLs) that the client has been assessed as being unable to perform. Various titles for these personnel include homemaker, home health aide, personal care worker, home health attendant, and home support worker. (p. 3)

Blackorby and Wagner (1996) also noted that many graduates with a disability are stuck in low-wage entry positions in the tertiary job market and have trouble finding full-time work. Employers often limited hours below full time employment to avoid paying benefits.

Postsecondary Education. This information provides insight on the efforts of students with disabilities in qualifying for careers with greater responsibility and wages. The literature shows that high school graduates with disabilities who continue their education are able to qualify for better jobs (Blackorby \& Wagner, 1996). However, because the STEP Follow-up Survey did not detail these questions clearly, participation in postsecondary was accounted for in the STEP Grant section previously reported and no further analysis of quantitative measures was done in RQs 3-6 for Postsecondary Education. Volunteered information regarding the type and amount of postsecondary education some students presented on their surveys was accounted for in RQ7 using qualitative measures. 
Independent Living. Students with disabilities who attend technical schools or college classes are often supported by their parents and are not as independent in their living arrangements as others who are employed full time. These students were accounted for in the Employment and Postsecondary sections above; there were no new quantitative measures in RQs 3-6 for Independent Living.

\section{Qualitative Measures (RQ7)}

Student comments provided in the STEP Follow-up Survey under Questions 8 and 9 that shed light on their perspective of how the STEP Grant helped them, and information volunteered in Question 4 about Postsecondary Education--where attended, hours completed, and hours currently enrolled--are addressed through qualitative analysis.

\section{Procedures}

Data for Demographic Factors, STEP Intervention, and Mediating Factors were obtained from JCPS records and archives. The Student Follow-up Survey was administered as part of the No-cost Extension of the STEP Grant to determine student status in transition outcomes.

\section{Data Collection}

The STEP Grant Student Follow-up Survey was available only via hard copy (not electronic) and was distributed and collected by this researcher when employed by the STEP No-cost Extension. Information gathered from the school district data base included ethnicity, gender, disability, high school grade point average, semesters of vocational education, vocational class grade point average, and test scores for Self-efficacy and Locus of Control tests. Other information was obtained through the survey.

The STEP Grant Student Follow-up Survey obtained permission from students who were included in this new research and provided their status in employment, postsecondary 
education, independent living, and satisfaction with program aspects. Additional information on Demographic, STEP Intervention, and Mediating Factors was gathered from school district archives via student records check. All information collected was coded to assure confidentiality and entered by this researcher into the Statistical Package for Social Sciences, Version 14 (SPSS-14) for analysis.

All data collection and coding were handled by the author according to IRB guidelines to maintain confidentiality for research on human subjects. Informed consent was obtained and adherence to the rules of privacy safeguarded participant information to the extent required by law. All raw data, both hard copies and electronic files, were securely stored for a minimum of five years. Any additional information was obtained through requests to the local district's research department and review of student records archives.

Missing data can occur if information is mishandled during collection, the individual is unable to participate, a specific item is left blank, or if the person is absent at the time of the collection procedure. One solution, according to Gall et al. (1996, pp. 202203) is to eliminate incomplete cases. In the present study, the $n$ is already small, so that listwise deletion of subjects with missing data is not a viable option with the exception of the two measures of dependent variables under Employment Outcomes, where three students had not had any employment and one student was employed ten hours per week (all four were attending Postsecondary Education classes). Another common solution, adopted for this study, is to estimate missing data by imputing the group mean into each empty cell. More sophisticated methods also exist, e.g., using regression analysis to estimate more precisely the missing values. However, those procedures go beyond the scope of this study and would not be supported by the limited number of cases available. 


\section{Survey Development and Instrumentation}

Steps in constructing and administering a research questionnaire were outlined by Gall et al. (1996) and were generally adhered to in this research. The Student Follow-Up Survey instrument (see Appendix A) was developed by reviewing other survey research in the area of transition projects, obtaining questionnaires from other transition research, drafting a composite questionnaire for the STEP Student Follow-up Survey, and editing draft copies with professionals, parents, teachers, and doctoral students enrolled in the ELFH 790 Doctoral research class at the University of Louisville. Questions that addressed transition from high school outcomes were considered for clarity and content. Through this process, and consistent with research in best practices in transition, criteria for success for adults with mild disabilities were identified in the areas of Employment, Postsecondary Education, and Independent Living (NTLS2, 2004). All instrument development was completed with the assistance and guidance of Dr. Simmons, the PI for the Grant, and Norm Terry, the PC for the STEP project.

The development of the survey was done in three stages. First, the survey was reviewed for content by four subject matter experts in the field of special education and two postsecondary professionals who had served on the Project Advisory Board for three years. Second, the survey was disseminated by the PC to the 12 special education teachers of the elective class and selected parents who had students participating in the project. Teachers and parents reviewed the survey and provided written input regarding content and wording. The survey was then presented to a doctoral seminar class by this researcher at the University of Louisville. The doctoral students and instructor evaluated the survey for wording and clarity. Based upon input from the professionals, teachers, parents, and doctoral students, changes in the questionnaire were made to clarify questions for students 
with mild disabilities.

This procedure used the steps suggested by Griffee (1999), except for piloting the survey. Since participants in the study were students with mild disabilities, the decision was made by the STEP Grant PI, PC, and Board of Directors not to do a pilot with this group because of the possibility of skewed perceptions due to their disability.

\section{Research Design}

The research design for this study represents a partial program evaluation of the STEP Grant for 50 participants who left JCPS in 1997, 1998, 1999, and 2000 school years. However, the field of program evaluation is complex. Experts point out that many evaluation models have emerged since the 1960s, including a systems approach, simple checklists, and others. The evaluation model that is followed essentially dictates the results that are found (Worthen, Sanders, \& Fitzpatrick, 1997). In brief, Worthen et al., provided examples of applying evaluation to curriculum evaluation: (a) by using professional judgment to assess the worth of curriculum; (b) by comparing performance indicators with behavior objectives and judging the worth of the curriculum; (c) by working closely with the decision-maker and the evaluator to list advantages and disadvantages of the available curriculums; or (d) by identifying curriculum goals so that the evaluator can judge the worth of the curriculum for students, parents and community served (p. 63). Each approach guides the evaluation process, and the way the evaluator views the evaluation process directly affects the activities selected. There is no universal philosophy of evaluation, just as there is no single philosophy of science (p. 64).

According to Fitzpatrick, Sanders, and Worthen (2004), Scriven provided distinguishing characteristics between formative and summative roles of evaluation in 1967. The two approaches guide the types of actions the stakeholders might take after the 
evaluation is completed. Formative evaluation leads to program improvement and provides information on the merit or worth of a part of a program (Fitzpatrick et al., p. 16, emphasis added). In contrast, summative evaluation focuses on providing information to make judgments about the overall worth of a program related to important criteria (p. 17).

This research attempted to balance formative and summative evaluation in order to provide a partial evaluation of the STEP Grant intervention for the 50 participants as well as program improvement suggestions for future consideration and overall worth. In refining the approach used for this research, a basic outcomes study, changes that occurred in program recipients as a result of the program were described and their impact on final community participation was noted. Since the researcher was involved with the delivery of program services, this evaluation was considered an internal evaluation rather than one conducted by an external group or outsiders. In this case, the two dimensions--internal vs. external--cannot be entirely separated since program improvements were suggested based on the original STEP Grant evaluation criteria as well as the closer examination of the existing data utilizing more refined analysis. Information from the Follow-up Survey provided participant observations after the passage of time (one to two years). The researcher, although involved with the program as an advisor, did not provide the daily instruction for the participants and was not an employee of JCPS. Thus, this research could be considered "quasi-external," this being a matter of degree. A combination of quantitative and qualitative data analysis techniques were employed to determine success for participants and the overall program.

Fitzpatrick et al. (2004) list five approaches to evaluation: (a) objectives-oriented approaches focus on specific goals and objectives to determine the extent they have been obtained; (b) management-oriented approaches identify and meet informational needs of 
managers who make decisions; (c) consumer-oriented approaches develop evaluative information on "products" for use by consumers (can include competing products, services, etc.); (d) expertise-oriented approaches depend primarily on direct application of professional expertise to judge quality of program; and (e) participant-oriented approaches involve stakeholders to determine values, criteria, needs, data, and conclusions for the evaluation. These are considered conceptual approaches, not techniques, and vary in formality and structure. Many other evaluation models could fit into this schema, but these were selected as most typical or influential examples to fit the scope of this research. For this study, the objectives-oriented approach was the primary method used to determine if transition outcomes were met. However, it is difficult to omit some influence from the management-oriented approach since recommendations were made for program improvement and dissemination. Also, due to the nature of the STEP Survey, information was directly solicited from the participants as to their transition outcomes and program suggestions, so the participant-oriented approach was utilized somewhat as well.

In addition to these familiar evaluation approaches, Bolland and Bolland (1984) suggested that program evaluation and policy analysis are closely related. Certainly, policy analysis is applicable to the current research. Decisions on continuation of the intervention program at the six participating high schools and program dissemination for the other sixteen high schools in the school district were made by administrators based on the success of the STEP Grant. Policy analysis can synthesize a wide variety of efforts and directly affect educational administration which can complement evaluation approaches. “Evaluators tend to study a particular program, whether ongoing or completed, to determine its effectiveness. Policy analysts, on the other hand, tend to study a number of policy options to determine which one should be adopted and ultimately implemented” 
(Bolland \& Bolland, p. 334). They suggest that the relationship between evaluation and policy analysis is "symbiotic," and that a combination of both is more effective than the use of either one in isolation (p. 339). For this research, findings from the partial program evaluation reflected on policies implemented by the local school district and ultimately affected the success of students with disabilities as they transitioned to adult life.

\section{Analysis of Data}

Research questions were formulated to guide the analysis of data collected for this partial program evaluation. Figure 1, p. 34 indicates hypothesized relationships among the three types of Independent Variables (Demographics, STEP Intervention Program, and Mediating Factors) and Dependent Variables (the three transition outcomes--Employment, Postsecondary Education, and Independent Living). However, these variables are not applicable to all aspects of this study. Because the type of information required to answer

the different research questions varies considerably, specific analyses are divided into three sections. For each type, the research questions included are listed for the convenience of the reader. Then the particular analysis that was conducted was described.

\section{Transition Plans}

Research Question 1 addresses the extent to which the Transition Plans of the students in the STEP Grant comply with special education regulations.

RQ1. With respect to transition planning:

a. How many of the students in the STEP Student Follow-up Survey have a completed Transition Plan on file in the school district archives?

b. Did the student's career goal listed on the Transition Plan match the area of enrollment in vocational training?

c. Did the student's career goal listed on the Transition Plan match the first job after high school as reported on the Student Follow-up 
Survey?

d. Did the student's career goal listed on the Transition Plan match the postsecondary education major enrolled in at the time of the Student Follow-up Survey?

e. How many students had a match between the Transition Planning Goal, vocational education enrollment, and job held and/or Postsecondary education major at the time of the Student Follow-up Survey?

Information to answer RQ1 was obtained from inspection of records--student and school district--and the STEP Grant Student Follow-up Survey. Descriptive statistics were computed to summarize the findings, specifically, frequency counts and percentages.

\section{STEP Grant Outcomes}

Research Question 2 investigates the extent to which the stated goals of the STEP Grant were accomplished.

RQ2. What proportion of the students had completed transition (met criterion for success specified in the STEP Grant) at the time of the Student Follow-up Survey in:
a. Employment?
b. Postsecondary Education?
c. Independent Living?

The criteria used in the original STEP Grant were used to determine "success." These were described under STEP Grant Criteria (RQ2), above. Frequencies and percentages are the descriptive statistics that were calculated.

\section{Relationships among Quantitative Measures}

Research Questions 3-5 explicate relationships that exist among the three types of independent variables and the dependent variables. These quantitative analyses are based upon the conceptual and operational definitions of the respective variables (see Description 
of the Variables, above, and Appendix E).

RQ3. To what extent are demographic factors related to:

a. Participation in the STEP Grant:

i. School Attended?

ii. Year Enrolled?

iii. Days Enrolled?

iv. Attendance?

v. Self-Improvement?

b. Mediating personality factors:

i. Self-efficacy scores?

ii. Locus of Control scores?

c. Transition in Employment reported on the Student Follow-up Survey?

RQ4. To what extent is participation in the STEP Grant
a. School Attended
b. Year Enrolled
c. Days Enrolled
d. Attendance
e. Self-Improvement

related to:

a. Mediating personality factors:
i. Self-efficacy scores?
ii. Locus of Control scores?

b. Transition in Employment reported on the Student Follow-up Survey? 
RQ5. To what extent are Mediating personality factors

a. Self-efficacy Scores?

b. Locus of Control Scores?

related to transition in Employment reported on the Student Follow-up Survey?

The statistical analysis for RQs 3-5 is conducted in a series of steps. First, descriptive statistics were reported for both independent and dependent variables. (Descriptive statistics for the four scales described below were included under psychometric analyses.) For the second step, psychometric testing (reliability analysis) was calculated for the Self-efficacy and Locus of Control Scales that were included as mediating variables. This step was necessitated because no psychometric data could be found to affirm the use of these scales for populations with mild disabilities (see Findley \& Cooper, 1983; Kalechstein \& Nowicki, 1997; Klein \& Keller, 1990; Luthar, 1991; Marsh \& Gouvernet, 1989). Because the Self-Improvement scale from the STEP Grant Intervention Project had not been previously analyzed, no psychometric data existed to confirm its sufficient reliability to be used as a single construct.

Therefore, Cronbach’s (1951) coefficient alpha was computed for all four of the scales utilized in this study: the two Self-efficacy subscales (Sherer et al., 1982), the Locus of Control Scale (Nowicki \& Strickland, 1973), as well as the Self-Improvement composite from the STEP Grant. For the Locus of Control Scale, the general coefficient alpha equates to the Kuder-Richardson 20 formula for dichotomous YES-NO answers. Cronbach demonstrated that the two formulas are essentially the same, adapted to the level of measurement (continuous vs. categorical). Nunnally and Bernstein (1994) have noted that an alpha of .7 or above is typically considered adequate, but in exploratory research 
such as this, a relaxed standard of .6 can be utilized.

In the third step, the relative influence of the independent variables on the dependent variables was investigated by computing Pearson $r$ correlations. Correlation "permits one to analyze relationships among a large number of variables in a single study" (Gall et al., 1996, p. 414). It should be noted that multiple regression is typically utilized to determine the effects of a set of predictors on a criterion variable. Regression allows the separate effect of each independent variable to be calculated as well as an overall effect size, $R^{2}$. However, the data in this study do not support the use of regression. There are simply too many variables and not enough cases to warrant that procedure. Yet regression is based upon the raw Pearson $r$ correlations among the set of variables. For this study, those direct measures of association were utilized. The variables, either singly or in combination, influence a particular pattern of behavior: student behavior during and after the transition phase in the case of this study. Correlations provide the degree of relationship between variables being studied, and can be helpful in understanding how a given variable may influence subjects’ scores on other variables (Gall et al., p. 415). Because there are so many variables in the analysis, an overall correlation matrix is impractical. Accordingly, a series of correlation matrices were presented, organized by the blocks of variables in the Demographic Controls, STEP Grant Intervention Factors, and Mediating Factors and consistent with Figure 1 and RQs 3-5.

An additional strength of multiple regression is that it is possible to combine variables with different levels of measurement in the same analysis. Pearson $r$ correlations, however, require continuous measurement (interval or ratio). Strictly speaking, Ethnicity and Gender are nominal level variables, but with respect to Transition Outcomes (Blackorby \& Wagner, 1996), these have implied ordering (Yaffee, 2003). Likewise, the 
Disability measures were found to have ordered outcomes in Blackorby and Wagner. For these correlation matrices, these two ordinal level measures were included, despite not having true continuous level status. For this set of quantified measures relevant to the STEP Grant, all of the variables meet this modified continuous level criterion except for one: the School Attended.

Accordingly, School Attended was not included in the correlation analyses just described. Instead, a series of five chi-squares were calculated--for Ethnicity (White), Gender (Male), and the MMD, BD, and LD Disability distributions across the six schools-to determine whether there was a relationship between School Attended and these nominal level measures. (For Ethnicity and Gender, Black and Female responses are the reciprocals so that these chi-squares are identical to the calculations given for White and Male.) Then for the Mediating variables and Employment Outcomes, a series of one-way ANOVAs were performed to examine whether there were differences across the six schools in the STEP Grant for the mean scores of these continuously measured variables. For any of these computations that proved significant, a post hoc comparison was performed. Field (2005) noted that the Games-Howell is the "most powerful but can be liberal when sample sizes are small” and is also "accurate when sample sizes are unequal” (Field, p. 341); this option best fits the data here (small sample and unequal cell size). These chi-square and ANOVA calculations were required for RQs 3-4.

RQ6. When controlling for demographic factors, to what extent are participation in the STEP Grant
a. Year Enrolled
b. Days Enrolled
c. Attendance 


\section{d. Self-Improvement}

and Mediating Personality Factors
a. Self-efficacy Scores
b. Locus of Control Scores

related to transition in Employment reported on the Student Follow-up Survey?

For RQ6, semipartial correlations were calculated to investigate the extent that the STEP Grant Intervention variables and the Mediating Factors, respectively, are related to the Transition Outcomes (Employment measures), when controlling for the demographic factors. School Attended was not included in these partial correlations for the same reasons that it was not included in Pearson $r$ calculations for RQ 3-4 above (nominal coding).

Partial correlations are calculated between two variables as the effects of the third variable are controlled. "Specifically, the effects that the third variable has on both variables in the correlation are controlled” (Field, 2005, p. 138). Field also explained that in a semipartial correlation, "the effect that the third variable has on only one variable in the correlation is controlled” (p. 139). Thus, semipartial correlations explain the variance in “one particular variable (an outcome) from a set of predictor variables” (p. 139), net of the influence of a third variable, in this case a demographic control factor. Applying this reasoning to the present study, a series of semipartial correlations were used to analyze data for RQ6. This process looked for predictor variables that exhibit significant relationships in the present study, beyond their overlap with the demographic factors. Twotailed probability was used for these calculations.

\section{Qualitative Analysis (RQ7)}

Research Question 7 details open-ended comments that students made on the STEP 
Grant Student Follow-up Survey in regard to program improvements in the areas of preparation for employment and postsecondary education. It should be noted that the STEP Grant Student Survey should have solicited comments for Independent Living to be consistent. Inadvertently, this item was omitted; therefore, no qualitative data were obtained for Independent Living.

RQ7. What are students' perceptions of the STEP Project with respect to:
a. Employment?
b. Postsecondary Education?

Qualitative analysis was done to answer RQ7 based on data from open response questions (see Appendices F \& G, respectively). This information was obtained from the STEP Grant Student Follow-up Survey, open-ended response comments to Questions 8 and 9.

An additional qualitative factor was reported for Postsecondary Education from Question 4. This was information that students voluntarily reported about the type of postsecondary education/training they had or were enrolled in at the time of the STEP Follow-up Survey (see Appendix H). Because the survey did not request this information, there is no quantitative measure of this supplemental data and only a limited number of students $(n=12)$ volunteered this.

Procedures for analyzing Appendix F, H, and G followed qualitative procedures. Qualitative research explores relationships with textual, rather than quantitative data, and results are usually considered transferable, but not generalizable (Anthony, 2006). "Qualitative research involves the studied use and collection of a variety of empirical materials; case study, personal experience, introspective, life story, interview, observational, historical, interactions and visual text; the described routine and problematic 
moments and meanings in individual' lives” (Denzin \& Lincoln, 2000, p. 2). Data collected for qualitative research can add rich background information to quantitative research. In the case of the current research, qualitative (open-ended comments) items were collected in STEP Follow-up Survey Q8 in regard to employment, and Q4 and Q9 on postsecondary education. All questions relied on self-reporting by participants. Self-reports are "usually easy to obtain, but many individuals bias the information they offer about themselves, or they cannot recall accurately the events of interest to the researcher” (Gall et al., 1996, p. 328). Due to the limited scope of the qualitative section, there was no opportunity to develop naturalistic observation to overcome this bias; therefore, few inferences can be made from this information.

Comments were strictly volunteered. There is no way to compare answers of those who volunteered with those who did not report this information. The statements made for Survey Questions 8 and 9, however, allowed participants to supply additional perspectives on the program and how it affected them. Survey Question 4 asked for participation in postsecondary education by credit hours completed or current enrollment. Some answers provided did not fit this format since the training or program was not at a college; some answers given were in clock hours, while others were simply overall completion of a training program with no hours listed. Comments for these three open-ended questions were sorted into categories by the researcher for reporting purposes to obtain the scope of the ideas presented. Had these statements been more extensive or if the questions were truly open-ended, a more complex coding system would have been necessary similar to those used with content analysis of documents and other communication media such as frequency count or readability formulas (Gall et al., p. 356) or coding of comments (p. 359). Coding systematically searches data to identify or categorize observable patterns or 
characteristics. Because the comments received in the STEP Student Follow-up Survey were small in number, it was not necessary to use a computer program to accomplish the classification system.

Lincoln and Guba (1985, as cited in Gall et al., p. 361) define "documents as written communications prepared for personal rather than official reasons” whereas "records are written communications that have official purpose. Lincoln and Guba point out that the qualitative researcher needs to study the context in which the information was produced. In the case of this current research, the participants composed their comments and mailed them on the STEP Grant Student Follow-up Survey or orally delivered them when contacted by phone. The researcher did not have the opportunity to observe the settings while the survey was being completed.

The results of categorization were reviewed by a member of the dissertation committee to verify grouping and reliability. Analyses of comments were interpreted by the researcher who was not present during the program delivery. Creswell (2002) noted that there is not "one single way to analyze qualitative data--it is an eclectic process in which you try to make sense of the information” (p. 258). Therefore, these results have extremely limited transferability beyond these program evaluation results.

\section{Validity Considerations}

"Validity is usually taken to mean that the questionnaire [survey] is in fact measuring what it claims to measure” (J. D. Brown, 1996, p. 231). For this study, validity interpretations depend upon the work done during the STEP Grant, since all surveys, instruments, and data collection procedures were developed or adapted during the planning and implementation stages of the project, including the STEP Grant Student Follow-up Survey. This section details steps that were taken to address validity issues. 


\section{Types of Validity}

Validity was defined by the 1985 Standards for Educational and Psychological Testing as the "appropriateness, meaningfulness, and usefulness of the specific inferences made from test scores” (as cited by Gall et al., 1996, p. 249). They described validity as having five parts. The first part, Construct Validity was the "theoretical construct about the nature of human behavior.” Constructs, such as self-concept, learning styles, or motivation for achievement, are not directly observable, but must be inferred from effects on behaviors. The second type of validity, Content Validity, was the degree the scores obtained on a test represent the content the authors say they measure (Gall et al., p. 250). The third type was Predictive Validity: the degree that predictions made by testing are confirmed by behavior of individuals after the test (p. 251). This was sometimes called Criterion-Related or Concurrent Validity (the fourth type) where new test scores are compared to previous test scores (p. 252). The fifth and final type of validity mentioned by Gall et al. was Consequential Validity--the fact that test scores, theory and beliefs behind the constructs and the language used to label the construct have "value and value-laden consequences when used to make decisions about individuals” (p. 252).

Guidelines associated with student assessment were proposed by Nitko (2001), who defined validity as “the soundness of your interpretations and uses of students' assessment results” (p. 36). The emphasis was on the results being interpreted, not the instrument or procedures itself. Nitko outlined four principles for validation of assessment as suggested by Messick:

1. Interpretations are valid only to the degree that evidence supports appropriateness and correctness;

2. Uses of assessment are only valid to the degree that evidence supports correctness and appropriateness; 
3. Interpretations and uses are valid only when the values implied by them are appropriate;

4. Interpretations and uses are valid only when consequences from interpretations and uses are consistent with appropriate values. (p. 37, emphasis added)

Each intended use of assessment results needs evidence provided separately.

Current interpretation of reliability relegates it to one of the eight types of validity (Nitko, 2001). "Reliability is information on whether the instrument is collecting data in a consistent and accurate way” (Seliger \& Shohamy, 1989, p. 185). In this study two adopted instruments were used to collect data on students' perceptions: the Self-efficacy Scale (Sherer et al., 1982) and the Locus of Control Scale (Nowicki \& Strickland, 1973). In addition, the reliability of the Self-Improvement scale, as derived from the STEP Followup Survey, is relevant.

\section{Validity Information on Existing Instruments}

In this partial program evaluation, external criterion validity (Nitko, 2001) ilwas the primary means of determining whether the factors delineated in the STEP Grant Intervention were related to success in transition employment outcomes--wages earned and hours worked. For this study, two tests were used as Mediating Factors to measure their influence on transition outcomes for the student participants--Self-Efficacy and Locus of Control. However, the evidence from these calculations was limited in generalizability. The scores might be highly valid when applied to participants from STEP Grant Follow-up Study, but not for the group who completed STEP intervention and who chose not to participate in the survey, or for those students in the mild disability category at the six grant high schools who chose not to participate in the STEP Grant. The records to compare these other groups are not available. 
Self-efficacy Scale. The Self-efficacy Scale was reported to have good “criterionrelated validity by accurately predicting that people with higher self-efficacy would have greater success than those who score low in self-efficacy in past vocational, educational, and monetary goals” (Sherer et al., as cited by Fischer \& Corcoran, 1994, p. 525).

Construct validity correlated significantly in predicted directions with other measures, e.g., the Ego Strength Scale, the Interpersonal Competency Scale, and the Rosenberg SelfEsteem Scale (Fischer \& Corcoran, p. 525). Reliability was also reported to have good internal consistency (alphas of .86 for general section and .71 for social section) with no test-retest data reported (p. 525).

Locus of Control Scale. This is a 40-item dichotomous response scale to measure perceived control in affiliation, achievement, and dependency (Nowicki \& Strickland, 1973). Watters and Thomas (1990) attempted to replicate the factor structure of this test and concluded that the dichotomous nature is the reason that replication of its factor structure has been so elusive (p. 515). Other authors attribute the difficulty of replication to small sample size; different sample characteristics (age, sex, socio-economic status, or culture); inconsistent administration of test; different factor analytic techniques and/or criteria; and incomplete reporting of findings (Barling; Comrey; Walters \& Klein; as cited by Watters \& Thomas, p. 516). Internal consistency was reported as “fair” by Sherer et al. (as cited by Fischer \& Corcoran, 1994, p. 503). Split-half reliabilities increased with age: .32 for grades $3-5, .68$ for grades $6-8, .74$ for grades $6-11$, and .81 for grade 12 . Stability of the instrument was also reported as "fair" in test-retest after six weeks with correlations of .63 (p. 503). Validity reported by Fischer and Corcoran correlated significantly with three other measures of locus of control, and also with academic and nonacademic behaviors. However, race, socioeconomic level, and sex tend to mediate findings (p. 503). Fisher and 
Corcoran (p. 503) also reported that test scores were sensitive to a therapeutically designed camping experience and found not to be affected by social desirability response sets. This test was designed to measure generalized self-efficacy only in vocational competence and social skills, and not in a variety of situations (Sherer et al., 1982). These research findings were upheld by more recent research by Choi (2003, p. 479) who reported that the internal consistency was satisfactory: “The Self-efficacy General subscale tended to be consistently higher (mid to high .80s) than the reliability of the Social Self-efficacy scores (far lower than .80). Choi (p. 479) noted that this is not surprising due to the small number of items (six) on the social section of the test, and rates the factor structure as "stable" and reliability as “acceptable.”

\section{Ethical Standards}

Because this study involved multiple sites in the local school system, the University of Louisville Human Subjects clearance was first required because the author was a student there. Then, permission and approval from the JCPS research department was obtained; administrators in special education and principals from the six local schools were brought into a collaborative agreement. In addition, one of the author's dissertation committee members, Dr. Simmons, had a long-standing relationship with Office of Special Education and Rehabilitation Services (OSERS) and secured funding for the original STEP Grant through a federal grant. A No-cost Extension was sought for the STEP Grant Student Follow-up Survey and granted through OSERS for the final year. To the extent possible, Dr. Simmons' assistance was tapped to coordinate yearly reviews necessary to all three sponsoring entities. Once the approval process was finalized (both human subjects and school district approval), the author developed a procedure for collecting the data in conjunction with the PI (Dr. Simmons), the PC (Norman Terry), Research Department and 
Exceptional Child Education Department from the school district. A meeting with the administrators of the six sites was held to explain the STEP Grant No-cost Extension as their cooperation was imperative to continuing the program an additional year: ensuring that teachers continued for the Elective Class, enlisting cooperation from other staff, contacting students, and informing parents.

At each location, students who responded to the invitation to join the STEP Grant Student Follow-up Survey signed a consent form. If a participant was not yet 18 years of age, parental consent was also obtained. The consent form, following the Institutional Review Board (IRB) guidelines, was incorporated with the survey, to be completed before proceeding to the questionnaire (see Appendix A for a copy of the student contact letter, consent form, and STEP Grant Student Follow-up Survey).

The cover letter, survey, and survey consent form required by the University of Louisville were written in easy to understand language so that participants with learning disabilities could comprehend the questions. Efforts were made to word the questions in non-threatening terms and follow-up interviewers were provided training to accept any answer that was offered without judgment.

The Institutional Review Board (IRB) process at the University of Louisville and school district research department was followed. Approval was gained from both governing institutions; the Human Subjects annual letters of verification are filed in Appendix B. This researcher took and passed the IRB training modules annually and in addition has kept the research study current by filing continuation grant permissions on a yearly basis.

\section{Summary}

Existing data from a three-year intervention program in a metropolitan school 
district was used to determine if students with mild disabilities (Learning Disabilities, Behavior Disabilities, and Mild Mental Disabilities) were able to make successful transition to adult life. The present study uses a mixed design with mostly quantitative data and additional qualitative information gathered from school district records and the STEP Grant Student Follow-up Survey. This is a partial program evaluation that focuses on key questions identified through a literature review of transition projects at state and national levels and targets the search for predictor factors, not model testing.

The population for this study was a group of fifty volunteer participants from six different high schools chosen by the school district administration due to high rates of drop out and unsuccessful transitions in the identified population. All participants were receiving services through special education and enrolled in the STEP Grant elective class for transition intervention.

Figure 1 (p. 34) shows the relationship between Independent and Dependent Variables used in this research. The Demographic Factors (Personal Identity and Educational History) were chosen because of their traditionally strong influence on student outcomes for schooling generally. The literature review supported the assumption that students with learning/behavior disabilities have difficulties in the transition to adult life in the areas of Employment, Postsecondary Enrollment, and Independent Living. Two personality factors--Self-efficacy and Locus of Control--were also selected due to their demonstrated influence on the way people interact with their world (Nowicki \& Strickland, 1973; Sherer et al., 1982). Similarly, the literature showed that these personality concepts were found to affect students' abilities to make choices and become successful, selfdetermined adults. The STEP Grant intervention (the primary alterable variables in Figure 1) was designed to help these students increase their ability to make the transition to adult 
life successfully.

Measures of the efficacy of the STEP Grant included School Attended, Year Enrolled, Days Enrolled, Attendance, and Self-Improvement. Student outcomes were examined to ascertain the strength of the relationships posited in Figure 1 and articulated in the research questions for this group of project students who completed the STEP Grant Student Follow-up Survey after high school. Relationships within and between groups of Independent Variables were examined for their influence on Dependent Variables: student outcomes of Employment (Hours worked and Wages earned).

The logic of the specific procedures for RQ 1-7, respectively, was detailed in the Research Design section. RQ1 focused on IDEA compliance for the IEP for the students in the STEP Intervention Grant. RQ2 addressed the criteria of success as defined by the STEP Grant. RQs 3-6 examined quantitative relationships among the demographic factors, STEP Grant Intervention measures, the personality measures that were utilized as mediating variables, and transition outcomes in employment. Analyses were primarily descriptive statistics and Pearson $r$ bivariate correlations. ANOVA was required for the analysis of the School Attended (measured nominally). Semipartial correlations were calculated for RQ6 which examined the strength of relationships after controlling for the demographic factors. The comments from the open-ended response questions on the survey were examined qualitatively (RQ7). SPSS was utilized for the quantitative computations.

Procedures for data collection included examination of existing data from school district records and the STEP Grant Student Survey which included both perceptual and open-ended response questions. The student survey was developed by the PI, PC, and this researcher, with the assistance of the STEP Grant Advisory Board. It was reviewed by experts in the Special Education Department and doctoral students enrolled in ELFH 790 
class at the University of Louisville, selected parents of students enrolled in the program, and teachers of the STEP Grant elective classes.

Validity issues surrounding the development of the survey were addressed. Information regarding the validity and reliability of the Self-efficacy Scale (Sherer et al., 1982) and Locus of Control Scale (Nowicki \& Strickland, 1973) was provided from the original authors' validation studies. More recent authors' findings were also reported as supporting the initial findings (Choi, 2003; Fischer \& Corcoran, 1994). Because research confirming the use of these scales for students with disabilities could not be found, Cronbach's coefficient alpha was computed to check reliability of these scales for this population of students with mild disabilities. The Self-Improvement Scale as derived from the STEP Grant Intervention Follow-up Survey was also subjected to this reliability analysis.

The ethical standards established by the University of Louisville Institutional Review Board and the Jefferson County Public Schools Research Department were followed throughout the application of all research procedures. Confidentiality of individual students' information was maintained throughout the data collection and analyses. The database has been secured for a period of five years as required.

This partial program review used program evaluation and policy analysis as the framework for examining existing data. Predictors of success become valuable to educators when they search for ways to improve the transition from high school to adult status for this population of students with mild disabilities. 


\section{CHAPTER IV}

\section{RESULTS}

\section{Introduction}

Students with disabilities have a much more difficult time preparing for current jobs in the technological business climate of today. Employers want better prepared, flexible workers with the ability to move to varied tasks or locations. A high school diploma with additional postsecondary training is the minimum preparation expected. Advocates for special education have developed transition services for high school students with disabilities to make the entry to employment, postsecondary education, and independent living more successful. However, despite federal mandates and identification of the necessary components, empirical research presented in this literature review demonstrated that, for most of these students, the results have been less than optimal.

Even after the passage of PL 94-142, students with mild disabilities (LD, BD, and MMD), the target of this investigation, were typically educated in separate special education classes. However, over the last 25 years, educational service delivery has evolved to provide supports for these students to be included in regular academic and vocational programs (Benz \& Halpern, 1993; Brolin, 1997; Eisenman, 2000; Flexer et al., 2008; Mastropieri \& Scruggs, 2007). Higher expectations for these students, along with identification of specific learning strategies, collaboration between academic, vocational, and special education teachers, and supports for self-determination led to small improvements (Flexer et al., 2008; Halpern et al., 1992; Rusch et al., 1992; Scuccimarra \& 
Speece, 1990; Wagner et al., 1993), but much more is needed.

Educational programs, including transition from high school to adult roles, were targeted by additional federal legislation subsequent to the passage of the IDEA (1975) mandates, but few changes have been seen in the final outcomes for students with mild disabilities. The new legislation (e.g., NCLB, IDEA 2004, ADA, Carl D. Perkins Vocational Education Act, and 504 Amendments to the Vocational Rehabilitation Act of 1973) has added requirements for educational changes and supports. Research has begun to focus on outcomes to determine where students with disabilities end up as adults in order to prepare them better for more independent lives. A myriad of federally supported empirical research projects supported the development of transition components to help students plan earlier for desired careers (deFur, 1999; Durlak, \& Rose, 1994; Kohler, 1993; Madaus, 2006).

Literature reviewed in the areas of evaluation in general, and special education programs more specifically, depicts the need to continue research on outcome measures in order to change high school programs effectively. The National Longitudinal Transition studies (Blackorby \& Wagner, 1996; SRI International, 2006) have followed large groups of special education students for over ten years. Little improvement has been seen in employment rates of students with mild disabilities. These groups (LD, BD, and MMD) are still dropping out at higher rates, have a higher unemployment rate, and lower completion of postsecondary programs than their non-disabled peers. With large numbers of these students accepting entry-level jobs, not pursuing additional training after high school, and having lowered ability to manage personality factors, their independence from family supports is much lower than their regular education peers.

Kentucky has followed the national trend in attempts to provide improved services 
for students with special needs. The STEP Grant was a collaborative effort between the local school district and the University of Louisville to develop a support system and improve outcomes for students with mild disabilities. The STEP Intervention Grant was implemented over a three-year effort to provide transition services in a large urban school district. Six high schools were targeted for this pilot project to reduce the large number of dropouts and improve their successful transition to employment, postsecondary education, and independent living. Services were provided through an elective class, work experiences, job placements, and an introduction to available postsecondary institutions in the local area. This research is a partial program evaluation to examine data from the STEP Grant and additional outcome information gathered through a Follow-up Survey after the students left public school. Specifically, factors that may have predictive power were targeted. The central research question was: What are the effects of the STEP Grant Intervention on the transition of students with mild disabilities to post-school outcomes?

The remainder of this chapter examines the relationships between Independent Variables (Demographic Factors, STEP Grant Intervention, and Mediating Factors) and the Dependent Variables (Transition Outcomes of Employment, Postsecondary Education, and Independent Living) as illustrated in Figure 1. Both quantitative and qualitative methods were employed in the analysis. Following a section on Data Checking and Coding, Descriptive Statistics are presented. Next, reliability of the scales employed in this study is addressed under Psychometric Analysis. Then the Research Questions are addressed with design specific to each question, as detailed in Chapter III. A Summary completes this chapter.

Data Checking and Coding

Data for the study were obtained from two distinct sources: via review of school 
district records and a survey of STEP Grant students. Student records on transition planning (documents required by IDEA legislation, e.g., IEP, Transition Plan, Addendum for Special Needs Students, and career interest testing), were obtained from student archives at C.B. Young Center. Elective class records and personality test results (SGEN, SSOC, and LOCUS tests) were obtained from the Project Coordinator. Attendance, GPA, and VGPA records were provided from the JCPS Research Office. The STEP Grant Student Follow-up Survey and Consent Forms were mailed to 108 participants and 50 were returned by mail to this researcher. All information was entered into a STEP Grant SPSS database by this researcher, being attentive to level of measurement in the process.

\section{Missing Values}

Three student records out of 50 were missing for GPA, VGPA, and Vocational semesters and classes. The missing values for all of these factors were replaced with the mean value. All 50 students took the personality tests, but a few questions in the Locus of Control tests were left blank (never more than four for any given question); mean values were also imputed for these items. The one female who listed being a homemaker for her occupation was assigned 40 hours per week at the $\$ 5.15$ minimum wage prevailing at the time of the STEP Grant Student Follow-up Survey (Department of Labor, 1999; Haddad \& Kapp, 1991; Keefe, 1999; and Redfearn, 1996). This brought the number of students with employment data to 46 .

During subsequent data analysis, Cronbach's (1951) coefficient alpha was computed for internal reliability of the personality scales and the Self-Improvement Scale from the STEP Grant Student Follow-up Survey. The results for the Self-efficacy (Social) Scale were $\alpha=.061$; further, the alpha-with-item-deleted value for two of the six items was negative, a red flag. Nichols (1999) notes that a negative alpha is due to a negative average 
covariance among the items. The most common explanation of this anomaly is that reverse score items were not correctly handled.

Accordingly, the original test results were re-analyzed. A disc with all data coding for the three personality tests (two Self-efficacy Scales plus Locus of Control) was provided by JCPS. Coding had been completed some seven years ago, prior to this researcher's joining the STEP Grant Follow-up Survey team. Because the Cronbach's alpha computations were suspect, all items, for each of the tests in question, were recoded, being careful to follow reverse-score protocol based on the scoring key for the three scales. The value for Cronbach's alpha increased considerably for each of the three scales and the negative alpha-with-item-deleted values disappeared as a result of these changes. This revised data set was utilized in all subsequent computations. Beyond these changes, the data revealed no other out-of-range values or inconsistencies.

\section{Descriptive Statistics}

Descriptive statistics for this study include measures of central tendency: the Mean for the group, the Standard Deviation, Minimum score, Maximum score, and the Range for the scores. Descriptive statistics presented are limited to the independent and dependent variables utilized in RQs 3-6. Descriptive statistics for Demographic data and STEP Intervention Factors are presented as ordered by variable categories in the theoretical model, Figure 1. Operational definitions and codings of variables can be found in Appendix E. The sub-group of 50 students from six JCPS high schools, who participated in the STEP Intervention Grant and completed the Student Follow-up Survey, was the target of this investigation.

\section{Independent Variables}

The Independent Variables for this study are divided into three conceptual 
groupings: Demographic Factors, STEP Intervention Factors, and Mediating Factors. Descriptive statistics for Demographic Controls and four of the five STEP Intervention Factors are presented here. Information for the other STEP variables (Self-Improvement) and Mediating Factors (all scales) is presented under Psychometric Analysis, below. Demographic Controls

Demographic Controls have two sections: (a) Personal Identity--Ethnicity (ETHN), Gender (GEN), and Disability (DIS) factors, and (b) Educational History--Semesters of Vocational Education (VSEM), Grade Point Average (GPA), and Vocational Grade Point Average (VGPA).

Personal Identity. Table 1 presents the ethnic distribution for students who participated in the STEP Intervention Grant and completed the Student Follow-up Survey. All students in the STEP Grant met Kentucky Department of Education criteria for the Mild Disability category in order to receive services in special education according to their IEPs. Within the Mild Disability category, all three major disabilities are represented with $10 \%$ Mild Mental Disabilities, 10\% Behavior Disabilities, and the majority $80 \%$ Learning Disabilities. 
Table 1

Descriptive Statistics for Demographic Controls, Personal Identity $(N=50)$

Measure $\quad$ Frequencies Percentages

ETHN

Black $\quad 124$

$\begin{array}{lll}\text { White } & 38 & 76\end{array}$

GEN

$\begin{array}{lll}\text { Female } & 24 & 48\end{array}$

$\begin{array}{lll}\text { Male } & 26 & 52\end{array}$

DIS

$\begin{array}{lll}\text { MMD } & 5 & 10\end{array}$

$\begin{array}{lll}\mathrm{BD} & 5 & 10\end{array}$

$\begin{array}{lll}\text { LD } & 40 & 80\end{array}$

Note. $\mathrm{MMD}=$ mild mental disability; $\mathrm{BD}=$ behavior disability; $\mathrm{LD}=$ learning disability.

Educational History. Table 2 presents three additional factors under Demographic Controls (VSEM, GPA, and VGPA). The mean of 11.30 for semesters of vocational education indicates that it is not unusual for students to enroll in more than one vocational class during a semester. All students got one credit for the STEP Elective class for each semester that they were enrolled in the STEP Grant. All vocational classes completed during the high school years were included in this count. In general, the students did better in their vocational education classes $(M=2.58$ for VGPA $)$ than their regular classes. For this program evaluation, data are available only for the 50 who completed the STEP Grant 
Student Follow-up Survey. Regular and Vocational class grade point averages were calculated by adding grades cumulatively, then dividing by the number of classes completed.

Table 2

Descriptive Statistics for Demographic Controls, Educational History $(N=50)$

\begin{tabular}{lccccc}
\hline Measure & $M$ & $S D$ & Min & Max & $\mathrm{R}$ \\
\hline VSEM & 11.30 & 3.66 & 4.00 & 20.00 & 16.00 \\
GPA & 2.36 & 0.62 & 1.29 & 3.89 & 2.60 \\
VGPA & 2.58 & 0.75 & 0.83 & 3.98 & 3.06 \\
\hline
\end{tabular}

Note. Min $=$ Minimum; Max $=$ Maximum; $\mathrm{R}=$ Range.

\section{STEP Grant Intervention Factors}

Table 3 presents frequencies and percentages for the numbers of students at each school location, ranging from a low of 4 to a high of 13 , and reflecting only those students from each location who returned the STEP Grant Student Follow-up Survey. This variable is reported separately since it represents nominal data. 
Table 3

Participation in STEP Grant by School $(N=50)$

\begin{tabular}{ccc}
\hline School & Frequency & Percentage \\
\hline A & 4 & 8 \\
B & 13 & 26 \\
C & 10 & 20 \\
D & 7 & 14 \\
E & 10 & 20 \\
F & 6 & 12 \\
Total & 50 & 100 \\
\hline
\end{tabular}

The descriptives for the next three STEP Intervention Factors (YEAR, DAYS, \%ATT) are presented in Table 4. The mean for YEAR (1996.94) reflects the middle of the three years that the STEP Grant operated (1996-1998). Most students were enrolled in the program slightly more than a full calendar year $(M=192.37$ days $)$.

Table 4

Descriptive Statistics for STEP Grant Intervention Factors $(N=50)$

\begin{tabular}{cccccc}
\hline Measure & $M$ & $S D$ & Min & Max & $\mathrm{R}$ \\
\hline YEAR & 1996.94 & 0.42 & 1996.00 & 1998.00 & 2.00 \\
DAYS & 192.37 & 74.68 & 69.00 & 340.00 & 271.00 \\
\%ATT & 86.74 & 13.76 & 34.90 & 100.00 & 65.10 \\
\hline
\end{tabular}

Note . Min $=$ Minimum; Max $=$ Maximum $; \mathrm{R}=$ Range. 


\section{Dependent Variables}

Dependent Variables for RQs 3-6 were Transition Outcomes for Employment

Hours and Wages for the first job after high school. These employment outcomes were the two constructs for which data were complete enough to include in this statistical analysis.

Table 5 presents the descriptives for these two measures.

Table 5

Descriptive Statistics for Transition Outcomes, Hours and Wages $\left(N=46^{\mathrm{a}}\right)$

\begin{tabular}{lccccc}
\hline Measure & $M$ & $S D$ & Min & Max & $\mathrm{R}$ \\
\hline HOUR & 23.33 & 11.66 & 10 & 40 & 30 \\
WAGE & 5.45 & 1.92 & 4.15 & 10.30 & 6.15 \\
\hline
\end{tabular}

Note Min $=$ Minimum; Max $=$ Maximum; $\mathrm{R}=$ Range.

${ }^{\mathrm{a}}$ Four of the 50 participants were not working because they were enrolled in Postsecondary Education at the time of the Follow-up Survey.

\section{Psychometric Analysis}

Along with better preparation and higher expectations, personality factors play an important role in how students with disabilities face the world. The concepts of Selfefficacy and Locus of Control were targeted for this research and testing was administered during the STEP Intervention Grant to try to determine the effects that personality factors have on the preparation and transition for these students. Neither the Self-Improvement construct from the STEP Grant Student Follow-up Survey, developed specifically for this project, nor the personality tests were pre-tested for use with students with mild disabilities. Therefore, reliability statistics (Cronbach's, 1951, coefficient alpha) were 
calculated for these scales. With scores ranging from 0 to 1 , the closer to the number one, the better the reliability of the test is judged. Nunnally and Bernstein (1994) have noted that an alpha of .7 or better is within the acceptable range of reliability, but a relaxed level of significance (.6) can be utilized for exploratory research.

\section{STEP Grant Self-Improvement}

Self-Improvement (the fifth of the STEP Intervention Factors) was identified by the STEP Grant administrators as important to assess growth after intervention of the STEP Elective class was experienced. The construct was calculated from students' answers to ten questions from the STEP Grant Student Follow-up Survey. The Likert scale answer reflected the students' perceptions about how the STEP Grant helped them. The first five questions focused on personal insight gained through the program to understand their abilities or learning styles and ways they could improve. The second five questions focused on assistance with understanding transition, employment and education choices, and planning for their future. Table 6 presents results of the reliability analysis for this scale. The Composite mean of 4.01 indicates that the student responses for these items were tending toward a ceiling effect. Cronbach's alpha for the scale is .748, an acceptable value, especially given the special nature of this population. 
Table 6

Psychometric Analysis for Self-Improvement Scale $(N=50)$

\begin{tabular}{|c|c|c|c|c|c|c|}
\hline Item & $M$ & $S D$ & Min & Max & $\mathrm{R}$ & $\alpha-d$ \\
\hline Q6a & 3.78 & .996 & 1 & 5 & 4 & .703 \\
\hline Q6b & 4.10 & .931 & 1 & 5 & 4 & .710 \\
\hline Q6c & 4.14 & .756 & 3 & 5 & 2 & .725 \\
\hline Q6d & 3.90 & .995 & 1 & 5 & 4 & .736 \\
\hline Q6e & 4.12 & 1.100 & 1 & 5 & 4 & .710 \\
\hline Q6f & 3.94 & 1.129 & 1 & 5 & 4 & .758 \\
\hline Q6g & 4.00 & 1.143 & 1 & 5 & 4 & .739 \\
\hline Q6h & 4.16 & .792 & 3 & 5 & 2 & .719 \\
\hline Q8 & 3.98 & .979 & 1 & 5 & 4 & .746 \\
\hline Q9 & 3.94 & 1.114 & 1 & 5 & 4 & .731 \\
\hline Composite & 4.01 & .591 & 2.7 & 5 & 2.3 & $.748^{\mathrm{a}}$ \\
\hline
\end{tabular}

Note. Min = Minimum; Max $=$ Maximum; $\mathrm{R}=$ Range $\alpha-\mathrm{d}=$ alpha with item deleted.

avalue for composite for $\alpha-\mathrm{d}$ is Cronbach's coefficient alpha for overall scale.

\section{Mediating Factors}

The Mediating Factors for this research are scores from personality scales for Selfefficacy--General and Social--and Locus of Control. These tests were selected as part of the STEP Grant by the PI, PC, and Advisory Board based on the evidence that these traits influence success for students with mild disabilities in gaining self-determination skills and planning for their futures (Wehmeyer, 1994). 
For both of the Self-efficacy scales (Tables $7 \& 8$ ), the scoring of the tests results in a numerical score with a higher score reflecting students' increased perception of their ability to affect what happens to them in life. The Self-efficacy test has 30 questions. Seven of these are filler items and are not included in either of the two subscales--17-item General or 6-item Social. Table 7 presents the reliability analysis and descriptive statistics for the General Self-efficacy scale. While the composite values $(M=3.49 ; S D=.464$ reflect good psychometric range for the items, the Cronbach's alpha of .640 demonstrates that the reliability for this sample of students with mild disabilities falls below the generally accepted threshold of .7 but does reach the marginally adequate reliability of .6 for exploratory research. However, the $\alpha-\mathrm{d}$ for item 12 shows that the scale would increase to an acceptable level of reliability if it were deleted. Therefore, the decision was made to discard this item. All consequent statistics were computed with a new composite of 16 items instead of $17(M=3.66, S D=.539)$, yielding the new Cronbach's coefficient of .719 . 
Table 7

Psychometric Analysis for Self-efficacy (General) Scale $(N=50)$

\begin{tabular}{|c|c|c|c|c|c|c|}
\hline Item & $M$ & $S D$ & Min & Max & $\mathrm{R}$ & $\alpha-d$ \\
\hline Q2 & 4.12 & .983 & 1 & 5 & 4 & .631 \\
\hline Q3 & 3.26 & 1.337 & 1 & 5 & 4 & .641 \\
\hline Q4 & 4.24 & .960 & 1 & 5 & 4 & .607 \\
\hline Q7 & 2.92 & 1.383 & 1 & 5 & 4 & .632 \\
\hline Q8 & 3.70 & 1.233 & 1 & 5 & 4 & .603 \\
\hline Q11 & 3.10 & 1.147 & 1 & 5 & 4 & .638 \\
\hline Q12 & 2.22 & 1.166 & 1 & 4 & 3 & .719 \\
\hline Q15 & 3.76 & 1.170 & 1 & 5 & 4 & .596 \\
\hline Q16 & 3.72 & 1.144 & 1 & 5 & 4 & .617 \\
\hline Q18 & 3.46 & 1.199 & 1 & 5 & 4 & .627 \\
\hline Q20 & 3.28 & 1.196 & 1 & 5 & 4 & .605 \\
\hline Q22 & 3.18 & 1.257 & 1 & 5 & 4 & .625 \\
\hline Q23 & 3.84 & 1.076 & 1 & 5 & 4 & .590 \\
\hline Q26 & 3.18 & 1.395 & 1 & 5 & 4 & .602 \\
\hline Q27 & 3.64 & 1.225 & 1 & 5 & 4 & .661 \\
\hline Q29 & 4.10 & 1.200 & 1 & 5 & 4 & .599 \\
\hline Q30 & 3.54 & 1.328 & 1 & 5 & 4 & .607 \\
\hline Composite & 3.49 & .464 & 1 & 4.94 & 3.94 & $.640^{\mathrm{a}}$ \\
\hline
\end{tabular}

Note . Min $=$ Minimum; Max $=$ Maximum; $\mathrm{R}=$ Range; $\alpha-\mathrm{d}=$ alpha with item deleted.

avalue for composite for $\alpha-\mathrm{d}$ is Cronbach's coefficient alpha for overall scale. 
The psychometric analysis of the second Self-efficacy subscale (Social, with 6 items) is given in Table 8. Again, the values for the scale composite are adequate $(M=$ 3.48; $S D=.657)$. However, the internal reliability analysis demonstrates that this subscale as validated by the authors does not have adequate consistency as a measure of Social Selfefficacy for these students with mild disabilities. The overall Cronbach's coefficient alpha is very low (.461). However, reliability would be increased to .589 if Q14 were deleted. That would bring the scale almost to the minimum acceptable level of .6 suggested by Nunnally and Bernstein (1994) for exploratory research. Thus, subsequent calculations were based on the Cronbach alpha of .589 from five items rather than the original six. The mean and standard deviation for the new composite are 3.57 and .760 , respectively.

Table 8

Psychometric Analysis for Self-efficacy (Social) Scale $(N=50)$

\begin{tabular}{lcccccc}
\hline Item & $M$ & $S D$ & Min & Max & $\mathrm{R}$ & $\alpha-\mathrm{d}$ \\
\hline Q6 & 3.76 & 1.519 & 1 & 5 & 4 & .372 \\
Q10 & 3.36 & 1.242 & 1 & 5 & 4 & .364 \\
Q14 & 3.04 & 1.385 & 1 & 5 & 4 & .589 \\
Q19 & 3.52 & 1.093 & 1 & 5 & 4 & .384 \\
Q24 & 3.40 & 1.278 & 1 & 5 & 4 & .425 \\
Q28 & 3.82 & .983 & 1 & 5 & 4 & .313 \\
Composite & 3.48 & .657 & 1 & 5 & 4 & $.461^{\mathrm{a}}$ \\
& \multicolumn{7}{l}{ Note. Min = Minimum; Max = Maximum; $\mathrm{R}=$ Range; $\alpha-\mathrm{d}=$ alpha with item deleted. } \\
alue for composite $\alpha-\mathrm{d}$ is Cronbach's coefficient alpha for overall scale.
\end{tabular}


The final Mediating Factor, the Locus of Control Scale (Nowicki \& Strickland, 1973), had 40 items, scored on a YES, NO basis. After reverse scoring, high scores (more YES answers) indicate an external locus of control. Table 9 presents the reliability analysis and descriptive statistics for the 40 items, with NO coded 0 and YES coded 1. The composite indicates that the respondents had an overall external motivational orientation of $39 \%$ YES answers. Among the 40 items, Q38 received the most external orientation (80\%) while Q4 was the most internal (only 6\% answered YES). The overall Cronbach's coefficient alpha of .719 was just above the minimal acceptable level for internal scale reliability. It should be remembered that Cronbach's coefficient alpha and the KuderRichardson 20 procedure for dichotomous responses are equivalent. 
Table 9

Psychometric Analysis for Locus of Control Scale $(N=50)$

\begin{tabular}{|c|c|c|c|c|c|c|}
\hline Item & $M$ & $S D$ & Min & Max & $\mathrm{R}$ & $\alpha-d$ \\
\hline Q1 & .29 & .452 & 0 & 1 & 1 & .707 \\
\hline Q2 & .72 & .454 & 0 & 1 & 1 & .721 \\
\hline Q3 & .60 & .484 & 0 & 1 & 1 & .707 \\
\hline Q4 & .06 & .240 & 0 & 1 & 1 & .716 \\
\hline Q5 & .64 & .485 & 0 & 1 & 1 & .703 \\
\hline Q6 & .10 & .303 & 0 & 1 & 1 & .713 \\
\hline Q7 & .28 & .454 & 0 & 1 & 1 & .708 \\
\hline Q8 & .38 & .476 & 0 & 1 & 1 & .732 \\
\hline Q9 & .49 & .500 & 0 & 1 & 1 & .712 \\
\hline Q10 & .48 & .494 & 0 & 1 & 1 & .722 \\
\hline Q11 & .52 & .484 & 0 & 1 & 1 & .709 \\
\hline Q12 & .50 & .505 & 0 & 1 & 1 & .706 \\
\hline Q13 & .29 & .452 & 0 & 1 & 1 & .721 \\
\hline Q14 & .48 & .494 & 0 & 1 & 1 & .711 \\
\hline Q15 & .20 & .404 & 0 & 1 & 1 & .715 \\
\hline Q16 & .37 & .482 & 0 & 1 & 1 & .705 \\
\hline Q17 & .42 & .499 & 0 & 1 & 1 & .712 \\
\hline Q18 & .37 & .482 & 0 & 1 & 1 & .719 \\
\hline Q19 & .44 & .491 & 0 & 1 & 1 & .707 \\
\hline
\end{tabular}


Table 9. (continued)

\begin{tabular}{lllllll}
\hline Item & $M$ & $S D$ & Min & Max & $\mathrm{R}$ & $\alpha-\mathrm{d}$ \\
\hline Q20 & .18 & .388 & 0 & 1 & 1 & .721 \\
Q21 & .56 & .501 & 0 & 1 & 1 & .702 \\
Q22 & .22 & .419 & 0 & 1 & 1 & .719 \\
Q23 & .32 & .457 & 0 & 1 & 1 & .714 \\
Q24 & .57 & .495 & 0 & 1 & 1 & .709 \\
Q25 & .35 & .476 & 0 & 1 & 1 & .720 \\
Q26 & .14 & .350 & 0 & 1 & 1 & .714 \\
Q27 & .50 & .495 & 0 & 1 & 1 & .709 \\
Q28 & .31 & .461 & 0 & 1 & 1 & .717 \\
Q29 & .51 & .500 & 0 & 1 & 1 & .706 \\
Q30 & .33 & .469 & 0 & 1 & 1 & .726 \\
Q31 & .48 & .594 & 0 & 1 & 1 & .719 \\
Q32 & .23 & .417 & 0 & 1 & 1 & .717 \\
Q33 & .35 & .476 & 0 & 1 & 1 & .719 \\
Q34 & .63 & .479 & 0 & 1 & 1 & .713 \\
Q35 & .31 & .460 & 0 & 1 & 1 & .705 \\
Q36 & .45 & .497 & 0 & 1 & 1 & .714 \\
Q37 & .12 & .328 & 0 & 1 & 1 & .711 \\
\hline & .80 & .404 & 0 & 1 & 1 & .732 \\
\hline & .487 & 0 & 1 & 1 & .709 \\
\hline & & & & & $($ table continues)
\end{tabular}


Table 9. (continued)

\begin{tabular}{lcccccc}
\hline Item & $M$ & $S D$ & Min & Max & $\mathrm{R}$ & $\alpha-\mathrm{d}$ \\
\hline Q40 & .11 & .302 & 0 & 1 & 1 & .717 \\
Composite & .39 & .464 & 0 & 1 & 1 & $.719^{\mathrm{a}}$ \\
\hline
\end{tabular}

Note. Min $=$ Minimum; Max $=$ Maximum $; \mathrm{R}=$ Range $; \alpha-\mathrm{d}=$ alpha with item deleted.

avalue for composite for $\alpha-d$ is Cronbach's coefficient alpha for overall scale.

\section{Research Questions}

Seven empirical questions guided this research. The specific variables and types of statistical calculations used for each research question are described in Chapter III. The findings are reported by Research Question; the specific type of analysis for each RQ was specified in Chapter III and is addressed under each.

In general, Research Question 1 reports on information required by IDEA legislation regarding transition. Research Question 2 indicates how students fared in Transition Outcomes according to the STEP Grant criteria. Research Questions 3-6 explore relationships between Independent and Dependent Variables to see if one or more factors influence transition choices and outcomes. Research Question 7 examines qualitative data volunteered by the students to add their perceptions about the STEP Grant. The variables were considered in the order hypothesized by Figure 1.

\section{Research Question 1}

With respect to transition planning:

1.a. How many of the students in the STEP Student Follow-up Survey have a completed Transition Plan on file in the school district archives?

A records review of permanent files in school district archives showed that all 
STEP Grant participants had an IEP on file, but only 34 of the $50(68 \%)$ had a Transition Plan on file as required by IDEA 1997 legislation (See Table 10). Of those, only one student (2\%) had Career Goals listed for all five years (grades 8-12) and an additional 16 $(32 \%)$ had Career Goals for three or four years, yielding a total of $17(34 \%)$ of the students who had Transition Plans with "completed" Career Goals as counted for purposes of this research. Among those who had a Transition Plan on file, six students (12\%) had no Career Goals listed.

Table 10

Evaluation of Individual Education Plan and Transition Plans $(N=50)$

\begin{tabular}{lcc} 
Status & $f$ & $P$ \\
\hline Individual Education Plan & 50 & 68 \\
Transition Plan & 34 & 32 \\
No Transition Plan & 16 & 56 \\
Career Goals Listed & 28 & $(2)$ \\
5 years & $(1)$ & $(32)$ \\
3-4 years & $(16)$ & $(22)$ \\
1-2 years & $(11)$ & 12 \\
No Career Goals & 6 & \\
\hline Note. Sub-categories $n s$ under Career Goals are in parenthesis and use the latest goal on the \\
Transition Plan.
\end{tabular}

1.b. Did the student's career goal listed on the Transition Plan match the area of enrollment in vocational training?

1.c. Did the student's career goal listed on the Transition Plan match the first job 
after high school as reported on the Student Follow-up Survey?

1.d. Did the student's career goal listed on the Transition Plan match the postsecondary education major enrolled in at the time of the Student Follow-up Survey?

1.e. How many students had a match between the Transition Planning Goal, vocational education enrollment, and job held and/or postsecondary education major at the time of the Student Follow-up Survey?

Table 11 addresses the consistency of actual transition outcomes and specific areas of transition planning as represented in RQs 1.b-1.e. In general, these students did not follow career paths as charted in their IEP Transition Plans. Based upon the researcher's inspection of each student's Transition Plan, four (14.3\%) of the 28 students with Career Goals on file had a match between their listed career goal and their vocational enrollment during high school. Only one student (3.6\%) had a match between the Career Goal on the Transition Plan, Vocational Training in high school, and the job reported on the STEP Student Follow-up Survey. No students $(0 \%)$ had a match between their Career Goal and their Postsecondary Enrollment; thus, no students ( $0 \%$ ) had a match between all three factors: Career Goals, Vocational Training, and either one of the Transition Outcomes (Employment or Postsecondary Enrollment). 
Table 11

Consistency of Transition Plan Goals and Transition Outcomes $(N=28)$

\begin{tabular}{lcc}
\hline \multicolumn{1}{c}{ Transition Outcome } & Match & Percentage \\
\hline Vocational training classes & 4 & 14.3 \\
Job reported on STEP Survey & 1 & 3.6 \\
Postsecondary major & 0 & 0 \\
All three areas & 0 & 0 \\
\hline
\end{tabular}

Note. The Transition Plan Goals in the IEP were compared to the actual transition outcomes on a student-by-student basis.

Table 12 displays the variety of choices made during and following high school. The student career choices are displayed in the 14 career clusters taken from the Kentucky Department of Education (2002) Individual Learning Plan Document designed for planning transition. Table 12 lists Career Goals $(N=28)$ in column one, Vocational Education $(N=47)$ in column two, and the Job reported on the Follow-up Survey $(N=46)$ in column three. Three clusters (Manufacturing, Science/Mathematics, and Social Sciences) have no student goals, vocational training, or job placements. Three clusters have no student goals, but 15 students participated in vocational training in those areas (Agriculture, 2; Business/Marketing, 11; Communication, 2); however, only two jobs were obtained in one of them (Agriculture). Four clusters had goals and related vocational training, but no jobs obtained in them: Public Services (8 goals, 3 in training); Health Services ( 2 goals, 3 in training); Information Technology (2 goals, 11 in training); and Arts and Humanities (3 goals, 8 in training). Two students had career goals in Education and 
two in Transportation; although there was no vocational participation in those clusters, one student did secure a job as a driver and car cleanup person. Construction and Human Services both had goals, training in jobs, and jobs. The top area for students' jobs (42 or 91.3\%) was Human Services (predominantly low skill/service-oriented jobs, mainly in restaurants, groceries, and cleaning) while only six of them chose that area and only one received vocational training for that career cluster. 
Table 12

Career Goals, Vocational Training, and Jobs Among STEP Grant Participants

\begin{tabular}{|c|c|c|c|c|c|c|}
\hline \multirow[b]{2}{*}{ Career Clusters } & \multicolumn{2}{|c|}{ Career Goals $^{\mathrm{a}}$} & \multicolumn{2}{|c|}{$\underline{\text { Vocational Training }^{\mathrm{b}}}$} & \multicolumn{2}{|c|}{ Jobs $^{\mathrm{c}}$} \\
\hline & $f$ & $P$ & $f$ & $P$ & $f$ & $P$ \\
\hline Agriculture & 0 & 0 & 2 & 4.26 & 2 & 4.35 \\
\hline Veterinarian & & & (2) & $(4.26)$ & & \\
\hline Cut tobacco & & & & & (1) & $(2.17)$ \\
\hline Plants/Nursery & & & & & (1) & $(2.17)$ \\
\hline Arts and Humanities & 3 & 10.71 & 8 & 17.02 & 0 & 0 \\
\hline Artist & $(2)$ & $(7.14)$ & (2) & $(4.26)$ & & \\
\hline Librarian & (1) & $(3.57)$ & & & & \\
\hline Interior Design & & & (3) & $(6.38)$ & & \\
\hline Graphic Design & & & (2) & $(4.26)$ & & \\
\hline Photography & & & (1) & $(2.13)$ & & \\
\hline Business \& Marketing & 0 & 0 & 11 & 23.40 & 0 & 0 \\
\hline Business Recordkeeping & & & (5) & $(10.64)$ & & \\
\hline Business Management & & & (1) & $(2.13)$ & & \\
\hline Legal Office & & & (3) & $(6.38)$ & & \\
\hline Medical Office & & & (1) & $(2.13)$ & & \\
\hline Marketing & & & (1) & $(2.13)$ & & \\
\hline
\end{tabular}


Table 12. (continued)

\begin{tabular}{|c|c|c|c|c|c|c|}
\hline \multirow[b]{2}{*}{ Career Clusters } & \multicolumn{2}{|c|}{$\underline{\text { Career Goals }^{\mathrm{a}}}$} & \multicolumn{2}{|c|}{$\underline{\text { Vocational Training }}^{\mathrm{b}}$} & \multicolumn{2}{|c|}{$\mathrm{Jobs}^{\mathrm{c}}$} \\
\hline & $f$ & $P$ & $f$ & $P$ & $f$ & $P$ \\
\hline Communications & 0 & 0 & 2 & 4.26 & 0 & 0 \\
\hline Radio-Electronics & & & (2) & $(4.26)$ & & \\
\hline Construction & 3 & 10.71 & 6 & 12.76 & 1 & 2.17 \\
\hline Construction Trades & (1) & $(3.57)$ & (3) & $(6.38)$ & & \\
\hline Electrician & (1) & $(3.57)$ & (2) & $(4.26)$ & & \\
\hline Welding & (1) & $(3.57)$ & & & (1) & $(2.17)$ \\
\hline Building Maintenance & & & (1) & $(2.13)$ & & \\
\hline Education & 2 & 7.14 & 0 & 0 & 0 & 0 \\
\hline Teacher & (2) & $(7.14)$ & & & & \\
\hline Health Science & 2 & 7.14 & 3 & 6.38 & 0 & 0 \\
\hline Registered Nurse & (1) & $(3.57)$ & & & & \\
\hline EMT & (1) & $(3.57)$ & (1) & (2).13 & & \\
\hline Respiratory Therapy & & & (1) & $(2.13)$ & & \\
\hline Dental Hygiene & & & (1) & $(2.13)$ & & \\
\hline Human Services & 6 & 21.43 & 1 & 2.13 & 42 & 91.30 \\
\hline Cosmetology & (2) & $(7.14)$ & & & & \\
\hline Cashier & (1) & $(3.57)$ & & & (3) & $(6.52)$ \\
\hline Grocery & (1) & $(3.57)$ & & & (1) & $(2.17)$ \\
\hline Child care & (2) & (7.14) & & & (1) & $(2.17)$ \\
\hline
\end{tabular}


Table 12. (continued)

\begin{tabular}{|c|c|c|c|c|c|}
\hline \multirow[b]{2}{*}{ Career Clusters } & $\underline{\text { Career Goals }}^{\mathrm{a}}$ & \multicolumn{2}{|c|}{ Vocational Training $^{b}$} & \multicolumn{2}{|c|}{ Jobs $^{\mathrm{c}}$} \\
\hline & $f \quad P$ & $f$ & $P$ & $f$ & $P$ \\
\hline Clothing/Textiles & & (1) & $(2.13)$ & & \\
\hline Cook & & & & (1) & $(2.17)$ \\
\hline Dishwasher & & & & $(1)$ & $(2.17)$ \\
\hline Fast Foods & & & & (3) & $(6.52)$ \\
\hline Food Service & & & & $(3)$ & $(6.52)$ \\
\hline Hostess/Waiter/Waitress & & & & $(4)$ & $(8.70)$ \\
\hline Restaurant & & & & $(2)$ & $(4.35)$ \\
\hline Server & & & & $(1)$ & $(2.17)$ \\
\hline Bagger & & & & $(4)$ & $(8.70)$ \\
\hline Sales & & & & (1) & $(2.17)$ \\
\hline Stocker & & & & (1) & $(2.17)$ \\
\hline Boat Repair & & & & $(1)$ & $(2.17)$ \\
\hline Cleanup & & & & $(3)$ & $(6.52)$ \\
\hline Custodial & & & & $(1)$ & $(2.17)$ \\
\hline Driver/Cleaning & & & & $(1)$ & $(2.17)$ \\
\hline Housekeeper & & & & $(1)$ & $(2.17)$ \\
\hline Maintenance/Secretary & & & & $(1)$ & $(2.17)$ \\
\hline Babysitting & & & & (1) & $(2.17)$ \\
\hline Camp Counselor & & & & (1) & $(2.17)$ \\
\hline
\end{tabular}


Table 12. (continued)

\begin{tabular}{|c|c|c|c|c|c|c|}
\hline \multirow[b]{2}{*}{ Career Clusters } & \multicolumn{2}{|c|}{$\underline{\text { Career Goals }}^{\mathrm{a}}$} & \multicolumn{2}{|c|}{$\underline{\text { Vocational Training }}^{\mathrm{b}}$} & \multicolumn{2}{|c|}{ Jobs $^{\mathrm{c}}$} \\
\hline & $f$ & $P$ & $f$ & $P$ & $f$ & $P$ \\
\hline Homemaker/Pregnant & & & & & $(1)$ & $(2.17)$ \\
\hline Lifeguard & & & & & (1) & $(2.17)$ \\
\hline Attendant Tanning Salor & & & & & (1) & $(2.17)$ \\
\hline Packing UPS & & & & & $(1)$ & $(2.17)$ \\
\hline Phones & & & & & $(1)$ & $(2.17)$ \\
\hline Ride operator & & & & & $(1)$ & $(2.17)$ \\
\hline Information Technology & 2 & 7.14 & 11 & 23.40 & 0 & 0 \\
\hline Computer Technology & (2) & $(7.14)$ & (4) & $(8.51)$ & & \\
\hline Data Entry/Keyboarding & & & (7) & $(14.89)$ & & \\
\hline Manufacturing & 0 & 0 & 0 & 0 & 0 & 0 \\
\hline Public Services & 8 & 28.57 & 3 & 6.38 & 0 & 0 \\
\hline Military & (2) & $(7.14)$ & & & & \\
\hline Police & (4) & $(14.29)$ & & & & \\
\hline Lawyer & (2) & (7.14) & & & & \\
\hline ROTC & & & (1) & $(2.13)$ & & \\
\hline Law Enforcement & & & (1) & $(2.13)$ & & \\
\hline Public Safety & & & (1) & $(2.13)$ & & \\
\hline Science \& Mathematics & 0 & 0 & 0 & 0 & 0 & 0 \\
\hline Social Sciences & 0 & 0 & 0 & 0 & 0 & 0 \\
\hline
\end{tabular}


Table 12. (continued)

\begin{tabular}{|c|c|c|c|c|c|c|}
\hline \multirow[b]{2}{*}{ Career Clusters } & \multicolumn{2}{|c|}{$\underline{\text { Career Goals }^{\mathrm{a}}}$} & \multicolumn{2}{|c|}{$\underline{\text { Vocational Training }}^{\mathrm{b}}$} & \multicolumn{2}{|c|}{$\mathrm{Jobs}^{\mathrm{c}}$} \\
\hline & $f$ & $P$ & $f$ & $P$ & $f$ & $P$ \\
\hline Transportation & 2 & 7.14 & 0 & 0 & 1 & 2.17 \\
\hline Pilot & (1) & $(3.57)$ & & & & \\
\hline Auto body & (1) & $(3.57)$ & & & & \\
\hline Transmission & & & & & (1) & $(2.17)$ \\
\hline Total & 28 & $100^{\mathrm{d}}$ & 47 & $100^{\mathrm{d}}$ & 46 & $100^{\mathrm{d}}$ \\
\hline \multicolumn{7}{|c|}{ Note. Percentages calculated for the 14 Career Clusters from KDE. Specific occupations } \\
\hline \multicolumn{7}{|c|}{ under a cluster are the labels given by the participants on the Follow-up Survey and are } \\
\hline \multicolumn{7}{|c|}{ noted in parenthesis. } \\
\hline \multicolumn{7}{|c|}{${ }^{\mathrm{a} C a r e e r}$ Goals were stated by students on the Individual Graduation Plans. Only 28 of 50} \\
\hline \multicolumn{7}{|c|}{ had completed Transition Plans on file. } \\
\hline \multicolumn{7}{|c|}{${ }^{\mathrm{b}}$ Vocational Training is listed for the 47 participants who had records available in the JCPS } \\
\hline \multicolumn{7}{|l|}{ database. } \\
\hline${ }^{\mathrm{c}} \mathrm{Jobs}$ for 46 part & state & n the STI & udent & ow-up Sur & & \\
\hline
\end{tabular}

\section{Research Question 2}

What proportion of the students had completed transition (met criterion for success specified in the STEP Grant) at the time of the Student Follow-up Survey in:
a. Employment?
b. Postsecondary Education?
c. Independent Living? 
Outcomes for successful transition to adult life as specified by STEP Grant criteria are displayed in Table 13. For employment, the first job following high school was utilized for this research. Only one of the three transition areas had to be met to be counted as successful according to the STEP Grant application (Benz et al., 1997; Simmons, 1996). Criteria are noted at the bottom of the table. Results were tabulated for all areas and were cross-checked for each participant to be measured on the overall success for the STEP Grant. The four unsuccessful students (one MMD and three LD) were not working, nor were they enrolled in postsecondary education; they were living with friends or family and not paying rent at the time of the survey.

Employment success was obtained by 34 out of 46 (73.9\%) who were employed between 20-40 hours per week. Twelve participants demonstrated postsecondary success by enrolling for any number of hours of vocational training or higher education since high school. For Independent Living, 46 of $50(92 \%)$ were paying rent or buying their condo/house. Table 13 presents this information for each of the three transition outcomes. Overall success according to STEP criteria was achieved for 46 of the 50 participants $(92 \%)$ 
Table 13

Attainment of STEP Grant Criteria for Success $(N=50)$

\begin{tabular}{|c|c|c|c|c|c|c|c|c|}
\hline \multirow[b]{2}{*}{ Status } & \multicolumn{2}{|c|}{ Employment $^{\mathrm{a}}$} & \multicolumn{2}{|c|}{$\underline{\text { Postsecondary Education }}^{\text {b }}$} & \multicolumn{2}{|c|}{$\underline{\text { Independent Living }}^{\mathrm{c}}$} & \multicolumn{2}{|c|}{ STEP Grant $^{\mathrm{d}}$} \\
\hline & $f$ & $P$ & $f$ & $P$ & $f$ & $P$ & $f$ & $P$ \\
\hline Successful & 34 & 73.9 & 12 & 100 & 46 & 92 & 46 & 92 \\
\hline Unsuccessful & 12 & 26.1 & 0 & 0 & 4 & 8 & 4 & 8 \\
\hline Total & 46 & 100.0 & 12 & 100 & 50 & 100 & 50 & 100 \\
\hline
\end{tabular}

${ }^{\mathrm{a}} N=46$ for Employment; 20-40 Hours per week was criterion for success in job reported on the Follow-up study.

${ }^{\mathrm{b}} N=12$ for Postsecondary Education; enrollment in any technical training or post secondary education was criterion for success.

${ }^{\mathrm{c}} N=50$ for Independent Living; criterion for success included the following: live alone, with friends or spouse, or pay rent to family.

${ }^{\mathrm{d}}$ Only one of the three transition areas had to be achieved for a student to be successful under the STEP Grant criteria. 


\section{Research Question 3}

RQ3 represents the relationships between Demographic factors and (a) STEP Grant Intervention Factors, (b) Mediating Factors, and (c) Transition Outcomes in Employment (Hours and Wages). The Demographic Factors are divided into two blocks--Personal Identity (ETHN, GEN, and DIS) and Educational History (VSEM, GPA, and VGPA).

3. To what extent are demographic factors related to:

a. Participation in the STEP Grant:

i. School Attended?

School attended is the first of the STEP Grant Intervention factors. Descriptive statistics for the first three Demographic Factors (Personal Identity--Ethnicity, Gender, and Disability), as broken down by school attended, are shown in Table 14. Frequencies and percentages are reported. Totals for the variables are summed within the categories (e.g., columns under Black and White sum to 50 participants). The values for the Total row are consistent with the figures in Table 1 . Numbers of participants $(N=108)$ were originally consistent at all the participating schools (approximately 18), but only those with completed consent forms and surveys were included in this research, resulting in the uneven numbers across the six schools. For White (the reciprocal holds for Black), School C had the largest attendance $(n=10)$ while School A had only two. For gender, the range for Male was from School B (7) to Schools A and E (3). For both MMD and BD, there were only five students with these two disabilities across the six schools. For LD, School B had 11 and School F had the least with three. 
Table 14

Descriptive Statistics for Personal Identity by School Attended $(N=50)$

\begin{tabular}{|c|c|c|c|c|c|c|c|c|c|c|c|c|c|c|c|}
\hline \multirow[b]{3}{*}{ School } & \multirow[b]{3}{*}{$N$} & \multicolumn{4}{|c|}{ Ethnicity } & \multicolumn{4}{|c|}{ Gender } & \multicolumn{6}{|c|}{ Disability } \\
\hline & & \multicolumn{2}{|c|}{ Black } & \multicolumn{2}{|c|}{ White } & \multicolumn{2}{|c|}{ Female } & \multicolumn{2}{|c|}{ Male } & \multicolumn{2}{|c|}{ MMD } & \multicolumn{2}{|c|}{$\mathrm{BD}$} & \multicolumn{2}{|c|}{ LD } \\
\hline & & $f$ & $P$ & $f$ & $P$ & $f$ & $P$ & $f$ & $P$ & $f$ & $P$ & $f$ & $P$ & $f$ & $P$ \\
\hline A & 4 & 2 & 4 & 2 & 4 & 1 & 2 & 3 & 6 & 0 & 0 & 0 & 0 & 4 & 8 \\
\hline $\mathrm{C}$ & 10 & 0 & 0 & 10 & 20 & 6 & 12 & 4 & 8 & 0 & 0 & 1 & 2 & 9 & 18 \\
\hline D & 7 & 1 & 2 & 6 & 12 & 2 & 4 & 5 & 10 & 0 & 0 & 1 & 2 & 6 & 12 \\
\hline $\mathrm{E}$ & 10 & 5 & 10 & 5 & 10 & 7 & 14 & 3 & 6 & 2 & 4 & 1 & 2 & 7 & 14 \\
\hline
\end{tabular}

Note. $\mathrm{MMD}=$ mild mental disability; $\mathrm{BD}=$ behavior disability; $\mathrm{LD}=$ learning disability. 
To determine whether these disaggregated nominal measures were associated with school attended, a series of five separate chi-square procedures were computed with subgroup $n$ s for Ethnicity (White), Gender (Male), Mild Mental Disabilities, Behavior Disabilities, and Learning Disabilities as dependent variables. For White, the relationship was not significant, $\chi^{2}=(5, N=6)=10.93, p=.072$. Next, Male was calculated and was found to be not significant, $\chi^{2}=(5, N=6)=4.957, p=.065$. Final chi-square calculations for the three disabilities were done separately by school: for MMD, $\chi^{2}=(5, N=6)=7.15$, $p=.018$; for BD, $\chi^{2}=(5, N=6)=.961, p=.087$; and for $\mathrm{LD}, \chi^{2}=(5, N=6)=5.941, p=$ .011. Thus, across these five different chi-square calculations, only MMD and LD disabilities were significant, i.e., unevenly distributed across these six schools.

The second section of Demographics, Educational History, includes Semesters of Vocational Education (VSEM) attended by participants while they were in high school, their Grade Point Average (GPA), and Vocational class Grade Point Average (VGPA). Obtained from the JCPS Research Office database, the descriptive statistics, disaggregated by school attended, are presented in Table 15. For Vocational Semesters attended, the means for the schools indicate there was a minimum of one vocational class per semester with individuals ranging from 4 for School B to 20 for School C over the four years of high school (figures include the STEP Grant Elective class which was counted as one credit per semester). The GPA was highest at School F $(M=2.9, S D=.419)$ and lowest at school E $(M=1.97, S D=.447)$ on a 4-point grading scale. For each school vocational grades were slightly higher than regular GPA, but School F was still highest $(M=3.17, S D$ $=.679)$ and School $\mathrm{E}$ was still lowest of the six schools $(M=2.21, S D=.564)$.

To determine whether these disaggregated results (Table 15) were associated with the school attended, one-way ANOVAs were calculated with VSEM, GPA, and VGPA as 
dependent variables. For Semesters of Vocational Education, the equation was $F(5,44)=$ $2.78, p=.137$ which was not significant. However, the ANOVA for Grade Point Average was significant, $F(5,44)=2.77, p=.029$. The Games-Howell post-hoc comparison demonstrated that School F scored lower than both School B and School E, $p=.047$ and $p=.017$, respectively. Similarly, the analysis of variance for Vocational Grade Point Average was significant with $F(5,44)=2.53, p=.043$. Although the overall equation was significant (barely beyond $.05 \alpha$ level), the Games-Howell post hoc comparison for VGPA indicated that none of the separate school-by-school contrasts were significant, a result likely because of the conservative criteria inherent in the Games-Howell post hoc test. The contrast between school E and School F came the closest to being significant at $p=.122$. 
Table 15

Descriptive Statistics for Educational History by School Attended $(N=50)$

\begin{tabular}{lcccccc}
\hline School & $n$ & $M$ & SD & Min & Max & R \\
\hline \multicolumn{7}{c}{ Vocational Semesters } \\
A & 4 & 11.000 & 1.414 & 10 & 13 & 3 \\
B & 13 & 10.146 & 3.521 & 4 & 16 & 12 \\
C & 10 & 12.800 & 3.425 & 10 & 20 & 10 \\
D & 7 & 8.857 & 3.848 & 6 & 16 & 11 \\
E & 10 & 11.900 & 3.665 & 6 & 17 & 9 \\
F & 6 & 13.333 & 3.882 & 8 & 17 & \\
\hline
\end{tabular}

Grade Point Average

\begin{tabular}{lrrrrrr} 
A & 4 & 2.408 & .783 & 1.59 & 3.15 & 1.56 \\
B & 13 & 2.155 & .386 & 1.33 & 2.80 & 1.47 \\
C & 10 & 2.643 & .730 & 1.73 & 3.89 & 2.16 \\
D & 7 & 2.409 & .722 & 1.67 & 3.50 & 1.83 \\
E & 10 & 1.973 & .447 & 1.29 & 2.81 & 1.52 \\
F & 6 & 2.877 & .419 & 2.45 & 3.40 & .95 \\
\hline
\end{tabular}

Vocational Grade Point Average

$\begin{array}{lrrrrrr}\text { A } & 4 & 2.593 & .664 & 1.88 & 3.36 & 1.48 \\ \text { B } & 13 & 2.257 & .602 & 1.33 & 3.43 & 2.10 \\ \text { C } & 10 & 2.916 & .765 & 1.65 & 3.89 & 2.24\end{array}$

(table continues) 
Table 15. (continued)

\begin{tabular}{lrlrrll}
\hline School & $n$ & $M$ & \multicolumn{1}{l}{ SD } & Min & Max & \multicolumn{2}{l}{ R } \\
\hline $\mathrm{D}$ & 7 & 2.721 & .921 & 1.00 & 3.50 & 2.50 \\
$\mathrm{E}$ & 10 & 2.210 & .564 & .83 & 2.71 & 1.88 \\
$\mathrm{~F}$ & 6 & 3.172 & .679 & 2.00 & 3.89 & 1.89 \\
\hline
\end{tabular}

Note. Min $=$ Minimum; Max $=$ Maximum; $\mathrm{R}=$ Range.

3.a. Participation in the STEP Grant:

ii. Year Enrolled?

iii. Days Enrolled?

iv. Attendance?

v. Self-Improvement?

Table 16 presents the matrix of the Pearson $r$ correlations between Demographic Factors and last four of the STEP Grant Intervention Factors (YEAR, DAYS, \%ATT, and SIMP) to answer the remaining subparts of RQ3.a. Among the six demographic variables, only GPA and VGPA have a significant relationship $(r=.758)$. Five of the relationships between the Demographic measures and STEP Grant Intervention variables were significant; notably four of the five have to do with vocational education (Semesters of Vocational Education with the Year Enrolled and the Self-Improvement scale; VGPA with Days Attended and Percent Attendance). Two of the correlations between the STEP Intervention Factors were significant (YEAR with DAYS and DAYS with \%ATT). With the exception of the positive GPA-VGPA relationship, none of the correlations were very strong. 
Table 16

Correlations between Demographic Factors and STEP Grant Interventions $(N=50)$

\begin{tabular}{|c|c|c|c|c|c|c|c|c|c|c|}
\hline Variable & ETHN & GEN & DIS & VSEM & GPA & VGPA & YEAR & DAYS & $\%$ ATT & SIMP \\
\hline ETHN & -- & -.165 & -.190 & .081 & .241 & .264 & .031 & -.016 & .133 & .102 \\
\hline GEN & & -- & .113 & -.145 & .135 & .177 & .244 & .221 & .239 & -.243 \\
\hline DIS & & & -- & -.010 & -.021 & -.100 & -.067 & -.116 & -.002 & .069 \\
\hline VSEM & & & & -- & .108 & .138 & $.300 *$ & .222 & -.007 & $.391 * *$ \\
\hline GPA & & & & & -- & $.758 * *$ & .160 & .278 & $.337 *$ & -.146 \\
\hline VGPA & & & & & & -- & .148 & $.310 *$ & $.329 *$ & -.106 \\
\hline YEAR & & & & & & & -- & $.311 *$ & .155 & -.112 \\
\hline DAYS & & & & & & & & -- & $.393 * *$ & -.060 \\
\hline$\%$ ATT & & & & & & & & & -- & -.203 \\
\hline SIMP & & & & & & & & & & -- \\
\hline
\end{tabular}

${ }^{*} p<.05 .{ }^{* *} p<.01$. 


\section{3.b. Mediating personality factors:}

i. Self-efficacy scores?

ii. Locus of Control scores?

Table 17 presents the Pearson $r$ correlations between Demographic Factors and Mediating Factors (personality tests for Self-efficacy-General, Self-efficacy-Social, and Locus of Control). (Correlations for Transition Outcomes in Employment are also part of this table but are addressed under sub-question 3.c., below.) The relationships among the demographic factors for Table 17 are identical to those on Table 16 (those factors are repeated here). As would be expected, there is a strong positive relationship between SGEN and SSOC $(r=.535)$. Self-efficacy General has a negative relationship with Locus of Control ( $r=-.323)$, explained by the direction of scoring for the Locus of Control test where higher scores indicate an external perception by the participants. None of the relationships among the three personality tests and the demographic variables reach significance. 
Table 17

Correlations between Demographic Factors, Mediating Factors, and Transition Outcomes in Employment $(N=50)$

\begin{tabular}{|c|c|c|c|c|c|c|c|c|c|c|c|}
\hline Variable & ETHN & GEN & DIS & VSEM & GPA & VGPA & SGEN & SSOC & LOC & HOUR & WAGE \\
\hline ETHN & -- & -.165 & -.190 & .081 & .241 & .264 & .114 & -.208 & -.176 & -.180 & .071 \\
\hline GEN & & -- & .113 & -.145 & .135 & .177 & .267 & .103 & -.075 & .015 & .110 \\
\hline DIS & & & -- & -.010 & -.021 & -.100 & .226 & .248 & -.009 & -.023 & $-.487 * *$ \\
\hline VSEM & & & & -- & .108 & .138 & -.241 & -.060 & .053 & .111 & .135 \\
\hline GPA & & & & & -- & $.758 * *$ & .259 & .139 & -.145 & -.103 & .143 \\
\hline VGPA & & & & & & -- & .234 & .213 & -.226 & -.048 & .111 \\
\hline SGEN & & & & & & & -- & $.535 * *$ & $-.323^{*}$ & -.119 & -.157 \\
\hline SSOC & & & & & & & & -- & -.236 & -.046 & -.053 \\
\hline LOC & & & & & & & & & -- & -.026 & -.082 \\
\hline HOUR & & & & & & & & & & -- & .226 \\
\hline WAGE & & & & & & & & & & & -- \\
\hline
\end{tabular}


3.c. Transition in Employment reported on the Student Follow-up Survey?

Table 17 also displays the relationship between Demographic Factors and Transition Outcomes for Hours and Wages. Again, the relationships among the Demographic Factors are the same as reported in Table 16 (repeated here). The only significant relationship found was between Disability and Wages earned from the first job after high school, $r=-.487, p<.01$.

\section{Research Question 4}

To what extent is participation in the STEP Grant

a. School Attended

related to:

a. Mediating personality factors:

i. Self-efficacy scores?

ii. Locus of Control scores?

b. Transition in Employment reported on the Student Follow-up Survey?

School Attended represents nominal measurement. The scores for the Mediating

Factors as disaggregated by the six schools in the STEP Grant are displayed in Table 18.

To determine if these outcomes are related to the school where the STEP Grant was

conducted, three one-way ANOVAs were calculated with the two Self-efficacy scales and the Locus of Control test as dependent variables. None of these were significant at the $p<.05$ level of significance, per the ANOVA outcomes. For Self-efficacy-General, F(5, $44)=1.979, p=.101$. Even higher $p$ values were found for Self-efficacy-Social, $F(5,44)=$ $1.146, p=.351$, and the final personality variable, Locus of Control, $F(5,44)=.461, p=$ .803 . 
Table 18

Descriptive Statistics for Mediating Factors by School Attended $(N=50)$

\begin{tabular}{lcccccc}
\hline School & $n$ & $M$ & SD & Min & Max & R \\
\hline & & \multicolumn{7}{c}{ Self-efficacy General } \\
A & 4 & 3.36 & .589 & 2.63 & 4.06 & 1.43 \\
B & 13 & 3.43 & .463 & 2.88 & 4.31 & 1.43 \\
C & 10 & 3.94 & .565 & 2.88 & 4.63 & 1.75 \\
D & 7 & 3.50 & .442 & 3.00 & 4.06 & 1.06 \\
E & 10 & 3.37 & .532 & 2.69 & 4.06 & 1.37 \\
F & 6 & 3.77 & .447 & 3.38 & 4.56 & 1.18 \\
\hline
\end{tabular}

Self-efficacy Social

$\begin{array}{lrrrrrr}\text { A } & 4 & 3.90 & .258 & 3.60 & 4.20 & .60 \\ \text { B } & 13 & 3.70 & .855 & 2.20 & 5.00 & 2.80 \\ \text { C } & 10 & 3.76 & .793 & 2.60 & 4.60 & 2.00 \\ \text { D } & 7 & 3.43 & .955 & 2.20 & 4.40 & 2.20 \\ \text { E } & 10 & 3.12 & .483 & 2.40 & 4.00 & 1.60 \\ \text { F } & 6 & 3.67 & .755 & 2.40 & 4.60 & 2.20\end{array}$

Locus of Control

$\begin{array}{lrrrrrr}\text { A } & 4 & .45 & .157 & .25 & .63 & .38 \\ \text { B } & 13 & .39 & .099 & .25 & .63 & .38\end{array}$

(table continues) 
Table 18. (continued)

\begin{tabular}{lrrrrrl}
\hline School & $n$ & $M$ & $S D$ & Min & Max & $\mathrm{R}$ \\
\hline $\mathrm{C}$ & 10 & .35 & .160 & .17 & .60 & .43 \\
$\mathrm{D}$ & 7 & .42 & .131 & .25 & .60 & .35 \\
$\mathrm{E}$ & 10 & .39 & .134 & .13 & .57 & .44 \\
$\mathrm{~F}$ & 6 & .35 & .154 & .19 & .58 & .39 \\
\hline
\end{tabular}

For the Transition Outcomes in Employment (Hours and Wages), Table 19 gives the disaggregated descriptives for these variables by school. The mean scores range from a high for School F (30.83 hours) to a low for School B (20.45 hours). In the Transition Outcome category of Wages, rates were highest at School F (\$6.80) down to School C (\$5.50). To explore whether a relationship existed between Hours and Wages and the School that was attended, two separate one-way ANOVAs were calculated. Neither was significant. The number of hours worked on the first job out of high school produced an ANOVA that was almost significant, across schools, $F(5,40)=2.087, p=.087$. The relationship between wages and school attended was not close to significance, $F(5,40)=$ $1.457, p=.225$.

Thus Research Question 4 indicates that there was no difference found when comparing participants in the STEP Grant based on the school they attended. None of the mediating factors--Self-efficacy-General, Self-efficacy-Social, and Locus of Control-differed significantly across schools. Likewise, for the two employment outcomes, both hours worked and wages earned fell short of varying significantly across the schools. 
Table 19

Descriptive Statistics for Transition Outcomes by School Attended $(N=50)$

\begin{tabular}{|c|c|c|c|c|c|c|}
\hline School & $n$ & $M$ & $S D$ & Min & Max & $\mathrm{R}$ \\
\hline \multicolumn{7}{|c|}{ Hours } \\
\hline A & 4 & 30.00 & 8.17 & 20 & 40 & 20 \\
\hline B & 11 & 20.45 & 9.54 & 10 & 40 & 30 \\
\hline $\mathrm{C}$ & 10 & 23.50 & 9.41 & 12 & 40 & 28 \\
\hline $\mathrm{D}$ & 5 & 20.50 & 9.75 & 15 & 38 & 23 \\
\hline $\mathrm{E}$ & 10 & 29.90 & 9.43 & 15 & 40 & 25 \\
\hline $\mathrm{F}$ & 6 & 30.83 & 8.01 & 20 & 40 & 20 \\
\hline \multicolumn{7}{|c|}{ Wages } \\
\hline A & 4 & 5.54 & .350 & 5.15 & 6.00 & .85 \\
\hline B & 11 & 5.98 & .915 & 5.15 & 8.00 & 2.85 \\
\hline $\mathrm{C}$ & 10 & 5.50 & .456 & 5.00 & 6.50 & 1.50 \\
\hline $\mathrm{D}$ & 5 & 5.53 & .466 & 5.00 & 6.00 & 1.00 \\
\hline $\mathrm{E}$ & 10 & 6.09 & 1.16 & 4.15 & 8.50 & 4.35 \\
\hline $\mathrm{F}$ & 6 & 6.80 & 2.04 & 5.25 & 10.30 & 5.05 \\
\hline
\end{tabular}

To what extent is participation in the STEP Grant

4.b. Year Enrolled

4.c. Days Enrolled

4.d. Attendance 


\section{4.e. Self-Improvement}

related to:

a. Mediating personality factors:

i. Self-efficacy scores?

ii. Locus of Control scores?

b. Transition in Employment reported on the Student Follow-up Survey?

For RQs 4.b-4.e., the relationships between the remaining four factors of participation in the STEP Grant and both the Mediating factors and Transition Outcomes are displayed in Table 20, which answers both RQ4 and RQ5. The reader is reminded that these correlations use the adjusted scores for SGEN with 16 questions after Question 12 was removed and the adjusted SSOC with 5 items after Question 14 was removed for greater reliability. For RQ4 (the top four rows of Table 20), no significant relationships were found between the STEP Grant Intervention Factors and the Mediating Factors. (The significant relationships among the three mediating personality scales are repeated from Table 17 and were discussed under RQ3.b., above.) Similarly, none of the correlations between the STEP Grant Intervention Factors and the Transition Outcomes of Employment for Hours and Wages were significant. 
Table 20

Correlations between STEP Grant Intervention, Mediating Factors, and Transition Outcomes (Hours and Wages) $(N=50)$

\begin{tabular}{|c|c|c|c|c|c|c|c|c|c|}
\hline Variable & YEAR & DAYS & $\%$ ATT & SIMP & SGEN & SSOC & LOC & HOUR & WAGE \\
\hline YEAR & -- & .079 & .109 & -.042 & -.016 & -.094 & .112 & .112 & .109 \\
\hline DAYS & & -- & $.393 * *$ & -.060 & .014 & .016 & -.003 & -.008 & .126 \\
\hline$\%$ ATT & & & -- & -.203 & -.021 & .108 & -.073 & .013 & -.096 \\
\hline SIMP & & & & -- & .026 & .098 & -.224 & -.069 & .092 \\
\hline SGEN & & & & & -- & $.535^{* *}$ & $-.323^{*}$ & -.119 & -.157 \\
\hline $\mathrm{SSOC}$ & & & & & & -- & .236 & -.046 & -.053 \\
\hline LOC & & & & & & & -- & -.026 & -.082 \\
\hline HOUR & & & & & & & & -- & .226 \\
\hline WAGE & & & & & & & & & -- \\
\hline
\end{tabular}

${ }^{*} p<.05 . * * p<.01$. 


\section{Research Question 5}

To what extent are Mediating personality factors

a. Self-efficacy Scores

b. Locus of Control Scores

related to Transition in Employment reported on the Student Follow-up Survey?

Table 20 also shows (in rows 5-7) correlations between the Mediating Factors (Self-efficacy-General, Self-efficacy-Social, and Locus of Control) and the Transition Outcomes (Hours and Wages). Although none of these relationships are significant, all six of these $r$ values are negative. That is to be expected for Locus of Control because high scores represent higher external orientation but is in the opposite direction predicted by the Self-efficacy construct. Also of interest is the non-significant correlation between Hours and Wages $(r=.226)$.

\section{Research Question 6}

When controlling for demographic factors, to what extent are participation in the STEP Grant

a. Year Enrolled

b. Days Enrolled

c. Attendance

d. Self-Improvement

and Mediating Personality Factors

a. Self-efficacy Scores

b. Locus of Control Scores

related to transition in Employment reported on the Student Follow-up Survey? Research Question 6 addresses relationships between the two types of independent 
variables--the STEP Grant Intervention Factors and the Mediating Factors--and the Transition Outcomes (Hours and Wages), net of the prior influence of the demographic factors. Table 21 presents semipartial correlations for the STEP Grant Intervention Factors and the Mediating Factors. The influence of the two sets of demographic variables-Personal Identity (Ethnicity, Gender, and Disability) and Educational History (Semesters of Vocational Education, regular GPA, and vocational GPA)--was partialed out, leaving the semipartial correlation for STEP Grant Intervention Factors by Employment and for Mediating Factors by Employment. These values were derived from multiple regression printouts from SPSS, although the regressions were not utilized in this study (see rationale in Chapter III). Inspection of Table 21 reveals that only one of the STEP Grant Factors was significant, $s r=-.324, p=.002$, for Attendance and Wages. Surprisingly, this effect is negative. None of the semipartials for the mediating personality tests were significant. 
Table 21

Semipartial Correlations for STEP Grant Intervention and Mediating Factors Related to Transition Outcomes, Controlling for Six Demographic Factors $(N=50)$

\begin{tabular}{|c|c|c|c|c|}
\hline \multirow{3}{*}{$\begin{array}{l}\text { Independent } \\
\text { Variables }\end{array}$} & \multicolumn{4}{|c|}{ Dependent Variables } \\
\hline & \multicolumn{2}{|c|}{ Hours } & \multicolumn{2}{|c|}{ Wages } \\
\hline & $s r^{\mathrm{a}}$ & $p$ & $s r$ & $p$ \\
\hline & \multicolumn{4}{|c|}{ STEP Grant Interventions } \\
\hline Year & -.058 & .702 & .048 & .728 \\
\hline Days & .004 & .979 & .038 & .784 \\
\hline Attendance & -.119 & .161 & -.324 & .002 \\
\hline Self-Improvement & -.226 & .127 & -.126 & .326 \\
\hline
\end{tabular}

Mediating Factors

Self-efficacy

$\begin{array}{lllll}\text { General } & -.039 & .809 & -.144 & .296 \\ \text { Social } & -.040 & .806 & .106 & .439 \\ \text { Locus of Control } & -.092 & .572 & -.088 & .520\end{array}$

Note. Values for semipartial correlations and significance are derived from Multiple Regression tables from SPSS with the six demographic factors controlled; these regressions were not utilized in the study.

${ }^{\mathrm{a}} \mathrm{sr}=$ semipartial correlation. 
What are students' perceptions of the STEP Grant with respect to:

a. Employment?

b. Postsecondary Education?

The qualitative data for Research Question 7 were obtained from open responses to the STEP Grant Student Follow-up Survey. Comments correspond to Questions 8, 9, and 4 on the student survey instrument; the actual student responses are found in Appendices F, $\mathrm{G}$, and $\mathrm{H}$, respectively. Thirty of the 50 participants answered these questions, but not all students volunteered answers to the same questions. The data disaggregate as follows (W= White; $\mathrm{B}=$ Black; $\mathrm{M}=$ Male; $\mathrm{F}=$ Female; $\mathrm{MMD}=$ Mild Mental Disability; $\mathrm{BD}=$ Behavior Disability; and LD = Learning Disability):

1. Five students (1 WF, LD; 3 WM, LD; 1 BM, LD) answered all three questions.

2. Thirteen students (4 WM, LD; 4 WF, LD; 2 BM, LD; 1 BF, LD; 1 WF, MMD; and 1WM, MMD) answered Q8 \& 9 only.

3. Three students (1 WF, LD; 1 WM, LD; 1 BF, LD) answered Q8 \& 4 only.

4. One student (1 WM, LD) answered only Q8.

5. Four students (2 WF, LD; 2 WM, LD) answered only Q9.

6. Four students (1 WF, MMD; 2 WF, LD; 1 WM, MMD) answered only Q4.

Comments were grouped according to topic and checked with a member of the dissertation committee for accuracy.

\section{STEP Grant Student Follow-up Survey Question 8}

Did the STEP Grant help you get ready for a job after high school?

Answers that were limited to YES/NO for this item were included with the SelfImprovement factor composite as one of the five STEP Grant Intervention variables. Written comments were analyzed separately in this section. Thirteen of twenty-two 
students responded positively that the STEP Grant offered them help in the area of job development and acquisition. Typical of positive responses were the following. Student 506 answered, "Really did pinpoint areas you are interested in" while student 513 said it was directly related to her career interest, "Got me ready for day care job." Student 584 commented that the training "Prepared a lot." Students 522, 532, and 581 all commented on interviews: "Interviews helped a lot"; "I know what to say in interviews"; and "Gave help with interviewing." Two students commented on help with resumes: 558 stated, "It helped with resumes" and 571 offered, "Yes, resumes, etc. Mock job interviews gave more confidence."

Four additional students considered the training less positively, indicating, while helpful, it was not enough for their purposes. Typical comments offered from this group were: "If it [the training] really did [help], you would have the job you want" (student 515); and from student 546, "Need to show more ways to train or choose school to get ready for my career." Student 555 added, "Interesting, but not enough depth for different jobs." Five unrelated comments were offered by respondents. For example, student 509 commented, "Likes [sic] STEP Project." Student 553's comment was similar, "It was a nice class to have because I learned what STEPS [sic] means." and, from student 573, "Can't get a job because enrolled in school." STEP Grant Student Follow-up Survey Question 9

Did the STEP Grant help you get ready for college or vocational training after high school?

Again, the simple YES/NO answers were included with the Self-Improvement composite scale, as reported in RQs 3-6. Supplemental comments were given by 22 students for this question (18 of them were the group of 18 who also answered Q8). 
Among these voluntary comments, 13 responses were positive and related to the topic regarding the help they received for postsecondary education; 2 were related, but the students wanted additional help in getting ready for postsecondary education; 2 were negative; and 7 were unrelated. Representative of these positive responses were, from student 522, "It showed me my best qualities and what I am good at so I could get a better understanding of what I will do for college or school after I graduate" while student 525 responded, "Before, I might not even look at a school, but now I think I might."

Two comments were related, naming aspects in which the students wanted more training or emphasis added to the program: 546 asserted, "Need to show more ways to train or choose school to get ready for my career." Similar beliefs were expressed by 588 who stated, "More emphasis on study habits [was needed]...look at more colleges and how to get registered." Two comments were negative: 543 asserted, "Not sure because not attending college or vocational training.", and 553 expressed, "Sorry, no, it did not help me at all." Five students volunteered comments that were unrelated; these included, "None" (4) or "I don't know" (1).

\section{STEP Grant Student Follow-up Survey Question 4}

Have you ever attended postsecondary education at any time after high school? Are your currently enrolled? Will you attend in the future?

The purpose of this section of the survey was to determine the participants' past, current, and projected enrollments. The question on the survey was worded imprecisely so that it was not possible to obtain any quantified data regarding postsecondary education as a transition outcome. Of the 30 respondents who volunteered qualitative information, only 12 students (40\%) answered the YES/NO question and typically gave comments about their program or major, hours completed or current enrollment, and name of the institution 
for postsecondary enrollment. Not all students gave information for all of these categories. Nine of the twelve respondents were in formal postsecondary institutions. Categorically, this group was comprised of the following ethnicities, gender, disabilities, and institutions:

1. Spalding College: 1 WM, LD

2. Jefferson Community College: 3 WF, LD; 2 WM, LD; 1 BM, LD

3. Jefferson Technical College: $1 \mathrm{WM}, \mathrm{MMD} ; 1 \mathrm{WM}, \mathrm{LD}$

4. Other: 1 Professional Animal Care by mail (WF, MMD); 1 Family Education Program (WF, LD); 1 Donta's Nail Technology (BF, LD).

Of the twelve who volunteered enrollment information, seven had completed college level courses with hours ranging from three to twenty-four. Jefferson Community College had five who completed from three to fifteen hours. One (596, WF, LD) had enrolled in the past, but did not complete a course. Three were currently enrolled for up to 15 hours: three hours (515, WF, LD); 12 hours (568, BM, LD); or 15 hours (571, WM, LD). All of the currently enrolled students were attending Jefferson Community College.

This supplemental information provided added depth of understanding about the nature of experiences for these STEP Grant students after high school. The reader is reminded that both employment and postsecondary enrollment were positive indicators of successful transition.

\section{Summary}

The STEP Grant was envisioned to support students with mild disabilities in their high school years and make their transition outcomes more successful. This chapter was organized to provide data that were collected and to explore relationships between Independent and Dependent Variables. Figure 1 was followed in reporting results. Both quantitative and qualitative methods were employed. 
Data checking and coding were explained and procedures detailed to replace missing values with means since the number of participants in this study was so small. Data obtained to answer each research question were described using descriptive statistics, ANOVA, chi-square, correlations, and semipartial correlations. Sources for data included records review, JCPS database, student test data for personality factors, and the STEP Grant Student Follow-up Survey. For the nominally measured School Attended, data were disaggregated by school to see if individual factors were influenced by attendance site. Reliability analysis was performed on four factors (Self-Improvement construct from the STEP Student Follow-up Survey, Self-efficacy--General and Social, and Locus of Control) since no literature showing reliability of these measures for use with students with mild disability could be found. Two of the three personality tests had to be modified to obtain acceptable Cronbach's alpha internal consistency (both of the Self-efficacy scales).The psychometric analysis showed that the STEP Self-Improvement construct had acceptable coefficient alpha. However, the tests of Self-efficacy (General and Social) and Locus of Control were only marginally reliable for this group of mildly disabled students.

Data for RQ1 and 2 were presented to demonstrate the amount of compliance with transition standards for the IDEA legislation and success level as measured by the STEP Grant criteria. The records check for IEP/Transition Plans showed that all students in the STEP Grant had completed IEPs, but many did not have completed Transition Plans on file as required by legislation (see Table 10). In addition, there seemed to be a lack of continuity in the high school programming for these students. The records check revealed that only one student had a match between their desired career goals, the vocational training they took while in high school, and their employment after high school (see Table11). The summary of the latest career goal on the Transition Plan (Table 12) displays 
the wide variety of goals, vocational training, and jobs this group of participants reported on the STEP Grant Student Follow-up Survey. Also displayed is the disparity in career clusters represented by training and jobs with $91.30 \%$ employed in the Human Services cluster. RQ2 (Table 13) showed results of application of the STEP Grant criteria to measure success for this group. Forty-six of the 50 were successful according to the standards set by the STEP Grant.

RQs 3-5 explored relationships among and between the different independent and dependent variables, highlighting those that were significantly correlated. First, the Demographics were compared to the School variable. Chi-squares were calculated for the five nominally measured constructs (Gender, Ethnicity, MMD, BD, and LD). Even though the 50 students were unevenly distributed by school, due mainly to differences in return rate of their survey forms, only two significant differences were found when the data were disaggregated by attendance site: MMD and LD, both from the Personal Identity block of Demographic controls. ANOVAs were then calculated to determine whether mean values for Vocational Semesters enrolled, GPA, and VGPA varied by school attended. Both of the grade point measures revealed a significant difference.

RQ3 further explored correlations among the demographic factors, STEP Grant Interventions, Mediating Factors, and Transition Outcomes in Employment. Few of these relationships were significant (Table 16); Percentage Attendance (one of the STEP Grant Intervention variables) had the most significant correlations, with GPA, VGPA, and Days enrolled. The strongest association $(r=.758)$ was between GPA and VGPA.

Research Questions 4 \& 5 explored relationships among STEP Grant Intervention factors, the Mediating personality tests, and the Transition Employment Outcomes. ANOVAs were calculated to see if mean scores for the three personality tests and two 
employment outcomes varied across school attended; none did. The correlation matrix (Table 20) revealed occasional significant relationships within the three blocks of variables (STEP Intervention, Mediating Factors, Employment Outcomes) but none across those groupings.

RQ6 explored the semipartial correlations for STEP Grant Interventions and for Mediating Factors with Transition Outcomes, when controlling for Demographic Factors. For the four factors under STEP Grant Interventions, only Attendance, with Wages, had a significant semipartial correlation, $s r=-.324, p=.002$. Surprisingly this was an inverse relationship. None of the semipartials for the three personality scales were significant.

Finally, RQ7 presented qualitative data from open-ended responses volunteered by participants about their perception of the helpfulness of the STEP Grant regarding employment and post-secondary education enrollment. Comments were generally positive toward the assistance the participants had received while in the STEP Grant. However, a few wanted additional job readiness or placement assistance for employment areas to match their interests. In regards to postsecondary education preparation, most participants were also positive. Specifically, they thought good interview skills, resume writing, and introduction to area postsecondary institutions were good aspects. A few participants expressed that they needed additional assistance in regard to making application to the desired training institution. Others wanted better study habits to help them after they were enrolled. The final qualitative section gathered information about postsecondary enrollment. Twelve of the 50 participants were or had been enrolled in academic or vocational training since high school. In this respect, the STEP Grant was successful in helping this sub-group in realizing that additional education was necessary for a more successful adult life. 


\section{CHAPTER V \\ DISCUSSION AND CONCLUSION}

The Study in Brief

The American educational system has pledged commitment to the education of all children between 3 and 21 years of age, including students with disabilities. For the past 30 years educators and legislators have tried to improve educational services for all students, but even with mandates from IDEIA and NCLB legislation, students with mild disabilities still struggle to earn a high school diploma. Longitudinal studies have shown but small improvements in functioning levels for this group in the adult world (Blackorby \& Wagner, 1996; Wagner et al., 2005).

Several factors contribute to the difficult task of enabling this group of students to become more successful adults: (a) The drop-out rate is high (28\%); (b) Employment in low-paying service-oriented jobs after high school is more likely than for their nondisabled peers; (c) Approximately 60\% are working for less than $\$ 7.00$ per hour, thereby making it difficult to live independently; (d) Few have benefits (paid vacation, sick leave, health insurance, or retirement plans) attached to their positions; (e) Postsecondary education enrollment has increased, but less than $50 \%$ of students with disabilities enroll and few complete a degree; (f) Independence from family support has increased only slightly; (g) Resistance continues from educational staff and community for full inclusion; and (h) Self-determination and planning skills are still lacking (Wagner et al, 2005).

The KERA legislation (1990) added standards and accountability for schools to 
improve programming and prepare students for adult life. To address these issues in the local school system, Jefferson County Public Schools and the University of Louisville secured a three-year (1996-1999) federal demonstration grant to improve transition services for students with mild disabilities. Extensive personnel development, organization of an elective class, and identification of at-risk students were accomplished. The goals of the project were to prevent drop-outs, to assist in achievement of high school diplomas, and to connect participants with postsecondary education or employment after graduation. The focus of this research, as described in Chapter I, was a group of 108 students with mild disabilities from six local high schools who participated in the STEP Grant. A one-year, No cost Extension was obtained in 2000 to support students in completing their graduation requirements and to conduct a STEP Student Follow-up Survey. Approval of this study was obtained from the Office for Human Subjects' Research at the University of Louisville and JCPS Research Department. This research includes only the sub-group of 50 students who voluntarily returned the STEP Student Follow-up Survey.

The review of literature in Chapter II identified essential transition elements for students with mild disabilities to become successful adults (Flexer et al., 2008; Kohler \& Chapman, 1999). A literature review in special education and transition to adult life revealed that both school programming and transition outcomes are critical elements of the secondary education models to culminate in greater success for mildly disabled students (Blalock \& Patton, 1996; Brolin, 1997; Halpern et al., 1992; Hughes et al., 1992; Kohler, 1993). Empirical research gleaned information from the federal transition demonstration grants to upgrade educational strategies. This research is similar to research accomplished by Benz et al. (1997) in the field of special education transition. A large body of information was revealed in the psychological aspects of personality development and how 
these affect individuals in the choices they make (Bandura et al., 2001; Kalechstein \& Nowicki, 1997; Nowicki \& Strickland, 1973; Sherer et al., 1982). The review of literature in the program evaluation field included a needs analysis framework for examining program elements (Fourqurean \& LaCourt, 1990; Kirkpatrick, 1994; Worthen et al., 1997). The following outcomes were chosen as the focus of this research: Employment; Postsecondary Education participation, and Independent Living. Self-Determination skills were viewed as a means to helping students improve their transition outcomes in these areas.

Information was collected from the JCPS Research Office (database of official school records), Elective Class records (student psychometric testing), and archives (IEP/Transition Plans). This body of information and results from the STEP Student Follow-up Survey were entered into SPSS version 14 for analysis. All variables were defined both conceptually (in Chapter III) and operationally (in Appendix E). Appropriate methodology for analyzing independent and dependent variables was specified for each separate research question. Because the number of participants was small, a plan to replace missing values for some items on psychometric testing and employment information was devised. Descriptive statistics, Cronbach's coefficient alpha, correlation, and analysis of variance were the primary statistical methods utilized. Information volunteered on the survey provided the qualitative information from the participants' perspective. The central research question to be answered was: What are the effects of the STEP Intervention Grant on the transition of students with mild disabilities to post-school outcomes?

Chapter IV reported the results of descriptive statistics, reliability measures, and statistical procedures that were used to investigate relationships between and among variables. These results are discussed in the sections below, organized by Descriptive 
Statistics, Psychometric Analysis, and the seven research questions that follow including an analysis pertinent to each. Because this research is a partial program review, recommendations based on these findings are offered for program improvement. Policy considerations are discussed to improve transition practices. Suggestions for future research are identified. Overall conclusions complete this research.

\section{Discussion}

This research was conducted with students from six high schools in a large, metropolitan school district in the Midwest. The literature review allowed comparison of this district's policies and practices to empirical research showing design and implementation of successful transition to adult life for similar groups of students across the United States. Amendments to the IDEA legislation of 1997 detailed even greater responsibility for the schools to include the transition process in the educational programming for students with disabilities.

The research was a mixed design, primarily quantitative analysis of secondary data made available from the Jefferson County Public Schools, as well as a STEP Grant Student Follow-up Survey, in effect a partial program evaluation. Data were analyzed to examine the influences that the STEP Grant Intervention had on Transition Outcomes for this subgroup of students with mild disabilities from six high schools. Relationships among certain Demographic Factors, Mediating Factors, STEP Intervention variables, and Transition Outcomes were analyzed. Program evaluation results relate to school programming, testing of students' self-perceptions, and service delivery. For each section, the information is briefly recapitulated and then analyzed to show contributions to the empirical research base for the field of transition.

Descriptive Statistics 
Descriptive statistics are provided only for RQs 3-6 which represented additional information beyond the assessment of IDEA compliance and STEP Grant criteria for success (RQs 1-2). Gathered from school district records and the STEP Grant Student Follow-up Survey, these data provide more in-depth, fine-grained knowledge of the transition process for the 50 participants. The Demographic Factors were divided into two sections: Personal Identity (Ethnicity, Gender, Disability) and Educational History (Semesters of Vocational Education, regular Grade Point Average, Vocational Grade Point Average). One of the entrance criteria for students was to be at risk of dropping out of high school (as suggested by their teachers, counselors, and parents), but reasons for this factor were not measured in this study. In addition, notably missing from this list of demographics is socioeconomic status, a common factor for research in schools and for students with disabilities. This element was not used because all participants were eligible for free or reduced lunch status, a criterion to enter the program.

Participants (see Table 1) were primarily White and were split approximately evenly between Males and Females. Within the Disability category, the three most frequent mild disabilities were represented, with the Learning Disabilities group the largest $(N=$ 40). The BD and MMD groups represented 10\% each from the population and were spread unevenly across the schools in the study (see Table 3). All participants were enrolled in vocational education (see Table 2) while in high school, but there was a wide range of the number of semesters completed. Overall Grade Point Average also had a wide spread (from 1.29 to 3.89) indicating that some students were making good grades in academic courses. The Vocational Grade Point Average was found to be slightly higher, perhaps indicating that students with mild disabilities do better in classes with hands-on curriculum. 
When STEP Interventions were considered (see Table 4), most participants received slightly more than one year of enrollment in the STEP Grant, but there was a wide range for both the length of time that students were enrolled in the program (range of 271 days) and the percentage attendance from a low of 34\% to 100\%. Even though these students were enrolled in a program to keep them in school, some students did not improve their attendance. For these supplemental data, only two Transition Outcomes had sufficient numbers to analyze quantitatively, both in Employment: Hours and Wages. Of the participants who were working, there was a wide range of hours worked, from 10-40. A similar disparate range for wages received indicates a low of \$4.15 up to \$10.30 (see Table 5).

Analysis

The ethnicity, gender, and disabilities represented in this study were typical of the local school populations for these variables, as estimated by M. Muñoz, (personal communication, September 17, 1999). Similar variables were compared by Benz et al. (1997) with significant differences in outcomes by gender and disability status noted. Taking into consideration the background information described, this research examined factors that might contribute to the participants' successful completion of transition from the public schools.

\section{Psychometric Analysis}

As a part of the STEP Grant Intervention, two measures of personality were given to the participants while they were in high school: the Self-efficacy Scale, with two subscales (Sherer et al., 1982) and the Locus of Control Scale (Nowicki \& Strickland, 1973. These tests were designed for use with regular education students and were used to see if pre-existing personality tendencies affected the way the participants viewed control of 
choices in their lives. For this research, these measures were designated as Mediating Factors (see Figure 1). Although the literature review and contact with the original developers provided a number of studies using both regular and special populations, research using Self-efficacy Scales (Sherer et al, 1982) with students with mild disabilities and detailing reliability were not located. Most studies involved application of self-efficacy to academic skills (academic achievement, reading skills, or mathematics skills) by regular education students (Hampton \& Mason, 2003; Pajares \& Kranzler, 1995). Klassen (2002) reviewed 22 studies involving students with learning disabilities that focused on similar academic skills (arithmetic, writing, reading, and general academic functioning), but again, reliability of the self-efficacy measurement with students with learning disabilities was not reported.

Given this lack of empirical analysis for this population, psychometric calculations for reliability were performed. The results showed that neither of the Self-efficacy Scales (Sherer et al., 1982) had adequate reliability for this sample of students with mild disabilities (see Tables 7 and 8). In order to include these psychometric results within this research, both the Self-efficacy-General and Self-efficacy-Social subscales were adjusted by removing one question based on the alpha-with-item-deleted for greater reliability. This increased the Cronbach alpha from .640 to .719 for Self-efficacy-General and from .461 to .589 for Self-efficacy-Social, thus raising the former to acceptable internal consistency and the latter almost to the relaxed standard of .6 for exploratory research (Nunnally \& Bernstein, 1994). The Locus of Control scale had a Cronbach alpha of .719, an acceptable value (see Table 9).

Also included in reliability calculations was the Self-Improvement construct that consisted of 10 items from the STEP Student Follow-up Survey. These items were 
designed to gather information about how the students perceived the assistance they were given through the STEP Grant. This construct was tested for internal consistency by calculating Cronbach's coefficient alpha. For these students, the value of .748 (Table 6) proved to be acceptable and higher (more reliable) than any of the other three scales, all of which are widely utilized in the literature.

Analysis

Self-efficacy and locus of control are personality concepts that are closely linked with self-advocacy and self-determination (Van Reusen \& Box, 1990; Wehmeyer, 1992; Westling \& Fox, 2000). The way persons perceive how they interact with the world around them affects the way they make decisions for the future and meet the stressors of life (Bandura, 1989; Getzel \& deFur, 1997; O’Brien \& Lovett, 1993). Although the research in the field was extensive, regular education students or adults were the participants in the studies found, not students with mild disabilities. In the few studies found involving selfefficacy and students with mild disabilities, no test reliability was noted.

Sherer et al. (1982) constructed the Self-efficacy Scale to measure vocational and social competence. Testing was done with 376 beginning psychology students at the university level. No students with mild disabilities were included in this original research. It would be expected that students studying psychology, even at the introductory level, would have a basic understanding about concepts of self-esteem and self-efficacy as they relate to vocational competence and social skills. Sherer et al. reported Cronbach alpha coefficients of .86 and .71 for the two subsections, and they noted the favorable comparison to the alpha level of .6 recommended by Nunnally. However, even in this original study, the social subscale is barely beyond the .7 criterion that is considered the minimal acceptable internal for scale reliability (Nunnally \& Bernstein, 1994). 
Furthermore, no controls for demographics were reported by Sherer et al., although they did report that past success in vocational, educational, and military areas were predictors for the General Self-efficacy subscale.

The implication by Sherer et al. (1982) that past experience and success are crucial to self-efficacy would be consistent with Bandura’s (1977) original theoretical formulations on past mastery being a powerful predictor for self-efficacy expectations. More specifically, the Social Self-efficacy subsection was associated with "ability to keep a job but not with success in education or military rank” (Sherer et al., p. 670). They suggested that the social subscale results relate to beliefs that dealing with people may be more important than success in education or gaining promotions in military ranks (p. 670). However, neither Sherer et al.'s original research nor any of the 22 subsequent studies supplied by M. Sherer (personal communication, August 15, 2000) supported these scales for use with students with mild disabilities. Likewise, none of the 22 studies in Klassen's (1992) analysis of work on these Self-efficacy Scales addressed reliability of the scales with populations of students with mild disabilities, although he did note that reliability and validity studies were needed on this population.

Bandura (1993) summarized the diverse effects on people’s thinking by pointing out that those with a low self-efficacy avoid challenging tasks due to their perception that the difficulty is a personal threat. People with low self-efficacy tend to focus on personal deficiencies, obstacles, and adverse outcomes. These reactions govern how people face the world's challenges and contribute significantly to quality of life functioning (p. 144). Bandura's theoretical framework has become widely accepted and a number of researchers have explored empirical work based on his thinking (see Pajares \& Kranzler, 1995; Pajares \& Schunk, 2001). However, studies of students with mild disabilities are relatively sparse 
as compared to other applications.

In contrast, this research was conducted with high school students with mild disabilities, all from low socioeconomic backgrounds. The results clearly demonstrate that the three personality tests selected for use with this group were problematic. The authors of the Self-efficacy Scales (Sherer et al., 1982) based their work on the premise that a person's past experiences and success influence attribution to skill or chance. Of course, it is possible that part of the problem is that the sample for this research did not have the past experiences on which to base their answers. Regardless, the two scales (General and Social) simply do not function as intended for this population. Both subscales had to be modified (deleting one item) and even then the Social subscale only increased to .589 coefficient alpha. This is noteworthy. Nowhere in the literature on these scales is there the statement that they are psychometrically inadequate and must therefore be modified when used with this population. To this author's knowledge, no other research has remarked on this inadequacy in measuring these traits for students with mild disabilities, vis-à-vis the self-efficacy scales.

The Locus of Control Scale (Nowicki \& Strickland, 1973) did not fare much better. Although the coefficient alpha of .719 meets Nunnally and Bernstein's (1994) criterion of .7 as adequate internal reliability, it should be remembered that this scale is 40 items long. Since coefficient alpha increases with length of scale (Nunnally \& Bernstein), an alpha of .719 is clearly marginal at best given the length of this measure. Further, a close reading of the items reveals that many of the questions are cumbersome, several are somewhat dated, and the internal-external orientation of the scoring key is not easily discernable. When those factors are coupled with the typically depressed reading level of this population (students with mild disabilities), it becomes apparent that use of this particular measure is 
highly questionable in this context.

Similar to the lack of studies on self-efficacy, research on students with mild disabilities and Locus of Control was sparse. A meta-analysis by Findley and Cooper (1983) demonstrated the association between locus of control and academic achievement but did not connect Rotter's social learning theory or any other theoretical framework to guide their analyses, according to Nowicki and Kalechstein (1997). Both sets of researchers (Findley \& Cooper; Nowicki \& Kalechstein) controlled for gender, age, race, and socioeconomic status, but neither included students with mild disabilities. Rotter (1993) conceptualized locus of control reinforcement as a type of learned behavior that links participants' actions and the reinforcements they receive. Rotter also connected a person's past experiences with the way they approach new situations, but did not include students with mild disabilities.

Hagborg (1999) found that LD students with adequate scholastic competence exhibited higher grades and more favorable teacher ratings but did not differ with regard to gender. His correlational findings comparing non-disabled and LD adolescents showed that those with LD have a greater need for integrating positive experiences into their selfconcept to overcome their long history of academic and school difficulties. Hagborg also noted that LD students maintain a high self concept despite their academic weaknesses and modest academic performance, which can be explained by these students' external locus of control orientation (the system is stacked against me). This idea is similar to the "optimistic mis-calibration" of self efficacy in specific contexts by students with LD as noted by Klassen (2002, p. 2) regarding performance of students with specific writing difficulties. He reported that this overconfidence "might be considered a warning sign of faulty task analysis or poor self-knowledge” (p. 19) and those teachers should focus on 
raising the students' understanding of the task, not in lowering their self-confidence.

The results from this study for both the Self-efficacy Scales (Sherer et al., 1982) and Locus of Control (Nowicki \& Strickland, 1973) clearly imply that the psychometric properties of various personality scales should always be checked empirically for their appropriateness for a given population--rather than just assuming that they are applicable based on measurements from different populations. Questions on all three measures--Selfefficacy-General and Social, and Locus of Control--require a level of sophistication and experience to relate personal insight to meaningful answers. Perhaps questions that are worded differently for clarity, or training for students with mild disabilities in how to relate test questions to personal experience may help results become more acceptable.

Perhaps other tests that would better depict these personality constructs could be identified. With respect to locus of control, both the Sense of Control in the Coleman Report (Coleman et al., 1996) and Student Sense of Academic Futility (Brookover et al., 1979) are school specific, shorter, and more appropriate in terms of reading level and complexity. The STEP Self-Improvement construct has been used only with this particular group of students since this factor is based on participation in the STEP Grant and therefore lacks more general psychometric validation.

Alternative self-efficacy scales also exist, e.g., Multidimensional Scales of Perceived Self-Efficacy (Bandura, as cited by Choi, Fuqua, \& Griffin, 2001), normed on regular education middle and high school students. This scale measured nine domains: "social resources, academic achievement, self-regulated learning, leisure-time skills and extracurricular activities, self-regulatory efficacy (to resist peer pressure for high risk behaviors), self- efficacy to meet others' expectations, social self-efficacy, self-assertive efficacy, and enlisting parental and community support” (Choi et al., p. 476). Klassen 
(2002) reported the names of tests in five of the studies he reviewed (SEAT, ASSESS, SASES, Career Self-Efficacy Scale, and Self-Efficacy Scale) but did not provide complete identification of the instrument, the authors, or the reliability of the test for students with mild disabilities. The number of items on these tests ranged from 5 to 34 .

Szymanski (1994) proposed an ecological model to understand the vocational behaviors of people with disabilities and included psychological factors of "work personality, self-concept, adjustment to disability, self-efficacy, and outcome expectancies that are important in a successful job search” (p. 207). Strauser and Berven (2006) adapted two other self-efficacy scales (The Career Search Efficacy Scale by Solberg, Good, Nord, Holm, Hohner, Zima, et al.; and a Job-seeking Self-Efficacy Scale for people with physical disabilities by Barlow, Wright, \& Cullen; as cited by Strauser \& Berven). Barlow et al.’s new Job Seeking Self-Efficacy Scale (JSSES) was designed to "overcome some of the limitations of the existing scales in measuring perceived self-efficacy in job seeking activities” (Strauser \& Berven, p. 208). The JSSES measured many of the factors proposed by Szymanski and included disability-specific considerations in job seeking. Strauser and Berven's scale was normed with 128 clients of rehabilitation agencies (primarily Female and White) including $19.5 \%$ with orthopedic disabilities and $12.5 \%$ with learning disabilities (a wide variety of disabilities were represented in the rest of the sample). The reliability measures for the four subscales (reduced from 334 to 88 items after review by experts and grouping into the four categories) showed high Cronbach's coefficient alphas from .811 to .968 on internal consistency. Many of these concepts go beyond the concepts represented in the STEP Grant research.

In sum, based on the results in this investigation, researchers should be extremely wary of using the two Self-efficacy Scales (Sherer et al., 1982) and the Nowicki and 
Strickland (1973) Locus of Control Scale with students with mild disabilities. The Locus of Control test is barely adequate and neither of the two Self-efficacy sub-scales can be used without modification (deleting an item). Even with this change, the Social subscale approaches but does not actually reach the relaxed .6 criterion for exploratory research.

\section{Research Question One}

Research Question 1 reports on compliance with transition planning as mandated by IDEA legislation. RQ1.a. asked for the number of students with a completed Transition Plan on file in the school district archives (see Table 10). Without planning goals available, obviously programming choices could not be coordinated or adjusted for personal choices. Even on the plans available, there did not seem to be a coordinated effort between plans and enrollment options.

To answer RQs 1.b-1.e., IEPs and transition plans were analyzed for agreement among career planning goals, enrollment in vocational education, and the transition outcome for employment (first job after high school was used, see Table 11). There were many missing items on the Transition Planning forms that were located. Only one student had goals listed for all five years (grades 8-12). Out of the 50 participants, only 38 had transition plans on file, and of those, only 28 had goals listed for any of the years (grades 8-12). Plans were counted as completed if there were at least 3 years of goals recorded. Agreement of school programming with student interests and whether or not the student obtained related employment or pursued postsecondary training in the chosen areas was evaluated and is displayed in Table 11. Career Goals were compared to vocational training that the participants completed during high school; only 4 students had goals matched with training. In general, the students in this study did not follow the career path that was part of their IEP/Transition plan. Only one student had a match in all three areas. 
The variety of career goals, vocational training areas and first jobs obtained after high school is displayed in Table 12. Many of the career goals and vocational training areas include jobs that require additional training after high school to be considered for employment, i.e., teacher, lawyer, police, and computer technician. The results of this comparison show clearly that the overwhelming majority of these students were employed in low-paying, service jobs after high school.

\section{Analysis RQ1}

The STEP Elective Class was organized to assist students in completing their transition plan and in working toward their chosen career, but little evidence of this type of planning was seen. The fact that over half of the missing transition plans were from School B might suggest that the teacher at that site did not follow the suggested planning and writing of the transition plans with those students, or perhaps, the school system's process of insuring those items were accomplished and transferred to permanent records did not work. Of course, other factors beyond the scope of this research may also have contributed to this lack of planning. These results were similar to those found by Powers et al. (2005) who found a lack of transition goals for special education students from school districts in the Western U.S. (only 63\% with employment goals, 50.4\% with postsecondary goals, and fewer than half with independent living goals). Differences between desired goals and jobs obtained may also have been affected by the over-estimation of ability by students with mild disabilities (Klassen, 1992).

Students enrolled in JCPS had other dilemmas in school choices. The district uses a system of "managed choice." The vocational courses at each school were limited to a few “magnet” careers. Applications for entrance were accepted in the 8th grade, and the student had to apply to attend the school with the selected program in order to access it; there was 
no part-day enrollment, and no transportation between schools for vocational services. As a result, the mildly disabled students in the district tend to attend their assigned school, with their friends, rather than choosing a school independently according to the vocational classes offered. In addition, vocational program teachers can limit the number of special education students in a program, so just because the student applies, there is no guarantee of acceptance to the chosen program. Often transportation to an elected school (after acceptance) is up to the student or parent to provide, not the school district. All of these potential barriers could be overcome with appropriate planning, but this would almost certainly require extensive planning, monitoring, and additional resources to do so.

\section{Research Question Two}

RQ2 indicates how students fared in Transition Outcomes according to the STEP Grant criteria (see Table 13). Criteria for success according to the STEP Grant were loosely written (following Benz et al., 1997), to maximize the number of successful students. In employment, success was counted if they were working between 20-40 hours per week. In postsecondary education, success was measured by any enrollment after high school. The final "success" indicator was living independently from parents (or paying rent to parents) which was directly impacted by both employment and postsecondary enrollment. When the STEP criteria were applied to outcomes for this group of 50 participants, 46 (92\%) could be counted as making a successful transition from high school because only one criterion had to be met.

Analysis RQ2

Twelve of the 46 students who were working reported 12-20 hours per week and were counted as unsuccessful in Employment according to STEP Grant criteria (see Table 13). However, some of these were counted as successful because they met one of the other 
two criteria (Postsecondary Education or Independent Living). Upon individual analysis, it was also evident that most of the participants in the STEP Grant were working fewer than 40 hours per week and were being paid at wages that fell below the federal minimum wage for that time (\$5.15 at the time of the STEP Grant). (Restaurant workers who received tips could be paid at a rate below minimum wage at that time.) Real world budget constraints would preclude workers employed less than a 40-hour week, even at minimum wage, from living independently and paying for their own expenses on these low wages. Many of these students had to rely on family to subsidize them, or perhaps were also drawing SSI or SSDI. (No information on either of these factors was collected in the survey.) Blackorby and Wagner (1996) found in the NLTS study that many students with mild disabilities were under-employed or un-employed for significant portions of their adult lives. Also, Repetto (2003) found that employment and quality of life are highly interconnected.

\section{Research Question Three}

Research Question Three explores the relationships that Demographic Factors (Ethnicity, Gender, Disability, Vocational Education Semesters, Grade Point Average, and Vocational Grade Point Average) have with respect to the STEP Grant, Mediating Factors, and Transition Outcomes. Because School (the first STEP Intervention factor) was a nominal level of measurement, this variable was analyzed first to see if the assigned placement was related to the demographic variables. Then, the next four STEP Intervention factors (Year, Days, \%ATT, and SIMP) were analyzed together with Demographics utilizing correlational statistics. The same procedures were used to compare the mediating personality factors and Transition Outcomes of Hours and Wages.

Descriptive statistics for the three Personal Identity demographic variables (Ethnicity, Gender, and Disability) were presented in Table 14. Chi-squares were 
computed for the five measures as disaggregated by school attended. Two were significant (unevenly distributed): MMD and LD. Similarly, Table 15 presented the number of Semesters of Vocational Education, regular GPA, and Vocational GPA as disaggregated by school. ANOVAs calculated on these school level means were significant for both GPA and VGPA.

Correlations were calculated between the Demographic Factors and the last four STEP Grant Intervention factors (see Table 16). Within the block of demographic controls, only the relationship between GPA and VGPA was significant $(r=.758)$. Within the block of STEP Intervention Factors, only the relationship between Days Attended and Percentage Attendance was significant $(r=.393)$. Several correlations between Demographic variables and STEP Intervention Factors were significant. Four of five of these had to do with vocational education.

When the Mediating Factors were correlated with the Demographic Factors, none of the relationships were significant. Within the block of Mediating personality tests, there was a strong positive correlation between the two sub-sections of the Self-efficacy Scale (General and Social), as well as a significant negative relationship between Self-efficacyGeneral and Locus of Control (see Table 17).

The final set of relationships considered for this group of participants was Demographics with the Transition Outcomes of Hours and Wages on first jobs that were secured out of high school (see Table 17). The correlation between Hours worked and Wages earned was not significant. However, Disability and Wages produced a strong negative correlation (students with MMD had higher wages; those with LD had lower wages).

Analysis for RQ3 
Data were not collected from the 58 students who did not return the STEP Grant Student Follow-up Survey; thus no direct comparison can be made on the results from this study $(N=50)$ to the remainder of the STEP Grant participants, nor to the larger population of mildly disabled students in the six STEP schools, district wide, or statewide. However, research by Benz et al. (1997) showed that $60 \%$ of females and $29 \%$ of males with disabilities compared to $40 \%$ of females and $35 \%$ of males without disabilities were typically unemployed one year after high school. Interestingly, the Benz et al. study demonstrates a significant negative effect for females with disabilities but males with disabilities actually had lower levels of unemployment than similarly-aged non-disabled men. Benz et al. named Gender, Minority Status, Drop-out Status, Student Parenting Responsibilities, and Total Household Income as associated with post school outcomes for students with and without disabilities.

In the Benz et al. (1997) regression model, predictor variables of career awareness and problem-solving skills at exit were unrelated to employment, but three academic variables (reading, writing, and math), identified in post-hoc tests for students with disabilities, were all significant at the .05 level. Since most students without disabilities were not high in these areas, empty cells were produced in the cross-tab matrices and no odds ratios with non-disabled students in the study were possible. However, this information was interpreted by Benz et al. to mean that the students with disabilities who did possess high reading, writing, or math skills were two to three times more likely to be competitively employed than students with low scores. No specific data for wages were reported by Benz et al.

In relation to the present research, this comparison raises the issue of the emphasis on academics--perhaps in the long run, higher academic status will lead to higher paying 
jobs. If this is true, the question of how to motivate students with mild disabilities to aspire in academic subjects becomes a primary issue. Teaching and learning strategies piloted by the STEP Grant were certainly on target to make a difference in education for students with mild disabilities.

Sucuccimarra and Speece (1990) reported in their study of mild disabilities that $90 \%$ of the males in their study and $52.4 \%$ of the females were employed two years after high school. Further analysis of their data showed $60.8 \%$ employed in unskilled capacities, 31.4\% in semi-skilled capacities, and 7.8\% in skilled positions. They then reported data from the U.S. Employment Service for 1965 for all workers to find that the highest percentages were in clerical/sales positions (22.4\%), service occupations (22.4\%), and structural occupations (18.4\%). Comparing those data with present findings, STEP participants had $91.30 \%$ employed in service-related positions, which was way out of proportion compared to Benz et al. (1997) and the national averages. Similarly, Sucuccimarra and Speece's study found for wages that males were more likely than females to earn more than $\$ 5.00$ per hour (25\% and $9 \%$, respectively).

In the current research, the relationship between the demographic factors GPA and VGPA were both significantly related to School Attended. Furthermore, students fared a little better in Vocational Education classes than in academic classes. But, there were no data collected on equivalent grading by teachers or whether some teachers were more lenient or more demanding in assigning grades to the students with mild disabilities, so it is not possible to distinguish whether this is an artifact of teacher grading or a substantive finding that these students with mild disabilities learn better in vocational courses. Generally though, students do better with hands-on learning than with courses taught with only reading and lecture. However, no data were collected on the mode of presentation in 
academic compared to vocational classes. With four relationships being significant, the efforts of these vocational education factors would certainly need additional analysis for educators to understand how students with disabilities fare in those settings.

Another factor that could influence differences in grade point averages is the context of the student body. The overall percentage of low socioeconomic students in each school site was not available to compare with the STEP Grant sample. Yet the percentages of students in low socioeconomic status in the school population could certainly affect the overall progress of students in academic classes and on high-states testing at schools, as cited by various researchers for Kentucky (Ennis, 2002; Lyons, 2006; Petrosko, 2000) and the Jefferson County Public Schools (Moore, 2003; Muñoz \& Dossett, 2001).

In this study there were no significant relationships between Demographics and Mediating Factors and no effects from Demographics connected to students’ perceived ability to approach problem solving or persevere in tackling new challenges. Some of this may be explained by the over-estimation of ability that students with mild disabilities seem to have in general (Klassen, 1992). Both the positive association between the two subsections of the Self-efficacy Scale and the negative correlation for self-efficacy and the Locus of Control Scale were expected; the scoring for the locus of control (higher values indicate a more external orientation) suggests that these students do not control things that happen to them, a low sense of efficacy. The lack of relationship between gender and selfefficacy in the current study is consistent with the work of other researchers (Gresham, Evans, \& Elliott; Pajares \& Johnson, as cited by Klassen).

When Demographics were considered with Transition Outcomes, Disability was significant and negatively related to Wages received on the first jobs after high school ( $r=$ -.487). This was surprising since LD students earned lower wages than MMD students. No 
measures of work ethics or family circumstances related to this were collected to compare these factors, but higher ability would generally be expected to translate into higher wages. The author could find no other research to support this finding. Thus, it is unknown whether this may be a substantive finding (perhaps LD students are believed to need less personalized assistance than MMD or BD students, with less success in job hunting accordingly) or simply sample specific (a small grant with only 108 students and only 50 of those actually returning the surveys upon which these findings were based.)

\section{Research Question Four}

Research Question Four explored the extent that participation in the STEP Grant (School attended, Year, Days, and Percent Attendance) was related to the Mediating Factors (psychological test results) and Transition Outcomes (Hours worked and Wages). First, for the nominally measured School Attended, test scores for Self-efficacy (General and Social) and Locus of Control were disaggregated by the six schools in Table 18. ANOVAs calculated on the school means were not significant. In parallel fashion, the Transition Outcomes (Hours and Wages) were disaggregated in Table 19. ANOVAs were also computed for these two measures, but neither was significant.

The remaining four STEP Grant Intervention Factors (Year Enrolled, Days Enrolled, Percent Attendance, and Self-Improvement) were correlated with the Mediating Factors--personality tests of Self-efficacy and Locus of Control--and Transition Outcomes (see Table 20). No significant bi-variate relationships were found across the three blocks of factors. (The significant correlations within these three blocks are the same as described for RQ3.).

Analysis for RQ4

The fact that there were no significant relationships found for RQ4 raises questions 
about the efficacy of the STEP Grant. The generally accepted wisdom on these personality tests is that they are important determinants in life and school outcomes. That would suggest a link to specific STEP Intervention variables such as percentage attendance or self-improvement efforts and similarly for indicators of employment success. One obvious explanation is simply that the STEP Intervention factors were either ineffective or not relevant to the students in the Grant.

But several alternative hypotheses exist. First, it could be that the 50 students for whom data were available were not representative of the 108 in the Grant. Another problem could be the instruments utilized for the personality tests. The psychometric analysis described above demonstrated the general inadequacy of these scales for this population of students with mild disabilities. Then, there is the possibility that these students lacked previous experiences on which to base their answers (Bandura, 1989). There is no way of discerning between these or possibly other possibilities.

It may be instructive that no research was located that specifically considered whether factors similar to the STEP Grant (School Attended, Year, Days, Percent Attendance, or Self-Improvement) related to Self-efficacy or Locus of Control tests. The same lack of studies was true for STEP Grant type variables and employment outcomes. These last two statements reflect a basic reality: the research on transition for students with mild disabilities generally is not sufficiently well developed to find empirical replications of specific relationships that are well established in the literature on non-disabled populations.

\section{Research Question Five}

Research Question five explored the relationship between the Mediating Factors (personality tests) and the Transition Outcomes (Hours and Wages). None of these 
correlations proved to be significant for this group of mildly disabled individuals.

However, the direction of the relationships between these personality measures and both Hours and Wages were negative for all six correlations. This was expected for the Locus of Control because high scores indicated an external orientation (external factors such as discrimination, powerful elites, and fate are perceived to control what happens). Analysis for RQ5

No research was found that considered Mediating Factors (Self-efficacy-General, Self-efficacy-Social, and Locus of Control) with Transition Outcomes. Jones and Jolly (2003) found that race, academic performance, income, and parental support were significant influences on self-efficacy of regular education adolescents in North Carolina, but reported no negative effects based on family structure. They had expected to find significance related to self-efficacy depending on whether teens resided in an intact marriage or divorced, blended, never married, or cohabitating households, but found no differences in self-efficacy outcomes. Their conclusions were that teens' self-efficacy was "either much more resilient to family disturbances and social stigma, or, in the face of such elements, youth garner other sources to maintain high levels of perceived agency” (p. 7). It is surprising that only negative correlations (not significant) were found between Transition Outcomes and Self-efficacy in the STEP Grant research. Two explanations for this are most likely. First, the sampling issue noted above (only 50 of 108 returned surveys) is relevant for all of the empirical findings in the study. Second, the particular scales (Sherer et al., 1982) could well be the issue (see the general inadequacy regarding these tests, as discussed under Psychometric Analysis, above).

\section{Research Question Six}

The last of the quantitative queries, RQ6, explored the extent of participation that 
the STEP Grant had on both Mediating Factors and Transition Outcomes (Hours and Wages) when Demographic Factors were controlled. These calculations used PART scores from Multiple Regression analysis to identify the semipartial correlations. When all the background indicators had been controlled, only one STEP Grant variable, Attendance, related significantly and negatively to one of the Transition Outcomes, Wages.

Analysis for RQ6

In the present research, only one significant factor was found when controlling for demographics. No other research was found for at-risk regular or special populations that reported on the effects of controlling for demographic factors while examining the influence of transition intervention factors either on tests of self-efficacy and locus of control or on transition outcomes. Therefore, the present research represents new findings, i.e., the negative effect from Attendance on Wages when controlling for the demographic factors. However, this finding needs further examination given the very small sample size and the fact that only 50 of the 108 participants in the STEP Grant returned the STEP Student Follow-up Survey. There is no way of knowing if a more complete sample might have changed this. Nevertheless, the negative results found in relation to Attendance are intriguing because the parallel finding for Hours was also negative, although not significant. This effect would need further investigation to pinpoint the causes of these negative relationships--perhaps sampling bias. But more substantively, could students with mild disabilities who attend school regularly, in fact, receive less attention from professionals in terms of finding jobs with higher wages and hours compared to those who do not come to school regularly (the squeaky wheel gets the grease phenomenon) and thus are not able to find full time employment with good earnings on their own?

RQ6 only compared STEP Interventions and Mediating Factors to the two 
Transition Outcomes where sufficient data were available. Had other data been collected, the additional Transition Outcomes of postsecondary education enrollment and status of independent living would also have been possible to compare. However, no other studies were located that attempted to do this.

\section{Research Question Seven}

The final Research Question--What are students’ perceptions of the STEP Grant with respect to Employment and Postsecondary Education?--was addressed through qualitative methods. These data were obtained from open-ended comments volunteered on Questions 8, 9, and 4 of the STEP Student Follow-up Survey. Participants responded to questions about job, college, or vocational training readiness and to their participation in postsecondary training after high school graduation. Although not all students who returned the survey volunteered answers to these items, 30 of the 50 participants did. Not all of the participants answered all three of the qualitative items.

For Question 8, thirteen of the 22 students who volunteered answers had positive comments about the STEP Grant job readiness while 4 of 22 wanted additional training or more career readiness added to the curriculum. In regard to readiness for college or vocational training, 13 students commented that the program did help them get ready for college or vocational training and two others wanted more college or vocational training added to the curriculum. The comments to the postsecondary training question listed one student who is attending a 4-year college and 11 others who were currently enrolled (at the time of the survey) or had been enrolled after high school. No information on completion of degrees was available since the survey was conducted between 1-3 years of graduation dates. Two of the participants had completed skill training which will help them access jobs with greater salary and advancement (Plumbing and Electricity). 
Analysis for RQ7

In spite of the focus of the STEP Grant on postsecondary education, only 12 of the 50 participants were enrolled or had been enrolled since high school. The participants gave good suggestions regarding for high school transition program improvement. Because of the voluntary nature of these comments, no information was available about the 20 other participants nor from the other 58 participants in the STEP Grant who chose not to return the Follow-up Survey. Yet the respondents were similar to those studies reviewed by Kohler (1996) who found that many school districts were not effective in developing or implementing transition services for postsecondary education.

In their follow-up study on affective issues (poor self-esteem, a lack of selfacceptance, vocational success, and personal independence) related to employment and postsecondary education, Fourqurean and LaCourt (1990) included student and parent comments about program improvement. Students in their study identified the need to develop positive personal images in high school, e.g., overcoming shyness, increasing social skills, and improving self-concept. Likewise, students in the STEP Grant provided valuable information for program improvement, but did not specifically enumerate the social issues named by Fourqurean and LaCourt's students.

Parent comments were not included in the STEP Grant, but were in the Fourqurean and LaCourt (1990) study. In addition to the negative stigma from assignment to special education classes, parents' comments suggested that increased attention was needed for their children's needs to be met. Those listed included: (a) lack of understanding of learning disabilities, (b) lower self-confidence, and (c) lower self-esteem. Information from parents whose children were included in the STEP Grant would certainly have added a dimension of understanding to this study. When following up by phone on non-responders 
for the STEP Grant Student Follow-up Survey, N. Terry, the PC for the STEP Grant, heard many positive comments from parents (personal communication, July 15, 2000). Unfortunately, these represent anecdotal evidence which was not gathered on a systematic basis.

\section{Recommendations}

The STEP Grant provided insight to planning, programming, and transition outcomes for a small group of students with mild disabilities who exited high schools during the 1997-2000 school years. Both specific issues related to the STEP Grant and to general transition are addressed below. Transition planning and services have been the focus of IDEA legislation since 1975, with more specific recommendations for transition added by the 1990, 1997, and 2004 amendments (CEC, 2006a). Transition planning and supports for transition were the primary foci of the STEP Grant; therefore, implementation practices by the school district are an integral aspect of this partial program review.

\section{STEP Grant and Transition Programs/Practice}

First, strategies and materials used in the STEP Grant should be disseminated to all schools in the district. One purpose for this Grant was to pilot strategies and materials for county-wide dissemination in classes for mildly disabled students; this was not accomplished at the end of the Grant. Materials and strategies were piloted, but data were not collected on effectiveness and were not part of this research. Two of the main approaches used were Content Enhancement Learning Strategies and IPLAN Self-

Determination Skills. These were based on research from the University of Kansas (Van Reusen \& Bos, 1990) and normed for students with mild disabilities. The Content Enhancement materials (Graphic Organizers, Course Organizers, Unit Organizers, Lesson Organizers, Survey Routine, Concept Mastery Routine, Concept Anchoring Routine, 
Concept Comparison Routine, Quality Assignment Routine, Clarifying Routine, and Framing Routine), were used by teachers in the STEP Grant to assist students in organizing their coursework in both academic and vocational classes. Self-Determination strategies helped students gain personal insight to their responsibilities in planning for their futures. Both organization and self-determination strategies need to be incorporated in P-16 educational programs for students with mild disabilities across the school district. Getzel et al. (2004) described a postsecondary model, in Virginia, for supported education using similar organizational strategies and self-advocacy. Students involved reported that the support gave them a better understanding of their disability and learning routines. Therefore, these strategies should begin with elementary schools and continue into postsecondary education.

Second, the professional development in transition services, programs, and outcomes provided by the STEP Grant should be continued for both administrators and teachers. This training helped educators at secondary and postsecondary levels to understand learning strategies, programs, and evaluation systems necessary for students with mild disabilities to be successful. The STEP Grant provided training for school district personnel and others connected to the grant at the six Grant high schools, but there was no county-wide continuation of training to include teachers at other high schools in the district or middle and elementary teachers. Development of this infrastructure needs to be done system-wide. Connections to postsecondary education and vocational training benefit all special needs students as they move from high school to adult venues.

Third, work-related classes, experiences, and employment opportunities for students with mild disabilities should be expanded. The STEP Grant included assistance from the PC and Job Trainer to model strategies, provide job placement, and implement a 
specially-designed Elective Class for the students to work on job-related skills. For the short duration of the grant, this was successful in keeping this small group of students in school. However, the district did not provide dissemination of these services system-wide. Limited numbers of students with mild disabilities participate in the C.O.V.E. program (a joint project with Vocational Rehabilitation to provide supervised work experience). However, only six job trainers serve approximately 60 students across the county; thus, many students with mild disabilities are not able to participate in these services. Previous to the STEP Grant a system of work experience classes (World of Work curriculum and job coordinators) was in place. These classes were eliminated when the academic focus under KERA shifted to help students meet higher standards and increased attention was placed on the state-wide KIRIS tests (now CATS). The system of initiatives and work experience delivery needs to be reinitiated and coordinated with accountability initiatives.

Fourth, how educators and parents view the IEP and Transition Planning process should be addressed. Is planning for post-high school an integral part of the IEP or an "add-on" responsibility? Without "living” the activities that constitute the IEP, words on the document become meaningless. At the time of the STEP Grant many educators and parents considered the IEP as a short-term academic plan, while the Transition Plan became the long-range planning document. Both the planning and activities guide the educational program toward desired goals for the individual (Flexer et al., 2005; Steere et al., 2007; Wehman, 2004). Planning connected to the Transition Plan as detailed in IDEA legislation should begin at age 14 or 8 th grade in order to plan the high school curriculum in coordination with career goals. This requirement necessitates coordination of the program with middle schools where culminating activities in planning and career exploration are accomplished. Important aspects of planning include: (a) Involve students 
in making realistic career choices; (b) Expand the students' ability to work toward selfdetermination; (c) Help students understand the educational requirements to reach their stated goals; and (d) Plan academic and vocational programs to support the attainment of the goals with the student and family. These items are necessary to develop the Transition Plan, which should be an evolving document that is reviewed at least annually prior to the IEP meeting. When interests or goals are changed by the student, the plan should be adjusted accordingly.

Fifth, long term follow-up should target students after they leave the schools. This is now required instead of optional, and as district information for outcomes is available, data should be analyzed on a continuing basis to make educational offerings more realistic for this group. An effective monitoring system was not in place at the time of the STEP Grant. New regulations, part of the IDEA legislation that was reauthorized in 2004, require extensive monitoring of the service delivery system. School districts are being held accountable for educational programming and tracking these students after they leave the public schools. The six-year State Performance Plans, submitted by school districts beginning in December 2005, included about 20 indicators on which data will be submitted annually to the U.S. Department of Education through the Office of Special Education Programs in Annual Performance Reports. Indicator 13 relates to transition services for students:

Percent of youth aged 16 and above with an individualized education program (IEP) that includes coordinated, measurable, annual IEP goals and transition services that will reasonably enable the student to meet the postsecondary goals. (20 U.S.C. 1416(a)(3)(B), as cited in NSTTAC, 2006, ף2)

The Indicator 13 Checklist, approved on September 8, 2006, is provided to states by NSTTAC as a resource to present evidence that students with disabilities receive an 
adequate education in the areas of Education and Training, Employment, SelfDetermination, and Independent Living.

Sixth, schools need to implement a better system of coordinating IEPs with educational offerings that target student interests. By analyzing school records, it was clear that career goals, vocational training, and jobs did not match. Many of these students with mild disabilities need ongoing support after high school to jobs related to their interests, retain jobs, and possibly to advance in their field. Although community agency involvement in IEPs was not a focus for this research, the literature review demonstrated that a continuing issue is long term follow-up information for adults with mild disabilities related to job retention and advancement. Similarly, schools need to involve community organizations early in the planning process to connect students with these resources in order to access continued support for long-range postsecondary training.

Seventh, schools need to implement a system that trains students with mild disabilities to participate actively in development of an IEP. Assurances are required by IDEA, Indicator 13 (CEC, 2006) that the IEP includes Education/Training, Employment, Independent Living, and Self-Determination goals (Szymanski, 1992, 1994; Wehmeyer, 1994). This suggestion entails professional development for staff, parents, and students. When students begin to internalize their responsibility for planning and understand that their future is in their own hands, greater involvement in the coordinated set of activities designed to develop successful transition will be seen. Students need to be taught the principles of self-determination and how to apply them in order to gain the skills to manage planning for adult life. Support from administrators, teachers, and parents at all levels (elementary, middle, and high) will be needed to support this policy and make it a reality. 
Eighth, school leaders need to insure that collaboration among academic, vocational, and special education teachers is of high quality and inclusion of students with mild disabilities is a reality. Collaboration and inclusion, when applied according to best practices, will insure that students with mild disabilities are members of the regular education class group and not regarded as an "extra” person just coming in to visit. Academic, vocational, and special education teachers need to implement speciallydesigned instruction for mildly disabled students to make better progress toward academic and vocational goals.

\section{Policy Considerations}

Policy considerations enable the district to develop strategies to guide practice for application at the school level. Research into effective transition delivery (Hasazi et al., 1999) suggested that a set of six policies and practices were common in model transition projects designed to improve outcomes at every level of transition. These authors also noted that measures for program evaluation and improvement should be expanded. Similar items were noted in this research and are included below.

First, the school district needs to implement a career education and counseling system for students with disabilities that begins in elementary school and continues through their high school years. This policy involves implementing the approved career education curriculum from the Kentucky Program of Studies (KDE, 1998b) and requires staffing changes as well as program changes to allow for work experiences. The Career Education element is an all-encompassing concept in which academic and vocational experiences overlap. This helps the student understand requirements for careers and obtain experiences in career fields as they develop in maturity. As a result of unrealistic choices students and parents need to be advised about the educational or physical requirements of a 
career field. This would require an ongoing parent education program as well as student counseling/advising. Most districts do not have "career classes" since they put most of their funds into academic classes. Educators need to take the students' career choices more seriously and build experiences that allow the students to explore their chosen profession. Career concepts need to be embedded throughout the curriculum. The STEP Grant records analysis showed a discrepancy between career choices, vocational training, and jobs obtained. Through effective career education, choices should become more realistic and related to student interests and abilities.

Second, the school district needs to investigate more effective methods for providing vocational education services to students with disabilities. Vocational offerings do not match the wide variety of career interests students expressed in this research. A different structure that allows job exploration and work experiences needs to be devised. Training in postsecondary education is more difficult for students with mild disabilities to access, so participation during high school is critical. Also, a system to insure interagency collaboration for continued support is a key element for success as an adult. Vocational programs have emphasized higher academic requirements and connections to mathematics and science for the regular curriculum in response to business recommendations. Vocational teachers have advisory boards which help them update their offerings. Those connections need to be strengthened and expanded to accommodate the entry-level positions in each field and to expand employment opportunities with area businesses.

Third, the school district needs to implement a policy that provides students with disabilities programming associated with adult independent lives. This includes responsibilities in life skills, budgeting, and many other skills outlined in the Life Skills Curriculum (Brolin, 1997; Super, 1990). This curriculum was used in the STEP Grant as 
well.

Fourth, articulation agreements with postsecondary teachers of students with mild disabilities need to be developed. Postsecondary teachers, as well as all levels of P-12 educators, need to use best practices in transition and specially-designed instruction. The school district needs to identify ways to collaborate with area postsecondary institutions in order to improve enrollment in postsecondary programs and ensure support for students with disabilities. Research has shown that with proper amounts of support, many students with mild disabilities can be very successful in postsecondary education (Getzel et al., 2004). Learning routines, organizational strategies, and other strategies similar to those used in the STEP Grant were utilized in college settings by Getzel et al. to continue exploring career outcomes. Students in their project identified this support as very helpful. As students gain maturity, expertise in technology, social skills, and more experience into career requirements, they will be able to make better decisions for continued success (KimRupnow \& Burgstahler, 2004).

\section{Future Research}

The present research has provided an overview for a sub-group of 50 students who received special programming to keep them in school to finish their high school diploma and connect them to postsecondary education or employment. Overall, by completing high school requirements and obtaining diplomas, the group is substantially better off than most students with mild disabilities (Blackorby \& Wagner, 1996; NTLS2, 2003). However, as was seen in the section on transition outcomes, many of these students still ended up in low-paying, service-related jobs. This study did identify a myriad of questions that need to be answered by future research. The questions are grouped by topic and are not allinclusive or mutually exclusive. 
First, the federal government has passed legislation that requires school districts to provide programming to all students. Two of these legislative acts, IDEA and NCLB, have consistently received less than full funding. Adequate funding to implement educational programs in general has been elusive. Research has identified many best practices for academic, vocational, and special education programs (Kohler, 1993), but future research needs to be done to show school districts how to budget for all of the needs that face them. The STEP Grant demonstrated several best practices for transition to adult life for students with mild disabilities, yet the school district was neither able to maintain these services at the six Grant high schools nor implement them across the district after the Grant funding was completed, mainly due to budget constraints. As is often the case with grant funding, initiatives are difficult to sustain without the extra funding. Society is demanding that school programs provide higher levels of learning for students to be competitive in the global job market. How can they do this while also providing the inclusive programming with long-range focus that special education students need to become successful?

Second, transition planning is required by the federal legislation, IDEA (1990, 1997), IDIEA (2004), and NCLB (2004) legislation. Transition planning requires students, parents, and teachers to review plans in conjunction with IEPs. Educators need to ensure courses are taken during high school years to prepare students for entrance into the work force or postsecondary education/training area. The research conducted for this study clearly showed that transition planning was lacking for this small group of participants. Future research is needed to see if this same lack of planning exists for the larger population of students with mild disabilities in the school district. Is this lack of planning noticeable within the state, and in the United States as well? To what extent does the IEP/Transition Plan actually follow good practices in the developmental stages and guide 
educators and students in the implementation of those plans? To make a difference in outcomes, good planning techniques are a critical component for successful transition. In addition to coordination between educators, the system for accomplishing the planning needs attention. Many questions remain; some examples of specific questions to be answered follow.

a. Why were so many career goals missing from the transition plans? Research should determine if goals are now more likely to appear on the IEP, since the electronic process has been implemented. Underlying this goal question is the measurement of the ability and experience of students with mild disabilities ability to choose a career area. Do these students have sufficient experiential base to allow them to decide what type of job they want for the future? Put more bluntly, many children with disabilities receive extra care and concern from both parents and educators, and rightly so. But does this in effect represent “over-protectiveness” that shields these young people from learning to make their own decisions as compared to non-disabled teenagers? Furthermore, many students with disabilities require extra assistance and supervised practice to master cognitive learning tasks. Does decision-making with respect to life processes such as transition to adulthood also require extra attention? (See paragraph below on this same point with respect to career testing.)

b. Who is responsible for ensuring that the transition/IEP is high quality and includes best practices? In the STEP Grant, elective class teachers were responsible for monitoring Transition Plans. Even with this added emphasis on planning, the records review revealed that only 28 of 50 students in the STEP Grant had completed plans. Middle and high schools assign different people to accomplish the completion of the Transition Plan. Sometimes, if the students were enrolled in Vocational Education, 
vocational teachers have responsibility for completing the planning. If the student were not enrolled in Vocational Education, the Special Education teachers typically have that responsibility. In other schools Transition Plans are filled out in an English class as a group project. In South Carolina, Zhang et al. (2005) found similar results that indicated various members of the school took responsibility for transition services. The IDEA legislation states that all educators have a responsibility to help in this planning and that a regular academic teacher must be part of the IEP planning (CEC, 2004). With the implementation of the state-wide electronic version of the IEP in which transition is embedded, what changes, if any, have occurred with respect to responsibilities for this process?

c. Career test results are also part of the Transition Planning system. In the local school district, the career interest and aptitude testing portion of transition planning is scheduled in Grade 10. Testing is usually done through the English classes to reach all students, but the English teachers are usually not assigned to monitor the Transition Plan. When students are absent for one or more days of testing, a system of make-up exams needs to be scheduled. Results of the career tests are compiled on the Transition Plan and should be compared to the career choice that the student lists in another section of the plan. Future research should investigate the effectiveness of the career aptitude and interest testing system. How are results applied to student planning when scores are returned to high schools from the two Career Testing Laboratories? If the test results do not match the student-selected career choice, is an advising session held? Can students with mild disabilities accurately report their interests and aptitudes on a paper/pencil test? Do they understand the questions and do they understand the Likert scale in making their choices? What type of preparation would this group of students need in order to participate more effectively in the testing process? Related to testing, the same types of questions apply to 
the state-wide, high-stakes academic testing. Are students with mild disabilities in need of some form of alternative testing procedures or alternate ways to demonstrate progress? What help is given to assist them with test-taking strategies on state-wide as well as classroom tests?

d. Regardless of who has responsibility for completing planning forms or ensuring that the career interest and aptitude testing is accomplished, planning must result. How effective is the system for transition planning? Does it meet best practices for students with mild disabilities?

Third, although the number of students in this study was small, results in connecting career goals, vocational training, and jobs held at the time of the Follow-up Survey showed a definite lack of coordinated transition planning. Even though the STEP project was designed to strengthen career planning and successful transition to adult outcomes, twenty-two out of fifty participants were missing transition goals. Additional research is needed to determine if coordinated planning of coursework exists in the district schools at the level of best practices. Is additional training of the administrators and teachers needed in order to improve implementation of best practices in transition (Kohler, 1993)? Why is there a difference between GPA and VGPA? Are there different strategies that would help make academic and vocational learning more effective?

Fourth, future research should address disconnects in communication and collaboration between academic, vocational, and special education teachers in educating and planning for transition. Academic, Vocational and Special education teachers all have responsibilities for providing these coordinated services and monitoring progress on the IEP. Recent legislation (IDIEA, 2004) has strengthened requirements for transition planning to be included in the IEP and the Indicator 13 checklist (CEC, 2004) has been 
provided to help schools measure their progress. School districts are required to send this checklist, along with other IDEA documentation, to the federal government annually to document their progress in providing quality transition services. Since this monitoring process did not exist at the time of the STEP Grant, how effective is its current implementation?

Fifth, is teacher preparation at the university level effective in helping teachers understand how to implement collaboration with other teachers and planning for diverse populations in their classrooms? Do teacher training programs demonstrate and require practice in inclusion and differentiated instruction? What are the attitudes of beginning teachers toward collaboration, inclusion, and transition/IEP planning? What are the attitudes of the university instructors toward these same concepts? The Kentucky Professional Standards Board is in the process of implementing a system to connect students' performance with the university that prepared the teachers. How will teacher education programs fare under this comparison?

Sixth, future research is needed to evaluate state-wide requirements for increased graduation requirements and provide alternate ways that students with disabilities can meet these goals more realistically. Students with mild disabilities usually do better in situations where they can directly apply what they learn. Additional studies are needed to determine if the increased graduation requirements will raise completion of high school diplomas beyond the reach of many of these students without some accommodations.

Seventh, there were a number of findings from the quantitative analyses conducted in this study that should be highlighted, all deserving of future research. These are enumerated briefly below. The reader should remember that all of these findings are based upon a small grant $(N=108)$ and that only 50 of those students returned the survey upon 
which these data are based, so both representativeness and generalizability are an issue for the current study. At the same time, the findings here clearly warrant more in-depth investigation.

a. Results of psychometric analysis indicate that the Self-efficacy-General and Social Scales are not acceptable for use with this population without modification. Both subscales were altered by removing one item to come closer to an acceptable alpha level, and even then the Social subscale was slightly below the relaxed standard of .6 for exploratory research. The Locus of Control measure also produced a barely acceptable alpha, especially considering the 40 item length. More research is clearly needed on these instruments for use with mildly disabled individuals. As well, more research on personality scales generally needs to be conducted to check whether they are adequate for this population.

b. The finding that disability (coded $1=\mathrm{MMD}, 2=\mathrm{BD}, 3=\mathrm{LD}$ ) was strongly and negatively associated with wages earned was unexpected. Is this a product of the particular sample in this study? Or, is it an indicator that LD students perhaps fall through the cracks, receiving less attention and career counseling than students with MMD or BD? Or, is the time spent with LD students totally focused on academics to master content for the high school diploma so that postsecondary education is the goal? How many students with mild disabilities from the local schools attend postsecondary education? What percentages of students with mild disabilities attend and finish their postsecondary education across the state? How many successfully complete their training course or degree? Of those who do complete their degree, what are the percentages that actually obtain careers in their chosen field? What are high schools doing to support these students in gaining entrance to vocational training or postsecondary education after high school? For those students who 
do not choose to further their education, what job supports exist in the local community? Often these students do not qualify for services through Vocational Rehabilitation. Do they have the personal and social skills to access job applications; interview successfully; and get and keep jobs? What are the employment and unemployment rates for this population? Was the $91.30 \%$ employment in service-related, generally low-status jobs specific to this study sample, or is this the norm for adults with mild disabilities?

c. The relationships for the two self-efficacy scales (General and Social) with both Hours and Wages, while not significant in this study, were all negative for this population, opposite of what would be expected. Does this have to do with the over-estimation of ability by many LD students in both self-efficacy and academic skills, as reported by Klassen (2002)? Research into understanding this phenomenon is needed.

d. The only semipartial correlation that was significant was the effect of Attendance on Wages, controlling for the six Demographic Factors. But that was negative. And the parallel $s r$ for Hours was also negative, although not significant. Why? Was this a product of this sample? Does this hold true for the larger population of mildly disabled students? Is less attention given to "better" students who attend regularly? Are there differences in assertiveness or other factors in students who attend less frequently than those who have higher attendance?

e. The Self-Improvement construct (one of the five STEP Intervention Factors) based on 10 questions (five on insight to personal understanding, strengths, ways to improve, learning styles, and how to become more successful; three on choosing job or career, training, and planning future goals; and two on job or college/vocational training readiness) had essentially no significant relationships throughout this study. The one significant correlation was with number of Vocational Semesters taken, but there was no 
relationship to Transition Outcomes (Hours worked or Wages earned). However, the two semipartial correlations for Wages and Hours, although not significant, were in the negative direction. Is this a product of the questions in the construct? Or is this a reflection that the students did not perceive or find these factors that beneficial? Do students understand the abstract concepts represented by personality constructs and insights for personal improvement? Do students with mild disabilities over-estimate their abilities in understanding these concepts, as reported by Klassen (2002)? Do these personality constructs affect the type of jobs obtained and job responsibilities that students with mild disabilities receive?

\section{Conclusions}

The STEP Grant was a three-year, federally funded grant to pilot best practices in transition from school to adult life for mildly disabled students (MMD, BD, and LD). The Grant was developed in six high schools in a Midwest metropolitan school district and served a population of 108 students. A No-Cost Extension of the project provided one additional year to continue support to the students who had entered during the final year of the grant (1998-1999) and assist them in finishing their diploma requirements. The extra year gave the PC and this researcher time to develop the STEP Grant Student Follow-up Survey, obtain permission through the school district and University of Louisville research departments to accomplish the follow-up study, and obtain the mailing list of participants.

During the grant years (1996-1999), materials and strategies were piloted; career exploration was accomplished and linked to postsecondary programs; students were given assistance in job development and placement; personality factors (self-advocacy, selfefficacy, locus of control) were explored with students; and self-determination skills were taught in the Elective Classes. Extended on-campus visits allowed the participants to spend 
time in vocational and academic college classes and learn about the Disability Centers at each postsecondary site. Travel to the postsecondary sites from the six high schools was done by utilizing the public bus system which gave the participants an introduction to travel training. The 108 students were encouraged to stay in school rather than dropping out, and the 50 students who participated in the STEP Follow-up Survey were able to complete requirements for their diplomas. In this respect, the program was highly beneficial for this group of students who were from low socioeconomic backgrounds and were at risk of dropping out of high school. Specifically, 46 of 50 were successful according to the STEP criteria and all 50 of the participants who completed the Follow-up Survey finished high school. Compared to typical experiences for students with mild disabilities (Blackorby \& Wagner, 1996; NTLS2, 2003), this program was tremendously successful.

As long as the STEP Grant was paying for the PC and Job Trainer, the six schools reaped excellent results. The PC benefited the school district by providing direct services to the project as well as professional development sessions for district teachers and administrators. Included in this training were postsecondary instructors to expand the infrastructure to teachers, vocational rehabilitation counselors, and other agency personnel who will work with these students in the adult world. Postsecondary instructors who participated in this training even included educational staff from one of the local prisons since they had identified many inmates with mild mental disabilities, behavior disabilities, and learning disabilities. Although this group of community persons was not part of this present research, including them in this summary shows the depth of the STEP Grant in trying to provide high-quality, far-reaching effects. However, as soon as the Grant ended, most of the services also stopped. The school district was not able to find ways to continue 
funding services, and chose not to continue the professional development for teachers on more effective methods in meeting the transition needs of these students with mild disabilities. Consequently, the STEP Grant model was not continued at the six high schools.

The literature reviewed at both state and national levels showed visionary programs and strategies that were successful in many parts of the United States. Best practices from demonstration grants need to be developed into standards for school districts to follow in providing programming and services. The best parts of these programs need to be identified and unified into a comprehensive transition system for students in the local district. By doing this, the district would be able to serve students with mild disabilities better as well as those students in regular education who are just below average who need additional supports to become successful. Methods to incorporate what has been learned into a collaborative, cooperative academic and vocational program would offer students a much greater chance of successful transition into adult life.

Teachers have their plate full with the new graduation requirements and mandates from IDIEA and NCLB legislation. The school district program emphasis has not been on transitioning students to the adult world unless it included academics and high-stakes testing. However, recent test scores released from the Kentucky Department of Education show that many schools are struggling with how to help students with disabilities become more successful in displaying what they are learning. Research strategies and alternate methods of testing, teaching, or measuring success for these students need to be demonstrated and integrated into the state-wide system. Many successful tactics have been displayed through the federal demonstration projects in the 1990s, but few have been implemented locally. 
Career education, as well as character and personality development, needs longer term development with at least a P-16 timeline for most students with mild disabilities. These students often find it difficult to gain personal insight about these factors and extra time can be quite beneficial. Typical emphasis in high school may not be sufficient to show success. Parents and students need to be included in education sessions to understand the program from elementary to postsecondary levels. Psychological concepts and personal insights must be developed with full cooperation and understanding with families.

Overall, this research seems to have raised more questions than answers. Widely variant experiences for advising, counseling, teacher preparation, and implementation exist. Administrators have different views for how this group of students with mild disabilities should be educated. Creative efforts toward meeting the demands of providing services need to be developed that do not depend on additional funding. Mandates from federal legislation require that all students are ensured of participation in the educational system and that schools focus on narrowing the gap between students with disabilities and the non-disabled. As long as schools are mandated to serve all students, sufficient funding and implementation systems (policies and practices) need to be in place to accomplish the task. Documentation, continued comparison of all these factors, and identification of ways to measure implementation of best practices need to be an integral part of future research. In today's society, education is a business. Regardless of whether this perspective is an adequate conceptualization of education (and many proponents suggest that it is not), return on investment is important for the future of citizens with disabilities. Unless policymakers and educators are committed to making this investment, both the individuals who have a disability and the country that is denied the potential of their contributions, will be shortchanged. 


\section{REFERENCES}

Akos, P. (2002). Student perceptions of the transition from elementary to middle school. Professional School Counseling, 5, 339-345.

Alston, R., Bell, T. J., \& Hampton, J. L. (2002). Learning disability and career entry into the sciences: A critical analysis of attitudinal factors. Journal of Career Development, 20, 263-275.

Alston, R., Hampton, J. L., Bell, T. J., \& Straus, M. (1998). Matriculation of persons with disabilities in science and engineering: Perceptions of rehabilitation counselors. Journal of Applied Rehabilitation Counseling, 29(3), 5-9.

Alvares, A., \& Adelman, H. S. (1986). Overstatements of self-evaluations by students with psychoeducational problems. Journal of Learning Disabilities, 19, 567-571.

Alwell, M., \& Cobb, B. (2006). A map of the intervention literature in secondary special education transition. Career Development for Exceptional Individuals, 29, 3-27.

Anthony, D. (2006). Qualitative analysis. Web-based training module, De Montfort University. Retrieved July 25, 2007 from http://writing.colostae.edu/references/research/casestudy/

Aquilino, W. S. (1991). Family structure and home leaving: A further specification of the relationship. Journal of Marriage and the Family, 53, 999-1010.

Bach, L., \& Berk, L. E. (1999, April). The role of imaginary companions in the development of social skills and play maturity. Poster presented at the biennial meeting of the Society for Research in Child Development, Albuquerque, NM.

Baer, R. (1996). The Summit County L.I.F.E. Project: Linkages for individual and family empowerment (Report). Kent, OH: Kent State University, Center for Innovation in Transition and Employment.

Baer, R., Simmons, T., \& Flexer, R. (1996). Transition practice and policy compliance in Ohio: A survey of secondary special educators. Career Development for Exceptional Individuals, 19, 61-71.

Bandura, A. (1977). Self-efficacy: Toward a unifying theory of behavioral change. Psychological Review, 84, 191-215.

Bandura, A. (1982). Self-efficacy mechanism in human agency. American Psychologist, 
$37,122-147$.

Bandura, A. (1986). Social foundations of thought and action: A social-cognitive theory. Englewood Cliffs, NJ: Prentice Hall.

Bandura, A. (1993). Perceived self-efficacy in cognitive development and functioning. Educational Psychologist, 28, 117-148.

Bandura, A., Barbaranelli, C., Capara, G. V., \& Pastorelli, C. (2001). Self-efficacy beliefs as shapers of children's aspirations and career trajectories. Child Development, 72, 187-206.

Bandura, A., Capara, G. V., Barbaranelli, C., Pastorelli, C., \& Regalia, C. (2001). Sociocognitive self-regulatory mechanisms governing transgressive behavior. Journal of Personality and Social Psychology, 80, 125-135.

Bandura, A., Pastorelli, C., Barbaranelli, C., \& Caprara, G. V. (1999). Self-efficacy pathways to childhood depression. Journal of Personality and Social Psychology, 76, 258-269.

Barclay, J., \& Cobb, J. (2001). Full life ahead: A workbook and guide to adult life for students and families of students with disabilities. Montgomery, AL: Southeast Regional Resource Center.

Beadles, R. J., Jr., McDaniel, R. S., \& Waters, S. (2000). Vocational outcomes of sensory impaired graduates of an adult vocational training program. Journal of Visual Impairment \& Blindness, 94, 275-280.

Benz, M. R., \& Halpern, A. S. (1993). Vocational and transition services needed and received by students with disabilities during their last year of high school. Career Development for Exceptional Individuals, 16, 197-211.

Benz, M., \& Kochhar, C. (1996). School-to-work opportunities for all students: A position statement of the Division on Career Development and Transition. Career Development for Exceptional Individuals, 19, 31-48.

Benz, M. R., Yovanoff, P., \& Doren, B. (1997). School-to-work components that predict post school success for students with and without disabilities. Exceptional Children, 63, 151-165.

Bergeson, T. (2004) Addressing the achievement gap: No Child Left Behind: The Elementary and Secondary Education Act. Office of Public Instruction, Olympia, WA. Retrieved July 28, 2006, from http://www.k12.wa.us/ESEA/

Berk, L. (1999). Infants and children (3rd ed.). Boston: Allyn \& Bacon.

Best, S. J., Heller, K. W., \& Bigge, J. L. (2005). Teaching individuals with physical or 
multiple disabilities (5th ed.). Upper Saddle River, NJ: Pearson Education, Inc.

Bingham, G. (1980). Career maturity of learning disabled adolescents. Psychology in the School, 17, 135-139.

Blackorby, J., \& Wagner, M. (1996). Longitudinal post school outcomes of youth with disabilities: Findings from the National Longitudinal Transition Study. Exceptional Children, 62, 399-413.

Blalock, G. \& Patton, J. R. (1996). Transition and students with learning disabilities. Journal of Learning Disabilities, 29, 7-17.

Blomquist, K. B., Brown, G., Peersen, A., \& Presler, E. P. (1998). Transitioning to independence: Challenges for young people with disabilities and their caregivers. Orthopaedic Nursing, 17(3), 27-35.

Boeree, C. G. (1998). Albert Bandura: 1925-present. Personality theories. Retrieved November 7, 2006, from http://www.ship.edu/ cgboeree/bandura.html

Bosscher, R. J., \& Smit, J. H. (1998). Confirmatory factor analysis of the General SelfEfficacy Scale. Behavior Research \& Therapy, 36, 339-343.

Bramston, P., \& Cummins, R. A. (1998). Stress and the move into community accommodation. Journal of Intellectual \& Developmental Disability, 23, 295-308.

Brickman, A. S., \& Deyo, S. (1991). A supervised independent living orientation program for adolescents. Child Welfare, 70, 69-80.

Brinkerhoff, L. D., McGuire, J. M., \& Shaw, S. F. (2002). Postsecondary education and transition for students with learning disabilities (2nd ed.). Austin, TX: PRO-ED.

Brolin, D. E. (1997). Life-centered career education: A competency-based approach. Reston, VA: The Council for Exceptional Children.

Brolin, D. E., \& Schatzman, B. (1989). Lifelong career development. In D. E. Berkell \& J. M. Brown (Eds.) Transition from school to work for persons with disabilities (pp. 22-41). New York: Longman.

Brookover, W., Beady, C., Flood, P., Schwetzer, J., \& Wisenbaker, J. (1979). School social systems and student achievement: Schools can make a difference. New York: Praeger Publishers.

Brown, B. L. (2003). The image of career and technical education (Practice Application Brief No. 25). ERIC: Educational Resources Information Center. (ERIC Document Reproduction Service No. ED 475 110)

Brown, J. D. (1996). Testing in language programs. Upper Saddle River, NJ: Prentice 
Hall Regents.

Brown, L., Branston, M., Hamre-Nietupski, S., Pumpian, I., Certo, N., \& Gruenewald, L. (1979). A strategy for developing chronological age-appropriate and functional curriculum content for severely handicapped students and young adults. Journal of Special Education, 13, 81-90.

Brown, L., Nietupski, J., \& Hamre-Nietupski, S. (1976). Criterion of ultimate functioning. In A. Thomas (Ed.), Hey, don't forget about me! Reston, VA: CEC Information Center.

Brown, R. I., Bayer, M. B., \& MacFarlane, C. (1988). Quality of life amongst handicapped adults. In R. I. Brown (Ed.), Quality of life for handicapped people. Rehabilitation education: A series in developmental handicap (pp. 111-140). New York: Croom Helm in association with Methuen, Inc.

Buck, N., \& Scott, J. (1993). She's leaving home: But why? An analysis of young people leaving the parental home. Journal of Marriage and the Family, 55, 863-874.

Burgstahler, S. (2001). Work-based learning and students with disabilities: One step toward high-skill, high-pay careers. American Rehabilitation, 26, 1-9.

Byrd, D. E., (1990). Peer tutoring with the learning disabled: A critical review. Journal of Educational Research, 84, 115-118.

Caballo, V. E. (1993). Relaciones entre diversas medidas conductuales y de autoinforme de las habilidades sociales [Relationships among some behavioral and self-report measures of social skills]. Psicologia Conductual, 1, 73-99.

Campbell, D. T. (1969). Reforms as experiments. American Psychologist, 24, 409-429.

Carnine, D., Silbert, J., \& Kameenui, E. (1990). Direct instruction reading. Columbus, $\mathrm{OH}$ : Merrill.

Chamberlain, M. (1988). Employers' rankings of factors judged critical to job success for individuals with severe disabilities. Career Development for Exceptional Individuals, 11, 141-147.

Choi, N. (2003). Further examination of the Self-efficacy Scale. Psychological Reports, 92, 473-480.

Choi, N., Fuqua, D. R., \& Griffin, B. W. (2001). Exploratory analysis of the structure of scores from the multidimensional scales of perceived self-efficacy. Educational and Psychological Measurement, 61, 475-489.

Chubb, N. H., Fertman, C. I., \& Ross, J. L. (1997). Adolescent self-esteem and locus of control: A longitudinal study of gender and age differences. Adolescence, 32, 113- 
129.

Clark, G. M., \& Kolstoe, O. P. (1995). Career development and transition education for adolescents with disabilities. Boston: Allyn and Bacon.

Clark, G., Carlson, B., Fisher, S., Cook, I., \& D’Alonzo, B. (1991). Career development for students with disabilities in elementary schools: A position statement of the Division on Career Development. Career Development for Exceptional Individuals, 14, 109-120.

Cobb, B., Halloran, W., Simon, M., Norman, M., \& Bourexis, P. (1999). Meeting the needs of youth with disabilities: Handbook for implementing community-based vocational education programs according to the Fair Labor Standards Act (2nd ed.).

Minneapolis: University of Minnesota, The National Transition Network, Institute on Community Integration.

Coleman, J. S., Campbell, E. Q., Hobson, C. J., McPartland, J., Mood, A. M., Weinfeld, F. D., et al. (1966). Equality of educational opportunity. Washington, DC: National Center for Educational Statistics.

Colley, D. A., \& Jamison, D. (1998). Post school results for youth with disabilities: Key indicators and policy implications. Career Development for Exceptional Individuals, 21, 145-160.

Committee on Labor and Human Resources. (1993). Goals 2000: Education America Act: Report together with additional and minority views. Calendar No. 106, Senate Report 103-85, 19-21.

Copeland, S. R., McCall, J., Williams, C. R., Guth, C., Carter, E. W., Fowler, S. E. et al. (2002). High school peer buddies: A win-win situation. TEACHING Exceptional Children, 35, 16-21.

Council for Exceptional Children. (2006a). Department of Education releases final IDEA 2004 Part B Regulations. Retrieved May 3, 2006, from http://www.cec.sped.org

Council for Exceptional Children. (2006b). Study synthesis shows gains and problem areas for students with disabilities. Retrieved July 30, 2006, from http://www.cec.sped.org

Coutinho, M. J., Oswald, D. P., \& Best, A. M. (2006). Differences in outcomes for female and male students in special education. Career Development for Exceptional Individuals, 29, 48-59.

Creswell, J. (2002). Educational research: Planning, conducting, and evaluating quantitative and qualitative research. Upper Saddle River, NJ: Merrill Prentice Hall. 
Crocker, L., \& Algina, J. (1986). Introduction to classical and modern test theory. New York: Holt, Rinehart, and Winston.

Cronbach, L. J. (1951). Coefficient alpha and the internal structure of tests. Psychometrica, $16,297-334$.

Cummings, R., Maddus, C. D., \& Casey, J. (2000). Individualized transition planning for students with learning disabilities. Career Development Quarterly, 49, 60-72.

Curnow, T. C. (1989). Vocational development of persons with disability. Vocational Guidance Quarterly, 37, 269-278.

Cutler, A., Ferry, F., Kauk, R., \& Robinett, R. (1995). Judgment of Occupational Behavior-Orientation (JOB-O Enhanced). Auburn, CA: CFKR Career Materials, Inc.

deFur, S. (1999). Transition planning: A team effort. National Information Center on Children and Youth with Disabilities (NICHCY). Washington, DC. Retrieved June 12, 2003, from http://www.lsi.ukans.edu/apps/riil/review.asp?9

Denzin, N. K., \& Lincoln, Y. S. (2000). Introduction: The discipline and practice of qualitative research. In N. K. Denzin \& Y. S. Lincoln (Eds.), Handbook of qualitative research (2nd ed., pp. 1-28). Thousand Oaks, CA: Sage.

Durlak, C. M., \& Rose, E. (1994). Preparing high school students with learning disabilities for the transition to postsecondary education: Teaching the skills of selfdetermination. Journal of Learning Disabilities, 27, 51-59.

Dweck, C. S. (1986). Motivational processes affecting learning. American Psychologist, 41, 1040-1048.

Dweck, C. S., \& Leggett, E. (1988). A social-cognitive approach to motivation and personality. Psychological Review, 95, 256-273.

Educational Professional Standards Board. (2006). Scoring Manual for Kentucky Teacher Internship Program (KTIP). Retrieved January 10, 2006, from http://www.kyepsb.net

Eisenman, L. T. (2000). Characteristics and effects of integrated academic and occupational curricula for students with disabilities. Career Development for Exceptional Individuals, 23, 105-119.

Ellis, E. S., Lenz, B. X., \& Sabornie, E. J. (1987). Generalization and adaptation of learning strategies to natural environments. Part 2: Research into practice. Remedial and Special Education, 8(2), 6-23.

Ennis, L. S. (2002). Effects of instructional strategies in seventh grade science 
achievement as perceived by Kentucky students. Unpublished doctoral dissertation, University of Louisville.

Erford, B. T. (1995). Parent autonomy-enhancement and development of self-efficacy. Psychological Reports, 77, 1347-1353.

Estrada, L., Dupoux, E., \& Wolman, C. (2006). The relationship between locus of control and personal-emotional adjustment and social adjustment to college life in students with and without learning disabilities. College Student Journal, 40, 43-54.

Everson, J. D., Zhang, D., \& Guillory, J. D. (2001). A statewide investigation of individualized transition plans in Louisiana. Career Development for Exceptional Individuals, 24, 37-49.

Field, A. (2005). Discovering statistics using SPSS (2nd ed.). London: SAGE Publications.

Field, S., Martin, J., Miller, R., Ward, M., \& Wehmeyer, M. (1998). A practical guide for teaching self-determination. Reston, VA: Council for Exceptional Children.

Findley, M., \& Cooper, H. (1983). Locus of control and academic achievement: A literature review. Journal of Personality and Social Psychology, 44, 419-427.

Fisher, J., \& Corcoran, K. (1994). Measures for clinical practice: A sourcebook. Volume 2: Couples, families, children (2nd ed.). New York: The Free Press, Macmillan.

Flavell, J. H. (1976). Metacognitive aspects of problem solving. In L. B. Resnick (Ed.). The nature of intelligence (pp. 231-235). Hillsdale, NJ: Erlbaum.

Flexer, R. W., Baer, R. M., Luft, P., \& Simmons, T. J. (2008). Transition planning for secondary students with disabilities (3rd ed.). Upper Saddle River, NJ: MerrillPrentice Hall.

Flexer, R. W., Simmons, T. J., Luft, P., \& Baer, R. M. (2001). Transition planning for secondary students with disabilities. Upper Saddle River, NJ: Merrill-Prentice Hall.

Flexer, R. W., Simmons, T. J., Luft, P., \& Baer, R. M. (2005). Transition planning for secondary students with disabilities (2nd ed.). Upper Saddle River, NJ: MerrillPrentice Hall.

Folkman, S., \& Lazarus, R. S. (1985). If it changes it must be a process: A study of emotion and coping during three states of a college examination. Journal of Personality and Social Psychology, 48, 839-852.

Fourqurean, J. M., \& LaCourt, T. (1990). A follow-up of former special education students: A model for program evaluation. Remedial and Special Education, 12, 16-23. 
Gall, M. D., Borg, W. R., \& Gall, J. P. (1996). Educational research: An introduction (6th ed.). White Plains, NY: Longman Publishers.

Gardner, H. (2003). How education changes: Considerations of history, science, and values. In M. Suarez-Orozco \& D. Qin-Hilliard (Eds.), Education and globalization: Culture and education in the new millennium. Berkeley: University of California Press. Retrieved September 23, 2006, from http://www.pz.harvard.edu/PIs/HG_HowEducationChanges.pdf

George, M. P., George, N. I., \& Grosenick, J. K. (1990). Features of program evaluation in special education. Remedial and Special Education, 11, 23-30.

Getzel, E. E., \& deFur, S. (1997). Transition planning for students with significant disabilities: Implications for student-centered planning. Focus on Autism and Other Developmental Disabilities, 12, 39-48.

Getzel, E. E., McManus, S., \& Briel, L. W. (2004). An effective model for college students with learning disabilities and attention deficit hyperactivity disorders. Research to Practice Brief, 2(1), 1-6. Retrieved September 15, 2006, from www.ncset.org

Giangreco, M. F., Cloninger, C. J., \& Iverson, V. S. (1993). Choosing outcomes and accommodations for children $(\mathrm{COACH})$. Baltimore: Paul H. Brookes.

Giordano, G., \& D’Alonzo, B. J. (1994). The link between transition and independent living. American Rehabilitation, 20, 2-7.

Godoy, J. F., Muela, J. A., Sanchez-Barrera, M. B., \& Sanchez-Huete, J. R. (1995). Marcadores de vulnerabilidad/factores de proteccion en la prevencion de la esquizofrenia [Vulnerability markers/protection factors in the prevention of schizophrenia]. Psicologia Conductual, 3, 35-46.

Goldhammer, R., \& Brinckerhoff, L. C. (1993). Self-advocacy for college students. National Center for Learning Disabilities. Retrieved July 15, 2002, from http://www.ldonline.org/ld_indepth/postsecondary/ncld_selfadv.html

Gonzalez, P. (1992). State procedures for the evaluation of special education program effectiveness. Project FORUM. Alexandria, VA: National Association of State Directors of Special Education.

Goldscheider, F. K., \& DaVanzo, J. (1989). Pathways to independent living in early adulthood: Marriage, semi-autonomy, and premarital residential independence. Demography, 26, 278-285.

Griffee, D. T. (1999). Questionnaire construction and classroom research. The Language Teacher. Retrieved November 17, 2006, from http://www.jalt=publications.org/tlt/articles/1999/01/griffee 
Grigal, M. E. (2001). A survey of parents and teachers of students in secondary special education regarding transition and self-determination. Dissertation Abstracts International, 62(03), 973. (UMI No. 300 9011)

Grigal, M. E., \& Neubert, D. A. (2004). Parents' in-school values and post-school expectations for transition-aged youth with disabilities. Career Development for Exceptional Individuals, 27, 65-85.

Grigal, M., Neubert, D. A., \& Moon, M. S. (2001). Public school programs for students with significant disabilities in post-secondary settings. Education and Training in Mental Retardation and Developmental Disabilities, 36, 244-254.

Grigal, M., Neubert, D. A., Moon, M. S., \& Graham, S. (2003). Parents' and teachers' views of self-determination for secondary students with disabilities. Exceptional Children, 70, 97-112.

Haddad, A., \& Kapp, M. (1991). Ethical and legal issues in home health care: Case studies and analyses. Norwalk, CT: Appleton \& Lange.

Hagborg, W. J. (1999). Scholastic competence subgroups among high school students with learning disabilities. Learning Disability Quarterly, 22, 3-10.

Halpern, A. (1985). Transition: A look at the foundations. Exceptional Children, 51, 479502.

Halpern, A. (1993). Quality of life as a conceptual framework for evaluating transition outcomes. Exceptional Children, 59, 486-498.

Halpern, A. S., Benz, M. R., \& Lindstrom, L. E. (1992). A systems change approach to improving secondary special education and transition programs at the community level. Career Development for Exceptional Individuals, 12, 167-177.

Halpern, A. S., Doren, B., \& Benz, M. R. (1993). Job experiences of students with disabilities during their last two years of school. Career Development for Exceptional Individuals, 16, 63-73.

Halpern, A. S., Yovanoff, P., Doren, B., \& Benz, M. R. (1995). Predicting participation in post-secondary education for school leavers with disabilities. Exceptional Children, 62, 151-164.

Hambleton, R. K. (1980). Test score validity and standard setting methods. In R. A. Berk (Ed.). Criterion-referenced measurement: The state of the art (pp. 80-123). Baltimore: Johns Hopkins University Press.

Hammill, D. D., \& Bryant, B. R. (1998). Learning Disabilities Diagnostic Inventory (LDDI). Austin, TX: PRO-ED. 
Hamilton, M. A., \& Hamilton, S. F. (1994). Toward a youth apprenticeship program: Progress report from the youth apprenticeship demonstration project in Broome County, New York. Cornell University, American Youth Policy Forum, Cornell Youth and Work Program, Jobs for the Future. (ERIC Document Reproduction Services No. ED 393 970)

Hampton, N. Z., \& Mason, E. (2003). Learning disabilities, gender, sources of efficacy, self-efficacy beliefs, and academic achievement in high school students. Journal of School Psychology, 41, 101-112.

Haring, K., Lovett, D., \& Smith, D. (1990). A follow-up study of recent special education graduates of learning disabilities programs. Journal of Learning Disabilities, 23, $108-113$.

Harp, H. (1990). Independent living with support services: The goal and future for mental health consumers. Psychosocial Rehabilitation Journal, 13, 85-87.

Harter, S., \& Connell, J. (1982). A comparison of alternative models of the relationships between academic achievement and children's perceptions of competence, control, and motivational orientation. In J. Nicholls (Ed.), The development of achievementrelated cognitions and behaviors (pp. 219-250). Greenwich, CT: J. A. I. Press.

Harvey, M. (2001). Vocational-technical education: A logical approach to dropout prevention for secondary special education. Preventing School Failure, 45, 108113.

Hasazi, S. B., Furney, K. S., \& DeStefano, L. (1999). Implementing the IDEA transition mandates. Exceptional Children, 65, 555-567.

Hays, J. R., \& Buckle, K. E. (1992). Self-efficacy among hospitalized mentally ill patients. Psychological Reports, 70, 57-58.

Helgeson, D. C., Mittan, R., Tan, S. Y., \& Chayasirisobhon, S. (1990). Sepulveda epilepsy education: The efficacy of a psychoeducational treatment program in treating medical and psychosocial aspects of epilepsy. Epilepsia, 31, 75-82.

Henderson, C. (2001). College freshmen with disabilities: A biennial statistical profile Heath Resource Center. American Council on Education, 1-50.

Henry, R. (2004). Putting it together: Planning an effective evaluation (IAMSE Web cast Audio Seminar). Retrieved on October 17, 2006, from http://www.iamse.org/development/2004/henry.pdf

Hershenson, D., \& Szymanski, E. M. (1992). Career development of people with disabilities. In R. M. Parker \& E. M. Szymanski (Eds.), Rehabilitation counseling: Basics and beyond (2nd ed., pp. 273-303). Austin, TX: PRO_ED. 
Hicks, J. S. (2002). Absenteeism within special education: An exploratory analysis. Dissertation Abstracts International Section A: Humanities and Social Sciences, 63 (5-A), 1784. (UMI No. AAI3052178)

Hoffman, F. J., Sheldon, K. L., Minskoff, E. M., Sautter, S. W., Steidel, E. F., Baker, D. et al. (1987). Needs of learning disabled adults. Journal of Learning Disabilities, 20, 43-53.

Holden, G., Cuzzi, L., Rutter, S., Chernack, P., \& Rosenberg, G. (1997). The Hospital Social Work Self-efficacy Scale: A replication. Research on Social Work Practice, 7, 490-499.

Holland, J. L., \& Powell, A. B. (1994). Self-Directed Search Career Explorer. Odessa, FL: Psychological Assessment Resources, Inc.

Horner, C., \& Maddux, C. (1985). The effect of Logo on attributions toward success. Computers in the Schools, 2, 45-54.

Hosmer, D., \& Lameshow, S. (1989). Applied logistic regression. New York: John Wiley.

Hudecki, P. (2006). Update on new legislation (Perkins III). Retrieved September 18, 2006, from http://vocserv.berkeley.edu/CW10.2/CW102_UPDATE.html

Hughes, C. (2001). Transition to adulthood: Supporting young adults to access social, employment, and civic pursuits. Mental Retardation and Developmental Disabilities Research Reviews, 7, 84-90.

Hughes, C., \& Carter, E. W. (2000). The transition handbook: Strategies for high school Teachers [to] use that work! Baltimore: Paul H. Brookes.

Hughes, C., Eisenmann, L. T., Hwang, B., Kim, J., Killian, D. J., \& Scott, S. V. (1997). Transition from secondary special education to adult life: A review and analysis of empirical measures. Education and Training in Mental Retardation and Developmental Disabilities, 32, 85-104.

Hughes, C., Hwang, B., Kim, J., Eisenman, L. T., \& Killian, D. J. (1995). Quality of life in applied research: A review and analysis of empirical measures. American Journal on Mental Retardation, 99, 623-636.

Hughes, C., Wethby, J. H., Carter, E. R., Plank, D. R., Wilson, L. R., Johnson, S. M. et al. (2004). Summer activities of youth with high-incidence disabilities from highpoverty backgrounds. Career Development for Exceptional Individuals, 27, 27-42.

Jastak, S., \& Wilkinson, G. (1984). Wide-range Achievement Test-Revised. Wilmington, DE: Jastak Assessment Systems.

Jang, H. S. (1997). The comparison of a 3-group model with a 4-group model of adult 
attachment. Korean Journal of Developmental Psychology, 10, 123-138.

Johnson, L. R. (1998). Program evaluation in special education: An examination of the practices utilized by local education agencies. Poster session presented at the Council for Exceptional Children Convention, Minneapolis. (ERIC Document Reproduction Service No. ED 424 291)

Joint Committee on Standards for Educational Evaluation. (1994). The program evaluation standards (2nd ed.). Thousand Oaks, CA: Sage.

Jones, A. L., \& Jolly, S. N. (2003). Power in North Carolina parents: Is there a relationship between family structure and adolescent self-efficacy? [Electronic version]. Sociation Today, 1. [The Official Journal of North Carolina Sociological Association: A refereed Web-Based Publication.] Retrieved August 16, 2006, from http://www.ncsociology.org/sociationtoday/v2/jones.htm

Kalechstein, A. D., \& Nowicki, S. Jr. (1997). A meta-analytic examination of the relationship between control expectancies and academic achievement: An 11-year follow-up to Findley and Cooper. Genetic, Social, and General Psychology Monographs, 123, 27-57.

Kavale, K. A., \& Forness, S. R. (1996). Social skill deficits and learning disabilities: A meta-analysis. Journal of Learning Disabilities, 29, 226-237.

Keane, M. C., \& Morgan, B. S. (1991). Perceived self-efficacy and language differences. Psychological Reports, 69, 291-298.

Keefe, J. (1999). Final Report on Human Resource Issues in Home Care: Comparative Analysis of Employment Arrangements. Knowledge and Dissemination Division, Health Canada. Retrieved July 18, 2007 from http://www.swc-fc.gc.ca/pubs/ pubspr/0662280857/199911_0662280857_2_e.pdf

Keesler, V. A. (2003, Aug). Learning to work: A study of secondary vocational education. Paper presented at the annual meeting of the American Sociological Association, Atlanta Hilton Hotel, Atlanta, GA. Retrieved October 5, 2006 from http://www.allacademic.com/meta/p107094_index.html

Kentucky Department of Education. (1990a). Kentucky Education Reform Act (KERA). Kentucky's Learning goals and Academic Expectations. Retrieved July 8, 2002, from http://www.kde.state.ky.us

Kentucky Department of Education. (1990b). Kentucky Systems Change Project Report. Retrieved April 15, 2003, from www.kde.ky.state.us

Kentucky Department of Education. (1993). Kentucky Transition Project Report. Retrieved December 16, 2002, from www.kde.ky.state.us 
Kentucky Department of Education. (1998a). Implementation Manual for the Program of Studies. Retrieved May 28, 2005, from http://www.kde.state.ky.us

Kentucky Department of Education. (1998b). Program of Studies. Retrieved May 28, 2005, from http://www.kde.state.ky.us

Kentucky Department of Education. (2001). Students receiving special education in KY for 2000-2001, and Exit data for 2000-2001. Retrieved January 11, 2007, from http://www.kde.state.ky.us

Kentucky Department of Education. (2002). A guide to selecting career clusters and career majors in Kentucky. Retrieved October 15, 2007, from http://education.ky.gov/ kde/Instructional+Resources/Career+and+Technical+Education/Career+Clusters/

Kentucky Department of Education. (2006). Definitions of Exceptional Children Categories. Division of Exceptional Children Services. Retrieved January 11, 2006, from www.kde.ky.state.us

Kentucky Department of Vocational Rehabilitation. (1995). Community Based Work Transition-Job Trainer Program. Retrieved March 15, 2004, from http://www.ihdi.uky.edu

Kim-Rupnow, W. S., \& Burgstahler, S. (2004). Perceptions of students with disabilities regarding the value of technology-based support activities on postsecondary education and employment. Journal of Special Education Technology, 19(2), 1-22.

Kirkpatrick, D. L. (1994). Evaluating training programs: The four levels. San Francisco: Berrett Koehler Publishers.

Klassen, R. (2002). A question of calibration: A review of the self-efficacy beliefs of students with learning disabilities. Learning Disabilities Quarterly, 25, 88-102.

Klein, J., \& Keller, J. (1990). Influence of student ability, locus of control, and type of instructional control on performance and confidence. Journal of Educational Research, 83, 149-146.

Kleinert, H. L., \& Kearns, J. F. (1999). A validation study of the performance indicators and learner outcomes of Kentucky's alternate assessment for students with significant disabilities. Journal of the Association for Severely Handicapped, 24, 100-110.

Kochhlar-Bryant, C. A., Shaw, S., \& Izzo, M. (2007). What every teacher should know about transition and IDEA 2004. Boston: Pearson Education, Inc.

Kohler, P. D. (1993). Best practice in transition: Substantiated or implied? Career Development for Exceptional Individuals, 16, 107-121. 
Kohler, P. D., \& Chapman, S. (1999). A literature review on school to work transition. University of Illinois at Urbana-Champaign, Transition Research Institute. Retrieved December 1, 1999, from http://www.ed.uniuc.edu/sped/tri/stwresearch.htm

Kortering, L., \& Braziel, P. (2000). A look at the expressed career ambitions of youth with disabilities. Journal for Vocational Special Needs Education, 23, 24-33.

Kortering, L., Haring, N., \& Klockars, A. (1992). The identification of high-school dropouts

identified as learning disabled: Evaluating the utility of a discriminant analysis function. Exceptional Children, 58, 422-435.

Kregel, J. (1992). A consumer empowerment approach to the design of human service systems. Implications for supported employment. In V. Brooke, M. Barcus, \& K. Inge (Eds.), Consumer advocacy and supported employment: A vision for the future (pp. 34-48). Richmond: Virginia Commonwealth University, Rehabilitation Research and Training Center on Supported Employment.

Kurtz, L. A. (1992). Cerebral palsy. In M. L. Bartshaw \& Y. M. Perret (Eds.), Children with disabilities: A medical primer (3rd ed., pp. 441-469). Baltimore: Paul H. Brookes.

Lackaye, T., Margalit, M., Ziv, O., \& Ziman, T. (2006). Comparisons of self-efficacy, mood, effort, and hope between students with learning disabilities and their nonLD-matched peers. Learning Disabilities Research and Practice, 21, 111-121.

Lakes, W. (2006). Asbury College Connection. Retrieved August 5, 2006, from http://www.qualitymall.org/products/prod5.asp?prodid=448

Lamb, P., Brown, M., Hodges, B., \& Foy, D. (2004). Building bridges toward science careers for youth with disabilities. Research to Practice Brief, 3(2), 1-6. National Center on Secondary Education and Transition. Retrieved September 15, 2006, from www.ncset.org

Lee, C., \& Bobko, P. (1994). Self-efficacy beliefs: Comparison of five measures. Journal of Applied Psychology, 79, 364-369.

Levesque, K., Lauen, S., Teitelbaum, P., Alt, M., \& Librera, S. (2000). Vocational education in the United States: Toward the year 2000. Education Statistics Quarterly, 2, 9-18. Retrieved September 18, 2006, from http://nces.ed.gov/programs/quarterly/vol_2/2_1/q9-1.asp

Levinson, E. M. (1993). Transdisciplinary vocational assessment. Issues in school-based programs. Brandon, VT: Clinical Psychology Publishing.

Levinson, E. M., \& Ohler, D. L. (1998). Transition from high school to college for students 
with learning disabilities: Needs, assessment, and services. High School Journal, $82,62-70$.

Liebert, R. M., \& Spiegler, M. D. (1990). Personality: Strategies and issues (6th ed.). Pacific Grove, CA: Brooks-Cole Publishers.

Lock, R. H., \& Layton, C. A. (2001). Succeeding in postsecondary education through selfadvocacy. TEACHING Exceptional Children, 34, 66-71.

Luthar, S. (1991). Vulnerability and resistance: A study of high-risk adolescents. Child Development, 62, 600-616.

Luther, B. (2001). Age-specific activities that support successful transition to adulthood for children with disabilities. Orthopaedic Nursing, 20, 23-29.

Lyons, R. (2004). The influence of socioeconomic factors on Kentucky's public school accountability system: Does poverty impact school effectiveness? Education Policy Analysis Archives, 12(37). Retrieved December 26, 2006, from http//epaa.asu.edu/epaa/v12n37/

Madaus, J. W. (2005). Navigating the college transition maze: A guide for students with learning disabilities. TEACHING Exceptional Children, 37(3), 32-37.

Madaus, J. W. (2006). Employment outcomes of university graduates with learning disabilities. Learning Disability Quarterly, 29, 19-31.

Madaus, J. W., Foley, T. E., McGuire, J. M., \& Ruban, L. (2001). A follow-up investigation of university graduates with learning disabilities. Career Development for Exceptional Individuals, 24, 133-146.

Madaus, J. W., \& Shaw, S. F. (2004). Section 504: The differences in the regulations regarding secondary and postsecondary education. Intervention in School and Clinic, 40, 81-87.

Mallinckrodt, B., Coble, H. M., \& Gantt, D. L. (1995). Working alliance, attachment memories, and social competencies of women in brief therapy. Journal of Counseling Psychology, 42, 79-84.

Mallincrodt, B., Gantt, D. L., \& Coble, H. M. (1995). Attachment patterns in the psychotherapy relationship: Development of the Client Attachment to Therapist Scale. Journal of Counseling Psychology, 42, 307-317.

Marascuilo, L. A., \& McSweeney, M. (1977). Nonparametric and distribution free methods for the social sciences. Monterey, CA: Brooks/Cole Publishing Company.

Marsh, H. W., \& Gouvernet, P. (1989). Multidimensional self-concepts and perceptions of control: Construct validation of responses by children. Journal of Educational 
Psychology, 81, 57-69.

Marsh, H. W., \& Hau, K. T. (2004). Explaining paradoxical relations between academic self-concepts and achievements: Cross-cultural generalizability of the internal/external frame of reference predictions across 16 countries. Journal of Educational Psychology, 96, 56-67.

Masterson, J. F. (1985). Treatment of the borderline adolescent: A developmental approach. New York: Brunner/Mazel.

Mastropieri, M. A., \& Scruggs, T. (2007). The inclusive classroom: Strategies for effective instruction (3rd ed.). Upper Saddle River, NJ: Pearson Education, Inc.

Matthews-Berenson, M. (1992). Innovations in rural independent living. American Rehabilitation, 18, 11-13.

Mattoo, S. K., \& Malhotra, R. (1998). Self-efficacy Scale: Hindi translation and factor structure. Indian Journal of clinical Psychology, 25, 154-158.

Maurer, T. J., \& Pierce, H. R. (1998). A comparison of Likert scale and traditional measures of self-efficacy. Journal of Applied Psychology, 83, 324-329.

May, K. M., \& Sowa, C. J. (1994). Personality characteristics and family environments of short-term counseling clients. Journal of College Student Development, 35, 59-62.

McCombs, B. (1991). Metacognition and motivation in higher level thinking. Paper presented at the annual meeting of the American Educational Research Association, Chicago.

McCrea, L. D. (1991). A comparison between the perceptions of special educators and employers: What factors are critical for job success? Career Development of Exceptional Individuals, 14, 121-130.

McNamara, C. (1998). Basic guide to program evaluation: Some myths about program evaluation. Retrieved September 29, 1999, from http://www.mapnp.org/library/evaluatn/fni_eval.htm

Meyer, J. W., \& Rowan, B. (1977). Institutional organizations: Formal structure as myth and ceremony. American Journal of Sociology, 83, 340-363.

Meyer, J. W., \& Rowan, B. (1978). The structure of educational organizations. In M. W. Meyer \& Associates (Eds.), Environments and organizations (pp. 78-109). San Francisco: Jossey-Bass Publishers.

Miller, D. (1983). The age between: Adolescence and therapy. New York: Jason Aronson Publisher. 
Miller, R. J. (1988). The effects of selected characteristics on the learning disabled subject's decision to participate in post-secondary education opportunities. Unpublished doctoral dissertation, University of Iowa, Iowa City.

Miller, R. J., Lombard, R. C., \& Corbey, S. A. (2007). Transition assessment: Planning transition and IEP development for youth with mild to moderate disabilities. Boston: Pearson Education, Inc.

Miller, S. K. (1992). Changing conceptions of "good schools": Implications for reforming urban education. Education and Urban Society, 25, 71-84.

Miller, S. K., \& Moore, B. D. (2005, July). Demography as destiny? Accountability data from urban high schools in Kentucky. Paper presented at the 2005 National Evaluation Institute. Memphis, TN.

Molenda, M., Pershing, J. A., \& Reigeluth, C. M. (1996). Designing instructional systems. In R. L. Craig (Ed.), The ASTD Training and Development Handbook: A guide to Human Resource Development (pp. 266-293). Alexandria, VA: American Society for Training and Development.

Moon, M.S., Grigal, M., \& Neubert, D.A. (2001). High school and beyond. Exceptional Parent, 31, 52-57.

Moore, B. L. D. (2003). An exploration of the influence of demographic factors on individual and aggregate student achievement measurements in the Kentucky accountability system. Unpublished doctoral dissertation, University of Louisville.

Morningstar, M. E., Turnbull, A. P., \& Turnbull, H. R. (1995). What do students with disabilities tell us about the importance of family involvement in the transition from school to adult life? Exceptional Children, 62, 249-260.

Morrow, G. (1986). Standardizing practice in the analysis of school dropouts. Teachers College Record. 87, 342-355.

Muñoz, M. A., \& Dossett, D. (2001). Equity and excellence: The effect of school and sociodemographic variables on student achievement. Journal of School Leadership, $11,120-134$.

Muris, P. (2001). A brief questionnaire for measuring self-efficacy in youths. Journal of Psychopathology and Behavioral Assessment, 23, 145-149.

Murray, C., Goldstein, D. E., Nourse, S., \& Edgar, E. (2000). The post-secondary school attendance and completion rates of high school graduates with learning disabilities. Learning Disabilities Research \& Practice, 15, 119-127.

Narita, K., Shimonaka, Y., Nakazato, K., Kawai, C., Sato, S., \& Osada. Y. (1995). A Japanese version of the generalized Self-efficacy Scale--Scale utility from the life- 
span perspective. Japanese Journal of Educational Psychology, 43, 306-314.

National Center on Educational Outcomes. (1999). Retrieved December 1, 1999, from http://www.coled.umn.edu/NCEO

National Center for Education Statistics. (2002). Retrieved May 25, 2003, from http://ed.gov/pubs2002/digest2001/sources_3.asp

National Center for Research on Vocational Education. (2006). Retrieved September 18, 2006, from http://vocserve.berkeley.edu/CW102-ECECUTI.html

National Collaborative on Workforce and Disability. (2003). Retrieved May 24, 2003, from www.ncwdyouth.info/resources_\&_Publications/ publications_browse.php?display +20

National Longitudinal Transition Study 2 (NLTS2): Youth with disabilities: A changing Population. A report of Findings from the National Longitudinal Transition Study (NLTS) and the National Longitudinal Transition Study-2 (NLTS2). Executive Summary. (Prepared by M. Wagner, R. Cameto, \& Lynn Newman). (2003). Menlo Park, CA: SRI International. Retrieved April 31, 2003, from http://www.nlts2.org/reports/2003_04-1/nlts2_report_2003_04-1_exesum.pdf

National Secondary Transition Technical Assistance Center. (2006). What is indicator 13? Retrieved September 24, 2006, from http://www.nsttac.org/?FileName=indicator13

Neubert, D. A., Moon, M. S., Grigal, M., \& Redd, V. (2001). Post-secondary educational practices for individuals with mental retardation and other significant disabilities: A review of the literature. Journal of Vocational Rehabilitation, 16, 155-168.

Nichols, D. P. (1999). My coefficient $\alpha$ is negative! SPSS Keywords, 68, 1-4. Retrieved August 22, 2006, from http://www.ats.ucla.edu/STAT/SPSS/library/negalpha.htm

Nirje, B. (1969). The normalization principal and its human management implications. In R. B. Jugel and W. Wolfensberger (Eds.), Changing residential patterns for the mentally retarded (pp. 227-254). Washington, DC: President's Committee on Mental Retardation.

Nirje, B. (1972). The right to self-determination. In W. Wolfensberger, (Ed.), Normalization: The principle of normalization (pp. 176-200). Toronto: National Institute on Mental Retardation.

Nitko, A. J. (2001). Educational assessment of students (3rd ed.). Upper Saddle River, NJ: Prentice Hall.

North Central Regional Educational Laboratory. (2005). [This website was one of 10 federal regional laboratories whose contract ended in 2005. This site has been taken over by The Learning Point Associates and will be available through REL.com 
(Regional Educational Laboratories]. Retrieved June 8, 2005, from http://www.ncrel.org/sdrs/areas/issues/student/learning/lr2locus.htm

Norton, J. (1998). Managing to learn. Changing Schools in Louisville, 2(2), 1-6. Retrieved January 23, 2007, from http:www.middleweb.com/CLSV4.html

Nowicki, S., Jr., \& Duke, M. P. (1974). A locus of control scale for non-college as well as college adults. Journal of Personality Assessment, 38, 136-137.

Nowicki, S., Jr., \& Strickland, B. R. (1971). Locus of Control Scale (Educational Testing Service Test Collection Library, Tracking Number: TC006839). Princeton, NJ.

Nowicki, S., Jr., \& Strickland, B. R. (1973). A Locus of Control Scale for children. Journal of Consulting and Clinical Psychology, 40, 148-154.

Nunn, G. D., \& Nunn, S. J. (1993). Locus of control and school performance: Some implications for teachers. Education, 113, 636-640.

Nunnaly, J. C. (1978). Psychometric theory (2nd ed.). New York: McGraw-Hill.

Nunnally, J. C., \& Bernstein, I. H. (1994). Psychometric theory. New York: McGraw-Hill.

O'Brien, J., \& Lovett, H. (1993). Finding a way toward everyday lives: The contribution of person-centered planning. Harrisburg: Pennsylvania Office of Mental Retardation.

Office of Special Education Programs Data Collection History. (2003). Retrieved June 6, 2005, from http://www.ideadata.org/docs/bfactshectex.pdf

Ohio Valley Educational Cooperative. (1999). A transition guide and transition checklist. Retrieved September 29, 2003, from http://www.nta.edu [This page is no longer available: Grant ended in 1999. Information is now at the National Center on Secondary Education and Transition: School to Work Sustainability: A Resource for States. (2001). NCSET Partner Resource]. Retrieved May 27, 2003, from http://ici.umn.edu/ncset/publications/nta/stwstoolkit/default.html

Olsen, K., \& Massanari, C. (1991). Special education program evaluation: What should states consider? Lexington: University of Kentucky, Mid-South Regional Resource Center.

Osipow, S. H. (1983). Theories of career development (3rd ed.). Englewood Cliffs, NJ: Prentice-Hall.

Pain, K., Dunn, M., Anderson, G., Darrah, J., \& Kratochvil, M. (1998). Quality of life: What does it mean in rehabilitation? Journal of Rehabilitation, 64(2), 5-19.

Pajares, F., \& Kranzler, J. (1995). Self-efficacy beliefs and general mental ability in 
mathematical problem-solving. Contemporary Educational Psychology, 20, 426443.

Pajares, F., \& Schunk, D. H. (2001). Self-beliefs and school success: Self-efficacy, selfconcept and school achievement. In R. Riding \& S. Rayner (Eds.), Perception (pp. 239-266). London: Ablex Publishing.

Parnell, D. (1986). The neglected majority. Washington, DC: Community College Press.

Patton, R. J., \& Polloway, E. A. (1982). The learning disabled: The adult years. Topics in Learning and Learning Disabilities, 2, 79-88.

Peters, T. L., \& Heron, T. E. (1993). When the best is not good enough: An examination of best practice. Journal of Special Education, 26, 371-385.

Petrosko, J. (2000). Assessment and accountability [Electronic version]. In J. Petrosko \& J. C. Lindle (Eds.), 2000 review of research on the Kentucky Education Reform Act (pp. 1-81). Lexington: Kentucky Institute for Education Research.

Phelps, L. A., \& Hanley-Maxwell, C. (1997). School-to-work transitions for youth with disabilities: A review of outcomes and practices. Review of Educational Research, 67, 197-226.

Pierro, A. (1997). Caratteristiche strutturali della scala di General Self-efficacy [Structural characteristics of the General Self-efficacy Scale]. Bollettino di Psicologia Applicata, 221, 29-38.

Pietsch, J., Walker, R., \& Chapman, E. (2003). The relationship among self-concept, selfefficacy, and performance in mathematics during secondary school. Journal of Educational Psychology, 95, 589-603.

Pines, S., Dickerson, V., \& Cates, L. (2002). O'NET Dictionary of Occupational Titles (2nd ed.). Indianapolis: Jist Publishing, Inc.

Powers, K. M., Gil-Kashiwabara, E., Greenen, S. J., Powers, L. E., Balandran, J., \& Palmer, C. (2005). Mandates and effective transition planning practices reflected in IEPs. Career Development for Exceptional Individuals, 28, 47-59.

Powers, L. E., Turner, A., Matuszewski, R. W., \& Loesch, C. (1999). A qualitative analysis of student involvement in transition planning. Journal for Vocational Special Needs Education, 21, 18-26.

Proctor, D., \& McElvey, R. (2001). Articulation within the Tech Prep Program. Techdirections, 61, 22-23.

Redfearn, S. (1996). The future is bright. Career options in home health. The Nursing and Allied Health Journal for Minorities, 4, 18-20, 28. 
Repetto, J. B. (2003). Transition to living. Exceptionality, 11, 77-87.

Ridings, J. M., \& Stufflebeam, D. (1981). Evaluation reflections: The project to develop standards for educational evaluation: Its past and future. Studies in Educational Evaluation, 7, 3-16.

Roe, A., Krumboltz, J., \& Hershenson, D. (1990). Personality development and career choice. In D. Brown, L. Brooks, \& Associates (Eds.), Career choice and development: Applying contemporary theories to practice (2nd ed., pp. 68-101). San Francisco: Jossey-Bass.

Roessler, R., Brolin, D., \& Johnson, J. (1990). Factors affecting employment success and quality of life: A one-year follow-up of students in special education. Career Development for Exceptional Individuals, 13, 95-107.

Roessler, R. T., Fitzgerald, S. M., Rumrill, P. D., \& Koch, L. C. (2001). Determinants of employment status among people with multiple sclerosis. Rehabilitation Counseling Bulletin, 45, 31-39.

Rojewski, J. W. (1993). Theoretical structure of career maturity for rural adolescents with learning disabilities. Career Development for Exceptional Individuals, 16, 39-52.

Rojewski, J. W. (1999). Applying theories of career behavior to special populations: Implications for secondary vocational transition programming. Issues in Special Education and Rehabilitation, 9, 7-26.

Rossi, P. H., Freeman, H. E., \& Lipsey, M. W. (1999). Evaluation: A systematic approach (6th ed.). Thousand Oaks, CA: Sage Publications.

Rotter, J. B. (1966). Generalized expectancies for internal versus external control of reinforcement. Psychological Monographs, 80(Whole No. 609).

Rotter, J. B. (1993). Expectancies. In C. E. Walker (ed.). The history of clinical psychology in autobiography (Vol. II, pp. 273-284). Pacific Grove, CA: Brooks/Cole. Retrieved August 8, 2006, from http://psych.fullerton.edu/jmearns/rotter.htm

Rotter, J. B. (1996). Locus of Control Questionnaire. Retrieved August 8, 2006, from http://www.psych.uncc.edu/pagoolka/LocusofControl-intro.html

Ruhland, S. K. (2003). Evaluating tech prep education programs: Implications for reporting program and student outcomes. Journal of Vocational Education Research, 28, 35-57. Retrieved August 8, 2006, from http://scholar.lib.vt.edu/ejournals/JVER/v28n1/ruhland.html

Ruhland, S. K., Jurgens, C., \& Ballard, D. (2003). Tech prep's role in education reform: 
Perceptions from state tech prep directors. Journal of Vocational Education Research, 20, 69-85. Retrieved August 8, 2006, from http://www.natpl.org/top/images/docs/JCTE-TP-State-Directors-NAT.pdf

Rusch, F. R., \& Chadsey, J. G. (1998). Beyond high school: Transition from school to work. Belmont, CA: Wadsworth Publishing Company.

Rusch, F. R., Kohler, P. D., \& Hughes, C. (1992). An analysis of OSERS-sponsored secondary special education and transitional services research. Career Development for Exceptional Individuals, 15, 121-143.

Rusch, F. R., \& Millar, D. M. (1998). Emerging transition best practices. In F. R. Rusch \& J. G. Chadsey (Eds.), Beyond high school: Transition from school to work (pp. 3660). New York: Wadsworth.

Sanders, W. L. (2004). A Summary of conclusions drawn from longitudinal analyses of student achievement data over the past 22 years (1982-2004). Paper presented to Governors Education Symposium, Asheville, NC. Retrieved September 27, 2006, from http://www.sas.com/goveduedu/bio_sanders.html

Sanders, W. L. (2006). Schooling effectiveness: SAS EVASS for K-12. Retrieved September 27, 2006, from http://www.sas.com/govedu/edu/services/effectiveness.html

Sarkees-Wircenski, M., \& Scott, J. L. (1995). Vocational special needs. Homewood, IL: American Technical Publishers, Inc.

Schrag, J. (1994). Evaluating the impact and effectiveness of special education based on program and student outcomes (Final report for National Association of State Directors of Special Education). Alexandria, VA. (ERIC Document Reproduction Service No. ED 374 588)

Schugurensky, D. (2006). History of education: Selected moments of the 20th century. Retrieved July 28, 2006, from http://fcis.oise.utoronto.ca/ daniel_sch/assignment1/1965elemsec.html

Schumaker, J. B., Deshler, D. D., \& Ellis, F. S. (1986). Intervention issues related to the education of LD adolescents. In J. K. Torgesen \& B. Y. L. Wong (Eds.). Learning disabilities: Some new perspectives (pp. 329-365). New York: Academic Press.

Scriven, M. S. (1967). The methodology of evaluation. In R. E. Stake (Ed.). Curriculum evaluation, AERA monograph series on curriculum evaluation (Vol. 1, pp. 39-83). Chicago: Rand McNally.

Scriven, M. S. (1969). An introduction to meta-evaluation. Educational Product Report, 2, 36-38. 
Scriven, M. S. (1980a). The logic of evaluation. Interness, CA: Edgepress.

Scriven, M. S. (1980b). The evaluation of college teaching. Syracuse, NY: National Dissemination Center, Syracuse University School of Education.

Scriven, M. S. (1991). Evaluation thesaurus (4th ed.). Newbury Park: SAGE Publications.

Scriven, M. S. (1996). Types of evaluation and types of evaluator. Evaluation Practice, 17, 151-161.

Scuccimarra, D., \& Speece, D. (1990). Employment outcomes and social integration of students with mild handicaps: The quality of life two years after high school. Journal of Learning Disabilities, 23, 213-219.

Sechrest, L. (1994). Program evaluation: Oh what it seemed to be! Evaluation Practice, $15,359-365$.

Seliger, H., \& Shohamy, E. (1989). Second language research methods. Cambridge, MA: Cambridge University Press.

Serebreni, R., Rumrill, P. D., Mullins, J. A., \& Gordon, S. E. (1993). Project Excel: A demonstration of the higher education transition model for high-achieving students with disabilities. Journal on Postsecondary Education and Disability, 10(3), 1-10.

Shadish, W. (1998). Some evaluation questions: Practical assessment [Adapted from presidential address: Evaluation theory is who we are]. American Journal of Evaluation, 19, 1-19. (ERIC Document Reproduction Service No. ED 423 311)

Sherer, M., Maddux, J. E., Mercandante, B., Prentice-Dunn, S., Jacobs, B., \& Rogers, R. W. (1982). The Self-efficacy Scale: Construction and validation. Psychological Reports, 51, 663-671.

Simmons, T. (1996). Steps Toward Educational Progress Grant. University of Louisville, Louisville, KY.

Simmons, T. (1997). Systematic Training in Transition Supports Grant. University of Louisville, Louisville, KY.

Sitlington, P. (1996). Transition to living: The neglected component of transition: Programming for individuals with learning disabilities. Journal of Learning Disabilities, 29, 31-39, 52.

Sitlington, P. L., Clark, G. M., \& Kolstoe, O. P. (2000). Transition education and services for adolescents with disabilities (3rd ed.). Needham Heights, MA: Allyn \& Bacon.

Sitlington, P., \& Frank, A. (1990). Are adolescents with learning disabilities successfully 
crossing the bridge into adult life? Learning Disability Quarterly, 13, 97-111.

Sitlington, P., \& Frank, A. (1993). Iowa statewide follow-up study: Adult adjustment of individuals with learning disabilities three vs. one year out of school. Des Moines: Iowa Department of Education.

Sitlington, P., Neubert, D. A., Begun, W., Lombard, R. C., \& Leconte, P. J. (1996). Access for success: Handbook on transition assessment. Reston, VA: Council for Exceptional Children.

Sitlington, P., Neubert, D., \& Leconte, P. (1997). Transition assessment: The position of The Division on Career Development and Transition. Career Development for Exceptional Individuals, 20, 69-79.

Smith, L. W., Smith, Q. W., Richards, L., Frieden, L., \& King, K. (1994). Independent living centers: Moving into the 21st century. American Rehabilitation, 20, 1-11. Retrieved on October 25, 2006, from http://www.findarticles.com/p/articles/mi_m0842/is_n1_v20/ai_15803114/print

Smith, S., Kass, S. J., Rotunda, R. J., \& Schneider, S. K. (2006). If at first you don't succeed: Effects of failure on general and task-specific self-efficacy and performance. North American Journal of Psychology, 8, 171-182.

Stanley, K. D., \& Murphy, M. R. (1997). A comparison of general self-efficacy with selfesteem. Genetic, Social, and General Psychology Monographs, 123, 79-99.

Steere, D. L., \& Cavaiuolo, D. (2002). Connecting outcomes, goals, and objectives in transition planning. TEACHING Exceptional Children, 34(6), 54-59.

Steere, D. L., Rose, E., \& Cavaiuolo, D. (2007). Growing up: Transition to adult life for students with disabilities. Boston: Pearson Education, Inc.

Stern, D. (2006). Executive summary: Whose performance should count? National Center for Research on Vocational Education. Retrieved September 18, 2006, from http://vocserve.berkeley.edu/CW10.2/CW102-EXECUTI.html

Strauser, D. R., \& Berven, N. L. (2006). Construction and field testing of the Job Seeking Self-efficacy Scale. Rehabilitation Counseling Bulletin, 49, 207-218.

Stufflebeam, D. L. (1971). The relevance of the CIPP evaluation model for educational accountability. Journal of Research and Development in Education, 5, 19-25.

Stufflebeam, D. L. (1977, April). Working paper on needs assessment in evaluation. Paper presented at the American Educational Research Association Evaluation Conference, San Francisco.

Stufflebeam, D. L. (2000). Foundational models for 21 st century program evaluation. In 
D. L. Stufflebeam, G. F. Madaus, \& T. Kellaghan (Eds.), Evaluation models: Viewpoints on educational and human services evaluation, (pp. 33-84). New York: Kluwer Academic Publishers.

Stumpf, S. H. (1990). Pathways to success: Training for independent living (Monographs of the American Association on Mental Retardation, \#15). Washington, DC: American Association on Mental Retardation.

Super, D. E. (1969). The development of vocational potential. In D. Malikin \& H. Rusalem (Eds.), Vocational rehabilitation of the disabled: An overview (pp. 75-90). New York: New York University.

Super, D. E. (1990). A life-span, life-space approach to career development. In D. Brown, L. Brooks \& Associates (Eds.), Career choice and development: Applying contemporary theories to practice (2nd ed., pp. 197-261). San Francisco: JosseyBass.

Szymanski, E. M. (1994). Transition: Life-span and life-space considerations for employment. Exceptional Children, 6, 402-410.

Szymanski, E. M., Turner, K., \& Hershenson, D. (1992). Career development of people with disabilities: Theoretical perspectives. In F. R. Rusch, L. DeStefano, J. Chadsey-Rusch, L. A. Phelps \& E. M. Szymanski (Eds.), Transition from school to adult life: Models, linkages, and policy (pp. 391-406). Sycamore, IL: Sycamore.

Tests of Adult Basic Education (TABE) Form 5, Level D. (1987). Monterey, CA: CTB/McGraw Hill.

Tobacyk, J. J., Wells, D. H., \& Miller, M. M. (1998). Out-of-body experience and personality functioning. Psychological Reports, 82, 481-482.

Tralli, R., Colombo, B., \& Deshler, D. D. (1996). The strategies intervention model: A model for supported inclusion at the secondary level. Remedial \& Special Education, 17, 204-216.

2005 Teacher Quality Summit. (2005, October). [Conference summary]. 6th annual Teacher Quality Summit, sponsored by The Council on Postsecondary Education and University of Louisville, Louisville, KY.

Tyler, D. K., \& Vasu, E. S. (1995). Locus of control, self-esteem, achievement motivation, and problem-solving ability: LogoWriter and simulations in the fifthgrade classroom. Journal of Research on Computing in Education, 28, 98-120.

U.S. Department of Education. (1997). State indicators in education. Retrieved September 30 1998, from http://nces.ed.gov/pubsearch/pubsinfo.asp?pubid=97376

U. S. Department of Labor. (1991). Secretary's Commission on Achieving Necessary 
Skills (SCANS) report. What work requires of schools: A SCANS report for America: 2000. Washington, DC. Retrieved September 24, 2006, from http://www.ncrel.org/engauge/skills/match1.htm

U. S. Department of Labor. (2002-2003 Edition). Occupational Outlook Handbook. CFLR Career Materials Inc.: Auburn, CA.

U. S. Department of Labor Statistics. (2000). Report on the youth labor force. Washington, DC: Author.

Vandercook, T., York, J., \& Forest, M. (1989). The McGill Action Planning System (MAPS): A strategy for building the vision. Journal of the Association for Persons with Severe Handicaps, 14, 205-215.

Van Reusen, A. K. (1996). The self-advocacy strategy for education and transition planning. Intervention in School and Clinic, 32, 47-52.

Van Reusen, A. K., \& Bos, C. (1990). I Plan: Helping students communicate in planning conferences. Teaching Exceptional Children, 22, 30-32.

Wagner, M. (1991). Dropouts with disabilities: What do we know? What can we do? (A report from the National Longitudinal Transition Study of Special Education Students). Menlo Park, CA: SRI International.

Wagner, M., Blackorby, J., Cameto, R., Hebbeler, K., \& Newman, L. (1993). The transition experiences of young people with disabilities: A summary of findings from the National Longitudinal Transition Study of special education students. Menlo Park, CA: SRI International.

Wagner, M., Blackorby, J., Cameto, R., \& Newman, L. (1993). What makes a difference? Influences on post school outcomes of youth with disabilities. Menlo Park, CA: SRI International.

Wagner, M., Newman, L., D’Amico, R., Jay, E. D., Butler-Nelson, P., Marder, C., et al. (Eds.). (1991). Youth with disabilities: How are they doing? The first comprehensive report from the National Longitudinal Study of Special Education Students. Menlo Park, CA: SRI International.

Wagner, M., Newman, L., Cameto, R., Garza, N., \& Levine, P. (2005). After high school: A first look at the postschool experiences of youth with disabilities. A report from the National Longitudinal Transition Study-2 (NLTS2). Menlo Park, CA: SRI International.

Waller, K. V., \& Bates, R. C. (1992). Health locus of control and self-efficacy beliefs in a healthy elderly sample. American Journal of Health Promotion, 6, 302-309.

Walonick, D. S. (2004). Survival statistics. Bloomington, MN: StatPac, Inc. 
Wang, L., Kick, E., Fraser, J., \& Burns, T. J. (1999). Status attainment in America: The roles of locus of control and self-esteem in educational and occupational outcomes. Sociological Spectrum, 19, 181-198. Retrieved August 8, 2006, from http://taylorandfrancis.metapress.com/(oabyabjaymgkbk3n5ix4ywrx)/app/home/ contribution

Washington, O. (1999). Effects of cognitive and experiential group therapy on self-efficacy and perceptions of employability of chemically dependent women. Issues in Mental Health Nursing, 20, 181-198.

Watters, D. A., \& Thomas, B. H. (1990). Factor analysis of the Nowicki-Strickland Locus of Control Scale: Why is replication so difficult? Educational and Psychological Measurement, 50, 515-524.

Wechsler, D. (1974). Manual for the Wechsler Intelligence Scale for Children-Revised. Cleveland, OH: The Psychological Corporation.

Wechsler, D. (1981). Manual for the Wechsler Adult Intelligence Scale-Revised. New York: The Psychological Corporation.

Wehman, P. (1996). Life beyond the classroom: Transition strategies for young people with disabilities. Baltimore: Paul H. Brookes.

Wehman, P., Kregel, J., \& Barcus, J. M. (1985). School to work: A vocational transition model. Exceptional Children, 52, 25-37.

Wehmeyer, M. L. (1992). Self-determination: Critical skills for outcome-oriented transition services. The Journal for Vocational Special Needs Education, 15, 3-9.

Wehmeyer, M. L. (1993). Perceptions of self-determination and psychological factors in career decision-making of adolescents with and without cognitive disabilities. Career Development for Exceptional Individuals, 16, 135-146.

Wehmeyer, M. L. (1994). Perceptions of self-determination and psychological empowerment of adolescents with mental retardation. Education and Training in Mental Retardation and Developmental Disabilities, 29, 9-21.

Wehmeyer, M. L., \& Gragoudas, S. (1994). Centers for independent living and transitionage youth: Empowerment and self-determination. Journal of Vocational Rehabilitation, 20, 53-58.

Wehmeyer, M. L., Kelchner, K., \& Richards, S. (1996). Essential characteristics of selfdetermined behavior of individuals with mental retardation. American Journal on Mental Retardation, 100, 632-642.

Wehmeyer, M. L., Lattin, D. L., \& Benitez, D. (2001). Western New York Independent 
Living Project. Rehabilitation Research and Training Center on Independent Living Management. Research Project 3A (Years 1-3): The role of CILs in transition services and secondary education: Serving youth with disabilities and their families. Manuscript submitted for publication, University of Kansas.

Wehmeyer, M. L., \& Schwartz, M. (1998). The relationship between self-determination and quality of life for adults with mental retardation. Education and Training in Mental Retardation and Developmental Disabilities, 33, 3-12.

Weinsenstein, G. R., Stowitschek J. J., \& Affleck, J. Q. (1991). Integrating students enrolled in special education into vocational education. Career Development for Exceptional Individuals, 14, 131-144.

Westberry, L. (2001). One school. One step. Techniques: Connecting Education and Careers, 76, 28-31.

Westling, D. L., \& Fox, L. (2004). Teaching students with severe disabilities. Upper Saddle River, NJ: Pearson Education, Inc.

Wilhelm, S. (2003). Accommodating mental disabilities in higher education: A practical guide to ADA Requirements. Journal of Law \& Education, 32, 217-237.

Will, M. (1983). Bridges from school to working life: OSERS programming for the transition of youth with disabilities. Rehabilitation World, 9, 4-7.

Wilson, K. E. (1998). Centers for Independent Living in support of transition. Focus On Autism and Other Developmental Disabilities, 13, 246-252.

Wolfensberger, W. (1972). Normalization: The principle of normalization. Toronto: National Institute on Mental Retardation.

Wonacott, M. E. (2000). Benefits of vocational education (Myths and Realities No. 8). Columbus: ERIC Clearinghouse on Adult, Career, and Vocational Education, The Ohio State University. (ERIC Document Reproduction Service No. ED 441 179)

Wonacott, M. E. (2001). Students with disabilities in career and technical education. ERIC Educational Resources Information Center. (ERIC Document Reproduction Service No. ED 459 324)

Woodcock, R. W., \& Johnson, M. B. (1989). Woodcock-Johnson Psycho-educational Battery-Revised. Allen, TX: DLM.

Woodruff, S. L., \& Cashman, J. F. (1993). Task, domain, and general efficacy: A reexamination of the Self-efficacy Scale. Psychological Reports, 72, 423-432.

Worthen, B. R., Sanders, J. R., \& Fitzpatrick, J. L. (1997). Program evaluation: Alternative approaches and practical guidelines (2nd ed.). New York: Longman. 
Wunder, M., \& Lindsey, C. (2004). The ins, outs of co-teaching. Missouri Innovations in Education, 31, 1-4. Retrieved on October 25, 2006, from http://www.cise.missouri.edu/publications/innovations/april-2004/lindsey.html

Yaffee, R. A. (2003, June). Common correlation and reliability analyses with SPSS for Windows. Retrieved December 6, 2006, from http://www.nyu.edu/its/statistics/docs/correlate.html

Young, T., \& Shoor, D. N. (1986). Factors affecting locus of control in school children. Genetic, Social, and General Psychology Monographs, 112, 405-417.

Ysseldyke, J., Krentz, J., Elliott, J., Thurlow, M. L., Erickson, R., \& Moore, M. L. (1998). NCEO Framework for Educational Accountability. University of Minnesota, National Center on Educational Outcomes. Retrieved January 29, 2007, from http://www.education.umn.edu/nceo/Online Pubs/Framework/FrameworkText.html

Ysseldyke, J., Thurlow, M., \& Gilman, C. (1993). Educational outcomes and indicators for students completing school. University of Minnesota, National Center on Educational Outcomes. Retrieved January 19, 1999, from http://www.coled.umn.edu//NCEO

Zhang, D., Ivester, J. G., Chen, L., \& Katsiyannis, A. (2005). Perspectives on transition practices. Career Development for Exceptional Individuals, 28, 15-25. 
APPENDIX A

COVER LETTER

STUDENT SURVEY

CONSENT FORM 


\section{Appendix A \\ Cover Letter}

Student Survey

Consent Form

Pages have been reduced from the original to fit dissertation margins. 


$\begin{array}{ll}\text { Department of Special Education } & \text { School of Education } \\ & \text { University of Louisville } \\ & \text { Louisville, Kentucky } 40292 \\ & \text { Office: (502) 852-6421 } \\ & \text { Fax: } \quad(502) 852-1419\end{array}$

\section{UNIVERSITYof LOUISVILLE}

February 25, 2000

Dear former S.T.E.P. Project student,

The enclosed survey and Informed Consent Form is for the STEPS TOWARD EDUCATIONAL PROGRESS (S.T.E.P.) Project that began in 1997 with Jefferson County Public Schools, University of Louisville, Jefferson Community College, and Jefferson Technical College (formerly Ky TECH). The University Human Studies Committee has reviewed this project.

We hope you will take a few minutes, enjoy a cup of complimentary and answer this survey.

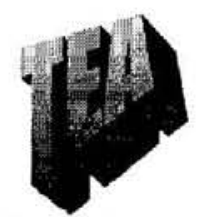

In addition to this survey, this research will include a review of your Transition/IEP records from Jefferson County Public Schools to see if planning during high school agrees with your present education, employment and living goals. Your answers may help us plan better training for students with learning disabilities as they move from high school to adult life. If you have questions regarding this survey, feel free to contact:

$\begin{array}{ll}\text { Norm Terry 458-6318 } & \text { Yvonne Kelley 852-0597 } \\ \text { S.T.E.P. Project Coordinator } & \text { S.T.E.P. Project Facilitator } \\ \text { VanHoose Education Center } & \text { School of Education, Room 143 } \\ \text { Jefferson County Public Schools } & \text { University of Louisville } \\ \text { 3332 Newburg Road } & \text { Belknap Campus } \\ \text { Louisville, Kentucky 40218 } & \text { Louisville, Kentucky 40292 }\end{array}$

Please sign the Informed Consent Form to give us permission to use your answers in this research. If you are 18 years old, or older, and have not had a Legal Guardian appointed by the court, you do not need a Legal Representative to sign it with you. Please use the enclosed, self-addressed envelope to return your Informed Consent Form and Student Survey.

Thanks for your help,

Yvonne Kelley 


\section{Steps Toward Educational Progress \\ S.T.E.P. Project Follow-Up Study Student Survey}

The S.T.E.P Project was designed to help high school students with Learning Disabilities from Jefferson County Public Schools to get ready for employment or further education after high school. Students earned one high school credit per year by attending the elective STEP Project class. This class targeted career exploration, learning strategies and self-advocacy skills training.

The University of Louisville, Jefferson Community College, and Jefferson Technical College (formerly Ky Tech) worked with this project.

During the summer, students earned additional high school credit by participating in activities on each campus. The Department of Vocational Rehabilitation helped with planning career options and applying for education after high school based on the student's interests and financial needs.

The STEP Project helped to provide successful transition to postsecondary adult life to over 125 students with learning disabilities from 1997 to present.

Please fill out this survey and let us know your thoughts about the S.T.E.P Project. Your answers will be kept in strict confidence.

Thank you,

The Follow-up Survey researchers.

Your Name

Address

City

State

Zip Code

Phone

Last Jefferson County Public School Attended

Year Graduated or Withdrew

Did you receive a Certificate of Attendance or a High School Diploma? (Please check one.) Certificate of Attendance High School Diploma 


\section{Page 1}

\section{Steps Toward Educational Progress \\ S.T.E.P. Project Follow-Up Study \\ Student Survey}

1. What was your first job?

Type of Job

Beginning Wage

\# Days per week

Phone\#

$-$
Full time

Part time

Supervisor

Did you get this job while you were in the STEP Project?

(Please check one.)

Why did you leave this job?

2. How many total jobs have you had since you left high school? (Count your first job and the job you have now.)

3. What is your job now?

Type of Job

\# Hours per week

Company

Why did you leave this job? $\begin{array}{llllllllll}1 & 2 & 3 & 4 & 5 & 6 & 7 & 8 & 9 & 10\end{array}$

more than 10

(Circle the number of jobs.)

Beginning Wage

Full time

Part time

\# Days per week

Supervisor

Phone\# 


\section{Page 2}

4. If you are enrolled in school, check all that apply:

\section{Number of Credit Hours/Year Major Area}

__ University of Louisville

_ Jefferson Community College

_ Jefferson Technical College

(Formerly Kentucky Tech)

Other: Please Name

OR, if you have been enrolled in the past,.......

$O R$, if you are not enrolled:

--do you plan to enroll in any classes next year?

YES

NO

If YES: 2 year college (JCC) or (Ky TECH)

4 year college (U of $\mathrm{L})$

Adult Education

_ Other, please name

--do you plan to enroll in two (2) years? YES NO NO

5. What are your EMPLOYMENT plans for the next 5 years?

Part-time work

Full-time work

Military

Other, please name 


\section{Page 3}

6. Did the S.T.E.P. Project help you...

(Circle your rating.)
a. Understand yourself?

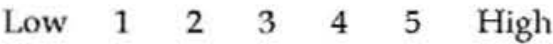
b. Identify your strengths?
Low $1 \begin{array}{llllll} & 2 & 3 & 4 & 5 & \text { High }\end{array}$
c. Identify areas for you to improve?
$\begin{array}{lllllll}\text { Low } & 1 & 2 & 3 & 4 & 5 & \text { High }\end{array}$
d. Identify how you learn best?
Low $\begin{array}{llllll}1 & 2 & 3 & 4 & 5 & \text { High }\end{array}$
e. Identify ways to become successful?
Low $\begin{array}{lllllll}1 & 2 & 3 & 4 & 5 & \text { High }\end{array}$
f. Choose job or career?
Low $1 \begin{array}{llllll} & 2 & 3 & 4 & 5 & \text { High }\end{array}$
g. Choose training after high school?
Low $1 \begin{array}{llllll} & 2 & 3 & 4 & 5 & \text { High }\end{array}$
h. Plan your future goals?
Low $1 \begin{array}{llllll} & 2 & 3 & 4 & 5 & \text { High }\end{array}$

7. Where do you presently live?

_ Alone __ With family __ With friends

In an Apartment In a House

Do you pay rent? _ YES _ NO

Do you own your house or apartment?

YES NO

(Circle your rating.)

8. Did the STEP Project help you get ready Low $\begin{array}{lllllll}1 & 2 & 3 & 4 & 5 & \text { High }\end{array}$ for a job after high school?

Comments:

\section{Did the STEP Project help you get ready} for more college or vocational training after high school?

Comments: 


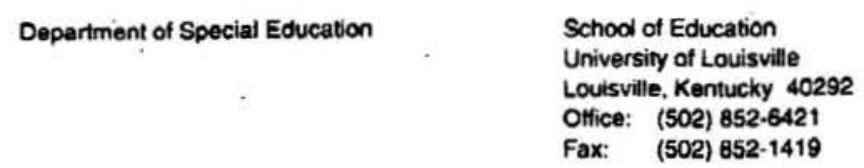

\section{UNIVERSITYofLOUISVILLE}

Steps Toward Educational Progress (S.T.E.P.) Follow-Up Study $\# 225-00$ Subiect Intormed Consent

Page 1

\section{Steps Toward Educational Progress (S.T.E P.) Follow-Up Study}

\section{Subject Informed Consent}

Introduction and Background Information

You are being invited to participate in a research study sponsored by Yvonne Anton Kelley and Thomas J. Simmons at the University of Louisville, Department of Special Education. This study will take place at Jefferson County Public Schools, University of Louisville. Jefferson Community College, and Jefferson Technical College (formerly Ky TECH).

\section{Purpose}

The purpose of this research study is to understand if the S.T.E.P. Project Elective Class helped students with Learning Disabilities get into college, vocational/technical school or improve their ability to get and keep a job after high school.

\section{Procedures}

In this study, you will be asked to answer questions about what you planned to do before you left high school and what you are doing now. The results of this survey will be used to help other students get ready to leave high school and go to college, vocationaltechnical school, or become employed. The survey will take about 10 minutes for you to answer.

\section{Potential Risks}

There are risks associated with this survey in that some of the questions may cause you discomfort in sharing this information. Other than this, there may be unforeseeable risks in answering this survey. You are free to decline to answer any particular questions that make you uncomfortable.

$$
\text { Revice 3-30-2000 }
$$


Steps Toward Educetional Progress (S.T.E.P.) Follow-Up Study

Subiect Informed Consent

Page2

\section{Benefits}

The possible benefits of this study include helping other students with learning disabilities get ready for coilege, vocationaVtechnical school, or employment. Also, the information collected may not benefit you directly, but may be of benefit to students and educators in the future.

\section{Compensation}

There is no payment for answering these questions.

\section{Confidentiality}

Although absolute confidentiality cannot be guaranteed, all of the things you write or tell us will be held in confidence to the extent permitted by law. The study sponsor and/or the University Human Studies Committee may inspect your records from Jefferson County Public Schools. In all other respects, the information will be held in confidence. If the information collected in this research study is published, no one will know that you gave us any information. .

\section{Voluntary Participation}

Your participation in this research study is voluntary. You can choose not to answer, quit at any time, or you can stop us from using your information at any time without loosing our support, friendship, or other help.

\section{Research Subject's Rights and Contact Persons}

All your present questions have been answered in language you can understand. All future questions will be answered in the same manner. You may call: Yvonne Anton Kelley at (502) 852-0597 or Thomas J. Simmons at (502) 852-0569 for an answer to any questions you may have.

You may call the University Human Studies Committee office (502) $852-5188$ and will be given an opportunity to discuss any questions about your rights as a research subject, in confidence, with a member of the Committee. This is an independent committee composed of faculty and staff of the University of Louisville and its affiliated hospitals, as well as lay members of the community not connected with these institutions. The Committee has reviewed this study. 
Steps Toward Educational Progress (S.T.E.P.) Follow-Up Study

Subiect informed Consent

Page 3

\section{Consent}

You have discussed and understand the above information and hereby consent to voluntarily participate in this study. You have been given a copy of the signed consent.

Signature of Subject

Legal Representative (Parent or Guardian)

(Only needed if Subject is under age 18, or has had a Legal Guardian appointed by the court.

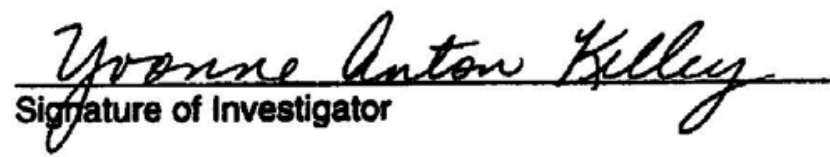

Date Signed

Date Signed
$3-30-2000$

Date Signed 


\section{APPENDIX B}

HUMAN SUBJECTS LETTERS OF APPROVAL 


\section{Appendix B}

\section{Human Subjects Letters of Approval}

\section{University of Louisville}

Jefferson County Public Schools

Pages have been reduced from the original to fit dissertation margins. 


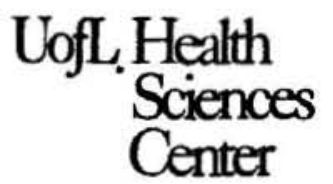

Dr. Richard L. Miller

Chairman

University Iluman Studies

Committee
Instructional Bullding

Room 230

500 South Preston Street

Louisville, Kentucky 40202

March 27, 2000

\author{
DR YVONNE KELLEY \\ DR THOMAS SIMMONS \\ SCHOOL OF EDUCATION
}

\title{
RE: UHSC 225-00 - Steps Toward Educational Progress (STEP): Follow-up Study \\ Dear Doctors Kelley and Simmons:
}

The above study and the revised consent form (dated $03 / 23 / 00$ ) have been reviewed by the University Human Studies Committee and were approved as submitted. Your study now has final committee approval. Please note that the UHSC operates in accordance with $\mathrm{ICH}$ guidelines and is further mandated by the Office of Protection from Research Risks (OPRR) and the Food and Drug Administration (FDA).

The study has approval through 03/26/2001, when the approval expires. You should complete and return the enclosed Progress ReportContinuation Request Form four weeks prior to this date in order to ensure that no lapse in approval occurs. Federal regulatory agencies have indicated that studies must be re-approved by the Committee by the expiration date. Otherwise, the approval will expire and regulatory agencies have indicated that no further subjects can be entered until the study is reapproved by the Committee (study suspension). It is the investigator's responsibility to obtain reapproval, including any changes needed in the consent form, prior to the expiration date.

\section{RESPONSIBILITIES OF THE INVESTIGATOR}

As a research investigator, you are responsible for obtaining informed consent in accordance with 45 CFR 46.116, and for ensuring that no human subject will be involved in the research prior to the obtaining of the consent. Unless otherwise authorized by the University Human Studies Committee, you are responsible for ensuring that legally effective informed consent shall: (1) be obtained from the subject or the subject's legally authorized representative; (2) be in a language understandable to the subject or the representative; (3) be obtained only under circumstances that provide the prospective subject or the representative sufficient opportunity to consider whether the subject should or should not participate and that minimize the possibility of coercion or undue influence; and (4) not include exculpatory language through which the subject or the representative is made to waive or appear to waive any of the subject's legal rights, or releases or appears to release the research investigator, the sponsor, the institution or its agents from liability for negligence.

As a research investigator, you are responsible for ensuring that informed consent is documented by the use of a written consent form approved by the IRB and signed and dated by the subject or the subject's legally authorized representative, unless this requirement is specifically waived by the IRB. Research investigators shall ensure that each person signing the written consent form is given a copy of that form.

You are responsible for maintaining in your files the original of each signed consent document. These documents shall be retained for at least three (3) years after termination of the last IRB approval period. These files will be available for inspection by the University Human Studies Committee or appropriate governmental officials. 


\section{Reporting Changes}

You are responsible for reporting promptly to the University Human Studies Committee proposed changes in a research activity. As a research investigator, you are responsible for the completion of a University Human Studies Committee Study Amendment Request Form, which will include: (a) a description of each specific change that has been made in the protocol and/or informed consent form, (and/or in appropriate cases, the Investigator's Brochure for investigational drugs or devices) and the location of each change in the referenced document; (b) a description of the rationale for the change(s); (c) the revised section(s) of the protocol and/or informed consent form, (and/or in appropriate cases, the Investigator's Brochure for investigational drugs or devices); and (d) unless the changes in the study are minor, copies of the above materials should be submitted for all committee members. Please visit our website to obtain the form at hittp://research.louisville.edu/uhsc/Forms.htm

Changes in research during the period for which IRB approval has already been given shall not be initiated by research investigators without IRB review and approval, except where necessary to eliminate apparent immediate hazards to the subject.

\section{Reporting Noncompliance}

As a research investigator, you are responsible for reporting promptly to the University Human Studies Committee any serious or continuing noncompliance with the requirements of this assurance or the determinations of the University Human Studies Committee.

Research investigators shall be responsible for complying with all University Human Studies Committee decisions, conditions and requirements.

\section{Reporting Adverse Events}

You are responsible for promptly reporting any injuries or unanticipated problems which involved risks to human subjects or others. In addition to reporting adverse events which occur in your local study, you should forward to the University Human Studies Committee all adverse event reports received from study sponsors. You should complete a separate Adverse Event Report Form for each subject in whom adverse events are reported.

\section{Obtaining Continuing Approval}

You are responsible for reporting the progress of your research to the University Human Studles Committee in the manner prescribed by the IRB, but no less than once per year. Generally, this requirement is met by completing a Progress Report Form, which is enclosed, and returning the completed form with copies of the five most recently signed consent forms. The reports are reviewed by the Committee and written approval of continuation is sent to the research investigator. You will need to complete a Progress Report Form each year. If the study is terminated before the expiration date, please return the completed form indicating the study has terminated. Please visit our website to obtain the form at http://research.louisville.edu/uhsc/Forms.htm 
Final Approval Letter

Page 3

Failure to return the completed progress report can result in the expiration of the study, whereby the University Human Studies Committee terminates the project. Termination of human subjects approval can result in loss of eligibility to publish collected research data.

Offlce of Research Administration Approval

Please note that, as indicated on the Human Studies Review Certification Form, if a Proposal Clearance Form was required for the study, then approval by Grants and Contracts, Office of Research Administration, is also required prior to activation of the study.

Best wishes for a successful study.

Sincerely,

$$
\text { Paxternian }
$$

Richard L. Miller, D.D.S., Ph.D.

Chair

University Human Studies Committee

RLM/bd 


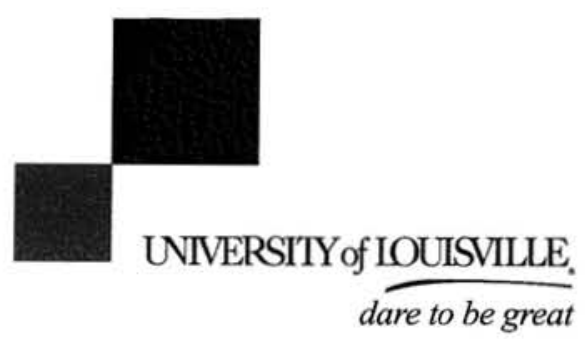

Tuesday, March 27, 2001

DR. YVONNE KELLEY

DR. THOMAS SIMMONS

SCHOOL OF EDUCATION
- DR. RICHARD L. MILLER CHAIRMAN
HUMAN STUDIES COMMITTEES
Instructional Building Room 230
Room 230
500 South Preston Street
University of Louisville
Louisville, Kentucky 40292
Office: $502-852-5188$
Fax: $\quad 502-852-2164$
research louisville edu

\section{RE: 225-00 Steps Toward Educational Progress (STEP): Follow-up Study}

DEAR DR. KELLEY:

We have received the Progress Report Form dated $3 / 26 / 01$ for the above referenced study.

Continuation has been approved through the Expedited Review Procedure. We understand that the study is closed to enrollment, that there are 50 subjects in follow up and results of data collected will be further analyzed to complete your doctoral dissertation.

The study has approval through $3 / 27 / 2002$, when the approval expires. You should complete and return a Progress Report/Continuation Request Form EIGHT weeks prior to this date in order to ensure that no lapse in approval occurs.

Please visit our website to obtain the form at http://research.louisville.edu/uhsc/Forms.htm

Thank you for the timely submission of your Progress Report Form.

Sincerely,

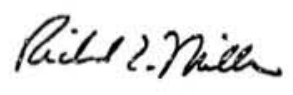

Richard L. Miller, D.D.S., Ph.D.

Chair, Human Studies Committee

RIm:klm 


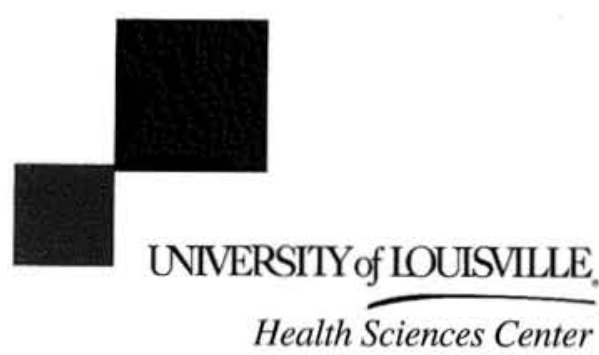

- DR. RICHARD L. MILLER CHAIRMAN

Human Studies Committees

Instructional Building

Room 230

500 South Preston Street

University of Louisville

Louisville, Kentucky 40292

Office: $502-852-5188$

Fax: 502-852-2164

research louisville edv

March 27, 2002

Dr. Yvonne Kelley

Dr. Thomas Simmons

School of Education

RE: 225-00 Steps Toward Educational Progress (STEP): Follow-up Study

Dear Drs. Kelley and Simmons:

We have reviewed the Progress Report Form, dated February 8, 2002, and the above referenced study. Continuation has been approved through the Expedited Review Procedure according to 45 CFR $46.110(b)(2)$.

The study has been approved for another year, through March 27, 2003, when the approval expires. You should complete and return a Progress Report/Continuation Request Form EIGHT weeks prior to this date in order to ensure that no lapse in approval occurs.

Please visit our website to obtain the form at http://research.louisville.edu/uhsc/index.htm

Thank you for the timely submission of your Progress Report Form.

Sincerely,

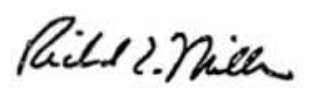

Richard L. Miller, D.D.S., Ph.D.

Chair, Human Studies Committee 


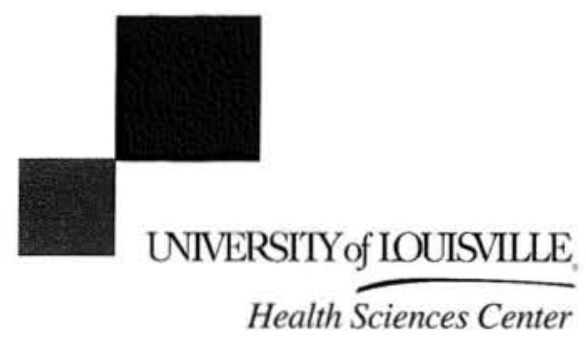

- hUMAN STUdies COMMITTEES

Instructional Bullding

Room 230

500 South Preston Street

University of Louisville

Louisville. Kentucky 40292

Office: $502-852-5188$

Fax: $\quad 502-852-2164$

research louisville edu

March 27, 2003

Dr. Yvonne Kelley

Dr. Thomas Simmons

School of Education

RE: 225-00 Steps Toward Educational Progress (STEP): Follow-up Study

Dear Dr. Kelley:

The above study was reviewed for continuation through the expedited review procedure according to 45 CFR 46.110 , category 8 , since the research is permanently closed to enrollment. This action will be taken to the fully convened Committee meeting on April 17, 2003 for ratification.

The study is re-approved for another year with an expiration date of March 26, 2004. Complete and return a Progress Report/Continuation Request Form EIGHT weeks prior to this date in order to ensure that no lapse in approval occurs.

Best wishes for a successful study.

Sincerely,

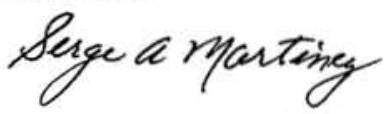

Serge A. Martinez, MD

Chair, Human Studies Committee-A

SAM/rsh 


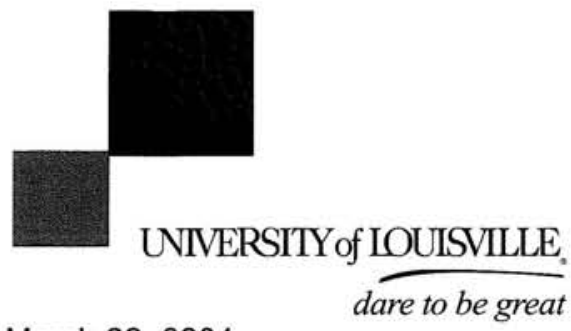

- human SUBJEcts PROTECTION PROGRAM MedCenter One, Suite 200 501 East Broadway Louisville, Kentucky 40202-1798 Office: $502-852-5188$

Fax: $\quad 502-852-2164$

March 22, 2004

Yvonne Anton Kelley Niemann, PhD

College of Education \& Human Development - Room 143

\section{RE: 225.00 - Steps Toward Educational Progress (STEP): Follow-up Study}

Dear Dr. Niemann:

The above study was reviewed for continuation by the chair of the Institutional Review Board (IRB) and approved through the expedited review procedure according to 45 CFR 46.110 since the study is closed to enrollment in follow-up status only. This action will be ratified by the next convened meeting of the full IRB on $4 / 22 / 04$.

The study is re-approved for another year with an expiration date of $2 / 26 / 05$. Complete and return a Progress Report/Continuation Request Form EIGHT weeks prior to this date in order to ensure that no lapse in approval occurs.

Best wishes for a successful study.

Sincerely,

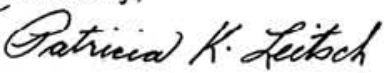

Patricia K. Leitsch, Ph.D.

Chair, Behavioral Institutional Review Board

PKL:jlk 


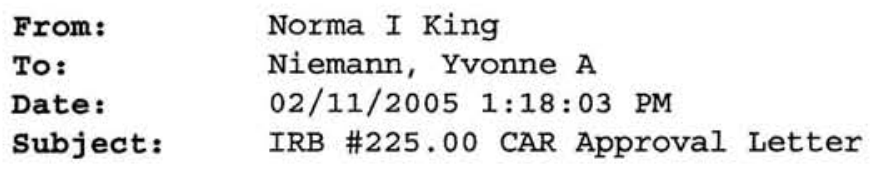

The following items were reviewed and approved:

- Progress Report, dated 2/2/05

The committee will be advised of this action at their next full board meeting.

*Reminder - Principal Investigator needs to sign consent forms within 2 weeks of the subject being enrolled and phone consents are not allowed, the subject's signature must be obtained.

Please submit a Progress Report/Continuation Request Form eight weeks prior to $3 / 26 / 06$, in order to ensure that no lapse in approval occurs.

Best wishes for the continued success of your study.

sincerely,

Norma I. King

Program Assistant Senior

UofL Human Subjects Protection Program

MedCenter one, Suite 200

501 East Broadway

(502) 852-5188 


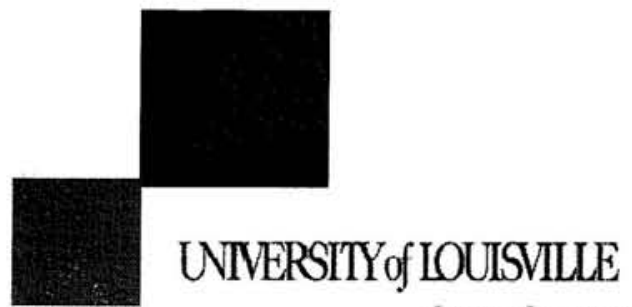

dare to be great
HUMAN SUBJECTS PROTECTION PROGRAM OFFICE

University of Louisville

MedCenter One, Suite 200

501 E Broadway

Louisville, Kentucky 40202-1798

Office: $\quad 502-852-5188$

Fax: $\quad 502-852-2164$

March 1, 2006

Yvonne Anton Kelly Neiman, PhD

Dept. of Teaching \& Learning

171 Apple Lane

Taylorsville, KY 40074

RE: $\quad 225.00 /$ Steps Toward Educational Progress (STEP): Follow-up Study

Dear Doctor Neiman:

The continuation request for the above study was reviewed by the Chair of the Institutional Review Board (IRB) through the expedited review procedure, according to 45 CFR 46.110(F)(8-9) and 21 CFR 56.110, since the remaining research activities are limited to data analysis. The study now has continued committee approval from 3/27/2006 through 3/26/2007.

The following items were reviewed and approved:

- Progress Report, dated 2/3/06

The committee will be advised of this action at their next full board meeting.

Please submit a Progress Report/Continuation Request Form eight weeks prior to 3/26/2007 in order to ensure that no lapse in approval occurs.

Best wishes for the continued success of your study. Please send all inquires and electronic revised/requested items to our office email address at hsppofc@louisville.edu.

Sincerely,

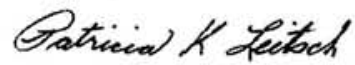

Patricia K. Leitsch, Ph.D., Chair,

Behavioral/Social/Educational Institutional Review Board

$\mathrm{PKL} / \mathrm{crn}$ 


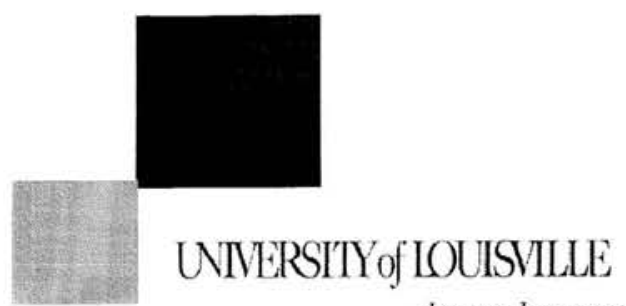

HUMAN SUBJECTS PROTECTION PROGRAM OFFICE

University of Louisville MedCenter One, Suite 200 $501 \mathrm{E}$ Broadway

Louisville, Kentucky 40202-1798 dare to be great

Office: $\quad 502-852-5188$ Fax: $\quad 502-852-2164$

March 1, 2007

Yvonne A Kelly-Niemann, PhD

Teaching and Learning-University of Louisville

171 Apple Lane

Taylorsville, KY 40071

\section{RE: IRB\#225.00 - Steps Toward Educational Progress (STEP): Follow-up Study}

Dear Doctor Niemann:

The continuation request for the above study was reviewed by the Chair of the Institutional Review Board (IRB) through the expedited review procedure, according to 45 CFR $46.110(F)(8-9)$ and 21 CFR 56.110, since the remaining research activities are limited to data analysis. The study now has continued committee approval from 3/27/2007 through 3/26/2008.

The following items were reviewed and approved:

- Progress Report, dated 1/16/07

- Protocol, not dated

The committee will be advised of this action at their next full board meeting

Please submit a Progress Report/Continuation Request Form eight weeks prior to $3 / 26 / 08$, in order to ensure that no lapse in approval occurs

Best wishes for the continued success of your study. Please send all inquires and electronic revised/requested items to our office email address at hsppofc@louisville.edu.

Sincerely,

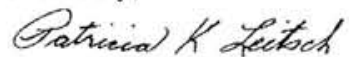

Patricia K Leitsch, Ph.D., Chair,

Behavioral/Social/Educational Institutional Review Board

$\mathrm{PKL} /$ nik 
1. Title and purpose of study

\section{Steps Toward Educational Progress (S.T.E.P.) Project Follow-Up Study}

Purpose: See attached Human Studies Application (HSA) for the University of Louisville.

2. What do you plan to do? Give specific information on experimental design, sampling, measuring instruments and data collection procedures. What instructions will be given to students or staff? If you have a graduate school or grant proposal, attach a copy. If unstandardized instruments are to be used, attach copies.

A follow-up study with:

- JCPS students in the S.T.E.P. Project 1997-2000

- JCPS teachers who have been teaching the elective class 1997-2000

- Instructors from JCPS, University of Louisville, Jefferson Community College, and Jefferson Technical College (formerly Ky TECH) who have been trained in Content Enhancement Strategies through the S.T.E.P. Project from 1997-2000.

Give specific information on

experimental design - Survey Research \& Student Records Review

sampling - 1. All students enrolled in the S.T.E.P. Project Elective Class 1997-2000

2. All faculty who have taught the S.T.E.P. Project Elective Class 1997-2000

3. All instructors from JCPS, University of Louisville, Jefferson Community College, and Jefferson Technical College (formerly Ky TECH) who have been trained in Content Enhancement Strategies through the S.T.E.P. Project

measuring instruments - Student Survey (see attached HSA for the University of Louisville, Appendix A) and Instructor Survey (see attached HSA, Appendix B). These are unstandardized questionnaires which have been developed by the researchers to gather information to answer the research questions as stated in Section 6 of the HSA which is attached. See Student Data Form which is attached for collecting information from student records.

data collection procedures - The student surveys will be mailed. The researchers will call students to help them understand the questions and encourage survey completion. The instructor surveys will be mailed or hand delivered in person or to faculty meetings. Student records will be reviewed by the researchers in the schools mentioned above or archives for JCPS records. 
What instructions will be given to students or staff?

See Student Cover letter and

Instructor Cover letter in attached University of Louisville HSA.

3. What request are you making of the Jefferson County Public Schools? Specify number of students and staff to be involved, length of time, and schools, if pertinent. If specific schools are to be involved, designate them, or describe the characteristics of the schools you wish to sample.

What request are you making of the Jefferson County Public Schools?

A. Permission to survey approximately 12 staff and 100 students from the present and former S.T.E.P. Project Elective Classes at Central, Fern Creek and Shawnee High Schools and former S.T.E.P. Elective Classes that were taught from 1997-1999 at Atherton, Fairdale, Iroquois High Schools. The survey (see Appendix A of HSA) will take about 15 minutes for students to complete and about 30 minutes for staff to complete. Survey contact period would be from time of approval to August 30, 2000. We would survey the present students prior to the end of the 2000 school year and continue through the summer contacting former students.

B. Permission to conduct a records review of Transition Plans and IEP's for the same students as listed in A above. (See attached Student Data Form.) Researchers would conduct this review from the time of approval to August 30, 2000.

C. Permission to survey staff from JCPS who participated in Content Enhancement Training through the S.T.E. P. Project. There are approximately 350 total participants including JCPS participants. (Permission will be obtained separately from JCC, Ky TECH, and $U$ of $L$ to survey their faculty who participated in this same training. (See attached Instructor Survey in Appendix B of the HSA.) Survey contact period would be from time of approval to August 30,2000 . Present staff would be contacted prior to the end of the 2000 school year and non-responders recontacted during the summer.

4. If you have discussed this proposal with Jefferson Counly School personnel, indicate with whom you have talked and the nature of your discussion.

We discussed the format for obtaining permission to conduct research in JCPS with Susan O'Daniel in the Research Department.

5 What practical implications does your study have to the Jefferson County school system? (If none, say "none", but describe what value the study may have for children in general.)

Positive results from this research would merit consideration for including S.T.E.P. procedures in additional schools to increase possibilities for students with leaming disabilities to access post-secondary education or employment following graduation. 
6. Have you conducted previous studies in the Jefferson County Public Schools? yes no If yes, give sufficient information about the most recent study or most pertinent study so that it can be located, i.e., date, who your contact was, title or nature of study.

No previous research has been conducted.

7. Is there previous research which would be helpful in understanding your proposal?

No

8. What procedures will you use to report the findings of your study to participating schools?

Copies of the findings will be provided to participating schools.

9. Have you received permission for this study from your institution's "Human Subjects" committee?

The application for Human Studies approval has been submitted on February 25, 2000.

10. List all funding sources for your study.

a. The S.T.E.P Project Coordinator, Norman Terry, is presently employed through JCPS.

b. Support will be provided through the secretary or other JCPS employees presently assigned to the project through JCPS.

b. The study coordinator, Yvonne Kelley, is presently employed as a Graduate Assistant through the S.T.E.P. Project and Kentucky State Department of Education State Improvement Grant for Special Education, and is a doctoral student at the University of Louisville.

c. Project expenses will be paid through the S.T.E.P. Grant at the University of Louisville.

d. The University of Louisville will provide office space and administrative support for the Follow-Up study activities. Thomas Simmons, Ph.D. will facilitate this study.

11. List the name of all personnel who will be involved in carrying out field operations.

See \#10 above.

12. Do you have any projections to publicity on your study at this time? yes no

Study findings will be submitted for publication in professional journals at completion. Applications for local, state and federal professional conventions presentations will be submitted. 
13. When do you wish to begin collecting your data?

Data collection will begin as soon as approval from JCPS and the Human Studies Committee at the University of Louisville is obtained.

I have read the statement of "Conditions Related to Conducting Research in the Jefferson County Public Schools System" and agree to abide by them if my research request is approved.

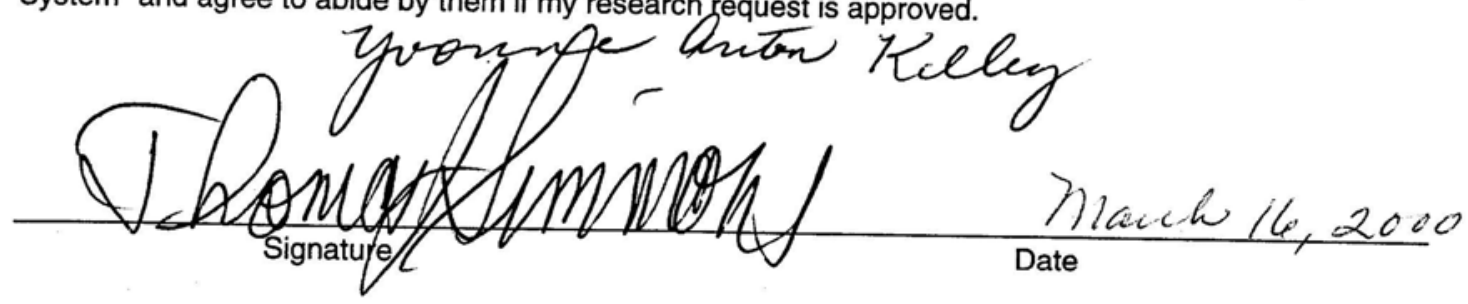

(See Human Studies Application)

Signature of Advisor or teacher (if appropriate)

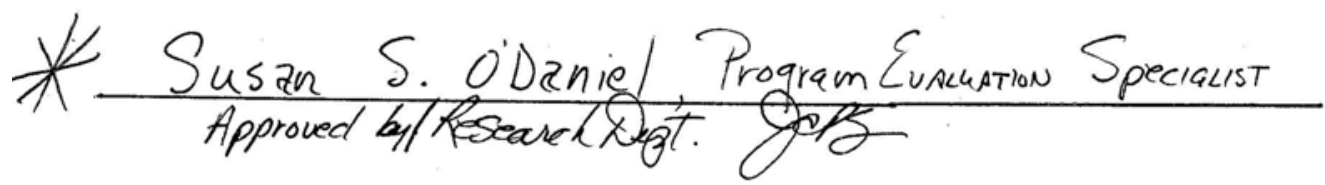

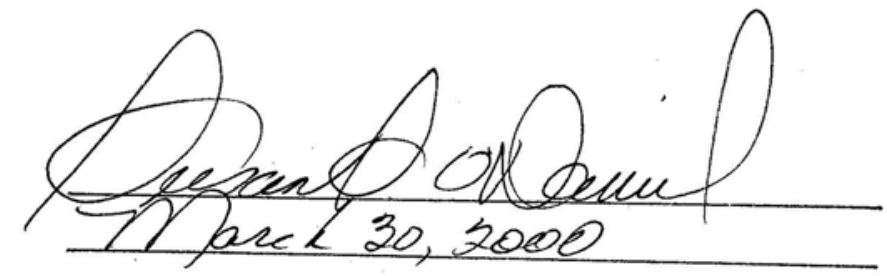

334 
APPENDIX C

SELF-EFFICACY SCALE

SCORING GUIDE FOR SELF-EFFICACY SCALE 


\section{Appendix C \\ Self-efficacy Scale \\ Scoring Guide for Self-efficacy Scale}

Pages have been reduced from the original to fit dissertation margins. 


\section{Self-Efficacy Scale (SES)}

Name

Directions: This questionnaire is a series of statements about your personal attitudes and traits Each statement represents a commonly held belief. Read each statement and decide to what extent it describes you. There are no right or wrong answers. You will probably agree with some of the statements and disagree with others. Please indicate your own personal feelings about each statement below by marking the box that best describes your attitude or feeling. Please be very truthful and describe yourself as you really are, not as you would like to be.

1. I like to grow house plants.

\begin{tabular}{ccccc}
$\square$ & $\square$ & $\square$ & $\square$ & $\square$ \\
Disagree & Disagree & Neither agree & Agree & Agree \\
Strongly & Moderately & nor disagree & Moderately & Strongly \\
\hline
\end{tabular}

2. When I make plans, I am certain I can make them work.

\begin{tabular}{ccccc}
$\square$ & $\square$ & $\square$ & $\square$ & $\square$ \\
Disagree & Disagree & Neither agree & Agree & Agree \\
Strongly & Moderately & nor disagree & Moderately & Strongly \\
\hline
\end{tabular}

3. One of my problems is that I cannot get down to work when I should.

\begin{tabular}{ccccc}
$\square$ & $\square$ & $\square$ & $\square$ & $\square$ \\
Disagree & Disagree & Neither agree & Agree & Agree \\
Strongly & Moderately & nor disagree & Moderately & Strongly \\
\hline
\end{tabular}

4. If I can't do a job the first time, I keep trying until I can.<smiles>[O]</smiles>

Disagree

Strongly
Disagree Moderately
Neither agree nor disagree
Agree Moderately
Agree Strongly

5. Heredity plays the major role in determining one's personality.<smiles>[TeH]</smiles>

Disagree

Strongly
Disagree Moderately
Neither agree nor disagree
Agree Moderately
Agree

Strongly

6. It is difficult for me to make new friends.

Disagree

Disagree

Neither agree

Agree

Agree

Sirongly Moderately nor disagree Moderately Strongly 
7. When I set important goals for myself, I rarely achieve them.

Disagree Disagree Neither agree Agree Agree

Strongly Moderately nor disagree Moderately Strongly

8. I give up on things before completing them.

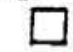

Disagree

Disagree Neither agree

Strongly Moderately nor disagree

\begin{tabular}{cc} 
Agree & Agree \\
Moderately & Strongly \\
\hline
\end{tabular}

9. I like to cook.

$\square$

Strongly

Disagree

Neither agree nor disagree

Moderately

10. If I see someone I would like to meet, I go to that person instead of waiting for him or her to come to me.

\begin{tabular}{ccccc}
$\square$ & $\square$ & $\square$ & $\square$ & $\square$ \\
Disagree & Disagree & Neither agree & Agree & Agree \\
Strongly & Moderately & nor disagree & Moderately & Strongly \\
\hline
\end{tabular}

11. I avoid facing difficulties.

\begin{tabular}{ccccc}
$\square$ & $\square$ & $\square$ & $\square$ & $\square$ \\
Disagree & Disagree & Neither agree & Agree & Agree \\
Strongly & Moderately & nor disagree & Moderately & Strongly \\
\hline
\end{tabular}

12. If something looks too complicated, I will not even bother to try it.

Disagree Disagree Neither agree Agree Agree

Strongly Moderately nor disagree Moderately Strongly

13. There is some good in everybody.

\begin{tabular}{|c|c|c|c|c|}
\hline$\square$ & $\square$ & $\square$ & $\square$ & $\square$ \\
\hline Disagree & Disagree & Neither agree & Agree & Agree \\
\hline Strongly & Moderately & nor disagree & Moderately & Strongly \\
\hline
\end{tabular}

14. If I meet someone interesting who is very hard to make friends with, I'll soon stop trying to make friends with that person.

\begin{tabular}{ccccc}
$\square$ & $\square$ & $\square$ & $\square$ & $\square$ \\
Disagree & Disagree & Neither agree & Agree & Agree \\
Strongly & Moderately & nor disagree & Moderately & Strongly \\
\hline
\end{tabular}

15. When I have something unpleasant to do. I stick to it until I finish it.

Disagree Disagree Neither agree Agree Agree

Strongly Moderately nor disagree Moderately Strongly


16 When I decide to do something, I go right to work on it.

\begin{tabular}{|c|c|c|c|c|}
\hline$\square$ & $\square$ & $\square$ & $\square$ & $\square$ \\
\hline Disagree & Disagree & Neither agree & Agree & Agree \\
\hline Strongly & Moderately & nor disagree & Moderately & Strongly \\
\hline
\end{tabular}

17. I like science.

Disagree

Disagree Neither agree

Agree

Agree

Strongly

Moderately nor disagree

Moderately

Strongly

18. When trying to leam something new, I soon give up if I am not initially successful.

Disagree Disagree Neither agree Agree Agree

Strongly Moderately nor disagree Moderately Strongly

19. When I'm trying to become friends with someone who seems uninterested at first, I don't give up very easily.

\begin{tabular}{ccccc}
$\square$ & $\square$ & $\square$ & $\square$ & $\square$ \\
Disagree & Disagree & Neither agree & Agree & Agree \\
Strongly & Moderately & nor disagree & Moderately & Strongly \\
\hline
\end{tabular}

20. When unexpected problems occur, I don't handle them well.

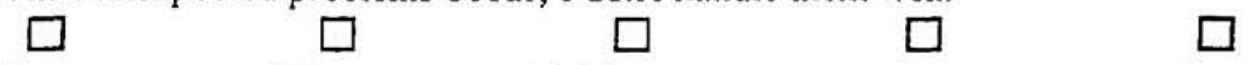

Disagree Disagree Neither agree Agree Agree

Strongly Moderately nor disagree Moderately Strongly

21. If I were an artist, I would like to draw children.

Disagree Disagree Neither agree Agree Agree

Strongly Moderately nor disagree Moderately Strongly

22. I avoid trying to learn new things when they look too difficult for me.

\begin{tabular}{ccccc}
$\square$ & $\square$ & $\square$ & $\square$ & $\square$ \\
Disagree & Disagree & Neither agree & Agree & Agree \\
Strongly & Moderately & nor disagree & Moderately & Strongly \\
\hline
\end{tabular}

23. Failure just makes me try harder.

\begin{tabular}{ccccc}
$\square$ & $\square$ & $\square$ & $\square$ & $\square$ \\
$\begin{array}{c}\text { Disagree } \\
\text { Strongly }\end{array}$ & $\begin{array}{c}\text { Disagree } \\
\text { Moderately }\end{array}$ & $\begin{array}{c}\text { Neither agree } \\
\text { nor disagree }\end{array}$ & $\begin{array}{c}\text { Agree } \\
\text { Moderately }\end{array}$ & $\begin{array}{c}\text { Agree } \\
\text { Strongly }\end{array}$ \\
\hline
\end{tabular}

24. I do not handle myself well in social gatherings.

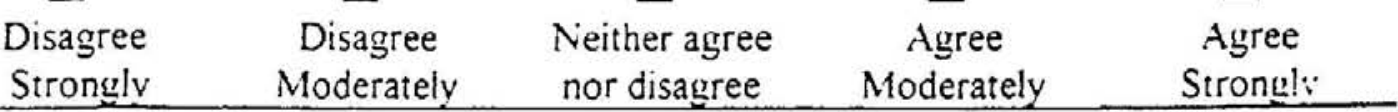


25. I very much like to ride horses.

\begin{tabular}{ccccc}
$\square$ & $\square$ & $\square$ & $\square$ & $\square$ \\
$\begin{array}{c}\text { Disagree } \\
\text { Strongly }\end{array}$ & Disagree & Neither agree & Agree & Agree \\
Moderately & nor disagree & Moderately & Strongly \\
\hline
\end{tabular}

26. I feel insecure about my ability to do things.

Disagree Disagree Neither agree Agree Agree

Strongly Moderately nor disagree Moderately Strongly

27. I am a self-reliant person.

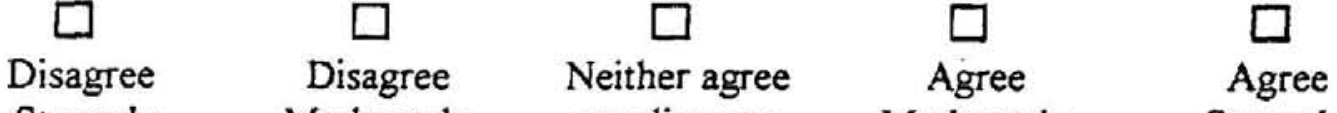

Strongly Moderately nor disagree Moderately Strongly

28. I have acquired my friends through my personal abilities at making friends.

\begin{tabular}{ccccc}
$\square$ & $\square$ & $\square$ & $\square$ & $\square$ \\
Disagree & Disagree & Neither agree & Agree & Agree \\
Strongly & Moderately & nor disagree & Moderately & Strongly \\
\hline
\end{tabular}

29. I give up easily.

\begin{tabular}{ccccc}
$\square$ & $\square$ & $\square$ & $\square$ & $\square$ \\
Disagree & Disagree & Neither agree & Agree & Agree \\
Strongly & Moderately & nor disagree & Moderately & Strongly \\
\hline
\end{tabular}

30. I do not seem capable of dealing with most problems that come up in my life.

Disagree Disagree Neither agree Agree Agree

Strongly Moderately nor disagree Moderately Strongly




\section{Student ID \\ Self-Efficacy Scale (SES)}

KiY:

Name

Directions: This questionnaire is a series of statements about your personal attitudes and traits. Each statement represents a commonly held belief. Read each statement and decide to what extent it describes you. There are no right or wrong answers. You will probably agree with some of the statements and disagree with others. Please indicate your own personal feelings about each statement below by marking the box that best describes your attitude or feeling. Please be very truthful and describe yourself as you really are, not as you would like to be.

NOT SOLRED 1. I like to grow house plants.

\begin{tabular}{lcccc}
$A \square 1$ & $B \square 2$ & $C \square .3$ & $D \square 4$ & $E \square .5$ \\
$\begin{array}{l}\text { Disagree } \\
\text { Strongly }\end{array}$ & $\begin{array}{c}\text { Disagree } \\
\text { Moderately }\end{array}$ & $\begin{array}{c}\text { Neither agree } \\
\text { nor disagree }\end{array}$ & $\begin{array}{c}\text { Agree } \\
\text { Moderately }\end{array}$ & $\begin{array}{c}\text { Agree } \\
\text { Strongly }\end{array}$ \\
\hline
\end{tabular}

2. When I make plans, I am certain I can make them work.

\begin{tabular}{ccccc}
$\square 1$ & $\square 2$ & $\square 3$ & $\square 4$ & $\square 5$ \\
Disagree & Disagree & Neither agree & Agree & Agree \\
Strongly & Moderately & nor disagree & Moderately & Strongly \\
\hline
\end{tabular}

REVESSE - 3. One of my problems is that I cannot get down to work when I should.

\begin{tabular}{|c|c|c|c|c|c|}
\hline CORE & $\begin{array}{c}\square 5 \\
\text { Disagree } \\
\text { Strongly }\end{array}$ & $\begin{array}{c}\square 4 \\
\text { Disagree } \\
\text { Moderately }\end{array}$ & $\begin{array}{c}\square .3 \\
\text { Neither agree } \\
\text { nor disagree }\end{array}$ & $\begin{array}{c}\square 2 \\
\text { Agree } \\
\text { Moderately }\end{array}$ & $\begin{array}{c}\square \text { / } \\
\text { Agree } \\
\text { Stronglv }\end{array}$ \\
\hline
\end{tabular}

4. If I can't do a job the first time, I keep trying until I can.

\begin{tabular}{ccccc}
$\square 1$ & $\square 2$ & $\square .3$ & $\square 4$ & $\square .5$ \\
$\begin{array}{c}\text { Disagree } \\
\text { Strongly }\end{array}$ & $\begin{array}{c}\text { Disagree } \\
\text { Moderately }\end{array}$ & $\begin{array}{c}\text { Neither agree } \\
\text { nor disagree }\end{array}$ & $\begin{array}{c}\text { Agree } \\
\text { Moderately }\end{array}$ & $\begin{array}{c}\text { Agree } \\
\text { Strongly }\end{array}$ \\
\hline
\end{tabular}

NOT SURED 5. Heredity plays the major role in determining one's personality.

\begin{tabular}{ccccc}
$\square$ & $\square$ & $\square$ & $\square$ & $\square$ \\
$\begin{array}{c}\text { Disagree } \\
\text { Strongly }\end{array}$ & Disagree & Neither agree & Agree & Agree \\
Moderately & nor disagree & Moderately & Strongly \\
\hline
\end{tabular}

REVELE - 6. It is difficult for me to make new friends.

\begin{tabular}{|c|c|c|c|c|c|}
\hline SUCRE & $\begin{array}{c}\text { 口.5 } \\
\text { Disagree } \\
\text { Strongly }\end{array}$ & $\begin{array}{c}\square+ \\
\text { Disagree } \\
\text { Moderately }\end{array}$ & $\begin{array}{l}\square .3 \\
\text { Neither agree } \\
\text { nor disagree }\end{array}$ & $\begin{array}{c}\square 2 \\
\text { Agree } \\
\text { Moderately }\end{array}$ & $\begin{array}{c}\square \text { i } \\
\text { Agree } \\
\text { Strongly }\end{array}$ \\
\hline
\end{tabular}


ReVESE - 7. When I set important goals for myself, I rarely achieve them.

SCURE $\square 50 \square 4 \quad \square, 3$

Disagree Disagree Neither agree Agree Agree

Stronglv Moderately nor disagree Moderately Strongly

REVESE 8. I give up on things before completing them.

SCORE

$\square 5$

$\square 4$

$\square .3$

Disagree

Disagree

Neither agree

Strongly

Moderately

nor disagree

Agree

Moderately

Agree

Strongly

Not SCoRen) 9. I like to cook.

Disagree

Disagree

Neither agree

Agree nor disagree

Moderately

Agree

Strongly

Moderately

10. If I see someone I would like to meet, I go to that person instead of waiting for him or her to come to me.

$\begin{array}{lllll}\square 1 & \square 2 & \square 3 & \square 4 & \square 5\end{array}$ Disagree Disagree Neither agree Agree Agree

Strongly Moderately nor disagree Moderately Strongly

REVERSE 11 . I avoid facing difficulties.

\begin{tabular}{cccccc} 
SCORE & $\begin{array}{c}\square \\
\text { Disagree } \\
\text { Strongly }\end{array}$ & $\begin{array}{c}\square 4 \\
\text { Disagree } \\
\text { Moderately }\end{array}$ & $\begin{array}{c}\square 3 \\
\text { Neither agree } \\
\text { nor disagree }\end{array}$ & $\begin{array}{c}\square 2 \\
\text { Agree } \\
\text { Moderately }\end{array}$ & $\begin{array}{c}\square 1 \\
\text { Agree } \\
\text { Strongly }\end{array}$ \\
\hline
\end{tabular}

12. If something looks too complicated, I will not even bother to try it.

\begin{tabular}{ccccc}
$\square 1$ & $\square 2$ & $\square 3$ & $\square 4$ & $\square 5$ \\
$\begin{array}{c}\square i s a g r e e \\
\text { Strongly }\end{array}$ & $\begin{array}{c}\text { Disagree } \\
\text { Moderately }\end{array}$ & $\begin{array}{c}\text { Neither agree } \\
\text { nor disagree }\end{array}$ & $\begin{array}{c}\text { Agree } \\
\text { Moderately }\end{array}$ & $\begin{array}{c}\text { Agree } \\
\text { Strongly }\end{array}$ \\
\hline
\end{tabular}

NOT SCORED 13. There is some good in everybody.

\begin{tabular}{ccccc}
$\begin{array}{c}\text { Disagree } \\
\text { Strongly }\end{array}$ & $\begin{array}{c}\text { Disagree } \\
\text { Moderately }\end{array}$ & $\begin{array}{l}\text { Neither agree } \\
\text { nor disagree }\end{array}$ & $\begin{array}{c}\text { Agree } \\
\text { Moderately }\end{array}$ & $\begin{array}{c}\text { Agree } \\
\text { Strongly }\end{array}$ \\
\hline
\end{tabular}

REVERS 14. If I meet someone interesting who is very hard to make friends with, I'll soon stop SCORE trying to make friends with that person.

\begin{tabular}{ccccc}
$\square .5$ & $\square 4$ & $\square .3$ & $\square 2$ & $\square 1$ \\
Disagree & Disagree & Neither agree & Agree & Agree \\
Strongly & Moderately & nor disagree & Moderately & Strongly \\
\hline
\end{tabular}

15. When I have something unpleasant to do, I stick to it until I finish it.

\begin{tabular}{ccccc}
$\square 1$ & $\square 2$ & $\square 3$ & $\square 4$ & $\square 5$ \\
Disagree & Disagree & Neither agree & Agree & Agree \\
Strongly & Moderately & nor disagree & Moderately & Strongly \\
\hline
\end{tabular}


16. When I decide to do something. I go right to work on it.

\begin{tabular}{ccccc}
$\square 1$ & $\square 2$ & $\square 3$ & $\square 4$ & $\square 5$ \\
$\begin{array}{c}\text { Disagree } \\
\text { Strongly }\end{array}$ & $\begin{array}{c}\text { Disagree } \\
\text { Moderately }\end{array}$ & $\begin{array}{c}\text { Neither agree } \\
\text { nor disagree }\end{array}$ & $\begin{array}{c}\text { Agree } \\
\text { Moderately }\end{array}$ & $\begin{array}{c}\text { Agree } \\
\text { Strongly }\end{array}$ \\
\hline
\end{tabular}

Nor Scionso 17. I like science.

\begin{tabular}{ccccc}
$\square$ & $\square$ & $\square$ & $\square$ & $\square$ \\
$\begin{array}{c}\text { Disagree } \\
\text { Strongly }\end{array}$ & $\begin{array}{c}\text { Disagree } \\
\text { Moderately }\end{array}$ & $\begin{array}{c}\text { Neither agree } \\
\text { nor disagree }\end{array}$ & $\begin{array}{c}\text { Agree } \\
\text { Moderately }\end{array}$ & $\begin{array}{c}\text { Agree } \\
\text { Strongly }\end{array}$ \\
\hline
\end{tabular}

REVERSE 18 . When trying to learn something new, I soon give up if I am not initially successful. SCORE

\begin{tabular}{ccccc}
$\square .5$ & $\square 4$ & $\square 3$ & $\square 2$ & $\square 1$ \\
Disagree & $\begin{array}{c}\text { Disagree } \\
\text { Strongly }\end{array}$ & $\begin{array}{c}\text { Neither agree } \\
\text { Moderately }\end{array}$ & $\begin{array}{c}\text { Agree } \\
\text { nor disagree }\end{array}$ & $\begin{array}{c}\text { Moderately } \\
\text { Strongly }\end{array}$ \\
\hline
\end{tabular}

19. When I'm trying to become friends with someone who seems uninterested at first, I don't give up very easily.

\begin{tabular}{ccccc}
$\square 1$ & $\square 2$ & $\square 3$ & $\square 4$ & $\square 5$ \\
$\begin{array}{ccc}\square i s a g r e e \\
\text { Strongly }\end{array}$ & $\begin{array}{c}\text { Disagree } \\
\text { Moderately }\end{array}$ & $\begin{array}{l}\text { Neither agree } \\
\text { nor disagree }\end{array}$ & $\begin{array}{c}\text { Agree } \\
\text { Moderately }\end{array}$ & $\begin{array}{c}\text { Agree } \\
\text { Strongly }\end{array}$ \\
\hline
\end{tabular}

REVERSE 20. When unexpected problems occur, I don't handle them well.

SCORE

\begin{tabular}{ccccc}
$\square 5$ & $\square 4$ & $\square 3$ & $\square 2$ & $\square l$ \\
$\begin{array}{c}\text { Disagree } \\
\text { Strongly }\end{array}$ & $\begin{array}{c}\text { Disagree } \\
\text { Moderately }\end{array}$ & $\begin{array}{c}\text { Neither agree } \\
\text { nor disagree }\end{array}$ & $\begin{array}{c}\text { Agree } \\
\text { Moderately }\end{array}$ & $\begin{array}{c}\text { Agree } \\
\text { Strongly }\end{array}$ \\
\hline
\end{tabular}

NGT SCORED 21. If I were an artist, I would like to draw children.

Disagree Disagree Neither agree Agree Agree

Strongly Moderately nor disagree Moderately Strongly

REVERSE, 22. I avoid trying to learn new things when they look too difficult for me.

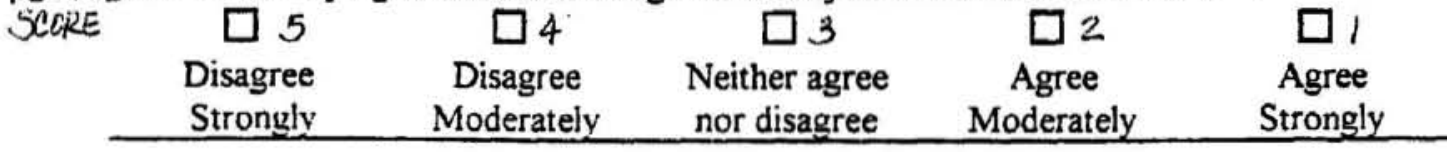

23. Failure just makes me try harder.

$\begin{array}{lllll}\square 1 & \square 2 & \square 3 & \square 4 & \square 5\end{array}$

Disagree Disagree Neither agree Agree Agree

Strongly Moderately nor disagree Moderately Strongly

REVERSE 24. I do not handle myself well in social gatherings.

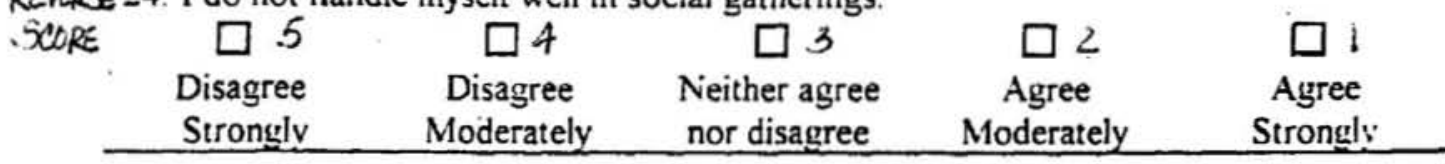


Wif SidREi) 25. I very much like to ride horses.

\begin{tabular}{ccccc}
$\square$ & $\square$ & $\square$ & $\square$ & $\square$ \\
$\begin{array}{c}\text { Disagree } \\
\text { Strongly }\end{array}$ & Disagree & Neither agree & Agree & Agree \\
Moderately & nor disagree & Moderately & Strongly \\
\hline
\end{tabular}

REVERSE 26. I feel insecure about my ability to do things.

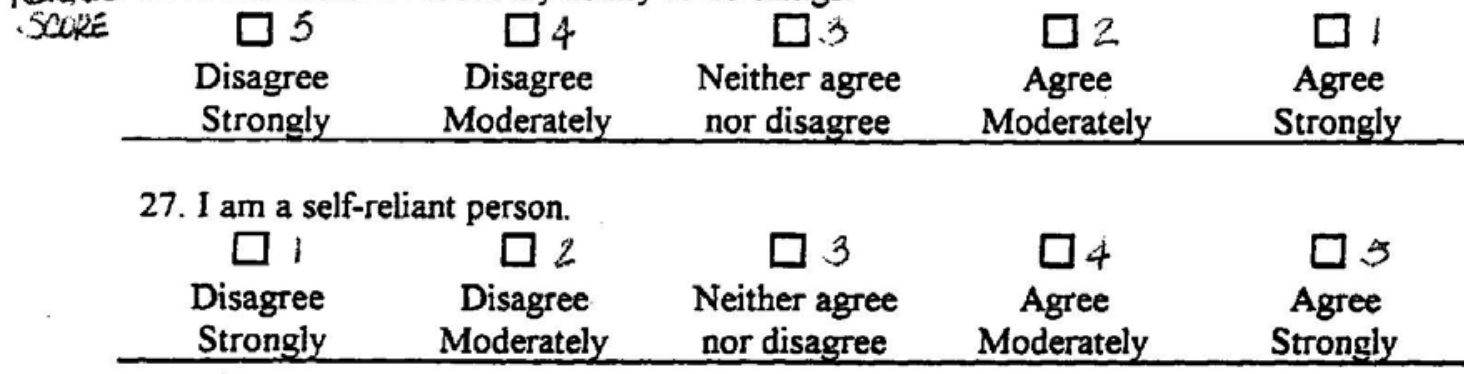

28. I have acquired my friends through my personal abilities at making friends.

$\begin{array}{ccccc}\square: & \square 2 & \square 3 & \square 4 & \square 5 \\ \text { Disagree } & \text { Disagree } & \text { Neither agree } & \text { Agree } & \text { Agree }\end{array}$

Strongly Moderately nor disagree Moderately Strongly

REVESE29. I give up easily.

\begin{tabular}{|c|c|c|c|c|}
\hline $\begin{array}{r}\square 5 \\
\text { Disagree } \\
\text { Strongly }\end{array}$ & $\begin{array}{c}\square 4 \\
\text { Disagree } \\
\text { Moderately }\end{array}$ & $\begin{array}{c}\square .3 \\
\text { Neither agree } \\
\text { nor disagree }\end{array}$ & $\begin{array}{c}\square 2 \\
\text { Agree } \\
\text { Moderately }\end{array}$ & $\begin{array}{c}\square / \\
\text { Agree } \\
\text { Strongly }\end{array}$ \\
\hline
\end{tabular}

REVERSE 30. I do not seem capable of dealing with most problems that come up in my life.

\begin{tabular}{cccccc} 
SCORE & $\square .5$ & $\square 4$ & $\square .3$ & $\square 2$ & $\square 1$ \\
$\begin{array}{c}\text { Disagree } \\
\text { Strongly }\end{array}$ & $\begin{array}{c}\square \text { Disagree } \\
\text { Moderately }\end{array}$ & $\begin{array}{c}\text { Neither agree } \\
\text { nor disagree }\end{array}$ & $\begin{array}{c}\text { Agree } \\
\text { Moderately }\end{array}$ & $\begin{array}{c}\text { Agree } \\
\text { Strongly }\end{array}$ \\
\hline
\end{tabular}


APPENDIX D

LOCUS OF CONTROL SCALE

SCORING GUIDE FOR LOCUS OF CONTROL SCALE 


\author{
Appendix D \\ Locus of Control Scale \\ Scoring Guide for Locus of Control Scale
}

Pages have been reduced from the original to fit dissertation margins 


\section{Nowicki-Strickland Locus of Control Scale}

Student

\section{Form A}

Circle Yes or No after each question.

1. Do you believe that most problems will solve themselves if you just don't fool with them?

2. Do you believe that you can stop yourself from catching a cold?

Yes No

3. Are some kids just bom lucky?

Yes No

4. Most of the time do you feel that getting a good grade means a great deal to you?

5. Are you often blamed for things that just aren't your fault?

Yes No

6. Do you believe that if somebody studies hard enough he or she can pass any subject?

7. Do you feel that most of the time it doesn't pay to try hard because things Yes No never turn out right anyway?

8. Do you feel that if things start out well in the moming that it's going to be Yes No a good day no matter what you do?

9. Do you feel that most of the time parents listen to what their children have Yes No to say?

10. Do you believe that wishing can make good things happen?

Yes No

11. When you get punished does it usually seem it's for no good reason at all?

12. Most of the time do you find it hard to change a friend's (mind) opinion?

13. Do you think that cheering more than luck helps a team to win?

Yes No

Yes No

14. Do you feel that it's nearly impossible to change your parent's mind about anything?

15. Do you believe that your parents should allow you to make most of your own decisions?

16. Do you feel that when you do something wrong there's very litule you can do to make it right?

17. Do you believe that most kids are just born good at sports?

Yes No

Yes No

Yes No

Yes No.

Yes No

Yes No

Y

18. Are most of the other kids your age stronger than you are?

Yes No

Yes No

19. Do you feel that one of the best ways to handle most problems is just not to think about them?

Yes No

20. Do you fee! you have a lot of choice in deciding who your friends are? Yes No 


\section{Nowicki-Strickland (Page 2)}

21. If you find a four leaf clover, do you believe that it might bring you good Yes No luck?

22. Do you often feel that whecher you do your homework has much to do with Yes No what kind of grades you get?

23. Do you feel that when a kid your age decides to hit you, there's little you Yes No can do to stop him or her?

24. Have you ever had a good luck charm?

Yes No

25. Do you believe that whether or not people like you depends on how you act?

Yes No

26. Will your parents usually help you if you ask them to?

Yes No

27. Have you felt that when people were mean to you it was usually for no reason at all?

28. Most of the time, do you feel that you can change what might happen tomorrow by what you do today?

29. Do you believe that when bad things are going to happen they just are going to happen no matter what you try to do to stop them?

30. Do you think that kids can get their own way if they just keep trying? Yes No

31. Most of the time do you find it useless to try to get your own way at home? Yes No

32. Do you feel that when good things happen they happen because of hard work? Yes No

33. Do you feel that when somebody your age wants to be your enemy there's little Yes No you can do to change matters?

34. Do you feel that it's easy to get friends to do what you want them to?

Yes No

35. Do you usually feel that you have little to say about what you get to eat at home?

36. Do you feel that when someone doesn't like you there's little you can do about it?

37. Do you usually feel that it's almost useless to try in school because most other children are just pläin smarter than you are?

38. Are you the kind of person who believes that planning and hard work makes things turn out better?

39. Most of the time, do you feel that you have little to say about what your family decides to do?

40. Do you think it's better to be smart than to be lucky?

Yes No

Yes No

Yes No

Yes No

Yes No

$\therefore$

Yes No

Tocal Score 


\section{Nowicki-Strickland Locus of Control Scale}

Student

Form A

Circle Yes or No "... after each question.

1. Do you believe that most problems will solve themselves if you just don't fool with them?

2. Do you believe that you can stop yourself from catching a cold ?

(Yes) No

3. Are some kids just bom lucky?

Yes No

(Yes) No

4. Most of the time do you feel that getting a good grade means a great deal to Yes No you?

5. Are you often blamed for things that just aren't your fault?

(Yes No

6. Do you believe that if somebody studies hard enough he or she can pass any subject?

Yes No

7. Do you feel that most of the time it doesn't pay to try hard because things never tum out right anyway?

(Yes) No

8. Do you feel that if things start out well in the moming that it's going to be a good day no matter what you do?

9. Do you feel that most of the time parents listen to what their children have to say?

10. Do you believe that wishing can make good things happen?

(3es) No

Yes No:

11. When you get punished does it usually seem it's for no good reason at all?

12. Most of the time do you find it hard to change a friend's (mind) opinion?

(Yes) No

Yes No

13. Do you think that cheering more than luck helps a team to win?

(Yeș No

14. Do you feel that it's nearly impossible to change your parent's mind _. : about anything?

15. Do you believe that your parents should allow you to make most of your own decisions?

16. Do you feel that when you do something wrong there's very little you can do to make it right?

17. Do you believe that most kids are just born good at sports?

18. Are most of the other kids your age stronger than you are?

Yes (No)

(res) No

Yes (No:

(Yes) No

(Y)s No

(Yes) No

19. Do you feel that one of the best ways to handle most problems is just not to think about them?

(yes) No

20. Do you feel you have a lot of choice in deciding who your friends are?

Yes No 


\section{Nowicki-Strickland (Page 2)}

21. If you find a four leaf clover, do you believe that it might bring you good luck?

22. Do you often feel that whether you do your homework has much to do with what kind of grades you get?

23. Do you feel that when a kid your age decides to hit you, there's little you can do to stop him or her?

24. Have you ever had a good luck charm?

25. Do you believe that whether or not people like you depends on how you act?

26. Will your parents usually help you if you ask them to?

(Yes) No

Yes No

(Yes) No

(Yes) No

Yes No

Yes (No)

27. Have you felt that when people were mean to you it was usually for no reason at all?

28. Most of the time, do you feel that you can change what might happen tomorrow by what you do today?

29. Do you believe that when bad things are going to happen they just are going to happen no matter what you try to do to stop them?

30. Do you think that kids can get their own way if they just keep trying?

(Yes) No

Yes $\mathrm{Ne}$

(2es) No

Yes No

31. Most of the time do you find it useless to try to get your own way at home?

(Yes) No

32. Do you feel that when good things happen they happen because of hard work?

33. Do you feel that when somebody your age wants to be your enemy there's little you can do to change matzers?

34. Do you feel that it's easy to get friends to do what you want them to?

Yes (No)

Yes) No

35. Do you usually feel that you have litule to say about what you get to eat at home?

36. Do you feel that when someone doesn't like you there's little you can do . about it?

37. Do you usually feel that it's almost useless to try in school because most other children are just pläin smarter than you are?

38. Are you the kind of person who believes that planning and hard work makes things tum out better?

39. Most of the time, do you feel that you have little to say about what your family decides to do?

40. Do you think it's better to be smar than to be lucky?

Yes (No)

(res) No

(Yes) No:

(Yes) No

(Yes) No

(4es) No -

Yes No:

Total Score

$25 \quad 15$ 
APPENDIX E

OPERATIONAL DEFINITIONS AND

CODINGS OF VARIABLES 


\section{Operational Definitions and Codings of Variables}

The variables listed in this appendix are organized according to Figure 1. The three types of Independent Variables--Demographic Factors, STEP Intervention Factors, and Mediating Factors--are followed by the Dependent Variables.

For each variable, the operational definition and variable label code, including scale items if applicable, are given. All data were self-reported by the students except where noted. Some information was not asked in the STEP Grant Student Follow-up Survey and was obtained from school district records and documents (Transition Plans and IEPs).

Independent Variables

\section{Demographic Factors}

Demographic Factors include two broad groups: Personal Identity (Ethnicity,

Gender, Disability) and Educational History (Vocational Education Enrollment, High School Grade Point Average, and Vocational Class Grade Point Average). All of this information was gathered from school district records.

\section{Personal Identity}

These three factors reflect student personal identities from their ethnic background, gender, and disability category. All students are included within the mild disability category (Learning Disabilities, Behavior Disabilities, and Mild Mental Disabilities) and have been identified according to state guidelines for services through special education.

Ethnicity (ETHN). This is nominal coding with implied ordering (Yaffee, 2003), coded 1 = Black, 2 = White.

Gender (GEN). Because females with disabilities typically fare worse during transition to adult life (Blackorby \& Wagner, 1996), this nominal level scale implies 
ordering, coded 1 = female, 2 = male .

Disability (DIS). The largest group of special education persons is that of mild disabilities with three levels of disability that are coded as nominal categories with implied ordering based on results of the NLTS study (Blackorby \& Wagner, 1996), such that $1=$ mild mental disability learning disability, 2 = emotional/behavior disability, and 3 = learning disability.

Educational History

The three factors included in this section reflect semesters enrolled in vocational training and grade point averages for both high school and vocational classes.

Vocational Education Semesters (VSEM). Vocational education semesters are recorded as a ratio variable, although all students in this study had at least one for the STEP Grant elective class. Participation is indicated by the actual number of semesters the student was enrolled in all vocational classes. Coding indicates $0=$ no semesters of participation, 1 = one semester, etc.

High School Grade Point Average (GPA). Grades for high school classes were averaged by the school district and obtained from JCPS records. The actual average is reported on a 4-point ratio scale.

Vocational Grade Point Average (VGPA). Grades for vocational education classes were obtained from JCPS records and averaged by this researcher. The actual VGPA is reported on a 4-point ratio scale similar to that used for reporting the overall high school GPA above.

\section{STEP Intervention Program}

STEP Intervention Factors are School Attended, Year of Enrolled, Days Enrollment, Attendance, and Self-Improvement during the Intervention Program. 
Information on the school attended, year enrolled, days enrolled, and attendance was obtained from school district records. Self-Improvement was derived from ten questions on the STEP Grant Student Follow-up Survey.

School Attended (SCH)

The six schools (nominal measurement) are reported as A, B, C, D, E, and F. Year Enrolled (YEAR)

The STEP Project began in 1996-1997 and continued through 1999-2000. The actual year of enrollment is recorded on a 4-point interval scale from 1997-2000.

\section{Days Enrolled (DAYS)}

Enrollment in the STEP Intervention Program is reported using a ratio scale with actual number of days enrolled in the STEP intervention program while in high school, reported from school district records.

\section{Percentage Attendance (\%ATT)}

A ratio scale is used to report percentage attendance in the intervention program. The percentage is calculated by dividing the actual number of days attended by the number of days enrolled (DAYS).

Self-Improvement (SIMP)

Self-Improvement scores were obtained from ten questions on the STEP Student Follow-up Survey. Each question was scored using a 5-point Likert-type scale with 5 = high. A composite score for Self-Improvement was obtained by summing the ten scores and dividing by ten. The questions are listed here numbered according to their designation on the STEP Student Follow-up Survey:

6. Did the STEP Project help you...

a. Understand yourself?

b. Identify your strengths?
(Circle your rating.)

Low 122345 High

Low 123345 High 
c. Identify areas for you to improve?

d. Identify how you learn best?

e. Identify ways to become successful?

f. Choose job or career?

g. Choose training after high school?

h. Plan your future goals?
Low 122345 High

Low 1223445 High

Low 1223445 High

Low $122 \quad 3 \quad 45$ High

Low 1223445 High

Low 12345 High

8. Did the STEP Project help you get ready for a job after high school?

Low 12345 High

9. Did the STEP Project help you get ready for more college or vocational training after after high school?

Low 12345 High

\section{Mediating Factors}

Mediating Factors are personality measures obtained from two tests administered to STEP project students while they were attending the Elective class. Results are divided into three sections: Self-efficacy General, Self-efficacy Social, and Locus of Control. Self-efficacy-General (SGEN)

The Self-efficacy test has two parts that are scored separately: General and Social. Seven items (1, 5, 9, 13, 17, 21, and 25) are filler items and are not scored. The General section is scored on an ordinal 5-point Likert scale. Students responded by circling the number for their degree of agreement or disagreement based on the following choices: Disagree Strongly, Disagree Moderately, Neither Agree nor Disagree, Agree Moderately, and Agree Strongly. However, considerable psychometric analyses have been done with this instrument, with the responses treated as though they were interval (continuous) data (see Choi, 2003). Thus, the responses were converted to a 5-point scale with $5=$ Agree Strongly. A composite scale mean was constructed across the seventeen items that compose this section. Higher scores indicate the student has higher general self-efficacy expectations. The actual questions are listed here as they are numbered on the Self-efficacy Scale with $\mathrm{R}$ = reverse scoring (Sherer et al., 1982). 
2. When I make plans, I am certain I can make them work.

R3. One of my problems is that I cannot get down to work when I should.

4. If I can't get a job the first time, I keep trying until I can.

R7. When I set important goals for myself, I rarely achieve them.

R8. I give up on things before completing them.

R11. I avoid facing difficulties.

12. If something looks too complicated, I will not even bother to try it.

15. When I have something unpleasant to do, I stick to it until I finish it.

16. When I decide to do something, I go right to work on it.

R18. When trying to learn something new, I soon give up if I am not initially successful.

R20. When unexpected problems occur, I don’t handle them well.

R22. I avoid trying to learn new things when they look too difficult for me.

23. Failure just makes me try harder.

R26. I feel insecure about my ability to do things.

27. I am a self-reliant person.

R29. I give up easily.

R30. I do not seem capable of dealing with most problems that come up in my life. Self-efficacy-Social (SSOC)

The Self-efficacy-Social section is scored on the same 5-point Likert scale. A composite scale mean is constructed across the six items with scoring as enumerated on the Self-efficacy General Scale (Sherer et al., 1982). Again, questions marked with R are reverse scored and the higher the score, the higher the social self-efficacy expectations. The actual questions are listed here as they are numbered on the Self-efficacy Scale (Sherer et al., 1982). 
R6. It is difficult for me to make new friends.

10. If I see someone I would like to meet, I go to that person instead of waiting for him or her to come to me.

R14. If I meet someone interesting who is very hard to make friends with, I'll soon stop trying to make friends with that person.

19. When I'm trying to become friends with someone who seems uninterested at first, I don't give up very easily.

R24. I do not handle myself well in social gatherings.

28. I have acquired my friends through my personal abilities at making friends. Locus of Control (LOC)

The Locus of Control test is scored via YES or NO questions that are circled. A composite scale mean is constructed across the 40 items (Nowicki \& Strickland, 1973). The authors provide a key that identifies the prototypical person with an external locus of control (answers to questions 1, 3, 5, 7, 8, 10, 11, 12, 14, 16, 17, 18, 19, 21, 23, 24, 27, 29, 31, 33, 35, 36, 37, 38, and $39=$ Yes with the remainder $=$ No). The more of these YES answers a person gives, the higher is his/her external status. The questions are listed here per the numbers on the Locus of Control Scale (Nowicki \& Strickland, 1973):

1. Do you believe that most problems will solve themselves if you just don't fool with them? YES NO

R2. Do you believe that you can stop yourself from catching a cold? YES NO

3. Are some kids just born lucky? YES NO

R4. Most of the time do you feel that getting a good grade means a great deal to you? YES NO

5. Are you often blamed for things that just aren't your fault? YES NO

R6. Do you believe that if somebody studies hard enough he or she can pass any subject? YES NO

7. Do you feel that most of the time it doesn't pay to try hard because things never 
turn out right anyway? YES NO

8. Do you feel that if things start out well in the morning that it's going to be a good day no matter what you do? YES NO

R9. Do you feel that most of the time parents listen to what their children have to say? YES NO

10. Do you believe that wishing can make good things happen? YES NO

11. When you get punished does it usually seem it's for no good reason at all? YES NO

12. Most of the time do you find it hard to change a friend's (mind) opinion? YES NO

R13. Do you think that cheering more than luck helps a team to win? YES NO

14. Do you feel that it's nearly impossible to change your parent's mind about anything? YES NO

R15. Do you believe that your parents should allow you to make most of your own decisions? YES NO

16. Do you feel that when you do something wrong there's very little you can do to make it right? YES NO

17. Do you believe that most kids are just born good at sports? YES NO

18. Are most of the other kids your age stronger than you are? YES NO

19. Do you feel that one of the best ways to handle most problems is just not to think about them? YES NO

R20. Do you feel you have a lot of choice in deciding who your friends are? YES NO

21. If you find a four leaf clover, do you believe that it might bring you good luck? YES NO

R22. Do you often feel that whether you do your homework has much to do with what kind of grades you get? YES NO

23. Do you feel that when a kid your age decides to hit you, there's little you can do to stop him or her? YES NO

24. Have you ever had a good luck charm? YES NO 
R25. Do you believe that whether or not people like you depends on how you act? YES NO

R26. Will your parents usually help you if you ask them to? YES NO

27. Have you felt that when people were mean to you it was usually for no reason at all? YES NO

R28. Most of the time, do you feel that you can change what might happen tomorrow by what you do today? YES NO

29. Do you believe that when bad things are going to happen they just are going to happen no matter what you try to do to stop them? YES NO

R30. Do you think that kids can get their own way if they just keep trying? YES $\mathrm{NO}$

31. Most of the time do you find it useless to try to get your own way at home? YES NO

R32. Do you feel that when good things happen they happen because of hard work?

33. Do you feel that when somebody your age wants to be your enemy there's little you can do to change matters? YES NO

R34. Do you feel that it's easy to get friends to do what you want them to? YES NO

35. Do you usually feel that you have little to say about what you get to eat at home? YES NO

36. Do you feel that when someone doesn't like you there's little you can do about it? YES NO

37. Do you usually feel that it's almost useless to try in school because most other children are just plain smarter than you are? YES NO

38. Are you the kind of person who believes that planning and hard work makes things turn out better? YES NO

39. Most of the time, do you feel that you have little to say about what your family decides to do? YES NO

R40. Do you think it's better to be smart than to be lucky? YES NO

Dependent Variables 
Dependent variables are the transition outcomes that are the focus for the STEP Intervention Grant for these students with mild disabilities: employment, postsecondary education, and independent living. Definitions of the criteria used to evaluate success for these goals are specified for two levels--the STEP Grant and a more detailed quantitative analysis (RQs 3-6).

\section{STEP Grant Criteria}

For the STEP Grant, successful transition from high school for these students with disabilities was defined by whether the individual was meeting the specific criterion, or not (RQ2). Successful transition was determined if the student met criterion for either employment or postsecondary education enrollment. The third goal, independent living, was not able to be measured since not enough information was gathered on the follow-up survey.

Employment (EMPL)

Categorical measurement, coded $0=$ not meeting criterion, $1=$ meeting criterion . For employment, “success” included: (a) regular employment of at least 20 hours per week, or (b) enlistment in the military, or (c) status as a full-time homemaker. Postsecondary Education (PSE)

Categorical measurement, coded $0=$ not meeting criterion, $1=$ meeting criterion . For postsecondary education, enrollment in college or vocational/technical school full or part-time was deemed successful. At the time of the STEP Grant Student Follow-up Study, students had been out of high school for 1, 2, or 3 years so that none had graduated from a 4-year college.

\section{Quantitative Measures}

Information for these measures is derived from the STEP Grant Follow-up Survey. 
The survey did not enumerate data on postsecondary education for all students. However, a few respondents volunteered information with respect to their educational progress including location, programs or hours completed, and current enrollment. These comments are reported under the qualitative data in RQ7. Thus no quantitative measures are included in RQs 3-6 for Postsecondary Education. The operational definitions in this section apply to RQs 3-6.

Employment

Employment is an outcome that society uses as a measure of value for the individual. The type of job, salary, and responsibility govern how the individual functions in the world. Employment history of the student with mild disability was obtained from the Follow-up Study Q1 for number of hours worked and the wages earned.

Hours Worked (HOUR). The first job the student held following graduation from high school was considered. The number of hours actually worked per week was reported using a ratio scale.

Wages Earned (WAGE). The beginning hourly wage for the first job held was listed and reported using a ratio scale. 
APPENDIX F

STEP GRANT STUDENT FOLLOW-UP SURVEY COMMENTS

QUESTION 8 
STEP Project Student Follow-up Survey

Student Open Response Comments

Question 8: Did the STEP Project help you get ready for a job after high school?

Student Comments

506 Really did pinpoint areas you are interested in.

$509 \quad$ Likes STEP Project

513 Got me ready for day care job.

515 If it really did, you would have the job you want.

$522 \quad$ It showed me my options.

525 I know what to say in interview.

$527 \quad$ None

$532 \quad$ Interviews helped a lot.

535 Yes, but already working at two jobs (four hours week teach gymnastics).

538 Don’t feel ready for job.

546 Need to show more ways to train or choose school to get ready for my career.

553 It was a nice class to have because I learned what STEPS means.

555 Interesting, but not enough depth for different jobs.

$558 \quad$ It helped with resumes.

$568 \quad$ More information about specific jobs.

$571 \quad$ Yes, resumes, etc. Mock job interviews gave more confidence.

573 Can't get a job because enrolled in school.

$581 \quad$ Gave help with interviewing.

$584 \quad$ Prepared a lot.

(continued next page) 
STEP Project Student Follow-up Survey

Student Open Response Comments Question 8 (continued)

$588 \quad$ Work with checks and interviews helped.

$595 \quad$ Already knew about work.

$597 \quad$ Needed more time to learn about available options. 
APPENDIX G

STEP GRANT STUDENT FOLLOW-UP SURVEY COMMENTS

QUESTION 9 
STEP Project Student Follow-up Survey

Student Open Response Comments

Question 9: Did the STEP project help you get ready for more [sic] college or vocational training after high school?

Survey \# Open-Response Comment

$506 \quad$ Really did pinpoint areas you are interested in.

509 I plan to go to JTC in the future. Interested in cosmetology. Having a baby any day.

513

None

515

Currently at JCC

522

It showed me my best qualities and what I am good at so I could get a better understanding of what I will do for college or school after I graduate.

525 Before, I might not even look at a school, but now I think I might

$527 \quad$ Helped decide on Fire \& Rescue career. Really already knew I wanted to do this.

535

None

538

Sites visits to JTC \& JCC were good.

541

Because discussed in class and field trips.

543

Not sure because not attending college or vocational training.

546 Need to show more ways to train or choose school to get ready for my career.

$548 \quad$ Visits to the schools, JTC \& JCC, were helpful.

$553 \quad$ Sorry, no, it did not help me at all.

555 Enjoyed visiting post-secondary sites and what they had to offer.

$568 \quad$ None.

571 Site visits helped out. If it wasn't for STEP Project, I wouldn't be in school. I don't know where I'd be.

(continued next page) 
STEP Project Student Follow-up Survey

Student Open Response Comments Question 9 (continued)

$581 \quad$ Identified choices and possible help

588 More emphasis on study habits. Look at more colleges \& how to get registered

$591 \quad$ Don’t know.

$595 \quad$ It lets you see options.

$597 \quad$ None. 
APPENDIX H

STEP GRANT STUDENT FOLLOW-UP SURVEY COMMENTS

QUESTION 4 
STEP Grant Follow-up Survey

Question 4: Have you ever attended postsecondary education at any time after high school?

$N=50 \quad(\mathrm{YES}=12, \mathrm{NO}=38)$

Study

Number

Hours

Postsecondary Institution

515

3 hours enrolled also attended

Jefferson Community College

Carl D. Perkins Rehabilitation Center, Thelma, Ky

532

9 hours completed

Jefferson Community College

546

3 hours completed

Jefferson Community College

$549 \quad$ Hours not stated

Professional Animal Care Specialist Program completed by mail

$550 \quad$ Hours not stated

Family Education Program, Adult Education

558

6 hours completed

Jefferson Community College

562

Hours not stated

Jefferson Technical College (completed 18 month course in Welding)

$568 \quad 12$ hours completed 12 enrolled

Jefferson Community College

$571 \quad 15$ hours completed 15 enrolled

Jefferson Technical College (Plumbing)

$573 \quad$ Hours not stated

Donta's Nail Technology completed and enrolled in Cosmetologist training

588

24 hours completed

Spalding College

596

Hours not stated

Jefferson Community College (attended but did not complete any hours) 


\section{CURRICULUM VITAE}

NAME:

ADDRESS:

DOB:

EDUCATION

\& TRAINING:
Yvonne Anton Kelley Niemann

171 Apple Lane

Taylorsville, KY 40071

Alton, Illinois - July 7, 1939

B.S., Secondary Education: Health, Psychology, Outdoor Education

Southern Illinois University, Carbondale, IL 1960

M.Ed., Music Education and Special Education University of Louisville, Louisville, KY 1971

Ed.S., Administration/Supervision in Special Education University of Louisville, Louisville, KY 1977

Ph.D., Curriculum and Instruction in Special Education University of Louisville, Louisville, KY 2007

AWARDS: \& TRAINING:
Advanc-ED Southern Association of Colleges and Schools SACS National Certified Quality Assurance Review Team Chairperson Training 2007

Southern Association of Colleges and Schools (SACS/CASI) Chair Training for Accreditation Teams Quality Assurance Reviews 2006

KY Teacher Internship Program Training University Representative for KTIP Teams 2001

Alternate Portfolio Training 2002-2005 
State Nominee for National Council for Exceptional Children, Clarissa Hug Teacher of the Year Award

1993

Teacher of the Year

Kentucky Association of Vocational Educators for Special Needs Personnel (KAVESNP) Award 1993

Outstanding Teacher, Jefferson County Board of Education Award Annually, 1989 to 1993

Kentucky Teacher of the Year

Kentucky Federation Council of Exceptional Children Award 1992

Jefferson County Nominee for the Stella A. Edwards Special Education Teacher of the Year Award 1986

PROFESSIONAL Spencer County Retired Teachers Association SOCIETIES: $\quad 2003$ to present

Jefferson County Retired Teachers Association 1993-2003

Kentucky Teacher Retirement Association 1993 to present

TASH: The Association for Severely Handicapped 1998 to present

University of Louisville Graduate Student Association 1996 to present

Council for Retarded Citizens

$1980-2000$

Council for Exceptional Children Division for Career Development 1968 to present

KY Federation of Council for Exceptional Children: Board of Directors; Division for Mental Retardation, President; Division for Career Development 1968 to present 
Jefferson County, Chapter 5, Council for Exceptional Children: Vice President, Parliamentarian, Executive Board, Program Chair 1970-1998

Phi Kappa Pi

1977-1993

National Education Association 1966-1993

Kentucky Education Association 1966-1993

Jefferson County Teachers Association Professional Representative 1966-1993

American Vocational Association 1975-1993

Kentucky Vocational Association Board of Directors 1975-1993

Jefferson County Vocational Association 1975-1993

National Association for Teachers of Special Needs Personnel 1975-1993

Kentucky Association for Teachers of Special Needs Personnel: President, Vice-President, Secretary, Treasurer, Membership Chair 1975-1993

PUBLICATIONS: Special Education Program Handbook, University of Louisville, Department of Teaching and Learning, (2005-2006).

University of Louisville, Wrote course content for Online classes, EDSP 634, EDSP 636, EDSP 614, EDSP 638, (2001-2006).

Growing up: Transition to adult life for students with disabilities by Steere, Rose \& Cavaiuolo. (2005). Book Reviewer.

Brochure, meeting \& conference flyers: Systematic Training in Transition Supports Grant, University of Louisville, Special Education Department (1997-1999). 
Brochure, meeting flyers: Partners in Alliance with Learning Systems Grant, University of Louisville. Special Education Department (1997-1998).

Transition Procedures Manual, Jefferson County Public Schools, (1993).

Brochure, Work Transition Program, Jefferson County Public Schools (1985-1993).

Emergency Procedures Handbook, Community Based Education, Jefferson County Public Schools, (1983, updated annually until 1993).

Kelley, Y. A. (1988). Transitioning students from school to workplace. SPLASH Flash, Office of Education for Exceptional Children, Kentucky Department of Education.

Kelley, Y. A. (1984). Vocational and transition planning for nondiploma students. SPLASH Flash, Office of Education of Exceptional Children, Kentucky Department of Education.

Kelley, Y. A. (1984). Apathy big problem! KAVESNP Exchange, VI (1).

Kelley, Y. A. (1984). Stand up and be counted! KAVESNP Exchange, VI (2).

Community Based Professional Development Training Modules, Jefferson County Public Schools (1981, updated annually until 1993).

\section{NATIONAL}

MEETING

PRESENTATIONS: Transition Projects Directors Conference, National

Transition Alliance, Washington, D. C., participant, presenter $1997-2000$

Building a work transition program from school to work for FMD students. National Convention, Council of Exceptional Children, San Francisco, CA: presenter 1987

INVITED Special Needs Vocational Conferences, KY

PRESENTATIONS: Department of Secondary Education, presenter 1975 to 2003

Transition Planning for Students with Disabilities Workshops: 
Organized meetings and presented professional development sessions in the following locations:

Trigg County High School.

For Trigg and Muhlenberg Counties, KY

Madisonville High School, Madisonville, KY.

For Madison and Ohio Counties, KY.

Bardstown High School, Bardstown Independent Schools, KY

Hart County High School, Munfordville, KY

Paducah Board of Education, Paducah, KY.

For 5 high schools in McCracken and Calloway Counties, KY

Lexington, KY.

For Woodford, Carlisle and Nicholas Counties, KY

Upper Cumberland Special Education Cooperative Special Education Directors Meeting. Professional Development Conference. For 21 public and independent school districts.

London, KY - organized workshop and presented training

Updated 11-23-2007

Yvonne Anton Kelley Niemann 